\title{
III. Stärke und Grenzen der „totalitären“ Provinzherrschaft
}

\section{Auf dem Weg zur Machtergreifung: endgültige Ausschaltung des Gegners und Sprengung des regionalen Rahmens}

Mit der Ausschaltung der republikanischen Gemeindeverwaltung war das Feld frei für die Hegemoniebestrebungen des Carrareser Fascio. Seine führende Stellung in der faschistischen Bewegung der Provinz hatte sich schon im Hochsommer 1921 herauskristallisiert, als er mit seiner Mitgliederentwicklung und durch seinen Aktivismus alle anderen Fasci der Region ins zweite Glied verwiesen hatte. Auf dem ersten Provinzialkongreß am 19. September in Massa wurde diese Position durch die Wahl von Renato Ricci zum politischen Sekretär der Federazione provinciale von Massa-Carrara besiegelt ${ }^{1}$. Ricci löste damit den noch vom Mailänder Zentralkomitee eingesetzten comissario provinciale Ernesto Buttini ${ }^{2}$ aus Pontremoli ab, der wegen seiner begrenzten Hausmacht eine rein dekorative Rolle gespielt hatte. Mit diesem Kongreß trat die faschistische Organisation von Massa-Carrara endgültig in den Kreis der bedeutenderen Provinzfaschismen. Symptomatisch für das gewonnene Selbstbewußtsein war die fast einstimmige Weigerung der Delegierten, ein Grußtelegramm an den wegen der Auseinandersetzung um die pacificazione in Bedrängnis geratenen Mussolini zu senden ${ }^{3}$. Man war sich seiner Autonomie und seines politischen Gewichts bewußt und war zu keinem Akt bereit, der als Solidarisierung mit den „Mailändern“ gegen die anderen radikalen Provinzfaschismen ausgelegt werden konnte. Freilich bestand im Herbst 1921 noch keineswegs eine hierarchisch festgefügte faschistische Provinzorganisation: Die mittelgroßen Fasci verteidigten ihre Autonomie verbissen gegenüber der Dominanz des Fascio von Carrara. Eine vom segretario regionale Perrone Compagni vorgeschlagene und später immer wieder von Ricci angestrebte Fusion der beiden faschistischen Lokalzeitungen Alalà (Carrara) und Giovinezza (Massa) scheiterte am erbitterten Widerstand der Masseser ${ }^{4}$.

Der ungleichgewichtige Dualismus zwischen den Fasci von Carrara und Massa bestand noch lange fort. Ihm lagen neben einer historisch festverwurzelten kommunalpatriotischen Rivalität auch politische Differenzen zugrunde. Der stärker mittelständisch strukturierte Fascio von Massa war „mazzinianisch“ orientiert und stand mit den örtlichen Republikanern in einem bemerkenswert guten Verhältnis, was bei den Carrareser Faschi-

1 Giovinezza vom 25. 9. 1921.

2 Nachdem der Fascio von Pontremoli ganz am Anfang eine Pionierrolle in der Provinz gespielt hatte, schwand seine Bedeutung sehr schnell. Der Rechtsanwalt Buttini hatte auch von seiner Persönlichkeit her nicht das „Zeug “ zu einem Ras. Er wurde später ein treuer Gefolgsmann von Ricci (siehe weiter unten, S. 255).

3 ACS, MI, DGPS 1922, b. 101, f. „Fasci Massa“: Präfekt an Innenministerium vom 20. 9. 1921; Giovinezza vom 25.9. 1921.

4 Ebenda und Giovinezza vom 30. 10. und 25. 12. 1921. Alalà wurde zwar im März 1922 zum Organ des PNF-Provinzialverbandes, und vom 9. 4. bis zum 26.11. 1922 stellte Giovinezzaangeblich wegen finanzieller Probleme - das Erscheinen ein. Anschließend erschien sie aber wieder regelmäßig. Erst im Juli 1923 verschwand Giovinezza endgültig von der Bildfläche (Bertozzi, Stampa, S. 175). 
sten wiederholt Befremden auslöste ${ }^{5}$. Die häufigen politisch-programmatischen Artikel von Giovinezza - in Alalà waren Beiträge, die diesen Namen verdienen, sehr dünn gesät - atmeten manchmal einen fast „demokratischen “ Geist; symptomatisch ist etwa ihre scharfe Abgrenzung von den Nationalisten ${ }^{6}$. Der Carrareser Fascio dagegen hatte ein ideologisch wesentlich unschärferes Profil, er definierte sich politisch im Grunde lediglich über seinen undifferenzierten Vernichtungskampf gegen alle Gruppen der sovversi$v i$. Der mehrheitlich "monarchistisch“-rechtsliberale Ursprung seiner Führungsgruppe gab ihm ein deutlich konservativeres Gepräge, und schon früh entwickelte er eine ausgeprägte politische Unduldsamkeit, die sich nicht zuletzt auch gegen die „abweichenden“ Tendenzen der Masseser richtete. Nie konnte allerdings ein Zweifel darüber aufkommen, zu wessen Gunsten dieser Dualismus sich entscheiden würde. Der Carrareser Fascio repräsentierte in sehr viel höherem Maße die wirtschaftlich und gesellschaftlich relevanten Gruppen der Region und war daher numerisch und finanziell wesentlich kräftiger. Während er im Frühjahr 1922 nochmals eine sprunghafte Aufwärtsentwicklung erlebte, stagnierte der Fascio von Massa bis zum „Marsch auf Rom“ in jeder Hinsicht”.

Neben dem Fascio von Massa führten auch der von Pontremoli, der für sich die Stellung des „Erstgeborenen“ in Anspruch nahm, und der von Aulla ein gewisses Eigenleben, in das das Provinzialsekretariat anfangs nicht so ohne weiteres hineinregieren konnte. Die tatsächliche Institutionalisierung der PNF-Provinzorganisation war noch im Frühjahr 1922 so wenig vorangeschritten, daß der Einfluß Riccis und des Carrareser Faschismus auf die außerhalb der Provinz Massa-Carrara liegenden und somit nicht zur Federazione gehörigen kleineren Fasci von Ortonovo, Lerici, Sarzana und der Versilia entschieden größer war als in Massa, Aulla und Pontremoli ${ }^{8}$. Die Machtstrukturen des

${ }^{5}$ Aus dem Provinzialkongreß im Dezember 1921 kamen die Konflikte zwischen den Carrareser und den Masseser Faschisten wegen der unterschiedlichen Haltung zu den Republikanern ausführlich zur Sprache. Bei dieser Gelegenheit erwirkten die Masseser die Rückgabe einer Fahne, die Republikanern aus Mirteto (Massa) in Avenza von den lokalen Faschisten geraubt worden war (Giovinezza vom 25. 12. 1921). Wenig später kritisierte der Sekretär des Fascio von Massa, Ubaldo Bellugi, die in Carrara übliche Praxis, Jagd auf alle rote Fahnen zu machen, und erteilte seinen Parteigenossen aus der Nachbargemeinde eine sarkastische Lektion über Farbsymbolik und die historischen Ursprünge des republikanischen Rot (Giovinezza vom 8. 1. 1922).

6 Das gilt vor allem für die Beiträge von Mario Morricone. Siehe seine politische Abrechnung mit den Nationalisten (Giovinezza vom 6. 11. 1921) und seine Kritik am stillschweigenden Unterschlagen der fortschrittlichen Postulate des alten Programms der Fasci auf dem nationalen Kongreß in Rom (Giovinezza vom 13. 11. 1921). Siehe außerdem den antikapitalistischen Artikel "Dedicato ai pescecani, ecc..." (Giovinezza vom 4. 12. 1921) und den unsignierten Artikel zur Wahlrechtsreform, der für das Verhältniswahlrecht und die Abschaffung der Wahlkreise plädiert (Giovinezza vom 19. 3. 1922). Daneben tauchen allerdings auch Artikel mit eindeutig antidemokratischem Gehalt auf, etwa „Verso un'oligarchia?", vermutlich von Bellugi (Giovinezza vom 2. 4. 1922), in dem der Faschismus als „oligarchisch“ (mit einer positiven Konnotation) und "antidemagogisch" bezeichnet wird.

7 Am 2. April 1922 berichtet der Präfekt nach Rom: „Der Fascio (von Massa) entwickelt wenig

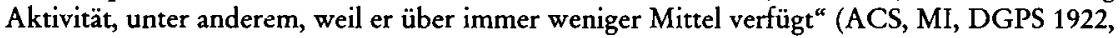
b. 134,f. „Fasci Massa“). Symptomatisch für die Situation der Masseser Faschisten sind die Schwierigkeiten, die sie im Februar/März 1922 bei der Suche eines neuen Parteilokals hatten, nachdem sie aus ihrem Domizil in den Räumen der Associazione industriale del marmo verbannt worden waren (Giovinezza vom 19. 3. 1922).

${ }^{8}$ Das läßt sich unter anderem auch an der Intensität der Berichterstattung von Alalà über die einzelnen Fasci ablesen. Hier finden sich regelmäßig Berichte über Sarzana, Pietrasanta und Seravezza, aber nur im Ausnahmefall über Massa oder Pontremoli. 
Faschismus in der Marmorregion wurden noch lange weitgehend außerhalb institutioneller Bahnen wirksam. Erst nach dem „Marsch auf Rom“ trat hier eine grundsätzliche Wende ein.

Die fatti di Bergiola beendeten die relativ schwierige Phase, die der Carrareser Faschismus vom August 1921 bis zum Jahresende durchlaufen hatte. Das Ausbleiben von durchschlagenden politischen Erfolgen war in Carrara wie auch in der restlichen Provinz mit einer weitgehenden Stagnation der Mitgliederentwicklung einhergegangen?. Im neuen Jahr veränderte sich die Situation in Carrara radikal; fast mühelos konnten die Faschisten ihre Positionen ausbauen und ihre Gegner in die Defensive drängen. Die Camera del lavoro behauptete sich zwar noch einige Monate, aber sie führte, obwohl ihr zunächst fast alle Mitgliedsligen treu blieben, ein ausgesprochenes Larvendasein. Alberto Meschi hielt sich aus Sicherheitsgründen ab Januar 1922 nicht mehr in Carrara auf ${ }^{10}$, und der Vizesekretär Gino Petrucci, der die Geschäfte führte, mußte notgedrungen auf jegliche gewerkschaftliche oder politische Initiative verzichten. Der Unternehmerverband steuerte schon seit dem Rücktritt von Carlo Andrea Fabbricotti im Oktober einen faschistenfreundlicheren Kurs ${ }^{11}$, und die Vorfälle von Bergiola hatten die konservativbürgerlichen Kreise und die Faschisten wieder fester zusammengeschweißt. Der stundenlange Kugelhagel auf Faschisten und Polizei hatte vermutlich auch bei den gemäßigteren bürgerlichen Kräften die Überzeugung genährt, daß sich die politischen Alternativen durch die mittlerweile eingetretene Polarisierung sehr viel radikaler stellten als

9 Die offizielle Statistik des Innenministeriums, die nur begrenzte Aussagekraft hat, weil die zugrundeliegenden Daten manchmal nicht oder nicht rechtzeitig aktualisiert wurden, enthält für die Provinz Massa-Carrara folgende Zahlen: 2299 (Oktober 1921), 2361 (November 1921), 2516 (April 1922); vgl. De Felice, Mussolini il fascista 1, S. 8 f. Trotz der angesprochenen statistischen Ungenauigkeiten dokumentieren diese Zahlen die (im Vergleich zur vorangegangenen und nachfolgenden Phase) äußerst zähe Mitgliederentwicklung. Dieses Bild wird durch die Daten für die faschistische Hochburg Bergiola Foscalina bestätigt: August 1921, 60 Mitglieder (ACS, DGPS 1923, b. 91, f. „Fasci Massa“, sf. „Costituzione fasci“: Präfekt an Innenministerium vom 30. 8. 1921); Januar 1922, 62 Mitglieder (ACS, MRF, b. 23, f. 113, sf. 53: PNF-Fragebogen ohne Datum, auf Januar 1922 datierbar).

10 Meschi war die meiste Zeit in La Spezia, wo er von der syndikalistischen Vecchia camera del lavoro aus, so gut es ging, an der Gewerkschaftsarbeit und am Cavatore mitwirkte (ACS, MI, CPC, b. 3249, f. „Alberto Meschi“: Bericht des Präfekten von Massa an das Innenministerium vom 1. 9. 1922).

11 Die Nachfolger von Carlo Andrea Fabbricotti, Gino Salvini und Cesare Frugoli, waren beide Mitglieder der liberalen Partei und relativ faschistenfreundlich. Frugoli, der Besitzer des einzigen größeren metallverarbeitenden Betriebs in der Region, war als „pescecane “ ("Haifisch“, Raffer) und Kriegsgewinnler verschrien (Il Cavatore vom 19.1. 1919). Ein sehr enges Verhältnis zum Faschismus ist bei ihm nicht erkennbar, aber unter seiner Geschäftsführung begünstigte der Verband den Fascio sehr viel stärker als vorher. Führungsmitglieder der Einzelverbände der Federazione fra le associazioni industriali del marmo waren Gino Salvini, Manager der Firma Walton, Goody \& Cripps, Ciro Faggioni und Battista Cucchiari für die Unione esportatori, Francesco Dazzi und Giovanni Gattini für den Gruppo esercenti cave, Cesare Frugoli, Primo Ascoli für den Gruppo esercenti segherie, Luigi Musetti für den Gruppo esercenti lizze, Emilio Quaglino, Ugo Patrizi und Mario Politti für das Consorzio laboratori. Die Genannten kamen fast alle aus Unternehmerfamilien, die in engeren Beziehungen zum Faschismus standen, waren aber persönlich kaum engagiert. Auffällig ist, daß selbst im Führungsgremium der Unione esportatori die Großunternehmer C. A. Fabbricotti und Lazzoni nicht mehr vertreten waren (ASM, Questura Massa, b. 13, f. „Federazione industriali“: Kommissar an Questore vom 25. 10. 1921). 
früher. In diesem Licht erschien das Schicksal der bestehenden Ordnung untrennbar mit dem des Faschismus verknüpft.

Als Ministerpräsident Bonomi unmittelbar nach diesen Ereignissen, auf den Vorschlag des Präfekten hin, für das Gemeindegebiet von Carrara alle Waffenscheine außer Kraft setzte und die Ablieferung der Waffen anordnete, brach im bürgerlichen Lager ein allgemeiner Proteststurm los. Der Unternehmerverband ging so weit, eine unbefristete Protestaussperrung anzukündigen, falls die Maßnahme nicht zurückgenommen werde, und der Händlerverband sowie die Sindacati economici hängten sich an und drohten mit Streik ${ }^{12}$. Angesichts dieser massiven Reaktion der "unpolitischen" Verbände konnten sich die Faschisten selbst im Hintergrund halten. Mit reichlich gekünstelter Gleichgültigkeit verkündeten sie, daß die Maßnahme sie eigentlich gar nicht betreffe, weil sie schon früher entwaffnet worden seien, was in Wirklichkeit gar nicht zutraf; zur Entwaffnung von Faschisten war es nur in Einzelfällen gekommen ${ }^{13}$. Ein zu großes Engagement des PNF in dieser Sache wäre dem Anliegen auch gar nicht zugute gekommen, weil es der Revolte politisch zu deutlich profaschistische Konturen verliehen hätte. Statt dessen wurde argumentiert, daß die Unternehmer - so der Wortlaut der Intervention des liberalen Abgeordneten Augusto Mancini bei Bonomi - „nicht unbewaffnet ihre Betriebe, bei denen es sich ja um Steinbruchbetriebe handelt, aufsuchen können “. Die "anarchoiden Elemente“ Carraras würden niemals ihre Waffen abliefern, und so wäre „der gesunde Teil der Bevölkerung“ ihrem ungezügelten Klassenhaß wehrlos ausgesetzt $^{14}$.

Nach anfänglichen Standhaftigkeitsbekundungen wich Bonomi, dessen Ministerpräsidentensessel im Kreuzfeuer der parlamentarischen Kritik von links und rechts schon gefährlich wackelte, zurück. Fünf Tage nach Ablauf der Frist für die Waffenablieferung, als also alle nicht renitenten Waffenbesitzer ihre Pflicht schon erfüllt hatten, und drei Tage bevor die Aussperrung anlaufen sollte, gab er dem Präfekten die Empfehlung, die Maßnahme vorerst auszusetzen und später die Waffenscheine „Fall für Fall“ einzuziehen ${ }^{15}$. Die solchermaßen verwässerte Praxis führte zu völlig unklaren Verhältnissen ${ }^{16}$ und lief tendenziell darauf hinaus, daß die Arbeiter die Waffen abliefern mußten, während das Bürgertum bewaffnet blieb. Damit wurde eine Situation legalisiert, die sich zuvor schon illegal ergeben und den Cavatore zu der Einschätzung veranlaßt hatte, das Dekret

12 Resolutionen siehe Alalà vom 21. 1. 1922.

13 Ebenda. Es gibt in den Polizeiquellen nicht den geringsten Anhaltspunkt für eine allgemeine und systematische Entwaffnung der Faschisten. Diese Anspielung kann sich daher wohl nur auf die Tatsache beziehen, daß einzelne einschlägig straffällig gewordene Faschisten ihren Waffenschein verloren hatten.

14 ACS, MI, Gabinetto Bonomi, b. 4, f. 43: Schreiben von Mancini an Bonomi vom 19. 1. 1922.

15 Ebenda: Telegramm von Bonomi an den Präfekten von Massa vom 15. 1. 1922.

16 Im Grunde hatte Bonomi einfach die „heiße Kartoffel“ an den Präfekten weitergereicht, ohne eine wirkliche Entscheidung zu fällen. Ohne ministerielle Rückendeckung ging dieser natürlich den Weg des geringsten Widerstands und ließ denen die Waffen, die am lautesten protestiert hatten. Das schwächliche und inkonsequente Vorgegen der staatlichen Stellen vermittelte ein solch desolates Bild, daß der unternehmerfreundliche Giornale di Carrara (23. 1. 1922) das chaotische Zurückweichen der Behörden einer härteren Kritik unterzog als die ursprüngliche Maßnahme, die - so das Blatt - „unverzüglich und allgemein“ hätte durchgeführt werden müssen, wenn man sie schon für notwendig hielt. 
sei gemacht worden, um die Arbeiter in die Unmöglichkeit zu versetzen, sich zu verteidigen ${ }^{17}$.

Der Ausgang der Auseinandersetzungen um die Entwaffnung erwies, daß der Staat sich gegen die lokale Front von Faschisten und bürgerlichen Kräften nicht mehr durchsetzen konnte oder wollte, selbst wenn das mit dem völligen Gesichtsverlust der Verantwortlichen verbunden war. Diese Erfahrung und die wiedergewonnene erfolgreiche "Aktionseinheit“ mit der Unternehmerorganisation gab dem Faschismus großen Auftrieb. Der PNF war mittlerweile die einzige Kraft in Carrara, die politisch wirklich initiativ werden konnte. Die anderen politischen Kräfte reagierten lediglich, wenn überhaupt, auf seine Vorstöße. Das galt auch für die Liberalen, die zwar eine entscheidende Rolle beim Sturz der republikanischen Stadtregierung gespielt hatten, aber später nicht in der Lage waren, die politischen Früchte des Umbruches zu ernten. Den Faschisten gelang es, trotz vergleichsweiser geringerer Sachkompetenz, die wichtigen Felder der Kommunalpolitik zu besetzen. Sie präsentierten sich als die eigentliche Alternative zu den Republikanern und hielten den Liberalen vergangene Schwäche und gegenwärtige Halbheiten vor ${ }^{18}$. Von Anfang an bombardierten sie die kommissarische Kommunalverwaltung von Carrara, die zunächst unter dem commissario prefettizio Conte Luigi Cioppi und später unter dem commissario regio Marchese Di Lungarini stand ${ }^{19}$, mit Kritik und Forderungen aller Art.

Gleich nach seiner Einsetzung warnten die Faschisten Cioppi davor, die ehemaligen politischen Verantwortlichen bei der Abwicklung der Verwaltungsgeschäfte in irgendeiner Weise miteinzubeziehen, weil sie sich sonst zu einem erneuten Eingreifen provoziert sähen, „um die Dreistigkeit gewisser Leute und ihrer im Palazzo Rosso verbliebenen Klientelen zu beseitigen ${ }^{20}$. Und als der commissario prefettizio später in einem Interview mit dem Giornale di Carrara die finanziellen Probleme Carraras auf den unerwartet schlechten Ertrag der kommunalen Marmorsteuer zurückführte, unterstellten sie ihm, er wolle die Mißwirtschaft der alten republikanischen Verwaltung vertuschen, und schlossen in diesen Vorwurf gleich auch die Redakteure des liberalen Lokalblatts mit ein ${ }^{21}$. Sie forderten von Cioppi die Säuberung des Ente autonomo per le case popolari, des kom-

17 Il Cavatore vom 21. 1. 1922. Daraufhin forderte das Organ der Camera del lavoro die Arbeiter ziemlich unverhohlen auf, die Entwaffnungsanordnung zu mißachten.

18 Alalà vom 4. 3. 1922.

19 Kommissarische Kommunalverwaltungen wurden im zentralistisch ausgerichteten Königreich Italien relativ schnell eingesetzt, vor allem in Fällen von Zahlungsunfähigkeit, Mißwirtschaft und Rechtsverstößen der gewählten Kommunalverwaltungen. Kurzfristig konnte vom Präfekten ein „commissario prefettizio“ berufen werden, der allerdings begrenzte Kompetenzen hatte. Der von der Regierung eingesetzte „commissario regio" vereinigte in seiner Person die Befugnisse des "consiglio comunale" (Gemeinderat) und der "giunta comunale" (kommunale Exekutive) und konnte bis zu einem halben Jahr im Amt bleiben. In der Phase der squadristischen Offensive 1920 - 1922 erfolgte die Einsetzung von Kommissaren automatisch überall dort, wo es zum gewaltsamen Sturz von gewählten Kommunalverwaltungen durch die Faschisten gekommen war, das heißt in unzähligen Gemeinden Nord- und Mittelitaliens, meistens den bedeutenderen der jeweiligen Provinz. Diese Kommissare waren, soweit sie nicht ohnehin von vornherein profaschistisch eingestellt waren, in der Regel einem enormen Druck von seiten der faschisierten lokalen Notabilität und der von den „squadristi“ beherrschten „Straße“ ausgesetzt und wurden so nicht selten zum Erfüllungsgehilfen der faschistischen Politik.

20 Alalà vom 28.1. 1922.

${ }^{21}$ Alalà vom 11. 2. 1922. 
munalen Amts für den sozialen Wohnungsbau, das im Mittelpunkt einer Affäre um eine anscheinend nicht ganz einwandfreie Ausschreibung stand, und überhaupt den Rücktritt der Republikaner und ihrer Sympathisanten aus allen öffentlichen Ämtern ${ }^{22}$. Der besonders unter Beschuß stehende Präsident des Ente autonomo per le case popolari, Oreste Pastorini, der gleichzeitig im Rathaus Leiter der Abteilung Lavoro e prevviden$z a$ sociale war, warf bald das Handtuch; er kündigte, ließ sich abfinden und ging ins „Exil“ nach Mailand ${ }^{23}$. Das zweite große Ärgernis für die Faschisten ließ sich nicht so schnell beseitigen: Der ehemalige Bürgermeister Starnuti blieb vorerst weiterhin auf dem hochdotierten Posten des Hafenamtspräsidenten ${ }^{24}$. Es bedurfte allerdings der energischen Intervention des Generalinspektors der Polizei Gaudino, der in der ersten Märzhälfte auf Mission in Carrara weilte, um die Faschisten in dieser Frage von Gewaltaktionen abzubringen ${ }^{25}$.

Im März wurde Cioppi durch den mit größeren Kompetenzen ausgestatteten commissario regio Di Lungarini ersetzt. Wenig später fand sich die Führung des Fascio bei ihm ein, um ihm ihre kommunalpolitischen Vorstellungen zu unterbreiten. Im besonderen forderten sie die zügige Inangriffnahme des sozialen Wohnungsbaus und einiger Straßenbauvorhaben im bergigen Hinterland von Carrara ${ }^{26}$. Die kommunale Bautätigkeit lag den Faschisten ganz besonders am Herzen, weil sie den zahlreichen arbeitslosen Marmorarbeitern in ihren Reihen allmählich einen politischen Erfolg präsentieren mußten, der diesen auch konkret zugute kam. Da ihnen bisher noch keine größeren Einbrüche in die organisierte Arbeiterschaft gelungen waren, bildeten die proletarischen Randgruppen nach wie vor einen wichtigen Teil ihrer sozialen Basis, auf dem sich wesentlich ihr Anspruch gründete, eine klassenübergreifende und keine bürgerliche Bewegung zu sein. Der Marchese Di Lungarini zeigte sich den Vorschlägen des Fascio gegenüber recht aufgeschlossen und hatte daher zunächst bei den Faschisten eine gute Presse ${ }^{27}$. Mit der weiteren Zunahme von Macht und politischen Ansprüchen des Fascio verschlechterte sich allerdings das Verhältnis zunehmend, wovon noch zu sprechen sein wird.

Nach der „Entmachtung“ der Republikaner verblieb dem Faschismus der Marmorregion als einziger erklärter Gegner nur noch die Gewerkschaftsbewegung mit ihrer anarchosyndikalistischen Zentrale. Ihr Weiterbestehen, auch im Zustand der Lähmung, war das letzte entscheidende Hindernis auf dem Weg zur vollständigen Erfassung der lokalen Gesellschaft, die von der Führung des PNF von Carrara mit zunehmender Deutlichkeit angestrebt wurde. Die Mehrheit der Arbeiterschaft blieb ihren alten Organisa-

${ }^{22}$ Ebenda und Alalà vom 25. 2. 1922. Zur Affäre des angeblich "getürkten " Wettbewerbs für ein Vorhaben des sozialen Wohnungsbaus siehe Alalà vom 4. und 18. 2. 1922.

${ }^{23}$ Alalà vom 25. 2. 1922.

${ }^{24}$ Die Initiative für den Ausbau des Hafens von Carrara, in dem damals keine größeren Schiffe anlegen konnten, ging auf die Republikaner und vor allem auf Eugenio Chiesa zurück. Zu diesem Zweck hob die republikanische Gemeindeverwaltung 1919 den „Ente per la costruzione del porto " aus der Taufe. Das Projekt wurde dann während des Faschismus verwirklicht. Zur Geschichte des Hafens von Carrara: A. Bernieri, L. und T. Mannoni, Il porto di Carrara, Storia e attualità, Genua 1983.

25 ACS, MI, DGPS 1922, b. 134, f. „Fasci Massa“: Ispettore generale Gaudino an Innenministerium vom 6. 3. 1922.

${ }^{26}$ Alalà vom 15. 4. 1922.

${ }^{27}$ Ebenda. 
tionen zunächst treu: Im Jahre 1922 verteilte die Camera del lavoro von Carrara immerhin noch 13000 Mitgliedsausweise, das heißt nur circa ein Drittel weniger als im Vorjahr ${ }^{28}$. Vor allem die älteren Arbeiter hatten keineswegs ein nur pragmatisches Verhältnis zu ihren angestammten Ligen, an denen ein guter Teil der eigenen sozialen Identität haftete und mit denen daher oft eine regelrecht emotionale Verbindung bestand. Der faschistischen Führung und vor allem Renato Ricci scheint das recht klar gewesen zu sein, denn er hatte von Anfang an und immer wieder die Übernahme einzelner Ligen oder gar der Camera del lavoro als ganzes angestrebt. Der Gedanke zur Gründung einer konkurrierenden faschistischen Gewerkschaftsorganisation im September 1921 war aus der Not geboren und brachte die Faschisten bei der Erfassung der Arbeiter monatelang nur wenig weiter. Zwar bedeuteten die Sindacati economici Carraras im toskanischen Maßstab schon einen gewissen Erfolg. Nicht ohne Grund entsandte Perrone Compagni im Oktober 1921 Ricci als Vertreter der Toskana zum nationalen Kongreß der faschistischen Gewerkschaften in Ferrara ${ }^{29}$. Doch taten sich die Faschisten trotz großer progagandistischer Anstrengungen schwer, der bei den Arbeitern verbreiteten Überzeugung entgegenzuwirken, die faschistischen Gewerkschaften seien lediglich ein trojanisches Pferd des Klassengegners. Man traute ihnen nicht zu, daß sie jemals ernsthaft Arbeiterinteressen wahrnehmen würden ${ }^{30}$.

Trotz der allgegenwärtigen Einschüchterung, die die Faschisten noch wochenlang nach den fatti di Bergiola aufrechterhielten, berief die Camera del lavoro für den 19. und 20. Februar 1922 ihren jährlichen Delegiertenkongreß ein, bei dem es ihr gelang, die Vertreter von knapp 80 Mitgliedsligen aus allen Teilen der Marmorregion, ebenso viele wie zum Kongreß vom Juni 1919, zu mobilisieren ${ }^{31}$. Die Carrareser Ligen waren fast vollständig vertreten. Von den Steinbrucharbeitergewerkschaften fehlte nur die aus der Faschistenhochburg Bergiola, welche sich schon seit längerer Zeit aufgelöst hatte, ohne daß die Faschisten in der Lage gewesen waren, eine eigene Nachfolgeorganisation aufzubauen $^{32}$. Außerdem fehlten von den wichtigen Gewerkschaften nur die der Hafenarbeiter und Seeleute aus Marina di Carrara sowie die Straßenbahnerliga und ansonsten einige kleinere Gewerkschaften, wie die der Kellner und Köche sowie die der Kommunalangestellten. Bei der Lega camerieri, cuochi, commessi ed affini, deren Führung in den Polizeiakten schon immer als politisch gemäßigt geführt wurde, und bei der Unione

28 Il Cavatore vom 10. 6. 1922.

29 ACS, Fondo Ricci, b. 5, f. „Carrara PNF 1921-23“: Perrone Compagni an Ricci vom 10. 10. 1921.

30 Diese Einschätzung des Cavatore (1. 4. 1922) entsprach wohl der Meinung vieler Arbeiter, zumal einige Unternehmer Druck ausübten, um ihre Belegschaften zum Eintritt in die Sindacati economici zu bewegen.

31 Il Cavatore vom 4. 3. 1922 und 5. 7. 1919.

32 ASM, Questura Massa, b. 12, f. „Lega cavatori Bergiola F.“: Kommissar von Carrara an Questore vom 23. 12. 1922. Hier steht als Auflösungsdatum September 1922. Das ist wohl ein Schreibfehler. Mit großer Sicherheit muß es September 1921 heißen. Außerdem ACS, MRF, b. 53, f. 113, sf. 53: Erhebungsbogen des PNF (Angaben von Januar 1922). Hier wird das Vorhandensein eines Sindacato economico zwar bejaht, bei "Anzahl der Mitglieder" steht aber ein Strich, was darauf hindeutet, daß es sich bei dieser Angabe um eine reine Absichtserklärung handelt. 
impiegati comunali gibt es gewisse Anhaltspunkte dafür, daß ihre Mitglieder zu diesem Zeitpunkt schon mehrheitlich zu den Sindacati economici übergelaufen waren ${ }^{33}$.

Auch die Abwesenheit der Straßenbahner-, Seeleute- und Hafenarbeitergewerkschaften ist aufschlußreich: In der relativ kleinen Gruppe der Straßenbahner, ihre Gewerkschaft umfaßte ganze 42 Personen, gab es von Anfang an Sympathisanten des Fascio und mindestens zwei aktive squadristi ${ }^{34}$. Die Abwesenheit der Lega buscaioli und der Lega marinai erklärt sich dagegen mit der Situation im Hafen von Marina di Carrara. Dort hatte die Allgegenwart der Squadren von Emilio Cucurnia und das Zusammenspiel der Faschisten mit den faschistenfreundlichen Spediteuren, Reedern und Kapitänen zu einer, wenn auch widerstrebenden Anlehnung der Hafenarbeiter und Seeleute an den Fascio geführt ${ }^{35}$. Obwohl der Terror so massiv war, daß Federico Menconi, der Sekretär der zu Giuliettis Federazione dei lavoratori del mare gehördenden Lega marinai, sich aus Furcht um Leib und Leben immer wieder aus Marina entfernen mußte, kam es erst am 13. Mai zum effektiven Übertritt der beiden Hafengewerkschaften und der zugehörigen Berufsgenossenschaft Garibaldi zu den Sindacati economic ${ }^{36}$. Sehr viel Freiwilligkeit war dabei nicht im Spiel. Die Squadren halfen kräftig nach: Die beiden Sekretäre, Menconi von den Seeleuten und Bruzzi von den buscaioli, und zahlreiche Gewerkschaftsmitglieder wurden nachts überfallen und zusammengeschlagen. Anschließend „verbannten“ die Faschisten Menconi endgültig aus Marina und zwangen ihn, noch in der gleichen Nacht abzureisen ${ }^{37}$.

Nicht ganz zuverlässige, zum Teil mit großem zeitlichen Abstand erfolgte Einträge in den Polizeiakten deuten auch auf frühzeitige Erfolge der Sindacati economici bei den Krankenpflegern, den Angestellten der Ferrovia marmifera, den metallurgici und den Steinmetzen hin $^{38}$. Außerdem waren nicht wenige Ligen, die auf dem Kongreß vom Februar 1922 vertreten waren, eigentlich nicht mehr wirklich funktionsfähig, nachdem ihre Vereinslokale von den squadristi heimgesucht worden waren. Viele Arbeiter, die früher am aktiven Gewerkschaftsleben teilgenommen hatten, blieben der Organisation

${ }^{33}$ ASM, Questura Massa, b. 11, f. „Lega camerieri“: Kommissar an Questore vom 14. 12. 1922; ebd., b. 13, f. „Unione salariati comunali“: Kommissar an Questore vom 23. 12. 1922. Hier wird behauptet, daß die beiden Gewerkschaften schon am Ende des Jahres 1921 zu den Sindacati economici übergegangen seien, was möglicherweise nicht stimmt, da nirgendwo sonst ein Anhaltspunkt für diesen Sachverhalt zu finden ist. In anderen Fällen sind entsprechende Angaben des Polizeikommissariats, die mit dem gleichen zeitlichen Abstand erfolgt sind, nachweislich falsch (vgl. Anm. 38).

${ }^{34}$ ASM, Questura Massa, b. 13, f. „Lega tranvieri“: „prospetto statistico“ vom 21. 1. 1919.

${ }^{35}$ Alalà vom 18. 3. 1922.

${ }^{36}$ ASM, Commissariato Carrara, b. 69: Kommissar an Questore vom 13. 5. 1922.

37 Il Cavatore vom 28. 5. 1922.

38 ASM, Commissariato Carrara, b. 71, f. „Unione marmisti“: Kommissar an Präfekten vom 10. 1. 1922; ASM, Questura Massa, b. 12, f. „Unione impiegati della ferrovia marmifera“: Kommissar an Questore vom 23. 12. 1922; ebenda, f. „Gruppo infermieri Carrara“: Kommissar an Questore vom 23.12. 1922. Auch hier sprechen die Quellen von Auflösung und Übergang zu den faschistischen Gewerkschaften vor dem Jahresende 1921. Der Gruppo infermieri und die Unione marmisti waren aber auf dem Kongreß der Camera del lavoro am 19./20. 2. 1922 noch vertreten. Bei den "marmisti“ ist es angesichts ihrer großen Zahl undenkbar, daß ein Übergang großer Teile der Organisation zu den Faschisten in anderen Quellen, etwa im Cavatore oder in Alalà, keinen Niederschlag gefunden hätte. Die Aussagen in den Polizeiakten deuten wohl lediglich auf ein schleichendes Abwandern hin. 
jetzt aus Angst oder Gleichgültigkeit fern ${ }^{39}$. Trotzdem bedeutete der Kongreß für die Camera del lavoro einen bemerkenswerten Erfolg, der der Öffentlichkeit klar vor Augen führte, daß trotz aller Organisationsanstrengungen der faschistischen Gewerkschaften und der eigenen weitgehenden Handlungsunfähigkeit ihre Basis noch nicht völlig abgebröckelt war. Die Faschisten reagierten auf diese einigermaßen gelungene Demonstration der gewerkschaftlichen Geschlossenheit auf ihre Weise: Sie „beschlagnahmten“ die folgende Ausgabe des Cavatore, die einen ausführlichen Kongreßbericht enthielt, an allen Verkaufsstellen und verbrannten die Zeitungen öffentlich in der zentralen Via Plebiscito ${ }^{40}$.

Ab dem Frühjahr 1922 ist ein deutliches Werben des Fascio um die Gunst der Arbeiter zu erkennen. Im Alalà vom 4. März fand sich ein Artikel über die lokale Wirtschaftslage, in dem zum ersten Mal und in ungewöhnlicher Schärfe betont wurde, daß der Fascio eine etwaige weitere Kürzung der Marmorarbeiterlöhne, wie sie gewisse Unternehmerkreise ins Auge fassen würden, um keinen Preis zulassen werde. Etwa gleichzeitig mußte die Camera del lavoro ihre erste große Niederlage einstecken. Ein nicht unbedeutender Teil der Lega lizzatori ai monti samt ihrem Sekretär Antonio Zanichelli trat Anfang März zu den Sindacati economici über ${ }^{41}$. Dieser Vorgang war für die Gewerkschaftsführung doppelt schmerzlich. Bei den lizzatori handelte es sich nämlich um eine der großen Arbeitergruppen der Marmorwirtschaft ${ }^{42}$, die bisher für besonders überzeugte und militante sovversivi gehalten worden waren. Ein Polizeibericht vom Februar 1921 bezeichnete alle Angehörigen der zwanzigköpfigen Führungsmannschaft der Lega lizzatori ai monti, auch diejenigen, die nun zu den Faschisten übergelaufen waren, als gefährliche Anarchisten, die zu überwachen seien ${ }^{43}$. Alberto Meschi pflegte die lizzatori die bersaglieri der Camera del lavoro zu nennen ${ }^{44}$.

Es wirft einige interpretatorische Schwierigkeiten auf, daß ausgerechnet diese Gruppe als eine der ersten von der Gewerkschaftszentrale abfiel. Nach Angaben der Gewerkschaftszeitung waren es hauptsächlich die jungen, ideologisch nicht gefestigen Ligenangehörigen, die sich aber in der Vergangenheit durch einen ausgeprägten gewerkschaftlichen Radikalismus hervorgetan hatten, die ihrer alten Organisation jetzt den Rücken

39 Das Moment der Gleichgültigkeit betont Il Cavatore vom 18. 3. 1921. Diese habe sich ausgebreitet, als die Ligen nicht mehr in der Lage gewesen seien, tarifliche Verbesserungen zu erstreiten.

40 ACS, MI, DGPS 1922, b. 134, f. „Fasci Massa“: Präfekt an Innenministerium vom 5. 3. 1922. Da der Großteil der Auflage aber über die Ligen verteilt wurde, also gar nicht in den öffentlichen Verkauf gelangte, hielt sich die Wirkung der Maßnahme in Grenzen.

${ }^{41}$ Il Cavatore vom 1. 4. 1922. Hier wird betont, daß die Mehrheit der Mitglieder bei der alten Liga geblieben sei. Es handelte sich aber mit Sicherheit um eine Abspaltung von bedeutender Größenordnung.

42 Die Lega lizzatori ai monti gehörte zu den größeren Einzelgewerkschaften der Camera del lavoro. Im Jahre 1913 hatte sie schon 250 Mitglieder (ASM, Questura Massa, b. 12, f. „Lega lizzatori ai monti": „prospetto statistico" vom 7. 1. 1913). Jüngere Zahlen sind nicht vorhanden.

43 Ebenda: Polizeikommissar von Carrara an Questore vom 14. 2. 1921.

44 Il Cavatore vom 1. 4. 1922. Unter den Initiatoren der "Arditi del popolo“, die im Juli 1921 den rudimentären Ansatz eines bewaffneten Widerstands gegen die Faschisten organisiert hatten, befanden sich drei Ligenführer der „lizzatori“: Andrea Giandalasini und Almo Granai aus Carrara, Ernesto Andreazzoli aus Massa. Alle drei waren seit Monaten in Haft. Die erzwungene Abwesenheit von Giandalasini, der zu den exponierten Arbeiterführern Carraras gehörte, mag das Auseinanderbrechen "seiner" Gewerkschaft begünstigt haben. 
kehrten ${ }^{45}$. Offensichtlich rechneten sie damit, daß sie unter dem Schutz der faschistischen Organisation ihren sozialen Besitzstand besser wahren würden. Tatsächlich erschien auch unmittelbar nach dem Übertritt in Alalà eine Bekanntmachung der frischgebackenen Corporazione lizzatori ${ }^{46}$, in der sie auf die zahlreichen Tarifverletzungen der esercenti lizza hinwies und betonte, daß sie dies zukünftig nicht mehr dulden wer$\mathrm{de}^{47}$.

Der Differenzierungsprozeß, der sich um die Jahreswende auf nationaler Ebene zwischen der auf Unabhängigkeit vom PNF bedachten Confederazione italiana dei sindacati economici und der am 24. Januar neugegründeten eindeutig faschistischen Confederazione nazionale delle corporazioni sindacali vollzogen hatte ${ }^{48}$, hatte keinerlei Niederschlag in der Marmorregion. Das Problem stellte sich hier gar nicht, weil die Camera carrarese dei sindacati economici ohnehin nie auch nur die geringste Unabhängigkeit von der lokalen faschistischen Führung gehabt hatte. Sie behielt auch noch längere Zeit diesen Namen, obwohl die Einzelgewerkschaften, soweit sie vorhanden waren, von nun an im Geiste des Bologneser Kongresses Corporazioni benannt wurden. Die dort diskutierten Pläne eines korporativen Zusammenschlusses von Unternehmern und Arbeitern unter einem Dach waren in Carrara sofort positiv rezipiert worden.

Am 29. Januar hoben die faschistischen Unternehmer die Corporazione industriali aus der Taufe, und Gualtiero Betti feierte das Ereignis als den Anfang der korporativen Organisation der lokalen Marmorwirtschaft ${ }^{49}$. Freilich waren die Faschisten von diesem Ziel noch weit entfernt, denn solange die Mehrzahl der Arbeiter sowie die großen Produzenten und Exporteure nicht bei ihnen organisiert waren, war an eine praktische Verwirklichung dieser Pläne nicht zu denken. Bei einigen Marmorindustriellen stießen die Initiative und der Kommentar von Betti auch sofort auf scharfe Ablehnung. Sie mutmaßten, und nicht zu Unrecht, daß die ins Auge gefaßte Korporativverfassung nicht nur ihre Tarifautonomie beseitigen würde, woran Betti ohnehin keinen Zweifel gelassen hatte, sondern auch jede Möglichkeit zur freien Preisgestaltung ${ }^{50}$. In einer Replik beteuerte Betti, daß den Korporationen eine "unbegrenzte innere Freiheit" zugestanden sei, bestätigte aber die Befürchtungen der freihändlerisch orientierten Unternehmer mit einer anschließenden wütenden Attacke auf die herrschende ruinöse Konkurrenz auf dem Marmormarkt, die es gelte, in den Griff zu bekommen, um Schaden von Unternehmerschaft und Arbeiterschaft abzuwenden ${ }^{51}$. Das Mißtrauen der führenden Unternehmer

45 Ebenda.

46 Sektretär der Corporazione lizzatori wurde - wie schon in der alten Liga - Antonio Zanichelli und Vizesekretär Andrea Scroglieri, der sich als Kassenwart der alten Liga Unregelmäßigkeiten hatte zuschulden kommen lassen und deshalb mit der Camera del lavoro in Schwierigkeiten geraten war. Es ist gut denkbar, daß dies bei seinem Übertritt zur Corporazione eine gewisse Rolle gespielt hat. Der ${ }_{n}$ Fall Scroglieri“ bildete jedenfalls den Gegenstand einer Presseauseinandersetzung zwischen Camera del lavoro und den Faschisten, die zum Schluß den Vizesekretär von seinem Amt suspendierten und eine Untersuchung gegen ihn einleiteten (Alalà vom 25. 3. 1922). Das Ergebnis ist nicht bekannt.

47 Alalà vom 4. 3. 1922.

48 Siehe dazu Cordova, Sindacati fascisti, S. $45-70$.

49 Gualtiero Betti, „Corporazioni“, in Alalà vom 11. 2. 1922.

so Die Kritik der Industriellen ist zwar nicht überliefert, aber aus der Entgegnung von Betti in der folgenden Nummer von Alalà (18. 2. 1922) herauszulesen.

51 Ebenda. 
gegenüber der korporativen Zwangsjacke war jedenfalls so groß, daß das Projekt zunächst überhaupt nicht vorwärtskam; man sprach nicht einmal mehr davon.

Die Meinungsunterschiede im Unternehmerlager bewirkten einen Dauerzwist in der Federazione industriali, der zu einem internen Patt führte, von dem aber wenig nach außen drang. Der Verband war, außer in Fällen wie der Entwaffnungsfrage, bei der die latente Bürgerkriegspolarisierung diese Differenzen einebnete, nahezu aktionsunfähig. Mit Rücksicht auf die innere Balance vermied er es, die Faschisten offen zu unterstützen, er legte ihnen aber auch keine Knüppel in den Weg, wie er es im September unter Carlo Andrea Fabbricotti getan hatte ${ }^{52}$. Vor allem die kleineren faschistischen und profaschistischen Unternehmer ließen es sich allerdings nicht nehmen, ihre Arbeiter mit Pressionen aller Art zum Eintritt in die faschistischen Gewerkschaften zu bewegen. Dieser Druck ließ sich schlecht nachweisen, weil er „unter der Hand“ ausgeübt wurde und die betroffenen Arbeiter sich nicht trauten, damit an die Öffentlichkeit zu gehen ${ }^{53}$. Die Camera del lavoro reagierte auf diese Praxis wie schon im September, indem sie mit einem Plakat denjenigen Unternehmern, die zweifelsfrei der Verletzung der Organisationsfreiheit in ihren Betrieben überführt würden, den Boykott androhte, was konkret das erneute Eingreifen der Hafenarbeiter von Livorno und Genua bedeutete ${ }^{54}$. Dieser Vorstoß der Camera del lavoro führte zu einer Untersuchung der Unternehmervereinigung bei ihren Mitgliedsunternehmen, die zu dem Ergebnis kam, solche Verstöße gegen die Gewerkschaftsfreiheit lägen nicht vor ${ }^{55}$. Das entsprach natürlich nicht der Wahrheit, doch die Drohung der Gewerkschaft und die Untersuchung der Federazione industriali scheinen für die Zukunft die gröbsten Übergriffe verhindert zu haben.

Es ist ein bemerkenswertes Faktum, daß gerade jene mittelgroßen Unternehmer, die sich schon frühzeitig im Fascio engagiert hatten, nicht durch besonders rigoroses Vorgehen gegenüber den eigenen Belegschaften auffielen. Die Firmen Faggioni, Gattini und Dell'Amico/Colombi hatten vor dem Auftreten des Faschismus sogar den Ruf, besonders „demokratische“, arbeiterfreundliche Unternehmen zu sein ${ }^{56}$. Vor allem der ehemalige Anarchist und „Held“ der Aufstandsbewegung von 1894, Carlo Gattini ${ }^{57}$, genoß, obwohl er inzwischen schon längst ein Liberalkonservativer geworden war, bei den

52 Vgl. oben, S. $127 \mathrm{f}$.

53 Vor allem die Kleinunternehmer der „lizzatura“ (Marmortransport) und der „laboratori“ (Steinmetzwerkstätten) scheinen diese Pressionen ausgeübt zu haben, was eine zusätzliche Erklärung für die Erfolge der faschistischen Gewerkschaften bei den „lizzatori“ und den „marmisti“ (Steinmetzen) darstellt. Als die Faschisten am 26. 3.1922 in Gragnana den Anarchisten Augusto (detto Giovanni) Musetti ermordeten, hatte dieser den Ausweis des Sindacato economico in der Tasche; er war von seinem Arbeitgeber Tognini zum Beitritt gezwungen worden (Il Cavatore vom 1.4. 1922).

${ }^{54}$ Ebenda.

55 Il Giornale di Carrara vom 1. 4. 1922.

${ }^{56}$ Il Cavatore vom 15. 10.1921. Snowden, Fascist Revolution, S. 115, erwähnt allerdings die Ersetzung der gesamten Belegschaft durch Arbeiter der faschistischen Gewerkschaft im Frühjahr 1922 bei der Firma Francesco Dell'Amico. Die Nachricht ist Il Paese vom 29. 5. 1922 entnommen, bezieht sich also möglicherweise auf die Zeit nach der Kaltstellung der Camera del lavoro.

57 Zur Vergangenheit von Carlo Gattini als anarchistischem „Volkshelden" siehe Gestri, Capitalismo, S. 149, 164, 203, 207, 219 und Mori, Lotta sociale, S. 202. Außerdem ACS, MI, CPC, b. 2313: Hier wird schon im Jahre 1909 seine völlige Hinwendung zu den Unternehmergeschäften und die Abkehr von den Anarchisten verzeichnet. Carlo Gattini verlor im Juli 1921 in Sarzana seinen Sohn Pietro, der dort als „squadrista“ im Einsatz war. 
Arbeitern ganz besondere Achtung. Es ist anzunehmen, daß das Engagement dieser relativ „arbeiternahen“ Unternehmer im Fascio der Popularität des Faschismus förderlich war. Alles weist darauf hin, daß die genannten Firmen auch mit dem Fortschreiten der faschistischen Machtausweitung in ihren Betrieben keine grundsätzlich andere Praxis einführten. Es gibt zum Beispiel keinen Hinweis dafür, daß die Arbeiter dort einem besonderen Druck ausgesetzt waren, in die faschistischen Gewerkschaften einzutreten. Die Nachrichten von derartigen Pressionen stammen ausschließlich von anderen, meist kleineren Firmen ${ }^{58}$. Das gleiche gilt für Verstöße gegen die geltenden Tarifverträge; bei keiner der genannten Firmen läßt sich in den Quellen auch nur der leiseste Hinweis dafür finden.

Ganz anders war das Verhalten von Guido Murray Fabbricotti, der Anfang Oktober 1921 - als ihm die Gewerkschaftsbewegung schon genügend geschwächt erschien - in seinen Steinbrüchen versuchte, die Tagesarbeitszeit einseitig um 40 Minuten heraufzusetzen, natürlich bei gleichem Tageslohn ${ }^{59}$. Er hatte sich allerdings verrechnet. Ohne übergeordnete gewerkschaftliche Organe zu bemühen, traten seine Arbeiter sofort in einen unbefristeten Streik. Als im nachhinein die Camera del lavoro die Leitung des Ausstands übernahm, weigerte sich Guido Fabbricotti, mit ihr zu verhandeln, mußte aber, angesichts der entschiedenen Haltung seiner Belegschaften, in der Sache nachgeben und zu den alten tariflichen Vereinbarungen zurückkehren. Fünf Tage nach dem mißlichen Ausgang seines Experimentes bat Guido Fabbricotti um die Aufnahme in den Fascio ${ }^{60}$. Der zeitliche Zusammenhang ist so deutlich, daß es sich vermutlich auch um einen kausalen handelte.

Mit Guido Fabbricotti trat einer der großen und sicherlich einer der reaktionärsten Marmorindustriellen offen in das Lager der Faschisten. Schon lange vor dem Auftreten des Faschismus hatte sich Fabbricotti beständig geweigert, mit der Camera del lavoro zu verhandeln. Außerdem hatte er schon früher verschiedentlich versucht, die Tarifverträge zu unterlaufen. So ließ er in seinen Steinbrüchen teilweise unter den Bedingungen eines kollektiven Akkords arbeiten ${ }^{61}$. Im Betrieb trat er ausgesprochen autoritär auf, und in der Öffentlichkeit gab er sich herrschaftlich, was unter den eher plebejisch gesitteten Marmorunternehmern von Carrara recht unüblich war. Er war in London geboren, seine Mutter Helen Murray war Britin, und auch er besaß einen britischen Paß ${ }^{62}$. Den britischen Stil pflegte er auch in Carrara: So hielt er sich einen Reitstall und ritt regelmäßig aus, was sein Feudalherrenimage zusätzlich nährte. Seine britische Staatsbürgerschaft hatte ihm außerdem den Kriegsdienst erspart, und so galt er als imboscato, als Drückeberger ${ }^{63}$.

58 Vgl. Anm. 53.

59 Zum Verlauf der Auseinandersetzung siehe Il Cavatore vom 15. 10. 1921; außerdem ASM, Commissariato Carrara, b. 69: Sonderdruck von Il Cavatore vom 16. 5. 1922.

60 ACS, Fondo Renato Ricci, b. 5, f. „Carrara PNF $1921-23^{4}$ : Schreiben von Guido Fabbricotti an Ricci vom 20. 10. 1921.

61 In der Rubrik „Uomini e bestie" widmete ihm Il Cavatore vom 26.6. 1920 einen Artikel mit dem Titel „L'asino carico d'oro“ (der goldbeladene Esel), in dem seine gewerkschaftsfeindliche Verbohrtheit und seine Feudalherrenallüren satirisch aufs Korn genommen wurden.

62 BCM, Archivio Fabbricotti: Stammbaum der Familie, bearbeitet von Mariangela Aranzulla und Antonio Bernieri, bei den allgemeinen Unterlagen (noch ohne Signatur).

${ }^{63}$ ACS, MI, Gabinetto Finzi, b. 12, f. 145: Memorandum von Ettore Viola ohne Datum (Mai 1924). 
Für den Fascio handelte es sich also um keine ganz unproblematische Neuerwerbung, weil sie mit dem Bemühen, das reaktionäre Image der Bewegung abzuschütteln, nicht in Einklang zu bringen war. Guido Fabbricotti genoß ein viel schlechteres Ansehen als sein „antifaschistischer" Vetter Carlo Andrea Fabbricotti, der sich als sozialer Wohltäter und im Krieg verdient gemacht hatte und deshalb zum „Grand Ufficiale della Corona d'Italia " ernannt worden war ${ }^{64}$. Überhaupt erscheint es nicht ausgeschlossen, daß die Rivalität zwischen den beiden Zweigen der Familie Fabbricotti den Beitrittsentschluß von Guido Fabbricotti, der in jeder Hinsicht im Schatten seines Vetters stand, gefördert hat. Aus welchen Gründen seine Hinwendung zum Fascio auch erfolgt sein mag, Renato Ricci konnte das Aufnahmeersuchen eines so potenten Geldgebers nicht zurückweisen, zumal er den Fascio vermutlich schon vorher finanziell unterstützt hatte. Guido Fabbricotti erwies sich gegenüber der faschistischen Organisation nicht als geizig: Er stellte unter seinem Kommando eine Reiterstaffel der squadre d'azione auf die Beine, die er im wesentlichen aus eigener Tasche finanzierte ${ }^{65}$.

Es blieb diesem reaktionären und etwas exzentrischen Unternehmer vorbehalten, den Anlaß für den Entscheidungskampf zwischen den Faschisten und der alten Camera del lavoro zu liefern. Im Laufe der Monate März und April hatten die faschistischen Gewerkschaften einen gewissen Zulauf. Es ist auf der Grundlage der vorhandenen Quellen nicht möglich, das Kräfteverhältnis zwischen der alten Camera del lavoro und der Camera dei sindacati economici genau zu bestimmen. Alalà behauptete am 15. April, daß die faschistische Gewerkschaft mittlerweile die "mächtigere" Organisation in Carrara sei; da sich das Blatt aber davor hütete, Zahlen zu nennen, ist anzunehmen, daß die Situation gar nicht so rosig aussah ${ }^{66}$. Trotzdem bereiteten sich die Faschisten auf ein Kräftemessen vor. Die Gelegenheit hierfür ergab sich bei der Auseinandersetzung um den Tag der Arbeit. Der PNF propagierte als Ersatz für den internationalistischen 1. Mai den „Tag der italienischen Arbeit“ am 21. April, dem fiktiven Gründungsdatum Roms. An diesem Tag sollte nicht gearbeitet werden, und eine Zeremonie mit der feierlichen Übergabe der Nationalfahne an die Camera dei sindacati economici war vorgesehen. Die Faschisten erwirkten vom Marmorunternehmerverband die Anerkennung des 21. April als Feiertag, und der Verbandsvorsitzende Frugoli forderte die Mitgliedsfirmen in einem Rundschreiben praktisch dazu auf, an diesem Tag zu schließen ${ }^{67}$. Mit diesem Flankenschutz gelang es den Faschisten, ihrem neuen Feiertag zum Durchbruch zu verhelfen. 3500 Per-

${ }^{64}$ ASM, Commissariato Carrara, b. 39, f. „Carlo Andrea Fabbricotti“: Kommissar von Carrara an Präfekten von Massa vom 21. 9. 1915 (Gutachten für die Ernennung Fabbricottis).

${ }^{65}$ ACS, MI, DGPS 1922, b. 134, f. „Fasci Massa“: Präfekt an Innenministerium vom 5. und 18. 4. 1922. Die Aufstellung von Reiterstaffeln war eigentlich nicht zulässig. Die Polizei intervenierte zunächst, und Fabbricotti und Ricci versprachen davon Abstand zunehmen, was dann aber nicht geschah. Später drückten die Behörden einfach beide Augen zu. Die „squadra a cavallo“ war eine Besonderheit und wurde bei allen Paradeaufmärschen der Carrareser Squadren stolz zur Schau gestellt (Photo der Carrareser Reiterstaffel von 1922 bei Gentile, Partito fascista, Abb. 25).

${ }^{66}$ Der Ende Mai in die Marmorregion entsandte Generalinspektor D'Orazio schrieb in seinem Abschlußbericht (ohne Datum), die Erfolge der Sindacati economici seien bisher gering gewesen; ACS, MI, DGPS 1922, b. 132,f. „Fasci Lucca“, sf. „Seravezza“.

${ }^{67}$ Wortlaut des Rundschreibens in Il Cavatore vom 1. 5. 1922. 
sonen konnten zu den Feierlichkeiten mobilisiert werden, zu denen auch Perrone Compagni und Costanzo Ciano anreisten ${ }^{68}$.

Obwohl der "Tag der italienischen Arbeit“ in Carrara, zumindest äußerlich, einen gewissen Erfolg gebracht hatte, gelang es den Faschisten nicht, die Niederlegung der Arbeit am 1. Mai zu verhindern. Sie hatten zwar für den Tag die Squadren der principi mobilisiert ${ }^{69}$, aber nur um eventuelle Demonstrationen zu verhindern. Daß die Arbeiter zuhause blieben, ließ sich nicht verhindern, schließlich handelte es sich um einen offiziell anerkannten Feiertag und eine in der Arbeiterschaft festverwurzelte Tradition. So ging die große Mehrheit der Arbeiter in Carrara wie auch in den anderen Gebieten der Marmorregion am 1. Mai nicht zur Arbeit. Viele Mitglieder der Sindacati economici blieben ebenfalls zuhause, was den Cavatore zu sarkastischen Bemerkungen über die Loyalität dieser Arbeiter gegenüber ihrer Führung veranlaßte ${ }^{70}$. Die Unternehmer, auch die Faschisten unter ihnen, tolerierten die Arbeitsniederlegung auch in diesem Jahr und vermieden so lästige Konflikte mit ihren Belegschaften.

Eine Ausnahme bildete Guido Fabbricotti, der in seinen Betrieben angeordnet hatte, daß alle Beschäftigten am 1. Mai zur Arbeit zu erscheinen hätten. Als doch einige Arbeiter daheim blieben, wurden sie kurzerhand entlassen ${ }^{71}$. Die Camera del lavoro reagierte mit einem Schreiben, in dem sie ihn aufforderte, die Arbeiter wieder einzustellen, ihnen den Verdienstausfall zu bezahlen und eine Erklärung abzugeben, daß er sich in Zukunft solcher Angriffe gegen die Meinungs- und Organisationsfreiheit enthalten werde, anderenfalls werde die Camera del lavoro den Boykott seiner Marmorlieferungen in Livorno erwirken ${ }^{72}$. Peinlicherweise waren einige der Betroffenen Mitglieder der Sindacati economici. Die faschistischen Gewerkschaften traten daher ebenfalls in Aktion und erreichten bei Fabbricotti die Wiedereinstellung aller entlassenen Arbeiter, einschließlich derer, die in der Camera del lavoro organisiert waren, sowie die Bezahlung der ausgefallenen Arbeitstage. Fabbricotti bestand allerdings darauf, daß kein Verhandlungsprotokoll unterzeichnet werde und daß die Arbeiter stillschweigend und ohne Aufforderung von seiner Seite an den Arbeitsplatz zurückkämen. Sein Einlenken wollte er nicht als Schuldbekenntnis, sondern als Gnadenakt verstanden wissen. Mit der Camera del lavoro trat er überhaupt nicht in Kontakt, ihren Brief ignorierte er einfach. Diese konnte es natürlich nicht dulden, daß sie solchermaßen ausgespielt wurde. Es gelang ihr, zwei der betroffenen Arbeiter davon abzuhalten, an ihre Arbeitsplätze zurückzukehren, und am 13. Mai ließ sie den Boykott der Marmorladungen Fabbricottis in Livorno anlau$\mathrm{fen}^{73}$.

68 ACS, MI, DGPS 1922, b. 134, f. „Fasci Massa“: Präfekt an Innenministerium vom 22. 4. 1922; Alalà vom 29. 4. 1922.

69 Mobilisierungsbefehl des Kommandanten der Carrareser Squadren Luigi Da Pozzo (Alalà vom 29. 4. 1922).

70 Il Cavatore vom 13.5. 1922.

71 ASM, Commissariato Carrara, b. 69: Polizeikommissar De Mase an Questore vom 8. 5. 1922, Handzettel der Camera del lavoro vom 16. 5. 1922, Handzettel des PNF Carrara (Sonderdruck von Alalà).

72 Ebenda.

73 Die beiden Arbeiter entfernten sich sogar aus Carrara, um den unvermeidlichen Pressionen aus dem Wege zu gehen, und so war der Polizeikommissar nicht in der Lage, sie aufzuspüren, um sie zu einer Rückkehr an den Arbeitsplatz zu überreden; ASM, Commissariato Carrara, b. 69: Kommissar an Questore vom 16. 5. 1922. 
Wie schon beim Boykott der Firma Pisani im September/Oktober 1921 versuchte Renato Ricci eine Arbeiterkolonne aus Carrara nach Livorno zu schaffen, die das Umladen des Marmors auf die Dampfschiffe besorgen sollte, aber wie damals scheiterte er an der Entschlossenheit der Hafenarbeiter und am Widerstand des dortigen Questore ${ }^{74}$. Über 2000 Tonnen Marmor der Firma G. Fabbricotti lagen im Hafen fest. Ricci ordnete daraufhin in Carrara den Boykott des Hafens von Livorno an und entsandte eine Squadra an den Bahnhof von Avenza mit dem Auftrag, jegliche Lieferung dorthin zu unterbinden, was zu einem weitgehenden Stillstand des Marmorexportes führte, da Genua gar nicht in der Lage war, Livorno zu ersetzen ${ }^{75}$. Außerdem setzte Guido Fabbricotti 150 der Camera del lavoro zugehörige Arbeiter auf die Straße. Faschistische Squadren bildeten Sperren an den Zugangsstraßen zu den Marmorsteinbrüchen und schickten die in den alten Ligen organisierten Arbeiter nach Hause zurück ${ }^{76}$. Die Situation spitzte sich gefährlich zu. Der Fascio ließ einen Handzettel mit einer nahezu offenen Morddrohung an die Adresse der Verantwortlichen der Camera del lavoro verteilen, und der Präfekt ordnete daraufhin an, den Polizeiposten vor der Gewerkschaftskammer auf 12 Mann zu erhöhen ${ }^{77}$.

Zwei Tage später, am 18. Mai um 7 Uhr morgens, fanden zwei Carabinieri des erwähnten Wachpostens in einem zum Gewerkschaftsgebäude gehörenden Raum, der durch ein Mauerloch von außen frei zugänglich war und zur Lagerung von Bauschutt verwendet wurde, „zufällig “ ein Paket mit Sprengstoff'8. Die Carabinieri nahmen daraufhin den in den Lokalen der Camera del lavoro wohnenden Vizesekretär Gino Petrucci fest. Dieser stritt entschieden ab, daß er und die Führung der Camera del lavoro damit etwas zu tun hätten, und verwies darauf, daß der Raum überhaupt nicht zu den Gewerkschaftslokalen gehöre und von jedermann betreten werden könne. Trotzdem wurde er und kurz darauf auch sein Bruder Egidio Petrucci wegen unerlaubten Sprengstoffbesitzes in Haft genommen. Später fand die Polizei im gleichen Raum noch zwei weitere Sprengsätze und eine alte Vorderladerpistole.

Die Faschisten waren sofort informiert. Sie ließen Handzettel drucken, auf denen sie die verbrecherischen Absichten der Gewerkschaftsführung anprangerten und zu einer Kundgebung noch am Abend des gleichen Tages aufriefen ${ }^{79}$. Faschisten und fiancheggiatori flaggten in Erwartung eines großen Ereignisses, und auf der Kundgebung, an der circa 3000 Personen teilnahmen, wurde feierlich der Tod der alten Camera del lavoro bekanntgegeben ${ }^{80}$. Mit Zustimmung der Polizeiverantwortlichen von Carrara besetzte eine Abteilung faschistischer Arbeiter die Räume der Gewerkschaftszentrale, welche

\footnotetext{
${ }^{74}$ Ebenda und Il Cavatore vom 28. 5. 1922.

75 ASM, Commissariato Carrara, b. 69: Carabinieri von Avenza an Kommissar vom 17. 5. 1922; Il Cavatore vom 28. 5. 1922. Zur Beilegung des Boykotts in Livorno nach der Ausschaltung der Camera del lavoro in Carrara siehe Abse, Sovversivi, S. 206.

76 Dieses interessante Detail findet sich in einem ausführlichen Bericht über die Vorfälle in Avanti! vom 23. 5. 1922.

77 ASM, Commissariato Carrara, b. 69: Kommissar an Carabinieri-Kommando vom 16. 5. 1922.

78 Ausführliche Darstellung des Hergangs in ASM, Tribunale Massa, Sentenza penale 1923/7 (20. 1. 1923).

79 ASM, Commissariato Carrara, b. 69: Flugblatt im Akt.

${ }^{80}$ Ebenda: Kommissar an Questore vom 18. 5. 1922.
} 
eigentlich von den Ermittlungsbehörden aus Gründen der Spurensicherung in Beschlag genommen worden waren, und hißte dort als Siegeszeichen die Nationalfahne ${ }^{81}$.

Um den Sieg zu vervollkommnen, starteten noch in der gleichen Nacht ein Lastwagen mit 40 squadristi und zwei Automobile mit dem „Generalstab“ der Carrareser Squadren nach Seravezza. Dort vereinigte sich die spedizione mit den schon bereitstehenden Squadren der Versilia und schritt dann zum Sturm auf die dortige Camera del lavoro ${ }^{82}$. Auch hier kulminierte die „Eroberung“ im Hissen der Nationalfahne. Anschließend begaben sich die Carrareser Renato Ricci, Luigi Da Pozzo, Pietro Prayer Galetti und die Sekretäre der PNF-Ortsvereine von Pietrasanta und Seravezza, Claudio Papini und Vincenzo Gasperetti, zur örtlichen Carabinieri-Station und bestellten den Sekretär der Gewerkschaftskammer, Attilio Fellini, dorthin. Als dieser sich weigerte, der Aufforderung Folge zu leisten, suchten die Faschistenführer ihn bei sich zuhause auf, und nach einer kurzen „Unterredung“, bei der ihm die Faschisten den Übertritt zu den Sindacati economici bei Wahrung seiner Stellung anboten und er dieses Ansinnen ablehnte ${ }^{83}$, lud man ihn in eines der Autos. Bei der Durchfahrt von Querceta wurde der Wagen allerdings von den örtlichen Carabinieri gestoppt und alle Insassen in Gewahrsam genommen. Es ist nicht zu ermitteln, mit welchen Drohungen Fellini eingeschüchtert worden war, jedenfalls erklärte er merkwürdigerweise gegenüber den Carabinieri, er sei freiwillig mitgegangen, und so kamen die Faschisten wieder frei. Fellini blieb bis zum nächsten Morgen in der caserma und wurde dann von den Carabinieri zum Bahnhof gebracht, wo er den Zug nach Genua nahm, dem Ort seines vorläufigen „Exils“.

Die Vorfälle von Seravezza führten zu einer parlamentarischen Anfrage der sozialistischen Abgeordneten Mingrino, Modigliani und Ventavoli ${ }^{84}$ und zur Entsendung des Polizeigeneralinspektors D'Orazio, der dem Innenminister nach Abschluß seiner Untersuchung die Versetzung des Polizeikommissars von Carrara, De Mase, empfahl ${ }^{85}$. Tatsächlich hatte die Carrareser Polizei den Faschisten so deutlich in die Hände gearbeitet, daß es sich auch mit viel Mühe nicht verbergen ließ. De Mase erklärte, er habe die Faschisten in die Camera del lavoro hineinlassen müssen, weil es sonst zu einem Blutvergießen gekommen wäre ${ }^{86}$. Außerdem beteuerte er entgegen den Feststellungen der Polizeistellen der Provinz Lucca und den von D'Orazio gesammelten Erkenntnissen, daß in der betreffenden Nacht kein Lastwagen mit squadristi von Carrara gestartet sei ${ }^{87}$. Die Willfährigkeit gegenüber den Faschisten war allerdings in den Amtsstuben und Cara-

81 Der Präfekt Berti meinte dazu, daß man mit etwas Standhaftigkeit wenigstens hätte verhindern können, daß die Faschisten dort einen ganzen Tag verbrachten; ACS, MI, DGPS 1922, b. 132, f. „Fasci Lucca“, sf. „Seravezza“: Präfekt an Innenministerium vom 26. 5. 1922.

82 Die Darstellung der „spedizione“ nach Seravezza folgt dem Untersuchungsbericht des Generalinspektors D'Orazio ohne Datum (wie Anm. 66), der wesentlich glaubwürdiger ist als die in einigen Punkten abweichenden Darstellungen der Polizei von Carrara.

${ }^{83}$ Il Cavatore vom 28. 5. 1922; außerdem ACS, MI, DGPS 1922, b. 132, f. „Fasci Lucca“", sf. „Seravezza": Untersuchungsbericht des Generalkommandos der Carabinieri vom 29. 6. 1922.

84 Wortlaut in Avanti! vom 23. 5. 1922.

${ }^{85}$ ACS, MI, DGPS 1922, b. 132, f. "Fasci Lucca“, sf. „Seravezza“: Abschlußbericht von D’Orazio ohne Datum.

86 ASM, Commissariato Carrara, b. 69: Kommissar an Questore vom 18. 5. 1922.

87 Ebenda: Kommissar an Questore vom 26. 5. 1922. Unter anderem verweist er dabei auf das „Ehrenwort“ von Prayer Galetti und anderen Faschisten. 
binieri-Stationen von Carrara und Massa ein allgemeines Problem und ließ sich nicht mit der Versetzung von De Mase beseitigen, die übrigens nicht erfolgte.

Trotz der windigen Indizien gegen die Führung der Camera del lavoro in der Sprengstoffsache hielten Staatsanwalt und Untersuchungsrichter Gino Petrucci bis zum 27. August in $\mathrm{Haft}^{88}$. Das Gebäude der Camera del lavoro wurde inzwischen von der Polizei direkt dem Eigentümer, der Gemeinde Carrara, vertreten durch den Regierungskommissar Di Lungarini, übergeben. Und Di Lungarini „verpflichtete“ sich gegenüber den Faschisten, es der alten Camera del lavoro in jedem Fall vorzuenthalten ${ }^{89}$. Der Präfekt Berti, der bei der lokalen Linken - weitgehend zu Unrecht - einen erstaunlich guten Ruf hatte, unterstützte dieses Vorgehen ohne Einschränkungen. Er versicherte dem Ministerium, daß es aus Gründen der „öffentlichen Ordnung“ unklug wäre, das Gebäude an die Gewerkschaftsführer zurückzugeben, von denen ohnehin niemand bereit sei, die Camera wieder in Betrieb zu nehmen ${ }^{90}$. Außerdem müsse man vor einem solchen Schritt die Ergebnisse der strafrechtlichen Untersuchung abwarten, und er erwarte ohnehin, daß sich die Rückgabe auf Dauer erübrige, weil die Ligen unterdessen zu den Sindacati economici übergehen würden ${ }^{91}$. Die Behörden trugen also ganz bewußt zur definitiven Ausschaltung der alten Gewerkschaftsorganisation bei und verliehen dem Vorgang so ein scheinlegales Gewand.

Das zwielichtigste Vorkommnis in der Affäre, die zur Beseitigung der Camera del lavoro führte, war die plötzliche Auffindung der Sprengsätze gerade auf dem Höhepunkt der Auseinandersetzungen um den Boykott der Firma G. Fabbricotti. Ohne viel Federlesens wurde die unglaubwürdigste aller Hypothesen, daß nämlich die Gewerkschaftsführung den Sprengstoff dort versteckt hielt, als der praktisch nachgewiesene Tatbestand ausgegeben. In Wirklichkeit waren die Indizien so schütter, daß der Strafsenat des Tribunale di Massa im Januar 1923, trotz der phantasievollen Zeugenaussagen von zwei ehemaligen Anarchisten, die früher Zugang zum engeren Kreis der Gewerkschaftsführung gehabt hatten und in der Zwischenzeit zu den Faschisten übergelaufen waren, in dieser

${ }^{88}$ ASM, Tribunale Massa, Sentenza penale 1923/7 (20.1. 1923).

89 De facto übergaben die Faschisten die Camera del lavoro an Di Lungarini (Alalà vom 27. 5. 1922), was im Bericht des Polizeikommissars De Mase natürlich unterschlagen wird, weil es offenlegen würde, daß er diese illegale Amtsanmaßung geduldet hat. Auch der Commissario regio hatte offensichtlich nichts daran auszusetzen, denn es war bei dieser Gelegenheit, daß er den Faschisten das erwähnte Versprechen gab (ebenda).

90 Am 24 5. 1922 rief der Polizeikommissar von Carrara die noch erreichbaren Mitglieder der Exekutivkommission der Camera del lavoro zusammen. Bei dieser Gelegenheit wurde ihm sehr wohl der Wunsch nach Rückgabe der Räumlichkeiten vorgetragen. Offensichtlich war aber die Polizei nicht bereit, die in diesem Fall drohende Besetzung durch die Faschisten zu verhindern, denn die Gewerkschaftsführer äußerten zum Schluß der Unterredung, daß sie den gegenwärtigen Zustand einer Inbesitznahme durch die faschistischen Gewerkschaften vorzögen (ASM, Commissariato Carrara, b. 69: Kommissar an Präfekt vom 26. 5. 1922). Unter den in Carrara verbliebenen Mitgliedern der Exekutivkommission waren durchaus solche, die in der Lage gewesen wären, die Geschäfte interims zu führen, so etwa der Republikaner Nello Tofanari oder der Kommunist Lamberto Bonci. Daß es sich bei beiden nicht um Anarchisten handelte, welche das Sekretariat bisher traditionsgemäß in der Hand hatten, hätte in dieser Situation wohl kaum eine Rolle gespielt.

91 ACS, MI, DGPS 1922, b. 132, f. „Fasci Lucca“, sf. „Seravezza“: Präfekt an Innenministerium vom 26. 5. 1922. 
Sache ausschließlich Freisprüche fällte ${ }^{92}$. Andere Fährten wurden von offizieller Seite nicht verfolgt, obwohl die Linkspresse offen mutmaßte, daß der Sprengstoff von den Faschisten oder gar von den Carabinieri selbst versteckt worden sei ${ }^{93}$.

Ein Zusammenspiel von Faschisten und Carabinieri erscheint tatsächlich durchaus möglich. Viele der einfachen Carabinieri sympathisierten ziemlich offen mit den Faschisten $^{94}$, und als am 14. Juni in die leere Camera del lavoro eingebrochen und das Aktenmaterial durchwühlt wurde, verdächtigte die Polizeiführung sogar von sich aus die zur Bewachung des Gebäudes abkommandierten militı ${ }^{95}$. Es drängt sich außerdem die Parallele zu dem ähnlich mysteriösen Bombenfund in Zusammenhang mit den fatti di Fossone auf. In beiden Fällen war die Schuld der als Tatverdächtige Verhafteten äußerst zweifelhaft, und in beiden Fällen machten die Carabinieri ihre Entdeckung "völlig zufällig" an äußerst merkwürdigen Stellen, die zuvor auch Dritten zugänglich gewesen waren. Damals wie im vorliegenden Fall wurden in entscheidenden Situationen weitreichende politische Folgen ausgelöst ${ }^{96}$.

Die Ausschaltung der Camera del lavoro erwies sich als wesentlich einfacher, als ihre Erbschaft anzutreten. Zunächst machten die Faschisten den Versuch, die Gewerkschaftsorganisation, so wie sie war, zu übernehmen. Schon am 19. Mai, einen Tag nach der Verhaftung Petruccis und der Besetzung der Gewerkschaftslokale, veröffentlichten sie ein triumphales Flugblatt, in dem sie den „Arbeitern der apuanischen Region“ einfach ankündigten, daß ihre Interessen ab heute von der Camera carrarese dei sindacati economici vertreten würden. Im gleichen Atemzug sicherten sie zu, daß alle Ligenführer ihre Stellungen in der neuen Organisation behalten könnten ${ }^{97}$. Für den nächsten Tag wurden die Sekretäre und consiglieri der Ligen in das Teatro degli Animosi geladen, wo Renato Ricci gedachte, eine neue regionale Gewerkschaftsorganisation unter der Schirmherrschaft des PNF aus der Taufe zu heben. Diese Pläne mißlangen völlig. Von den Gewerkschaftsführern der „alten “ Ligen erschien nur ein einziger, der Sekretär der Lega tranvier $^{98}$, einer Gewerkschaft, die sich, wie erwähnt, schon vor einiger Zeit von der Camera del lavoro entfernt hatte. Ricci startete einen zweiten Versuch, er setzte die Versammlung für den 28. Mai neu an und lud alle gewerkschaftlichen Funktionsträger diesmal mit einem persönlichen Schreiben ein. Aber wieder war der Erfolg fast gleich null. Es kamen nur vier Mitglieder der Lega cavatori von Gragnana, die weder ein Amt noch ein Mandat besaßen. Selbst der Sekretär der Straßenbahner machte jetzt einen Rückzieher und erschien diesmal nicht ${ }^{99}$.

92 Wie Anm. 88.

93 Il Cavatore vom 28. 5. 1922; Avanti! vom 23. 5. 1922.

94 ASM, Commissariato Carrara, b. 69: Anonymes Schreiben an den Präfekten vom 18. 5. 1922. Hier ist die Rede von Carabinieri und Guardie regie, die unter der Jacke das Abzeichen des PNF trügen.

95 ACS, MI, DGPS 1922, b. 134, f. „Fasci Massa“: Präfekt an Innenministerium vom 16. 6. 1922.

96 Vgl. oben, S. $145 \mathrm{f}$.

97 ASM, Commissariato Carrara, b. 69: Flugblatt und Plakat der Federazione provinciale des PNF vom 19.5. 1922.

98 Il Cavatore vom 28. 5. 1922 und Alalà vom 27. 5. 1922. Bezeichnenderweise führt die PNF-Zeitung das Fiasko allein auf Gerüchte über die bevorstehende Rückgabe des Gebäudes der Camera del lavoro an die alte Gewerkschaftsführung zurück.

99 Il Cavatore vom 10.6. 1922 und Alalà vom 3. 6. 1922. 
Auch als im Laufe der Zeit klar wurde, daß die Camera del lavoro in einem absehbaren Zeitraum nicht wieder auferstehen würde, gelang es den Faschisten nicht, im größeren Stil Übertritte von ganzen Organisationen oder bedeutenden Teilen von ihnen zu erreichen. In einigen frazioni von Carrara, so in Linara, Bedizzano und Gragnana, ließen sie sich unter Drohungen die Kasse und das Mobiliar der Lega cavatori aushändigen, aber die organisierten Steinbrucharbeiter fühlten sich trotzdem nicht dazu veranlaßt, dem Vermögen ihrer Organisationen zu folgen ${ }^{100}$. Gewisse Erfolge der Sindacati economici sind lediglich bei Maurern, Bäckern, Elektrikern und Fuhrleuten zu registrieren ${ }^{101}$. Es handelte sich hier um kleine Berufsgruppen, deren Arbeit sich relativ individualisiert vollzog und die daher wohl geringere Solidaritätsstrukturen ausbildeten. Allerdings erscheint es auch bei der großen Gruppe der segatori im Frühsommer 1922 eine gewisse Übertrittsbewegung gegeben zu haben ${ }^{102}$.

Zum Übertritt ganzer Organisationen kam es nur noch im Fall der völlig unbedeutenden Lega barbieri und bei der Lega tranvieri, die der faschistischen Gewerkschaftskammer am 17. August beitrat ${ }^{103}$. Sie hatte diesen Schritt nach langem Zögern vollzogen, wahrscheinlich erst als sie ganz sicher war, daß die alte Camera del lavoro ihre Arbeit nicht wieder aufnehmen würde, und nachdem sie wohl bestimmte Garantien hinsichtlich ihrer Autonomie erhalten hatte ${ }^{104}$. Auch sind interne Widerstände gegen den Wechsel zu vermuten, aber die Mehrzahl der Straßenbahner dürfte zugestimmt haben. Hinsichtlich der Führungsgremien ist die Kontinuität zwischen der alten Liga und der neuen Corporazione jedenfalls überdeutlich: von den acht Gewerkschaftern, die im Januar 1919 das consiglio direttivo bildeten, wurden vier, einschließlich des Sekretärs Ugo Raffo, in der neuen Corporazione tranvieri in ihrer Position bestätigt ${ }^{105}$.

Die kleine Straßenbahnergewerkschaft war allerdings eine große Ausnahme. Viele Gewerkschaften, vor allem die Steinbrucharbeiterligen, zogen es vor, sich aufzulösen. Auch individuelle Übertritte verhalfen den Corporazioni zu keinem richtigen Durch-

100 Il Cavatore vom 22. 7. 1922.

101 Bei den Gewerkschaften dieser Gruppen registrierten Polizeiberichte vom Dezember 1922 den Übergang zu den Sindacati economici im Mai 1922 (ASM, Questura Massa, b. 12, f. „Lega barocciai“, f. „Lega elettricisti“, f. „Lega muratori Carrara“, und ebenda, b. 13, f. „Lega fornai“). Das ist so sicher unrichtig, weil es in diesem Fall von Il Cavatore und Alalà registriert worden wäre (vgl. auch Anm. 38). Es ist denkbar, daß diese mit großem zeitlichen Abstand erfolgten Angaben auf zahlreiche individuelle Übertritte und der bald anschließenden Auflösung der alten Ligen zurückgehen.

102 Bei der Lega segatori besteht das gleiche quelleninterpretatorische Problem wie bei den ebenda genannten Ligen.

103 ACS, MI, DGPS 1922, b. 134, f. „Fasci Massa“: Präfekt an Innenministerium vom 23. 8. 1922.

104 Dies ist aus einer während der Gründungsveranstaltung von Ricci abgegebenen Erklärung herauszulesen, in der er dem neugewählten Führungsgremium „alle Vorteile“ und in der „unmittelbaren Verwaltung die größte Autonomie" versprach (Alalà vom 19. 8. 1922).

105 Ebenda und ASM, Questura Massa, b. 13, f. „Lega tranvieri“ : "prospetto statistico “ vom 21. 1. 1919. 
bruch $^{106}$. In der Steinbrucharbeitergemeinde der Versilia, Seravezza, wo die Camera del lavoro auch ohne ihren „verbannten “ Sekretär einigermaßen weiterarbeiten konnte, erreichten die Sindacati economici kaum 100 Mitglieder $^{107}$, und in der Garfagnana, wo Attilio Fellini jetzt als segretario propagandista tätig war, beherrschte die alte Camera del lavoro konkurrenzlos das Feld ${ }^{108}$. Dem Faschismus gelang es auch mit dem Fortschreiten seiner Machtausweitung noch längere Zeit nicht, die ehemals organisierten Arbeiter in seine Gewerkschaften einzubinden ${ }^{109}$. Viele Arbeiter verzichteten lieber auf jeglichen gewerkschaftlichen Schutz, als an der Tür der Sindacati economici anzuklopfen, was für sie einen Unterwerfungsakt bedeutet hätte.

Trotz ihrer nicht überwältigenden Erfolge führte das Engagement der Faschisten der Marmorregion in der Gewerkschaftspolitik zu den ersten Reibereien mit faschistischen Unternehmern. Die Corporazione lizzatori befand sich mit den esercenti lizza, bei denen es sich zum größten Teil auch um Faschisten handelte, in einer Dauerauseinandersetzung um die Einhaltung des Tarifvertrages, bei der sie mit Unterstützung des Carrareser PNF bis hart an die Grenze der Streikdrohung ging ${ }^{110}$. In Massa, wo der Tarifabbau noch wesentlich weiter gegangen war als in Carrara, kam es gar zu einem ernsten sozialpolitischen Konflikt unter den führenden Faschisten. Die Mehrheit des Direktoriums trat für die Wiederanhebung der Löhne ein, eine Orientierung, die das Fußfassen der Sindacati economici unter den Arbeitern fördern sollte. Aus Protest gegen diese „extremistische“ Tendenz erklärte der Marmorunternehmer Umberto Chiappe mit einem Eklat seinen Austritt aus dem PNF. Der Sekretär des Masseser Fascio, Umberto Magnani, antwortete auf Chiappes Anschuldigungen, die dieser in zwei nichtfaschistischen Lokalzeitungen veröffentlicht hatte: „Wir haben niemals beabsichtigt und beabsichtigen nicht, hinsichtlich der Arbeiterorganisationen kommunistische Methoden zu verfolgen, vielmehr ist es unser Ziel, die Arbeiter um jeden Preis, wenn nötig auch mit Gewalt, von der Ausbeutung durch die Unternehmer zu emanzipieren. " 111 Magnanis verbalradikale Töne erhielten zwar zunächst die Zustimmung von Alalà, das als Organ der Federazione die Linie von Ricci vertrat, doch mittelfristig entschied sich der Machtkampf im Fascio von

${ }^{106}$ Im Frühsommer lösten sich folgende Ligen auf, ohne daß eine wie auch immer geartete organisatorische Kontinuität mit etwaigen faschistischen „Nachfolgeorganisationen“ zu erkennen ist: Unione cavatori città (Carrara), Steinbrucharbeiterligen von Gragnana, Linara, Miseglia, Fossola, Nazzano, Sorgnano, Lega contadini in Fossone und Nazzano, Lega segatori Nazzano und Lega muratori Avenza (ASM, Questura Massa, b. 11, 12, 13, entsprechende Faszikel). Nur bei der Lega cavatori im weit entfernten Castelpoggio scheint es eine gewisse Kontinuität gegeben zu haben (ASM, Questura Massa, b. 12, f. „Lega cavatori Castelpoggio“: Kommissar von Carrara an Questore vom 23. 12.1922).

107 Alalà vom 3. 6.1922: Angaben von Gasperetti, dem PNF-Sekretär von Seravezza. Das sind möglicherweise weniger als noch ein Jahr zuvor, als Claudio Papini - nicht ganz glaubwürdig - 150 Mitglieder angab; APC, b. B 4, f. 6: Schreiben an Perrone vom 5. 7. 1921.

108 In Gorfigliano kam es im Juli 1922 sogar noch zu einem Streik der zur alten Camera del lavoro gehörigen Ligen gegen das zum Montecatini-Konzern gehörende Marmorgroßunternehmen "Nord Carrara S. A.", der von Attilio Fellini geleitet wurde. Angesichts des Monopolcharakters der Firma als lokaler Arbeitgeber handelte es sich praktisch um einen örtlichen Generalstreik.

109 ACS, SPD/CR 1922 -43, b. 48, f. „R. Ricci“": Aussage Riccis vor der Untersuchungskommission der MVSN vom 18. 4. 1923.

110 Alalà vom 8. 7. 1922.

111 Alalà vom 17. 6. 1922. 
Massa zugunsten der „Gemäßigten“. Chiappe nahm seinen Austritt zurück, Magnani wurde ausgebootet, und der Marmorindustrielle Carlo Giorgini avancierte zum „starken Mann" des Masseser Faschimus ${ }^{112}$. Das Problem des enormen Lohngefälles zwischen Carrara und Massa blieb ungelöst und bedeutete weiterhin eine Hypothek für die Entwicklung der lokalen faschistischen Arbeitergewerkschaften ${ }^{113}$.

Mit der Beseitigung der linken Gewerkschaftsorganisationen begann das faschistische Machtsystem in der Marmorregion "totalitäre ${ }^{a}$ Züge anzunehmen. Es hatte jetzt die wichtigen gesellschaftlichen Bereiche durchdrungen: Von den fünf Unternehmervereinigungen der Federazione industriali del marmo waren vier, die der produttori, der segatori, der lizzatori und der laboratori, praktisch in faschistischer Hand. Nur die Associazione esportatori, in der die Crème der Großunternehmer vereinigt war, bewahrte ihre Unabhängigkeit ${ }^{114}$. Die liberale Partei war von fiancheggiatori der reinsten Sorte beherrscht, die sich politisch immer weniger von den eigenlichen Faschisten abhoben ${ }^{115}$. Es bestand ein faschistisches Gewerkschaftsmonopol, das zwar noch längst nicht die Größenordnung der alten Camera del lavoro hatte, aber auf Dauer mangels Konkurrenz zum Bezugspunkt für die Arbeiter werden mußte. Auch die mittelständischen Gruppen, soweit sie überhaupt organisiert in Erscheinung traten, bewegten sich im Dunstkreis des Faschismus ${ }^{116}$. Militär und Polizei waren auf allen Ebenen von seinen Sympathisanten durchsetzt ${ }^{117}$. In den staatlichen und kommunalen Institutionen schließlich war er zwar

112 Umberto Chiappe war als "seniore“ der Miliz an herausragender Stellung an den Aktionen während des "Marsches auf Rom “ in Massa beteiligt. Später wurde er sogar „console“ der 85. Legion der MVSN. Giorgini, ein ausgesprochener Großbürger, wurde Vertreter der „zona Mas-

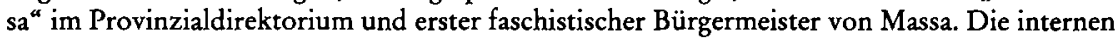
Machtkämpfe im Masseser Fascio waren allerdings ein Dauerzustand, der eine permanente Fluktuation in den Führungspositionen des örtlichen PNF mit sich brachte.

113 Nach ihrem Wiedererscheinen im November 1922 finden sich in Giovinezza kaum mehr Gewerkschaftsnachrichten und Artikel zu den Problemen der Arbeiterschaft. Auch die „republikanischen" Töne sind völlig verschwunden.

114 In der zentralen Frage der Festpreise beugten sich die freihändlerisch orientierten Unternehmer vorläufig den Protektionisten, die nahezu alle Parteigänger des Faschismus waren und vom PNF in ihrem Anliegen tatkräftig unterstützt wurden (Il Giornale di Carrara vom 5. 8. 1922). Die Vereinbarung wurde aber bald wieder durchbrochen, und die Auseinandersetzungen um die Preisfestsetzungen flammten unmittelbar nach dem Marsch auf Rom wieder auf (Il Giornale di Carrara vom 20.1.1923).

115 Zum ersten Jahrestag der Gründung des Fascio carrarese di combattimento schrieb das liberale Organ, nachdem es ein Loblied auf die gewaltsame Beseitigung der politischen Linken in Carrara durch den Faschismus gesungen hatte: „Der Gruß, den sie [die Liberalen] euch [den Faschisten] aus der Tiefe ihres Herzens senden, ist so herzlich, leidenschaftlich und brüderlich, als wenn er von euren eigenen Glaubens- und Kampfgenossen käme. " (Il Giornale di Carrara vom 13. 5. 1922)

116 Das gilt vor allem für die Lehrer, die sich von Anfang an stark an den Fascio anlehnten, und für die Angestellten, unter denen die der Ferrovia marmifera mit ihrer relativ langen gewerkschaftlichen Tradition hervorstechen. Andrea Camponi, in Carrara der einzige faschistische Gewerkschaftsfunktionär mit einem gewissen intellektuellen Format, stammte aus der Angestelltenschaft der Ferrovia marmifera. Die Kaufleute konnten sich dem allgemeinen Trend auch nicht entziehen, obwohl sie in Carrara nicht zur Hauptklientel der Faschisten zu zählen sind. Vgl. oben, S. $72 \mathrm{f}$.

${ }^{117}$ Für die Polizeikräfte ist das schon mehrfach gezeigt worden. Beim Militär erwies es sich auf frappierende Weise während des „Marsches auf Rom“, als sich die Garnison von Carrara einfach widerstandslos überwältigen ließ. Siehe weiter unten, S. 210. 
noch nicht direkt mit seinen Vertretern präsent, aber aufgrund seiner erdrückenden Machtpositionen in der lokalen Gesellschaft war er in der Lage, sie von außen zu beeinflussen ${ }^{118}$.

Der Institutionalisierungsprozeß der faschistischen Herrschaft war bezeichnenderweise dort am weitesten fortgeschritten, wo er die bestehende staatliche Ordnung am grundlegendsten in Frage stellte, auf der Ebene der militärischen Organisation. Auf den Squadren ruhte ja letztlich das ganze Gebäude der faschistischen Macht, das ohne das Korsett der ständigen latenten und manifesten Gewalt schwerlich hätte zusammengehalten werden können. Nach dem Kongreß von Rom war auf Anregung von Mussolini und unter Mitwirkung von General Gandolfo, Italo Balbo, Pietro Bolzon, Ulisse Igliori und Perrone Compagni die Ordnung einer einheitlichen und streng hierarchisch gegliederten Miliz konzipiert worden, mit der der vielfältige Wildwuchs des Squadrismus in geordnete und kontrollierbare Bahnen geführt werden sollte ${ }^{119}$. An der Spitze stand das Generalkommando, das von den vier ispettori generali Gandolfo, Balbo, Igliori und Perrone Compagni gebildet wurde, aber eigentlich bis zum „Marsch auf Rom“ keine wirkliche Funktion erfüllte. Perrone Compagni war theoretisch außer für die Toskana auch für Süditalien zuständig, aber seine Position war durch die internen Kämpfe des Florentiner Faschismus und den Bedeutungsgewinn der anderen toskanischen Provinzorganisationen so geschwächt worden, daß er selbst in seinem angestammten Aktionsfeld eigentlich nur noch eine dekorative Funktion ausübte, zumal er im Gegensatz zu den anderen ispettori keine große militärische Qualifikation besaß ${ }^{120}$.

In der neuen Squadrenorganisation hatte militärische Erfahrung eine ungleich größere Bedeutung als in der Anfangsphase des Squadrismus. In die Positionen des ispettore generale, später console, der Legion von Massa-Carrara und in die des Kommandanten der Carrareser Squadren der principi, die beiden wichtigsten Kommandostellen der Provinz, rückten Pietro Prayer Galetti und Luigi Da Pozzo ein, beides keine Faschisten der ersten Stunde, aber hochdekorierte Weltkriegsoffiziere ${ }^{121}$. Erst auf der Ebene der capi squadra finden sich die Faschistenführer der Anfangszeit Goffredo Corsi, Giuseppe Aloisi, Italo Barattini, Francesco Trombella. Renato Ricci behielt sich als segretario federale das Oberkommando über die Legion vor; eine eindeutige Hierarchie sowie die

${ }^{118}$ Das gilt sogar für die Präfektur, die sich zunächst gegenüber den lokalen Einflüssen noch am unempfindlichsten zeigte, bei der aber später ein kontinuierlicher Anpassungsprozeß an das Machtsystem des Provinzfaschismus festzustellen ist.

${ }_{119} \mathrm{Vgl}$. Gentile, Partito fascista, S. 387 - 393. Einzelheiten zur Squadrenorganisation bei Chiurco, Rivoluzione fascista, Bd. 4, S. $485-495$.

120 Perrone wurde 1905 wegen einer Ehrenstreitsache, in deren Verlauf es auch zu einem Duell gekommen war, vom ,sottotenente“ zum einfachen Soldaten degradiert. Während des Krieges, an dem er als Freiwilliger teilnahm, brachte er es wieder zum „caporale“ (Information von Giorgio Perrone Compagni vom 20.11. 1991). Die ehrenrührigen Angaben von Cantagalli, Fascismo fiorentino, S. 145, Anm. 18, geben Gerüchte wieder, die vor allem vom Perrone-Rivalen Tullio Tamburini in die Welt gesetzt wurden und größtenteils unzutreffend sind.

${ }^{121}$ Der wohlhabende Juwelier Pietro Prayer Galetti, Hauptmann der Reserve, und der Zahnarzt Luigi Da Pozzo, Leutnant der Reserve, stießen erst unmittelbar nach den „fatti di Sarzana" mit der zweiten großen Eintrittswelle im August 1921 zum Faschismus. Sie waren beide mehrfach dekoriert: Prayer war Inhaber von zwei "medaglie d'argento“ und drei „medaglie di bronzo“, Da Pozzo ebenfalls von zwei "medaglie d'argento" und einer "medaglia di bronzo“. 
Trennung von politischen und militärischen Kompetenzen war in der Praxis nicht gegeben ${ }^{122}$.

Auf der unteren Ebene bestand ein spontaner Squadrismus neben der festgefügten Milizorganisation fort. Der Kleinkrieg gegen die sovversivi lief in den gleichen Bahnen ab wie zuvor, doch entstand zusätzlich eine straff durchorganisierte Bürgerkriegsarmee für etwaige Großaktionen. Die aktiven Squadren der sogenannten principi ${ }^{123}$ wurden regelmäßig zu militärischen Übungen, Aufmärschen und „Propagandaexpeditionen“ abkommandiert, die neben der Einübung von militärischer Disziplin zur Machtdemonstration dienten. Bei großen Gelegenheiten wie am „Tag der nationalen Arbeit“" oder dem Jahrestag der Fascio-Gründung marschierten auch die „Reserve“-Squadren der triari auf und führten so den politischen Gegnern wie den Verantwortlichen in den staatlichen Stellen das militärische Potential des Faschismus vor Augen. Das wiederholte erdrückende Schauspiel von vielen Hunderten uniformierten "Schwarzhemden" in militärischer Formation hinterließ in Carrara eine Atmosphäre, die die Anwendung von offener Gewalt zunehmend überflüssig machte. Der Faschismus der Marmorregion war mittlerweile ein Staat im Staate mit einer eigenen Armee und Polizei, er erließ Anordnungen verschiedenster Art und überwachte deren umgehende und korrekte Ausführung. „Verbannungen “ wie im Fall von Federico Menconi und Attilio Fellini, die Einstellung des Güterzugverkehrs nach Livorno während des Boykotts der Firma G. Fabbricotti, Beschlagnahmungen von Gewerkschaftsvermögen mit anschließender Quittungsausstellung ${ }^{124}$ sind Beispiele für eine fast zur Selbstverständlichkeit gewordene Anmaßung hoheitlicher Kompetenzen, die zur De-facto-Etablierung einer, wenn auch rudimentären, parallelen faschistischen Staatsgewalt schon vor dem Oktober 1922 führte. Sie war nur möglich, weil sie von den örtlichen Vertretern der offiziellen Staatsgewalt toleriert und gegenüber der Zentralregierung vertuscht und verharmlost wurde.

Am deutlichsten wird die schleichende Machtergreifung des Faschismus auf der Ebene der Presse. Nachdem die sozialistischen und kommunistischen Lokalzeitungen schon im Sommer 1921 in einem Zuge mit den Parteigliederungen eliminiert worden waren, blieben als offen antifaschistische Lokalblätter nur die Sveglia repubblicana und der Cavatore übrig. Nach dem Sturz der republikanischen Gemeinderegierung im Januar

122 Renato Ricci nahm während des „Marsches auf Rom“ den in der militärischen Hierarchie streng genommen inexistenten Titel des "commandante generale“ der Carrareser Squadren an (Chiurco, Rivoluzione fascista, Bd. 1, S. 391), um die beanspruchte militärische Stellung über dem „console“ Prayer Galetti zu betonen. Auch weiter unten in der Hierarchie gab es Überlagerungen von politischen und "militärischen" Kompetenzen. So war Giuseppe Aloisi gleichzeitig "capo squadra" der "Disperata“ von Carrara und als „segretario politico“ von Avenza „Oberkommandierender" aller dortigen Squadren; APC, b. B 1, f. 1: Aufstellung über die Squadren von Avenza vom 21. 3. 1922; ebenda, f. 6: Aufstellung über die Squadren von Carrara ohne Datum (März 1922).

${ }^{123}$ Die eigentlich aktiven „squadristi“" waren die „principi“. Sie wurden militärisch trainiert und kamen bei gezielten Aktionen, wie der während des „sciopero legalitario“ im August 1922 oder beim „Marsch auf Rom“, zum Einsatz. Zu den Squadren der „triari“ kamen alle übrigen, die sich aus Alters-, Gesundheits- oder sonstigen Gründen nicht für den Einsatz an vorderster Front eigneten. Sie traten vorwiegend bei feierlichen Aufmärschen auf und hatten ohne ausdrückliche Anordnung nicht einmal das Recht, das Schwarzhemd zu tragen (Chiurco, Rivoluzione fascista, Bd. 4, S. 492).

${ }^{124}$ Il Cavatore vom 22. 7. 1922. 
1922 gilt das aber für die Sveglia nur noch mit großen Einschränkungen. Ab dann sind bei ihr die Spuren der journalistischen Selbstzensur so deutlich, daß sie als Quelle für die bei den Carrareser Republikanern herrschenden Stimmungen und Überzeugungen fast wertlos ist. Beim Cavatore ist die genau entgegengesetzte Tendenz zu erkennen. Gerade in der Endphase seines Erscheinens von März bis Juli 1922 nahm die Gewerkschaftszeitung kein Blatt vor den Mund, wurde aber dafür regelmäßig und systematisch an den öffentlichen Verkaufsstellen „requiriert ${ }^{\text {"125 }}$. Sie konnte nur noch über die verbliebenen Gewerkschaftsgliederungen und über informelle Kanäle der „subversiven “ Subkultur verteilt werden und nahm daher praktisch den Charakter eines Untergrundblattes an ${ }^{126}$.

Eine grundlegende Voraussetzung für die mutigen Töne des Cavatore war der Aufenthalt seiner exponierten Redakteure Alberto Meschi und Eugenio Girolo in La Spezia, wo sie dem direkten Zugriff der Carrareser squadristi entzogen waren. Ein weiterer wichtiger Mitarbeiter des Cavatore, der sozialistische Rechtsanwalt Vico Fiaschi, war insgesamt dreimal von den Faschisten überfallen worden. Er war gleichzeitig Korrespondent von Avanti! und Il Paese und wegen seiner entlarvenden Berichte in diesen Zeitungen eine der Hauptzielscheiben des faschistischen Hasses ${ }^{127}$. Im Frühjahr 1922 erschien im PNF-Organ eine überaus häßliche Hetztirade gegen ihn mit der aufschlußreichen Formulierung: „Er kann sich frei bewegen, weil die Gnade der vielen ihn bisher aus übermäßigem Großmut verschont hat. ${ }^{~}{ }^{128}$ Diese offene Drohung machte den sanftmütigen und von den erlittenen bastonature psychisch schon gezeichneten Sozialisten endgültig mundtot ${ }^{129}$. Zur Berichterstattung über die Carrareser Mai-Ereignisse mußte die Avanti-Redaktion einen Sonderkorrespondenten entsenden ${ }^{130}$.

Ganz ähnlich erging es der Voce Repubblicana. Jedesmal, wenn sie einen kritischen Korrespondentenbericht aus Carrara veröffentlichte, wurde Renato Ricci-umringt von squadristi - bei Starnuti vorstellig, der als der Autor der Artikel verdächtigt wurde, bis sich das republikanische Zentralorgan von selbst Zurückhaltung auferlegte, um ihre exponierten Parteigänger in Carrara keiner Gefahr auszusetzen ${ }^{131}$. Die Verteilung der überregionalen linken und antifaschistischen bürgerlichen Presse wurde ohnehin derartig behindert, daß sie in Carrara nur noch mit Schwierigkeiten erhältlich war. Schon im

125 Il Cavatore vom 8. 7. 1922.

126 Angeblich soll die Auflage des Cavatore in den letzten Monaten seiner Existenz, als er nicht mehr frei erhältlich war, sogar gestiegen sein (ebenda). Er war im Jahre 1921 mit der Auflage von 3300 Exemplaren ohnehin das größte Lokalblatt der Provinz. Erst an zweiter Stelle kam Alalà mit 2500 bis 3000 Stück (ASM, Commissariato Carrara, b. 72).

127 Bemerkenswerterweise wurde ihm seine interventionistische Vergangenheit von den Faschisten in keiner Weise zugute gehalten. Die faschistischen Steinbruchbesitzer haben ihm wohl auch nie seine $1920 \mathrm{im}$ Gewerkschaftsblatt veröffentlichte Artikelserie unter dem Titel "Cavatori, le cave sono vostre!" verziehen (siehe oben, S. 39).

128 Alalà vom 1.4. 1922.

129 Die zentrale politische Kartei des Innenministeriums enthält zu seiner Person einen ganz außergewöhnlich positiven Eintrag aus dem Jahre 1896: „sanftmütiger Charakter, gute Erziehung [...] er ist ein Idealist und nicht gefährlich“. Fiaschi war ab 1922 ein gebrochener Mann; unter dem Faschismus fiel er politisch nicht mehr auf (ACS, MI, CPC, b. 2053, f. „V. Fiaschi“).

130 Avanti! vom 23. 5. 1922.

131 Ebenda. Auf eine tätliche Drohung Riccis gegenüber Starnuti wegen der Berichterstattung der Voce repubblicana spielt auch dessen Schreiben an Perrone vom 24. 2. 1922 an (APC, b. B 1, f. 6). 
Herbst 1921 hatten die squadristi durch massive Bedrohung der Zeitungshändler den Vertrieb des besonders verhaßten Paese völlig unterbunden, nachdem sie das Blatt vorher wiederholt "beschlagnahmt" und verbrannt hatten ${ }^{132}$. Ähnlich ist es wohl auch den anderen nicht genehmen überregionalen Zeitungen ergangen, wenn auch die Quellen darüber widersprüchliche Aussagen machen ${ }^{133}$. Gegen La Stampa und Il Corriere della Sera scheinen grobe Anschläge nicht mehr vorgekommen zu sein, nachdem im Juli 1921 auch diese keineswegs antifaschistischen Blätter auf den Scheiterhaufen gekommen waren ${ }^{134}$. Maßnahmen gegen die regionalen Zeitungen La Nazione, Il Nuovo Giornale und Il Tirreno erübrigten sich vollständig, weil sie allesamt in höchstem Grade profaschistisch waren.

Spätestens im Frühsommer 1922 war die „öffentliche Meinung“ in Carrara weitgehend uniformiert; von Pressefreiheit konnte nicht mehr die Rede sein. Dennoch meinte der Giornale di Carrara, angesichts der Kritik an den Carrareser Zuständen in einigen überregionalen Zeitungen, behaupten zu können, daß es in Carrara in der Vergangenheit niemals soviel Freiheit gegeben habe und daß man sich nur wünschen könne, daß in ganz Italien die gleiche Freiheit wie in Carrara herrsche ${ }^{135}$. Dieses Zitat dokumentiert den Verlust jeglicher demokratischer und freiheitlicher Maßstäbe im Carrareser „Liberalismus" und verweist darauf, daß die politisch führenden Kreise des lokalen Bürgertums auf den $\mathrm{Zug}$, der in die Diktatur führte, bedingungslos aufgesprungen waren.

Es ist bemerkenswert, daß die Zustimmung, die der Faschismus im Bürgertum erntete, mit der unmißverständlichen Offenbarung seines ,totalitären "Wesens nicht schwand, sondern zunahm. In den wenigen Monaten von der Entmachtung der Camera del lavoro bis zum „Marsch auf Rom“, in der Zeit also, als die Zukunft der politischen Ordnung auf dem Spiel stand, scharte der Faschismus die etablierten Kreise in einem Ausmaß um sich, wie es weder vorher noch nachher der Fall war. Das überproportionale Wachstum der militärischen Schlagkraft des Carrareser Squadrismus war nicht zuletzt auf die üppigen Geldströme zurückzuführen, die dem PNF in der Marmorregion jetzt sogar von seiten jener Großunternehmer zuflossen, die dem wirtschafts- und sozialpolitischen Programm des Fascio von Carrara kritisch bis feindlich gegenüberstanden ${ }^{136}$. Diese Indu-

132 ASM, Commissariato Carrara, b. 58: Questore an Kommissar von Carrara vom 11. 11. 1921.

133 In den Dokumenten steht hier wiederum Aussage gegen Aussage. Die Quellen aus dem Bereich der politischen Linken verzeichnen einhellig, daß antifaschistische Zeitungen spätestens ab März 1922 in Carrara nicht mehr offen verkauft werden konnten; Avanti! vom 23. 5. 1922; ASM, Commissariato Carrara, b. 58: Camera del lavoro an Präfekten vom 8. 3. 1922; ACS, MI, DGPS 1922, b. 134, f. „Fasci Massa": Hinweis auf eine parlamentarische Anfrage der sozialistischen Abgeordneten Ventavoli und Fazzi in einem Schreiben der DGPS an den Präfekten vom 24. 5. 1922. Der Polizeikommissar von Carrara De Mase dementierte diese Stimmen und behauptete, daß es keine nennenswerten Einschränkungen der Pressefreiheit gebe (ASM, Commissariato Carrara, b. 58: Schreiben an Questore vom 18. 3. und 28. 5. 1922). Seine Ausführungen erscheinen aber nicht glaubwürdig, weil sie auch mit Akten des eigenen Amtes vom Herbst 1921 im Widerspruch stehen. Daß sich die Situation hinsichtlich der Pressefreiheit im Laufe des Jahres 1922 gebessert haben könnte, ist nicht anzunehmen.

134 ASM, Commissariato Carrara, b. 58: Polizeikommissar an Questore vom 26. 7.1921. Vgl. oben, S. 98, Anm. 35.

135 Il Giornale di Carrara vom 27. 5. 1922.

136 ACS, MI, Gabinetto Finzi, b. 12, f. 145: Memorandum von Ettore Viola ohne Datum (Mai 1924), S. 23. Hier ist die Rede von wiederholten Zahlungen in der Höhe von 20000 Lire durch Carlo Andrea Fabbricotti und die Familie Lazzoni. 
striellen versuchten offensichtlich, über ihre Zuwendungen politischen Einfluß auf den lokalen PNF zu gewinnen. Gleichzeitig finanzierten sie damit die Machtergreifung des Faschismus auf nationaler Ebene.

Obwohl im Frühjahr 1922 kein Zweifel mehr darüber aufkommen konnte, daß der Faschismus mehr war als die temporäre Reaktion auf den revolutionären Rausch des biennio rosso, fand sich in Carrara kein Vertreter des Liberalismus, der sich der Zementierung seiner terroristischen Praxis entgegengestellt hätte. Dieser Umstand ist um so erstaunlicher, als die pathologischen Züge des faschistischen Gewaltsystems immer deutlicher zutage traten. Im Februar wurde in Colonnata der Sozialist Alcimedonte Cattani und im März in Gragnana der Anarchist Augusto Musetti von Faschisten ermordet, ohne daß ein ernstzunehmendes politisches Motiv oder ein verständlicher Anlaß vorgelegen hätte ${ }^{137}$. Trotz der Disziplinierung der squadristi in den neuen strafferen militärischen Formen bestanden die Verselbständigungstendenzen der faschistischen „Alltagsgewalt" weiter. In der Nacht beherrschten Horden von Faschisten, die zum Teil dem Milieu der gewöhnlichen Kriminalität angehörten, die Straßen Carraras und pflegten alle, die sie zur vorgerückten Stunde noch antrafen, unsanft „ins Bett zu schicken“138.

Außerdem begann die Machtkonzentration in den Händen Renato Riccis bedrohlich zu werden und der Kult um seine Person Formen anzunehmen, die schon den Weg in seine spätere persönliche Provinzdiktatur erahnen ließen. Ricci kontrollierte als segretario federale die Provinzorganisation. Im Bereich seiner Hausmacht im engeren Sinn, den Fasci des Gruppo di Carrara und den PNF-Organisationen von Monzone und Vinca, herrschte er fast unumschränkt. Außerhalb der Provinz waren die Faschistenführer der Versilia, Gasperetti und Papini, seine persönlichen Gefolgsleute, auch wenn sie formal zur Federazione von Lucca gehörten. Er war gleichzeitig Sekretär der Camera Carrarese dei sindacati economici mit ihrer Monopolstellung in der Marmorregion. Seine Stellung als oberster Squadrenführer war völlig unbestritten; die höhere militärische Qualifikation von Prayer Galetti etwa hätte niemals das Charisma Riccis aufwiegen können. Im Sommer 1922 tauchten in Alalà schon Formulierungen wie „euer oberster Führer, der tapfere und hochherzige Renato Ricci ${ }^{\prime 139}$ auf. Es war deutlich abzusehen, daß dieser „Emporkömmling “ aus der Arbeiterschaft mit seinem außerordentlichen Macht- und Geltungsdrang und seinem populistisch-autoritären Gehabe auf Dauer auch vor den Positionen der lokalen Eliten nicht haltmachen würde.

Im Frühsommer 1922 hatte der PNF in Carrara endgültig die politische Monopolstellung errungen. Jetzt erhoben die Faschisten öffentlich den Anspruch, der kommissarischen Kommunalverwaltung die Politik zu diktieren. Einige ungenehme Beschlüsse des commissario regio Di Lungarini und die Tatsache, daß den Republikanern und Liberalen der Haushaltsentwurf vor ihnen bekannt geworden war, veranlaßten die Faschisten zur kategorischen Feststellung, daß sie „die wirkliche und legitime Vertretung“ Carraras seien und daß der commissario die Pflicht habe, sich in allen wichtigen Fragen

137 Il Cavatore vom 4. 3. und vom 1. 4. 1922; ACS, MI, DGPS 1922, b. 134, f. „Fasci Massa“" Präfekt an Innenministerium vom 27.3. und 14.4. 1922; ASM, Corte d'assise Massa, Sentenze 1923/3 (16. 2. 1923) und 1923/11 (27. 4. 1923). Im Fall Augusto Musetti machten sich Polizei und Gericht die (abwegige) Version der Faschisten zu eigen, nach der das Opfer angeblich die Auseinandersetzung provoziert habe.

138 ASM, Commissariato Carrara, b. 58: Camera del lavoro an Präfekten vom 8. 3. 1922.

139 Alalà vom 12. 8. 1922. 
„zuerst mit den Führern des Fascio zu beraten“. Bei der Zuweisung von Ämtern seien in erster Linie Faschisten zu berücksichtigen und in der Verwaltungspraxis habe er sich an die Vorstellungen und Verfügungen der Partei zu halten ${ }^{140}$. Interessanterweise stellten sie im gleichen Atemzug fest, daß „die Kräfte der liberalen Partei zum größten Teil vom Partito Nazionale Fascista aufgesogen worden“ seien, und deuteten damit schon unmißverständlich an, daß sie gedachten, auch ihre liberalen Bundesgenossen aufs politische Abstellgleis zu stellen ${ }^{141}$.

Wie stark die gesellschaftliche Verankerung des faschistischen Machtsystems und die Schlagkraft der Squadrenorganisation in der Marmorregion geworden waren, zeigte sich in den ersten Augusttagen während des sogenannten sciopero legalitario. Im Frühsommer hatte sich die Situation für die Arbeiterbewegung in ganz Nord- und Mittelitalien gefährlich zugespitzt. Außer in den Großstädten Mailand, Turin und Genua war der Faschismus überall stark auf dem Vormarsch, und die Organisationen der Linken begannen allmählich auch auf nationaler Ebene ihre Handlungsfähigkeit einzubüßen. Schon im März wardie Alleanza dellavoro, der Zusammenschlußaller linken Gewerkschaftsverbände, aus der Taufe gehoben worden, um dem Faschismus gemeinsam entgegentreten zu können. Das heterogen zusammengesetzte Bündnis, das von den Anarchisten über die Sozialisten und Republikaner bis zu den „nationalrevolutionären“ Kräften reichte, hatte sich zunächst als nicht recht handlungsfähig erwiesen ${ }^{142}$. Als jedoch im Juli eine neuerliche faschistische Offensive, vor allem in der Romagna und den Marken, den Führungsgruppen der italienischen Linken drastisch vor Augen führte, daß es fünf Minuten vor zwölf war, kam ein etwas überstürzter und nicht ganz rationaler Entscheidungsprozeß in Gang, der mit der Ausrufung eines landesweiten unbefristeten Generalstreiks „zum Schutz der politischen und gewerkschaftlichen Freiheiten“ am 1. August endete ${ }^{143}$.

Hinter diesem Generalstreik stand keine klare praktische und politische Konzeption. Eine Einbettung in eine wirklich „legalitäre“ Politik, wie sie die Reformsozialisten gern verfolgt hätten, fand nicht statt, und für den Auftakt zu einer revolutionären Entscheidungschlacht gegen die Faschisten, wie am anderen Ende des politischen Spektrums die Anarchosyndikalisten den Generalstreik begriffen ${ }^{144}$, fehlten jegliche Voraussetzungen. Die Faschisten fühlten sich so stark genug, den Fehdehandschuh aufzunehmen. Die PNFFührung gab ,dem Staat 48 Stunden Zeit, seine Autorität unter Beweis zu stellen “, danach würde „der Faschismus für sich volle Aktionsfreiheit in Anspruch nehmen und an die Stelle des Staates treten "145. Der Generalstreik endete für die Linke in einem großen Fiasko. Im Zuge der Aktionen gegen den sciopero legalitario gelang es den Faschisten fast durchwegs, neue Positionen zu erobern ${ }^{146}$.

140 Alalà vom 15. 7. 1922.

141 Ebenda.

142 Zur Entstehung der Alleanza del lavoro siehe De Felice, Mussolini il fascista 1, S. $218 \mathrm{f}$.

143 Ebenda, S. 222. Die Wortprägung "sciopero legalitario " stammt vom Führer des reformistischen PSI-Flügels, Filippo Turati, der beim endgültigen Streikbeschluß eine wichtige Rolle gespielt hat.

${ }^{144}$ Ebenda, S. 221. Siehe die hier zitierte Passage aus Umanità nova vom 23. 7. 1922.

145 De Felice, Mussolini il fascista 1, S. 223.

146 Die größten Squadrenaufmärsche betrafen Mailand, Genua, Livorno und Parma, also Städte, wo der Faschismus bisher keine durchschlagenden Erfolge gehabt hatte. Außer in Parma endeten die Kraftproben überall zugunsten der Faschisten (ebenda, S. 275). Zu den Vorgängen in Livorno, wo die meisten anderen toskanischen Squadren beteiligt waren, siehe Abse, Sovversivi, S. $225-245$. 
Die einschneidendste Wende vollzog sich in Genua unter der maßgeblichen Mitwirkung der Carrareser Squadren. In der Marmorregion selbst kam der Streik erst gar nicht in Gang. Am zweiten August streikten in Carrara nur etwa 50 Arbeiter; es handelte sich um die erste Schicht in vier Marmorsägewerken. Die Streikenden wurden kurzerhand durch Arbeitslose ersetzt, und damit war hier der Ausstand beendet ${ }^{147}$. Angesichts der Ruhe in der Marmorregion wurde das gesamte Squadrenpotential des Carrareser Faschismus für auswärtige Aktionen freigesetzt. Renato Ricci leistete sich sogar den Luxus, die Kräfte seiner Legione apuana zu zersplittern. Hundert Mann schickte er nach Pontremoli, wo die Eisenbahner des örtlichen Depots in den Streik getreten waren, und etwa weitere 100 squadristi kamen in La Spezia zum Einsatz, wo es galt, mit einer noch relativ intakten örtlichen Arbeiterbewegung „abzurechnen“. Der größte Teil aber, circa 150 Mann, nahm noch in der Nacht vom 2. August den Zug nach Genua ${ }^{148}$, um an einer Großaktion teilzunehmen, die vom Mitglied der nationalen PNF-Führung Massimo Rocca koordiniert wurde.

In Pontremoli und La Spezia setzten sich die Faschisten noch im Laufe des folgenden Tages durch. In Pontremoli stürmten sie den Circolo ferrovieri und den sozialistischen Ortsverein. Anschließend besuchten sie die streikenden Eisenbahner einzeln in ihren Häusern und erreichten so den Streikabbruch ${ }^{149}$. In La Spezia war die Durchführung des Streiks schon durch Polizeimaßnahmen stark behindert worden. Hier konzentrierten sich die Squadren auf die Zerstörung der politischen und gewerkschaftlichen Einrichtungen der Arbeiterbewegung. Zeitungskioske gingen in Flammen auf, und in den Arbeitervierteln Pegazzano, Rebocco und Chiappa wurden die Lokale der sozialistischen Vereine heimgesucht. Hauptzielscheibe der faschistischen Aktion waren allerdings die Gebäude der verschiedenen Gerwerkschaftsorganisationen. Die Cooperativa facchini del porto, der Ortsverein der Federazione dei lavoratori del mare, die sozialistische Camera confederale und die anarchosyndikalistische Camera sindacale wurden überfallen und verwüstet ${ }^{150}$. Als die Squadren auch die linksinterventionistische Vecchia camera del lavoro stürmen wollten, in der die Redaktion des Cavatore nach der Beseitigung der Gewerkschaftszentrale von Carrara Obdach gefunden hatte, wurden sie von Revolverschüssen empfangen. Sie mußten von diesem Vorhaben ablassen; die Verhaftung der verbarrikadierten Gewerkschafter besorgten die Polizeikräfte ${ }^{151}$.

Die squadristi der Legione apuana, die an den Aktionen in Pontremoli und La Spezia teilgenommen hatten, und weitere Squadren aus Carrara, Massa, Monzone und Vinca, die zunächst in ihren Heimatorten zurückgeblieben waren, trafen im Laufe des 4. August in Genua ein. Die unter dem Kommando von Ricci stehenden Squadren waren hiermit

${ }^{147}$ ASM, Commissariato Carrara, b. 58: Kommissar an Questore vom 2. 8. 1922. ACS, MI, DGPS 1922, b. 57, f. „Sciopero generale Massa": Präfekt an Innenministerium vom 2. 8. 1922.

148 Detaillierter Bericht der Ereignisse in Alalà vom 12. 8. 1922.

149 ACS, Fondo Ricci, b. 5, f. „Carrara PNF 1921 - 23“: Gino Dani an Ricci vom 6. 8. 1922. Bezeichnenderweise steht im Bericht des Präfekten, in Pontremoli sei es zu keinen Ausschreitungen gekommen; ACS, MI, DGPS 1922, b. 57,f. „Sciopero generale Massa“: Präfekt an Innenministerium vom 3. 8. 1922.

150 Bianchi, Lotte sociali, S. 220 f.; ACS, MI, DGPS 1922, b. 56, f. „Sciopero generale Genova“: Präfekt von Genua, Cesare Poggi, an Innenministerium vom 4. 8. 1922.

151 Ebenda. 
auf circa 500 Mann angewachsen ${ }^{152}$. In Genua war die Situation für die Faschisten bedeutend schwieriger als in Pontremoli und La Spezia. Der Streik war fast vollständig befolgt worden und wurde aus Protest gegen die Besetzung der Stadt durch die squadristi auch noch fortgesetzt, als die Alleanza del lavoro ihn am 4 . August wieder abblies ${ }^{153}$. Außerdem hatten die Faschisten mit einer Vielzahl von militanten Kommunisten und Anarchisten zu kämpfen, die ihnen zum Teil auch bewaffnet entgegentraten. Die Carrareser Squadren reagierten mit Brachialgewalt. Beim ersten schweren Zusammenstoß wurden zwei sovversivi getötet und sieben weitere verletzt ${ }^{154}$. Die Polizeikräfte von Genua gingen wie üblich völlig einseitig gegen die Linke vor. Während die Squadren unbehelligt blieben, nahmen sie über 500 sovversivi fest, die Verteidigungsmaßnahmen gegen sie ergriffen hatten $^{155}$.

Als am 5. August der Streik langsam abbröckelte, zeigte sich, daß die Faschisten weitergehende Ziele hatten. Massimo Rocca, der die Aktionen in Ligurien bisher ohne rechte Rückendeckung durch die PNF-Spitze durchgeführt hatte, erhielt jetzt die Zustimmung Mussolinis ${ }^{156}$ und rüstete zum Angriff auf das Consorzio autonomo del porto, das Selbstverwaltungsgremium des Hafens. Die Hafenorganisation, die einer festen Anzahl von Hafenarbeitergenossenschaften eine Monopolstellung bei der Verteilung der Arbeit gewährte und die Tarife auf einem beachtlichen Niveau hielt, war den Genueser Reedern und Handelsfirmen schon lange ein Dorn im Auge. Mit enormen Summen finanzierten sie den Squadrenaufmarsch, in der Hoffnung, daß die squadristi in der Hafenfrage einen Durchbruch in ihrem Sinn erzielen würden ${ }^{157}$. Die Faschisten stilisierten das Problem

152 ASM, Commissariato Carrara, b. 58: Kommissar an Questore vom 7. 8. 1922. Alalà vom 12. 8. 1922 spricht sogar von 600 Mann. Auf jeden Fall handelt es sich hier nur um knapp die Hälfte der "principi“ der "Legione apuana“.

153 ACS, MI, DGPS 1922, b. 56, f. „Sciopero generale Genova“: Präfekt von Genua an Innenministerium vom 4. 8. $1922,12^{30}$.

${ }^{154}$ Ebenda: Präfekt an Innenministerium vom 4. 8. 1922, $2^{10}$; Alalà vom 12. 8. 1922.

155 Wie Anm. 153.

156 Ab dem 4. 8. 1922, als der durchschlagende Erfolg der „ligurischen Kampagne“ von Rocca absehbar wurde, unterstützte Mussolini sein Vorgehen durch die Entsendung weiterer Squadren (ACS, MI, DGPS 1922, b. 56, f. „Sciopero generale Genova“: Präfekt an Innenministerium vom 4. 8. $\left.1922,17^{00}\right)$. Zur generalstabsmäßigen Durchführung der Besetzung von Sampierdarena und Genua durch Rocca siehe seinen Brief an Mussolini und Michele Bianchi vom 4. 8. 1922, abgedruckt in Gentile, Partito fascista, S. 467-470. Hieraus geht hervor, daß er selbständig vorgeprescht war und nicht nur die engere Parteiführung, sondern auch die Genueser Faschisten vor vollendete Tatsachen gestellt hat. Die Idee von einem Coup in Genua war ihm am 30. Juli auf einer faschistischen Gedenkveranstaltung in Sarzana beim Anblick der anwesenden Squadren gekommen, nachdem der bevorstehende Generalstreik unmittelbar zuvor von den rechtssozialistischen Genueser Zeitung Il lavoro angekündigt worden war. Höchstwahrscheinlich kam es noch in Sarzana zu einer Absprache mit Ricci. Der ehemalige Anarchist Rocca hatte damals gute Beziehungen zum Fascio von Carrara; Anfang Juli sprach er auf einer Kundgebung der Sindacati economici vor Carrareser Arbeitern über seine Konversion zum Faschismus (Il Giornale di Carrara vom 8. 7. 1922).

157 ACS, MI, DGPS 1922, b. 56, f. „Sciopero generale Genova“: General Carmelo Squillace, Kommandant der 14. Infanteriedivision, an Innenministerium vom 9. 8. 1922. Squillace war nach der Ausrufung des Belagerungszustands am 6. 8. 1922 für die öffentliche Ordnung in der Provinz Genua zuständig. 
des Hafens von Genua zu einer nationalen Frage hoch ${ }^{158}$. Sie bestellten den Präsidenten des Consorzio, den Senator Nino Ronco, zu sich und unterbreiteten ihm ultimativ einen Forderungskatalog, der auf die Ausschaltung der bestehenden Hafenarbeitergenossenschaften und auf die Beseitigung des bisherigen zünftlerischen Systems der Arbeitszuweisung zielte ${ }^{159}$. Um dem Entscheidungsprozeß nachzuhelfen, schritten sie allerdings sofort zum Sturm auf den Palazzo S. Giorgio, dem Sitz des Consorzio, wo der Verwaltungsrat gerade zusammengetreten war, und preßten Ronco die entscheidende Unterschrift $a b^{160}$.

Bei dieser Aktion kam es zu Gefechten mit bewaffneten Gruppen von sovversivi, die zwei Linken und einen Faschisten das Leben kosteten. Bei dem Faschisten handelte es sich um den lizzatore Primo Martini aus Carrara, der sogleich zum Märtyrer der „Wiederauferstehung" Genuas geweiht wurde. Die Legione apuana erhielt eine pathetische Belobigung von Mussolini, und Alalà erschien mit dem Titel „Carrara an der Vorhut des Faschismus $^{\alpha 161}$. Tatsächlich waren die Aktionen in Genua in erster Linie von den Squadren Riccis getragen worden, die zahlenmäßig und von der militärischen Einsatzfähigkeit her die stärkste Gruppe im faschistischen „Expeditionsheer" bildeten. Die schwersten Gefechte und die „Einnahme“ des Palazzo S. Giorgio gingen auf ihr Konto ${ }^{162}$.

Die „Eroberung“ der Großstadt Genua durch die faschistischen Truppen der kleinen Provinz Massa-Carrara verweist auf ein bemerkenswertes Charakteristikum der faschistischen Ausbreitung in dieser Phase, die durch eine zunehmende politische Hegemonie der Provinzfaschismen über die noch nicht faschisierten Metropolen gekennzeichnet ist. Die außergewöhnliche politische und militärische Stärke der PNF-Organsisation von Carrara in den entscheidenden Monaten vor dem „Marsch auf Rom “ verschaffte Rena-

${ }^{158}$ Rocca bekagte im erwähnten Schreiben an Bianchi und Mussolini (Anm. 156), daß die PNFFührung bei der Squadrenmobilisierung nicht ausreichend an Genua gedacht habe, "das doch ein nationales Problem darstellt". In diesem Punkt gingen die Faschisten allerdings mit großen Teilen der bürgerlichen öffentlichen Meinung konform. Symptomatisch ist hierfür, daß Alalà den Artikel, in dem die Notwendigkeit der Aktion gegen das „Consorzio“ dargestellt wurde, vollständig vom rechtsliberalen Giornale d'Italia übernahm („Il primo porto d'Italia liberato dall'incubo e dalla camorra che lo soffocavano" in Alalà vom 12. 8. 1922).

159 Die Punkte im einzelnen bei Chiurco, Rivoluzione fascista, Bd. 4, S. 201.

160 ACS, MI, DGPS 1922, b. 56, f. „Sciopero generale Genova “" Präfekt an Innenministerium vom 5. 8. 1922, $24^{\circ}$. Bemerkenswerterweise wurde das Diktat der Faschisten umgehend in die Tat umgesetzt, als handle es sich um eine ordnungsgemäß zustandegekommene Entscheidung. Ronco stand allerdings als der Hauptverantwort liche für das alte System der Hafenorganisation weiterhin im Mißkredit der Sieger, die ihn auch anscheinend beständig unter Druck hielten, bis er am 10. 8. 1922 seinen Rücktritt einreichte.

161 Alalà vom 12. 8. 1922. Die Trauerfeierlichkeiten für den „Märtyrer“ Primo Martini wurden mit einem selbst für faschistische Verhältnisse bis dahin unüblichen Aufwand inszeniert: Trauerzug in Genua mit Parade der "Legione apuana " und der "Legione ligure“, faschistische Aufmärsche an allen Bahnhöfen der Strecke Genua-Carrara bei der Überführung nach Carrara, nochmaliger Aufmarsch der "Legione apuana“ in Carrara mit einer kombinierten Sieges- und Trauerkundgebung.

162 Das ergibt sich eindeutig aus einem Vergleich des Berichts von Gualtiero Betti in Alalà vom 12. 8. 1922 mit dem Präfektenbericht aus Genua (ACS, MI, DGPS 1922, b. 56, f. „Sciopero generale Genova“). Das Gros der „squadristi“ war durch Polizeikräfte vor dem Eindringen in das Gebäude abgehalten worden, da gelang es einer Squadra der „Legione apuana“, auf der Rückseite mit Strickleitern einzusteigen (ebenda: Präfekt Poggi an Innenministerium vom 5. 8. 1922, $\left.24^{00}\right)$. 
to Ricci im PNF plötzlich ein enormes Prestige. Vor dem Sturm auf den Palazzo S. Giorgio war er der politisch und intellektuell unscheinbare Sekretär einer recht vitalen, aber kleinen Provinzorganisation, die erst auf ein Jahr des Bestehens zurückblicken konnte. Danach gehörte er zum Kreis der landesweit bekannten Faschistenführer, und am Vorabend des „Marsches auf Rom“ war er nach Perrone Compagni bereits der zweite Mann in der Toskana ${ }^{163}$.

Auf dem Weg zum „Marsch auf Rom“ hatte die faschistische Provinzorganisation noch eine entscheidende Kraftprobe mit dem Staat zu bestehen, deren Ausgang endgültig deutlich machte, daß die Faschisten das Heft in der Hand hatten. Als in den ersten Septembertagen nach monatelangen Ermittlungen der Oberstaatsanwaltschaft Genua wegen der schon erwähnten Ermordung von drei arditi del popolo im Juli 1921 bei Bergiola acht Faschisten in Haft genommen wurden, faßte der PNF von Carrara das als Kriegserklärung auf. Am 6. September 1922 ließ Ricci die squadristi der gesamten Provinz mobilmachen und erklärte die Direktorien aller Fasci der Provinz für aufgelöst und durch ein „geheimes Aktionskomitee“ ersetzt. Die Maßnahmen wurden mit einem Flugblatt bekanntgegeben, das weiter ausführte: „Es handelt sich um eine Verschwörung, von der wir nicht genau wissen, von wem sie geleitet wird und von wo sie ausgeht, ob von hier oder von Genua, oder ob sie im Einvernehmen zwischen allen denen stattfindet, die hier wie in Genua durch den jugendlichen Ansturm unserer Offensive besiegt worden sind, zwischen allen denen, die die überwältigenden Siege des Faschismus und die Ausbreitung seiner täglichen Errungenschaften nicht ertragen können. "164

Noch am gleichen Tag wurde eine Abordnung von Carrareser Faschisten unter der Führung des faschistischen Abgeordneten Costanzo Ciano beim Oberstaatsanwalt Filippi in Genua vorstellig und erklärte, daß der Sturm auf das Gefängnis von Massa drohe, wenn die Betroffenen nicht umgehend entlassen würden ${ }^{165}$. Schon am folgenden Tag marschierten alle verfügbaren Squadren der principi, insgesamt über $1500 \mathrm{Mann}$, auf. Am nächsten Tag wurden auch die triari nach Massa kommandiert, und so standen dort über 3000 Faschisten ${ }^{166}$. Ricci drohte damit, auch die squadristi der benachbarten Provinzen zur Hilfe zu rufen, was nach seinen eigenen Angaben die Konzentration von 20000 Mann in Massa bedeutet hätte ${ }^{167}$. Mittlerweile drohte er nicht nur mit dem Sturm auf das Gefängnis, sondern auch mit der Besetzung des Divisionskommandos der Carabinieri, das nach wie vor dem von den Faschisten schlecht gelittenen Major Cenesio Fusi unterstand. Die Verhaftungen gingen ausschließlich auf die Ermittlungen des CarabinieriKommandos zurück, denn die Questura von Massa hatte sich peinlichst aus der Affäre herausgehalten ${ }^{168}$. Wieder einmal hatte sich Fusi als der einzige Polizeiverantwortliche der Provinz gezeigt, der bereit war, dem Rechtsstaat zuweilen auch gegenüber den Faschisten Geltung zu verschaffen.

$163 \mathrm{Vgl}$. weiter unten, S. $208 \mathrm{f}$.

164 ASM, Commissariato Carrara, b. 58: Flugblatt vom 6. 9. 1922.

165 ACS, MI, DGPS 1922, b. 134, f. „Fasci Massa": Avvocato generale Filippi an Präfekten von Massa vom 6. 9. 1922.

166 Alalà vom 9. 9. 1922.

167 ACS, MI, DGPS 1922, b. 134, f. „Fasci Massa“: Vizepräfekt von Massa, Severini, an Innenministerium vom 8. 9. 1922.

168 Es ist bezeichnend für den Präfekten Berti, daß er diesen Umstand gegenüber dem Ministerium lobend erwähnt; ACS, MI, DGPS 1922, b. 134, f. „Fasci Massa“: Bericht vom 8. 9. 1922. 
Sicherlich handelte es sich bei den Drohungen der Faschisten im wesentlichen um einen Bluff, denn ein lokaler Aufstand gegen die Staatsgewalt wäre die größte politische Torheit gewesen, die der Faschismus in der damaligen Lage hätte tun können. Doch Renato Riccis Aufgebrachtheit scheint nicht nur taktischer Natur gewesen zu sein. Es ist klar zu erkennen, wie Bernardo Pocherra und Ghino Faggioni sich bemühten, mäßigend auf ihren Führer und die Situation einzuwirken ${ }^{169}$. Eine Unterredung zwischen dem Präfekten, Ricci und Pocherra endete mit der Abmachung, daß die Faschisten sich auch dann zurückziehen würden, wenn nur ein Teil der Angeklagten freigelassen werde ${ }^{170}$. Unterdessen waren der stellvertretende Oberstaatsanwalt und der zuständige Ermittlungsrichter aus Genua angereist. Während die Kolonnen der squadristi durch Massa marschierten, vernahmen sie schnell einige Zeugen und hoben dann alle Haftbefehle mit der Begründung auf, daß die Indizien jetzt zu ihrer Aufrechterhaltung nicht mehr ausreichten $^{171}$.

Die squadristi zogen befriedigt nach Carrara, um dort ihren Sieg zu feiern, und bei dieser Gelegenheit hielten Ghino Faggioni und Renato Ricci zwei sehr unterschiedliche, aber gleichermaßen bezeichnende Reden: Faggioni bemühte sich, die Drohungen gegen die Staatsorgane herunterzuspielen, und verkündete, die Faschisten hätten nicht im Sinn gehabt, auf die Entscheidungen der Justiz Einfluß zu nehmen, sondern beabsichtigt, deren Unabhängigkeit wiederherzustellen, die durch antifaschistische Intrigen bedroht gewesen sei. Ricci schlug einen ganz anderen Ton an. Er feierte den Faschismus als „die einzige gesunde Kraft inmitten der sich überall ausbreitenden Verwesung " und griff die Staatsorgane scharf an, die aus Individuen beständen, die nur den jeweils nächsten Zahltag abwarteten und besser daran täten, ihre Stellungen zu verlassen, um „in den verwesenden Camere del lavoro weiterzusiechen ${ }^{* 172}$. Zur gleichen Zeit und am gleichen Ort zeigte der Faschismus seine beiden Gesichter: das des biederen Marmorindustriellen Ghino Faggioni, der versuchte, auch dem offenen Aufruhr ein pseudolegalistisches Mäntelchen umzuhängen, und das des plebejischen Squadrenführers Renato Ricci, der es kaum noch vermochte, die Stunde abzuwarten, in der er die Vertreter der alten Ordnung endlich aus dem Weg räumen konnte.

Es ist im Rahmen dieser Arbeit nicht möglich, auf Vorgeschichte und Verlauf des „Marsches auf Rom" näher einzugehen. Es sollen daher nur einige aufschlußreiche lokale Aspekte des Vorgangs betrachtet werden: Die Legione apuana war der Colonna Perrone zugeteilt worden und sollte bei Civitavecchia-Santa Marinella Stellung beziehen,

169 Bei beiden handelte es sich um relativ gemäßigte Faschisten und um Juristen (Pocherra war sogar praktizierender Rechtsanwalt), die durchaus in der Lage waren, die strafrechtlichen Implikationen ihres Handelns zu erkennen. Auf ihren Einfluß geht es vermutlich zurück, daß die Drohungen immer indirekt formuliert wurden, so daß die Strafverfolgungsbehörden hinterher die Möglichkeit hatten, die Affäre versanden zu lassen. Zum Versuch der Regierung, Ricci und andere Faschisten strafrechtlich zu belangen, siehe einige Dokumente der DGPS, die ausführlich wiedergegeben sind bei Setta, Ricci, S. 58-60.

170 Beleg wie Anm. 168.

171 ACS, MI, DGPS 1922, b. 134, f. „Fasci Massa“: Abschrift der Haftbefehlsaufhebung vom 8. 9. 1922.

172 ASM, Commissariato Carrara, b. 58: Inhaltsangabe der Reden im Bericht von Vizekommissar Maselli vom 8. 9. 1922. Interessanterweise ist in Alalà vom 9. 9. 1922 nur die Rede von Faggioni ausführlich wiedergegeben. Die von Ricci ist nur ganz knapp und unter Auslassung der im Polizeibericht zitierten Stelle zusammengefaßt. 
um im Eventualfall mit den Squadren der „Legionen“ von Pisa, Lucca und Grosseto von Nordwesten auf die Hauptstadt zu marschieren ${ }^{173}$. Da man anfangs mit einer resoluten Reaktion von Regierung und König rechnen mußte, schien eigentlich klar zu sein, daß die der Colonna Perrone zugeteilten Provinzorganisationen den Großteil ihres militärischen Potentials nach Civitavecchia entsenden sollten. Der console Prayer sagte Perrone Compagni angeblich 8000 Mann zu, und das faschistische Generalkommando rechnete bei seinen Planungen mit dieser Zahl ${ }^{174}$. Doch die Mobilisierung im Einzugsbereich der Colonna Perrone nahm einen merkwürdigen Verlauf. Die Provinzorganisationen von Pisa, Lucca und Grosseto entsandten tatsächlich ziemlich bald nach dem Anrollen der Aktion große Teile ihrer „Legionen“ nach Civitavecchia-Santa Marinella. Sie stellten das Gros der rund 6000 Mann, die Perrone am 28. Oktober im Falle eines tatsächlichen Marsches auf die Hauptstadt zur Verfügung gestanden wären ${ }^{175}$. Ricci kommandierte dagegen nur den console Prayer mit einem symbolischen Kontingent von knapp 100 squadristi ab. Der Rest der Legione apuana hielt unter seinem Kommando die Provinzhauptstadt Massa und Pontremoli besetzt, bis die Nachricht von der Berufung Mussolinis zum Ministerpräsidenten bekannt wurde ${ }^{176}$.

Es ist nicht ganz leicht, dieses Verhalten von Ricci zu interpretieren, das fast an „Meuterei" grenzte und im Falle einer harten Kraftprobe vor den Toren Roms die Erfolgschancen der dort aufmarschierten Kolonnen durchaus herabgesetzt hätte. Vermutlich kamen verschiedene Motive zusammen. Quellenmäßig deutlich faßbar ist eine Verstimmung zwischen Perrone und Ricci im Zuge der Vorbereitungen zum Staatsstreich. Nach den ursprünglichen Plänen sollte Perrone nach Sizilien entsandt werden, angeblich um der dort schwachen „Bewegung“ während des Aufstandes auf die Sprünge zu helfen. In Wirklichkeit handelte es sich wahrscheinlich um den Versuch der PNF-Führung, diesen politisch wie militärisch für seine Aufgabe nicht übermäßig gut qualifizierten Mann kaltzustellen $^{177}$. Ricci wurde zunächst zu seinem Stellvertreter an der Spitze der toskanischen Milizen designiert und wäre damit in herausragender Stellung am „Marsch auf Rom“ beteiligt gewesen. Die PNF-Führung disponierte jedoch plötzlich anders, möglicher-

${ }_{173}$ Zum Aufmarschplan siehe Chiurco, Rivoluzione fascista, Bd. 4, S. $138-141$.

174 ACS, Fondo Ricci, b. 5, f. „Carrara PNF 1921-23“: Dino Perrone Compagni an Ricci vom 1. 11. 1922. Die Zahl 8000 scheint zu hoch gegriffen. Nach der Statistik der DGPS hatte die PNF-Provinzorganisation im Mai 19226060 Mitglieder, nach der PNF-internen Statistik der ausgegebenen Mitgliedsausweise sogar nur 3950 am Ende des Jahres (Gentile, Partito fascista, S. 547).

175 Vgl. Chiurco, Rivoluzione fascista, Bd. 4, S. 167.

176 Diese Tatsache, die sich unmißverständlich aus Alalà vom 4. 11. 1922, dem erwähnten Brief von Perrone an Ricci (siehe Anm. 174) und anderen Quellen (Setta, Ricci, S. 61 f.) ergibt, wird bezeichnenderweise im (fiktiven) Tagebuch von Perrone kaschiert, das die Ankunft Riccis um einen Tag vordatiert (Chiurco, Rivoluzione fascista, Bd. 4, S. 168). In seinem Schreiben an Ricci erwähnt Perrone die Zahl von nur 30 Carrareser Faschisten, die mit Prayer nach Santa Marinella gekommen seien. Das Polizeikommissariat von Carrara meldete dagegen die Abfahrt von rund hundert „squadristi“ nach Rom (ASM, Commissariato Carrara, b. 58: Kommissar an Questore vom 27. 10.1922).

177 Zum Zeitpunkt des "Marsches auf Rom“ war der Stern von Perrone schon deutlich im Sinken begriffen. Seine ehemalige toskanische Hausmacht entzog sich ihm immer stärker, nicht zuletzt

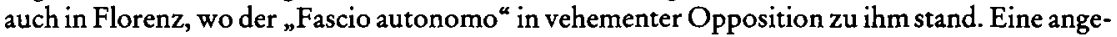
messene militärische Qualifikation besaß er nicht (vgl. Anm. 120). Unter anderem deshalb wurde seiner Kolonne der pensionierte General Sante Ceccherini zur Seite gestellt. 
weise unter anderem auch, um genau diese Eventualität zu vermeiden. Sie hatte für die infragestehende Position eigentlich den Weltkriegsmajor und Vizesekretär der Partei Attilio Terruzzi vorgesehen, aber Perrone Compagni hatte sich gegen einen Nicht-Toskaner gesperrt und Ricci vorgeschlagen, der ja gewissermaßen sein „Zögling “ ${ }^{\text {war }}{ }^{178}$. Als dann Perrone nach dem Willen der PNF-Leitung doch in der Toskana blieb und Ricci noch nicht einmal, wie versprochen, zum viceispettore generale di zona ernannt wurde, kam es zu dieser Verstimmung, denn Ricci lastete Perrone den demütigenden Ausgang der Affäre an ${ }^{179}$.

Der Ärger über die Parteileitung und Perrone ist wohl in der entscheidenden Situation des Staatsstreichs nicht das allein ausschlaggebende Moment gewesen, aber er beeinflußte sicherlich das Verhalten Riccis. Es lag psychologisch nahe, daß er sich nun auf die Durchführung der „nationalen Erhebung “ in „seinem Reich“, Carrara und Massa, konzentrierte, wo ihm niemand Befehle erteilte und wo er persönliche Lorbeeren erwerben konnte, zumal dieses Verhalten politisch durchaus im Einklang mit dem engen lokalistisch-regionalistischen Horizont des Carrareser Faschismus stand. Der Provinzfaschismus war ein relativ geschlossenes System, und speziell in der Marmorregion war er fast ausschließlich von lokalen Auseinandersetzungen und Problemen bestimmt. Die Führer des Carrareser Faschismus schauten selten über den Horizont der regionalen Verhältnisse hinaus ${ }^{180}$. In dieser Hinsicht waren sie alles andere als "national“. Aus der Perspektive des Provinzfaschismus stellte sich die „nationale Erhebung“ als die Summe der lokalen Machtergreifungen dar. Der „zweite Mann“ des Carrareser Faschismus, Gualtiero Betti, der im Rahmen des lokalen Faschismus politisch noch einen relativ weiten Horizont hatte, schreibt, indem er die Situation in Massa-Carrara und anderen „schwarzen“ Provinzen verabsolutiert, schon Anfang September 1922: „Es tut mir leid für die Regierung, aber die einzige Kraft, die in Italien wirklich etwas zu sagen hat, ist der Faschismus. [...] Uns bleibt nur noch, die Staatsgewalt zu erobern. Auch dies werden wir tun, und zwar in der Form, die uns am angebrachtesten erscheinen wird, aber fürs erste begnügen wir uns damit, die wirklichen Machthaber Italiens zu sein. “181 Der „Marsch auf Rom" war in dieser Sicht quasi nur noch eine Formalität, eine große spedizione punitiva der "gesunden" Provinzen gegen die korrupten und in der Praxis schon entmachteten Cliquen der Hauptstadt.

Der politische Horizont von Renato Ricci war sicherlich enger als der des Studenten großbürgerlicher Herkunft Gualtiero Betti. Sein Denken kreiste um das Fronterlebnis, die Fiume-Erfahrung und um einige ordnungspolitische Probleme, die im Zusammenhang mit der heimischen Marmorwirtschaft standen ${ }^{182}$. Man darf nicht vergessen, daß

178 ACS, Fondo Ricci, b. 5, f. „Carrara PNF 1921-23“: Perrone Compagni an Ricci vom 1. 11. 1922.

179 Die Verstimmung von Ricci gegenüber Perrone hielt noch einige Zeit an; APC, b. B 11, Bd. VI, S. 191: Perrone an Prayer ohne Datum (Ende Dezember 1922).

180 Beleg hierfür ist der Inhalt des Parteiorgans Alalà, das nur selten Themen der nationalen Politik anschnitt und sich auch für die großen innerparteilichen Kontroversen kaum interessierte (vgl. oben, S. 177).

181 Alalà vom 2. 9.1922.

$182 \mathrm{Da}$ er aus der Frühzeit nur sehr wenige schriftliche Zeugnisse hinterlassen hat (vgl. weiter unten, S. 215, Anm. 16), ist es nicht ganz leicht, sein damaliges Denken zu rekonstruieren. Die hier gemachte Feststellung basiert auf dem Gesamteindruck, den seine (seltenen) Alalà-Artikel und seine in Presse und Polizeiakten (schlecht) dokumentierten öffentlichen Reden hinterlassen. 
der gerade erst 26jährige gelernte Buchhalter bisher eine äußerst begrenzte Bildung erfahren hatte. Seine politische Sozialisation reduzierte sich auf das, was er an der Seite D'Annunzios und in den anderthalb Jahren faschistischer Aktion mitbekommen hatte. Er war ein Mann der Tat mit einem ausgeprägten Machtinstinkt. Das komplizierte Ineinandergreifen der verschiedenen politischen und militärischen Faktoren während des Staatsstreichs hat er mit großer Wahrscheinlichkeit nicht völlig durchschaut. Er plante mit konspirativem Geschick und mit militärischer Präzision die Ausschaltung der Staatsorgane in der eigenen Provinz und setzte seinen lokalen Putsch mit äußerster Konsequenz durch. Eigensinn und Fixierung auf die überschaubare lokale Konfrontation ließen ihn den Beitrag vernachlässigen, den er zum „Marsch auf Rom“ hätte leisten sollen.

Der erste Akt des faschistischen Staatsstreiches in der Provinz Massa-Carrara wirft ein bezeichnendes Licht auf die Persönlichkeit Riccis, der sich nach wie vor in der Rolle des capo squadra am wohlsten fühlte. In der Nacht vom 27. zum 28. Oktober um $2^{30}$ Uhr erschien er in Offiziersuniform vor der Kaserne der Carrareser Garnison und verlangte dringend, mit dem Kommandanten, Major Moroni, zu sprechen. Die Wachen öffneten und wurden augenblicklich von 30 bereitstehenden Faschisten überwältigt. Etwa 400 squadristi drangen in die Caserma Dogali ein. Den Faschisten gelang es, wahrscheinlich mit Hilfe von Schlüsseln, die ihnen vorher zugespielt worden waren ${ }^{183}$, schnell und lautlos in die Schlafräume der Offiziere und des Kommandanten einzudringen. Major Moroni wurde entwaffnet, die vier diensthabenden Offiziere in ihre Zimmer gesperrt. Die squadristi verschafften sich Zugang zum Waffenlager der Garnison und erbeuteten 180 Gewehre, vier Maschinengewehre sowie eine enorme Menge Munition, für die Maschinengewehre allein 24000 Schuß. Die Maschinengewehre wurden auf der über der Stadt liegenden Anhöhe Monterosso in Stellung gebracht, wo sich das Gros der Carrareser Squadren, insgesamt mehrere tausend Mann, versammelte ${ }^{184}$.

Es ist klar ersichtlich, daß die Offiziere und Soldaten der Garnison nicht alles unternommen haben, um diesen Coup zu verhindern; er hätte sonst nur schwerlich ohne Blutvergießen gelingen können ${ }^{185}$. Doch trotz der passiven Begünstigung, die den Faschisten in der Caserma Dogali zuteil geworden war, fühlten sie sich vor einer Reaktion von Polizei und Militär zunächst nicht ganz sicher, sonst hätten sie sich nicht den ganzen Tag auf dem Monterosso verschanzt. Die einzige Aktion, die sie am 28. Oktober noch durchführten, war die Besetzung der Post und des Telegraphenamts. Die Telephonverbindungen wurden unterbrochen, und die Telegramme mußten eine "faschistische Zensur “ passieren $^{186}$; damit war Carrara von der Kommunikation mit der Außenwelt weitgehend abgeschlossen.

${ }^{183}$ Der Polizeikommisssar von Carrara verdächtigte hier den Hauptmann der Reserve und Fechtlehrer Augusto Dovati, einen der führenden Faschisten Carraras, der als Leiter der „vormilitärischen Erziehung" Zugang zur Kaserne hatte; Schilderung der Vorgänge in ASM, Commissariato Carrara, b. 58: Kommissar an Questore vom 28. 10. 1922.

184 Ebenda; außerdem Alalà vom 4. 11. 1922 (entscheidende Passagen abgedruckt bei Setta, Ricci, S. 60 f.) und Chiurco, Rivoluzione fascista, Bd. 4, S. 155.

185 Dies läßt auch Alalà vom 4. 11. 1922 mit folgender Bemerkung durchblicken: „Weder er [der Kommandant] noch seine Offiziere hätten zugelassen, da sind wir sicher, daß brüderliches Blut geflossen wäre."

186 Ebenda und ASM, Commissariato Carrara, b. 58: Kommissar an Questore vom 28. 10.1922. 
Ricci mußte mit der Möglichkeit eines Angriffs aus Massa rechnen, wo analoge Aktionen der dortigen Squadren am Widerstand von Garnison und Polizei gescheitert waren und der Präfekt dem Stadtkommandanten die Polizeigewalt übertragen hatte ${ }^{187}$. Als nichts dergleichen geschah, schritt Ricci zur Offensive. Am 29. Oktober ließ er alle verfügbaren squadristi auf die Provinzhauptstadt marschieren und besetzte sie. Maschinengewehre wurden auf dem Hauptplatz aufgestellt und auf das Gebäude der Präfektur gerichtet. Auch hier brachten die Faschisten jetzt die Telefonverbindungen und das Telegraphenamt unter ihre Kontrolle, doch erst als die Berufung Mussolinis zum Ministerpräsidenten bekannt geworden war, kam es zu einer „friedlichen“ Besetzung der Präfektur $^{188}$. In der Nacht bestieg Ricci mit 200 squadristi und den vier erbeuteten Maschinengewehren den Zug, mit dem Mussolini von Mailand nach Rom zu seinem Regierungsantritt unterwegs war ${ }^{189}$. Dem Duce kam die martialische Umrahmung durch die Carrareser Squadren sehr gelegen, und er ließ es sich gern gefallen, daß sie als seine Ehreneskorte auftraten. Mussolini benutzte Ricci und seinen reparto mitragliatrici für einen theatralischen Auftritt in Santa Marinella, und dieser profitierte ausgiebig von der zur Schau gestellten Nähe zum Duce ${ }^{190}$.

Angesichts der erhaltenen Weihe hatte natürlich niemand den Mut, Ricci wegen seines späten Eintreffens zur Rede zu stellen. Obwohl er Perrone desavouiert hatte, ernannte dieser ihn jetzt doch noch zu seinem Stellvertreter und zum Gruppenkommandanten über die Legionen von Carrara, Pisa, Siena und Grosseto. In der Euphorie des Erfolges war kein Raum für Vorwürfe und Zwistigkeiten. Zu seiner Verteidigung hätte Ricci geltend machen können, daß der Stufenplan der „Erhebung“ als ersten Schritt die Überwältigung der staatlichen Organe in den Provinzen vorsah, und dies war ihm ohne Zweifel besser gelungen als vielen anderen faschistischen Provinzfürsten. Eine tagelange Bindung von Kräften, die eigentlich für den „Marsch auf Rom“ vorgesehen waren, konnte damit allerdings nicht gemeint sein, auch wenn die Direktiven nicht ganz eindeutig waren ${ }^{191}$. Es gibt keinerlei Hinweise dafür, daß die Carrareser Squadren Schwierigkeiten damit gehabt hätten, samt ihren Waffen wenigstens am 29. Oktober nach Civitavecchia zu gelangen. Ein Großteil der Pisaner Squadren etwa startete trotz des Scheiterns der dortigen Präfekturbesetzung noch am 28. Oktober in Richtung Rom ${ }^{192}$. Ricci war allerdings nicht der einzige toskanische Squadrenführer, der die Anordnungen von Perrone mißachtete. Die „Manöverkritik“ des ispettore generale nach dem „Marsch auf Rom" enthält eine Vielzahl von weiteren Verfehlungen, von denen die meisten ebenfalls durch persönliche Rivalitäten und Eitelkeiten bedingt waren ${ }^{193}$.

187 ASM, Commissariato Carrara, b. 58: Questore an Kommissar von Carrara vom 28. 10. 1922 (2 Berichte).

188 Alalà vom 4. 10. 1922 (Setta, Ricci, S. 61). Der Besetzung waren Verhandlungen zwischen dem Präfekten auf der einen Seite und den faschistischen Rechtsanwälten Pocherra und Faggioni sowie dem liberalen Politiker Arturo Micheli auf der anderen Seite vorausgegangen.

189 Ebenda.

190 La Stampa vom 30./31. 10. 1922, zitiert nach Setta, Ricci, S. 61 f.

191 Vgl. Lyttelton, Seizure, S. 87.

192 Ebenda, S. 89, und Nello, Vocazione, S. 640. Die Pisaner Faschisten kamen mit dem Stadtkommandanten zu folgendem Arrangement: Die Squadren verzichten auf die Besetzung der öffentlichen Gebäude und werden dafür nicht an der Abfahrt nach Santa Marinella gehindert.

${ }^{193}$ APC, b. C 1, f. 4: "Circolare riservatissima“ von Perrone an alle "consoli, commandanti provvisori, segretari federali“ vom 12.11.1922. 
Letztlich ist es aber gar nicht klar, wo die Squadren dem politischen Ziel der Machtergreifung objektiv dienlicher waren, denn ein wirklich militärischer Sieg der Squadren vor Rom wäre ohnehin nicht denkbar gewesen, solange die zur Verteidigung bereitgestellten Truppen loyal blieben ${ }^{194}$. Das faschistische Erfolgsrezept bestand in der Kombination von politischer und militärischer Pression, und hier spielte das Zerbröckeln der Staatsautorität in den Provinzen eine mindestens ebenso wichtige Rolle wie der Aufmarsch vor den Toren Roms ${ }^{195}$. Der Grundlegung seiner persönlichen Provinzdiktatur war das Vorgehen Riccis sicherlich dienlicher. Der lokalen Gesellschaft wurde eine wirkliche „Revolution“ vorgeführt und die Verantwortlichen der Staatsmacht in Massa, die den Faschisten in der Vergangenheit nicht immer bedingungslos zu Diensten gewesen waren, gedemütigt. Mit der Hissung des gagliardetto des Masseser Fascio di combattimento an der Präfektur demonstrierten die Faschisten, von wem nach ihrer Meinung von jetzt an die Staatsmacht ausgehen sollte.

\section{Das Aufbrechen der Widersprüche: „dissidentismo“" im System der Provinzdiktatur}

Mit dem „Marsch auf Rom“ begann in der Provinz Massa-Carrara die Institutionalisierung des faschistischen Machtsystems. Am Anfang dieses Prozesses stand die Eroberung der Rathäuser von Massa und Carrara. Die direkte Kontrolle der Kommunalverwaltungen der beiden wichtigsten Gemeinden der Provinz und der Marmorregion war eine entscheidende Voraussetzung für die Realisierung weitergehender Ziele der Faschisten. Vor allem im Fall Carrara sollte die Kommune eine zentrale Rolle bei der Erfassung und „Unterwerfung“ der lokalen Gesellschaft spielen. Denn bemerkenswerterweise gingen auch unter der "nationalen“ Regierung Mussolinis die radikalisierenden Impulse von der faschistischen Peripherie aus. Bis 1925 griffen der Staat und die nationale PNF-Führung, wenn überhaupt, nur bremsend ein.

Die Masseser Gemeindewahl fand am 1. Oktober 1922 noch vor dem Staatsstreich statt und verlief noch in vergleichsweise demokratischen Bahnen. Der Absolutheitsanspruch des Fascio war in Massa längst nicht so ausgeprägt wie in Carrara, und die Ausschaltung der Linken war hier nicht mit der Beseitigung von jeglichem politischen Pluralismus einhergegangen. Dies lag daran, daß in Massa außer den Rechtsliberalen auch die Mehrheit der popolari und Republikaner scharf antisozialistisch eingestellt war und die faschistische Aktion oft mit kaum verhohlener Genugtuung betrachtet hatte ${ }^{1}$. Über längere Zeit war sogar die Bildung einer Einheitsliste aus Faschisten, Liberalen, Republikanern, popolari und unabhängigen „Sachverständigen “ im Gespräch gewesen ${ }^{2}$, die

194 Zur Verteidigung der Hauptstadt standen 12000 Mann unter der Führung des loyalen Generals Emanuele Pugliese zur Verfügung, die nicht zuletzt wegen ihrer ungleich besseren Bewaffnung den Faschisten militärisch überlegen waren. Zum Problem der Loyalität der Armee siehe Gentile, S. 672, 676 .

195 Vgl. Lyttelton, Seizure, S. $87-90$.

1 Zur antisozialistischen und im ganzen faschistenfreundlichen Haltung der Masseser Republikaner und "popolari“ siehe oben, S. 77, 141.

2 Bericht über diese Verhandlungen in Il Nuovo (Organ der Unione politica nazionale, Massa) vom 12. und 26.3. 1922. 
ohne Konkurrenz angetreten wäre, da die anhaltende faschistische Bedrohung es den Sozialisten und Kommunisten unmöglich machte, sich zur Wahl zu stellen. Vor allem die nationalliberale Unione politica nazionale hatte sich für dieses Blockverfahren stark gemacht; sie hoffte, auf diese Weise der Absorption durch den Faschismus zu entgehen und ihm gleichzeitig die schärfsten Zähne ziehen zu können. Doch die Verhandlungen über die Zusammensetzung der Liste gingen nicht recht voran, und als die Masseser Faschisten meinten, ihre „Partner" mit der Veröffentlichung einer von ihnen im Allein-

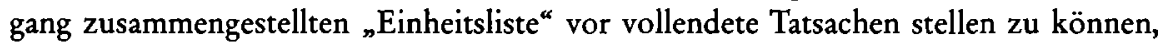
sprangen erst die Republikaner und danach auch die popolari $\mathrm{ab}^{3}$. Es hat den Anschein, daß ihnen der Fauxpas des lokalen PNF sehr gelegen kam, denn eine Blockbildung dieser Art stand im offenen Gegensatz zu den Richtlinien des PRI und des PPI und war auch innerhalb der Masseser Ortsvereine auf Widerspruch gestoßen.

Die Faschisten hatten zu hoch gepokert. Sie mußten jetzt alleine antreten und riskierten eine Wahlniederlage, was sie nach ihrem Selbstverständnis kaum akzeptieren konnten. Als unmittelbar vor der Wahl ein nochmaliger Versuch, ein Wahlbündnis zu bilden, scheiterte, kam es in Massa zu schweren Spannungen: Der Präfekt befürchtete Gewaltaktionen von seiten der Faschisten und forderte 100 zusätzliche Guardie regie $\mathrm{an}^{4}$. Doch buchstäblich in letzter Minute verzichtete die Unione politica nazionale zugunsten des PNF auf die Wahlteilnahme und ermöglichte so den Sieg der Faschisten ${ }^{5}$. Bei einer Wahlbeteiligung von rund 50 Prozent fiel den Faschisten mit einem Stimmenanteil von 38,5 Prozent die sogenannte maggioranza im Stadtrat zu. Die Republikaner erhielten mit 31,8 Prozent die acht Sitze der minoranza, und die popolari gingen mit ihren 28,7 Prozent leer aus ${ }^{6}$.

Dieses Wahlergebnis ist in mehrerer Hinsicht aufschlußreich: Die schwache Wahlbeteiligung wie auch die magere Mehrheit der Faschisten lassen darauf schließen, daß die Wähler zumindest keinem massiven Druck ausgesetzt waren. Außerdem zeigt es, daß in Massa Faschisten und Liberale selbst nach der Ausschaltung der Arbeiterparteien nicht in der Lage waren, die Mehrheit der Wählerstimmen auf sich zu vereinen. Der laute Jubel über die „erste faschistische Gemeinde Italiens“ konnte nicht darüber hinwegtäuschen, wie prekär hier die Basis des Faschismus war.

In Carrara war die Situation grundsätzlich anders. Hier hatten die Faschisten schon vor dem Regierungsantritt Mussolinis eine solche Position der Ausschließlichkeit errungen, daß keine politische Kraft mehr gegen sie antreten mochte. Die Kommunalwahl war hier ursprünglich für den 26 . Oktober 1922 vorgesehen und mußte dann wegen der sich überstürzenden Ereignisse des „Marsches auf Rom“ um einen Monat verlegt werden. Die Liberalen hatten schon von vornherein zugunsten des PNF auf eine eigene Liste verzichtet $^{7}$, und die Republikaner entschieden sich am 19. November nach langem Zögern

3 Ebenda.

${ }^{4}$ ACS, MI, DGPS 1922, b. 94, f. „Elezioni amministrative Massa“: Präfekt an Innenministerium vom 27. 9. 1922.

${ }_{5}^{5}$ Ebenda: Präfekt an Innenministerium vom 2. 10. 1922.

6 Ebenda: Daten des Innenministeriums umgerechnet in Prozentwerte.

7 Ebenda: Präfekt an Innenministerium vom 21. 10. 1922. Zwischen den Faschisten und Liberalen Carraras kam es im Endeffekt zu folgender Übereinkunft: Die Liberalen rufen zur Wahl der ausschließlich mit Faschisten besetzten Liste für das "consiglio comunale“ auf. Dafür erhalten die Liberalen vier der acht Listenplätze für die Wahl zum politisch unwichtigeren consiglio provinciale“ (Il Giornale di Carrara vom 28. 10. 1922). 
gegen eine Wahlteilnahme ${ }^{8}$. Sie begründeten ihren Verzicht mit dem Hinweis auf einige unmittelbar vorausgegangene Übergriffe der Faschisten. Aber der eigentliche Grund war, daß sie keinen Wahlkampf hatten führen können und der ordnungsgemäße Ablauf des Urnengangs in Frage gestellt war.

Der "Wahlsieg" der Faschisten war somit gesichert, doch bemerkenswerterweise reichte ihnen das nicht. Sie veröffentlichten einen Wahlaufruf, auf dem sie die Stimmenabgabe zur Pflicht erklärten, und mobilisierten für den Wahltag alle squadristi ${ }^{9}$. Die Bevölkerung wurde um sechs Uhr von der „faschistischen Fanfare“ geweckt. Ein Teil der squadristi bezog an den Wahllokalen Stellung, wo sie mit der Verteilung der Wahlscheine und der Überwachung der Wahl beauftragt waren, und die anderen patrouillierten im Gemeindegebiet, um die Bevölkerung zur Wahl anzuhalten. Die Bewohner von abgelegenen Siedlungen wurden mit Lastwagen zu den Wahllokalen geschafft. Die Wahlbeteiligung war in den ländlichen Stimmbezirken der ville im Durchschnitt höher als in der Stadt ${ }^{10}$, wo die soziale Kontrolle wohl nicht so lückenlos funktionierte. Insgesamt erreichte sie 61 Prozent $^{11}$. Das ist enorm hoch, wenn man bedenkt, daß in Carrara bisher, unter anderem wegen der Wahlabstinenz der Anarchisten, nicht einmal die Hälfte der Berechtigten zur Wahl zu gehen pflegten ${ }^{12}$, und es obendrein diesmal gar nichts zu wählen gab. Anders als in Massa hatten die Wahlen in Carrara schon einen eindeutig „totalitären" Charakter, der sich etwa auch in der Kommentierung des Wahlgeschehens durch das faschistische Parteiorgan zeigt: „In allen Gesichtern sah man die Freude darüber, eine heilige Pflicht erfüllt zu haben", schrieb Alalà mit einer sehr charakteristischen Wortwahl ${ }^{13}$. Der erfolgte $Z$ wang bedurfte schon der Uminterpretation in eine besonders begeisterte Freiwilligkeit.

Dieser „Wahlerfolg“ führte zu einer breiten Repräsentation der verschiedenen Gruppen des lokalen Faschismus im Gemeinderat von Carrara: Die Squadrenführer der „ersten Stunde", die faschistischen Unternehmer, die Ortsvereinssekretäre der frazioni waren breit vertreten ${ }^{14}$. Bürgermeister wurde Bernardo Pocherra, der einzige Faschist der ersten Stunde, der über eine langjährige kommunalpolitische Erfahrung und vielfältige Ver-

8 Ebenda: Präfekt an Innenministerium vom 20. 11. 1922.

9 Alalà vom 25. 11. 1922.

10 Alalà vom 2. 12. 1922. Es ist sehr bezeichnend, daß das faschistische Parteiorgan die einzige Quelle ist, die Auskunft über den Ablauf des Wahlgeschehens in Carrara gibt. Der Präfekt begnügte sich damit, das Ergebnis zu melden und zu versichern, daß die Wahl „ohne Zwischenfälle“ vonstatten gegangen sei (ACS, MI, DGPS 1922, f, „Elezioni amministrative Massa“: Telegramm vom 26. 11. 1922).

11 Ebenda (in Prozentwert umgerechnet).

12 Selbst bei der durch eine extreme Polarisierung gekennzeichneten Parlamentswahl vom Mai 1921 blieb die Wahlbeteiligung in Carrara unter 50\% (La Sveglia repubblicana vom 21.5. 1921), obwohl sie im Wahlkreis insgesamt (Pisa, Lucca, Livorno und Massa-Carrara) auf 55,6\% anstieg. Zum Vergleich die Wahlen 1919: Pisa/Livorno und Lucca/Massa zusammengenommen 48,2\%. Daten in Statistica elezioni, S. 120-122.

13 Alalà vom 2. 12. 1922.

14 Ebenda: Liste der faschisitschen Gemeinderäte. Ein gutes Viertel der 40 Gemeinderäte gehörte zur Kategorie der Squadrenführer der ersten Stunde. Fast ebensoviele waren Vertreter der „ville" des Berglands, was dokumentiert, daß die faschistische Organisation nach wie vor dort einen ihrer Schwerpunkte hatte. Der Anteil der Marmorunternehmer machte circa ein weiteres Viertel aus. Die Akademiker, die dem PNF Carrara zur Verfügung standen, waren fast alle aufgeboten. Es handelte sich um vier Juristen, von denen zwei Marmorunternehmer (Ghino Faggio- 
bindungen in den Kreisen der lokalen Notabilität verfügte ${ }^{15}$. Er war sicherlich eine Integrationsfigur und schien noch am ehesten der Aufgabe gewachsen zu sein, die widerstreitenden Interessen und Vorstellungen zu versöhnen, die bis zur Stunde unter dem breiten Mantel des lokalen Faschismus Zuflucht gefunden hatten. Doch sollte sich bald erweisen, daß die Vermittlung zwischen unterschiedlichen Standpunkten und die Herbeiführung von Kompromißlösungen auf dem Wege der Diskussion und der Verhandlung nicht die Konfliktlösungsstrategien waren, die dem System des Provinzfaschismus gemäß waren. Pocherra, der solche Wege favorisierte, war dem Vorkriegsliberalismus seiner politischen Lehrjahre noch so sehr verhaftet, daß er auf dem Weg in die „neue Ordnung" schon bald zum Bremser werden mußte. Manifeste soziale und politische Konflikte standen im Widerspruch zu der zelebrierten Gemeinschaft aller sozialen Gruppen, und autoritäre „Konfliktregelungen" entsprachen dem "militärischen“ Wesen der lokalen faschistischen Organisation besser.

Die entscheidenden Impulse zur Ausbildung einer „totalitären“ Ordnung im lokalen Rahmen gingen von Renato Ricci aus. Ihm waren die traditionellen politischen Spielregeln völlig fremd. Hinsichtlich der grundsätzlichen sozialen und wirtschaftlichen Probleme der Region hatte er sich im Laufe seiner knapp zweijährigen „politischen Tätigkeit" in der Region feste und unverrückbare Überzeugungen gebildet. Die Lösungen dieser Probleme im Sinne des Allgemeinwohls lagen für ihn auf der Hand, und alle jene, die sich seinen Zielen entgegenstellten, konnten in seinen Augen daher nur Sachwalter von trüben Sonderinteressen sein. Ricci war mit Sicherheit nicht der begabteste Politiker in der Führung des Carrareser Faschismus. Soweit man das anhand der Quellen beurteilen kann, waren ihm Männer wie Pocherra oder der Vizesekretär der Federazione, Gualtiero Betti, in den Fähigkeiten zur politischen Analyse und Argumentation weit überlegen ${ }^{16}$. Aber das spielte keine Rolle, denn er war „ der Führer“, der mit seinem „soldatischen" Charisma und seinen einfach und eindringlich vorgetragenen Überzeugungen in der Lage war, die Masse der Faschisten für sich einzunehmen. Sein milizärischer Führungsstil hatte sich in der „Kampfzeit“ vor dem „Marsch auf Rom“ bewährt, als rasches zupackendes Handeln gefordert war, und seine Position wurde in dieser Phase

ni, Renato Lazzoni) und zwei Rechtsanwälte (Bernardo Pocherra, Giuseppe Onniboni) waren, einen Zahnarzt (Luigi Da Pozzo) und einen Arzt (Ferdinando Pellini), einen Chemiker und Unternehmer (Dario Orlandi) und einen Professor der Kunstakademie (Adolfo Angeli).

15 Pocherra war einer der wenigen "Vollblutpolitiker" in den Reihen des Carrareser Faschismus. Vor 1914 Führer der "Jungliberalen" in Carrara und 1914/15 Hauptwortführer des lokalen Interventionismus, Kriegsfreiwilliger, Hauptmann der Infanterie, Mitbegründer der Federazione industriali im Jahre 1919. Er vertrat einen rechten nationalen Liberalismus, der aber gegenüber sozialen Forderungen nicht unaufgeschlossen war, wie seine Tätigkeit als Rechtsberater der Gewerkschaft der Köche und Kellner zeigt, die der Camera del lavoro angehörte. Als Mentor der jungen Radikalen um Renato Ricci folgte er diesen mit nur zwei Tagen Verzögerung in den Fascio. Er war weder an Squadrenaktionen beteiligt noch hatte er je einen Sitz im Direktorium des Fascio, griff aber den politisch unerfahrenen "squadristi“ wiederholt als Kundgebungsredner und Verhandlungsführer unter die Arme. Quellen: ASM, Questura Massa, b. 11, f. „Partito giovanile liberale italiano"; Il Cavatore vom 28. 5. 1922; Missori, PNF, S. 260; Bernieri, Carrara moderna, S. 201; Bertozzi, Stampa, S. 152, 156.

16 Von Ricci ist aus der Frühphase des Faschismus wenig Schriftliches erhalten. Anfangs ist sein Bemühen zu erkennen, D'Annunzios pathetischen Stil nachzuempfinden. Siehe etwa „12 settembre ${ }^{\alpha}$ in Alalà vom 10. 9.1921 und den handgeschriebenen Brief an Mussolini vom 31. 8. 1921 (ACS, SPD/CR $1922-43$, b. 48, f. „R. Ricci“). 
niemals in Frage gestellt, auch wenn zunächst andere führende Faschisten die Erscheinung der Bewegung in der Öffentlichkeit Carraras entscheidend mitprägten ${ }^{17}$. Erst mit den Aktionen des Hochsommers 1922 kam es zu einer deutlichen Heraushebung und zum Teil auch schon zur Überhöhung seiner Person. Mit dem „Marsch auf Rom“ bürgerte sich für Ricci dann schon die Bezeichnung Duce apuano oder Duce dell'Apuania ein, und seine regionale Führungsrolle war jetzt praktisch nicht mehr angreifbar.

Im Januar 1923 zog Mussolini die Konsequenzen aus der Stellung Riccis an der Spitze des außerordentlich geschlossenen und unangefochtenen Provinzfaschismus von Carrara und ernannte ihn zum alto commissario politico des PNF für Massa-Carrara, Pisa und Livorno ${ }^{18}$. In den anderen Provinzen hatte sein Amt keine größere politische Bedeutung: In Pisa war die Ernennung eines Auswärtigen wegen eines schweren innerfaschistischen Dauerzwistes nötig geworden ${ }^{19}$, und in Livorno wirkte er faktisch als Statthalter von Costanzo Ciano, mit dem ihn eine enge persönliche und politische Freundschaft verband ${ }^{20}$. Doch im Bereich seiner Hausmacht verlieh ihm das alto commissariato die Aura und die Machtmittel, die ihn endgültig zum Ras ${ }^{21}$, zum faschistischen „Provinzfürsten“, machten. Ricci ließ keinen Zweifel daran, daß er sich als der Vertreter der Regierung mit weitgehenden Vollmachten verstand ${ }^{22}$, obwohl er eigentlich nur ein Parteiamt innehatte, das ihm keineriei exekutive Befugnisse zusprach ${ }^{23}$. Mit dem tatsächlichen Leiter der Exekutive in der Provinz, dem Präfekten Berti, gab es allerdings keine Kompetenzkonflikte, weil dieser ihm völlig zu Diensten war. Der Tenor seiner Berichte nach Rom zeigt ganz deutlich, daß es sich bei ihm mittlerweile um einen Parteigänger Riccis handelte ${ }^{24}$.

Unmittelbar nach seiner Ernennung zum commissario politico nahm Renato Ricci die korporativen Pläne bezüglich der Marmorwirtschaft, die im Jahr zuvor im Ansatz steckengeblieben waren, wieder auf. Die im Februar 1922 gegründete Corporazione industriali del marmo war sang- und klanglos wieder eingeschlafen. Zwar gelang es den faschi-

${ }^{17}$ An erster Stelle ist hier Ghino Faggioni zu nennen, der auch oft als Kundgebungsredner auftrat, und ferner Bernardo Pocherra, Ottorino Biscioni, Gualtiero Betti, Prayer Galetti und Luigi Da Pozzo. Von diesen hatte aber nur Betti die Aura des Squadrenführers der ersten Stunde. Von den sonstigen "capi squadra" der Frühzeit hatte niemand das Format eines politischen Führers.

18 Alalà vom 20.1.1923.

19 Vgl. Canali, Dissidentismo, S. 34 -38, und Nello, Vocazione, S. 640. Bemerkenswert ist, daß Ricci den aus Carrara stammenden und früher mit ihm verbundenen Gründer des Pisaner Fascio, Bruno Santini, nicht gegen den extremistischen Sekretär des Provinzialverbands, Filippo Morghen, unterstützte.

${ }^{20}$ Ciano hatte sich als Mitglied der faschistischen Parlamentsfraktion immer wieder der Sache des Carrareser Faschismus angenommen und hatte wahrscheinlich auch einen gewissen Anteil an der PNF-Karriere von Ricci, der als sein Protegé galt; ACS, MI, Gabinetto Finzi, b. 12, f. 145: Memorandum von Ettore Viola ohne Datum (Mai 1924).

21 Zur Herkunft des Titels "Ras" siehe oben, S. 11.

22 So verlangte er vom Bürgermeister Pocherra, daß er nur über ihn mit Rom verkehre (ACS, MI, Gabinetto Finzi, b. 6, f. 61: Memorandum von Pocherra vom 24. 4. 1923). Bei der Auseinandersetzung um die Frage der Marmorpreisbindung betonte er mehrmals, daß er mit Rückendeckung der Regierung handle (ebenda und Alalà vom 24. 2. 1923).

${ }^{23}$ Zur Rolle der "commissari politici“ siehe De Felice, Mussolini il fascista 1, S. $418 \mathrm{f}$.

24 ACS, MI, Gabinetto Finzi, b. 6, f. 61: Berichte zu den Auseinandersetzungen mit den Dissidenten vom 23. und 25.3.1923. 
stischen und anderen protektionistisch orientierten Unternehmern im Juli, die Verkündung einer Preisbindung des Marmors durch den alten Verband durchzusetzen ${ }^{25}$, aber die Maßnahme wurde bald so massiv unterlaufen, daß sie stillschweigend wieder außer Kraft gesetzt werden mußte. Es ist unzweifelhaft, daß ein großer Teil der Unternehmer eine Preisbindung befürwortete. Auch die Mehrheit der Liberalen und die Experten der lokalen Handelskammer betrachteten die „ruinöse Konkurrenz “ im Gefolge des Nachfragerückgangs der Jahre 1921/22 mit Sorge ${ }^{26}$. Sogar unter den Großexporteuren gab es Anhänger der protektionistischen Linie: Die englische Firma Walton und die Firma Lazzoni gehörten zu den Initiatoren der gescheiterten Preisbindungsmaßnahme vom Juli ${ }^{27}$. Carrara-Marmor hatte auf dem Weltmarkt eine Quasi-Monopolstellung, und man glaubte, die Preise künstlich auf einem relativ hohen Niveau halten zu können, ohne den Absatz dadurch negativ zu beeinflussen ${ }^{28}$. Die Gegner der Preisbindung, die von Carlo Andrea Fabbricotti angeführt wurden, befürchteten dagegen, daß ein höheres Preisniveau die schwächliche Nachfrage weiter drosseln und die Marmorwirtschaft ganz in die Krise stürzen würde ${ }^{29}$.

Die Auseinandersetzung um die Preisbindung war allerdings kein reiner Glaubenskrieg. Sicherlich spielten hier die Verhältnisse der einzelnen Firmen eine Rolle. Ihr finanzieller Zustand, ihre Vermarktungskanäle und die Größe der ihnen zur Verfügung stehenden Marmordepots beeinflußten zweifellos die Positionen der jeweiligen Unternehmer. Die herrschende Marktlage führte zum Abbau der großen Marmordepots, die während der Kriegsjahre angehäuft worden waren. Das ermöglichte den Unternehmern am Rande oder manchmal sogar unter den derzeitigen Produktionskosten zu verkaufen, denn der Marmor der Depots war seinerzeit, vor den starken Lohnerhöhungen der Jah-

${ }^{25}$ Il Giornale di Carrara vom 1. 7. und 5. 8. 1922.

${ }^{26}$ Il Giornale di Carrara vertrat anfangs eine im ganzen noch freihändlerische Linie(siehe den Artikel ihres Wirtschaftsexperten Enrico Marchetti vom 8. 4. 1922) und ging später immer vehementer zu einer protektionistischen Position über. Die Wende zeichnete sich in einem Artikel vom 6. 5. $1922 \mathrm{ab}$, wo noch auf eine freiwillige Preisdisziplin gebaut wurde. Als Sekretär der Federazione industriali war der liberale Parteisekretär, Oreste Nori, an der Ausarbeitung der Preisbindungsinitiative vom Juli 1922 maßgeblich beteiligt.

27 Die Initiative ging von einigen großen Exportfirmen aus, was beweist, daß auch in diesem Bereich die protektionistischen Vorstellungen Fuß gefaßt hatten. Es handelte sich um folgende Firmen: Adolfo Corsi, Lazzoni Nicolao \& Figlio, Fabbricotti Augusto Eredi, Italo Faggioni, Agostino Marchetti; Odling Anselm \& Sons, Walton Goody \& Cripps, Pisani Figli \& Comp., Guglielmo Vennai. Die genannten Firmen kontrollierten weit über die Hälfte des Marmorexports (Il Giornale di Carrara vom 5. 8. 1922). Die Auffassung von Bernieri, Carrara moderna, S. 203, daß die „Marmoroligarchie “ prinzipiell freihändlerisch orientiert war, ist daher nur mit großen Vorbehalten zu akzeptieren.

${ }^{28}$ Die Ansicht, daß Preisniveau und Absatz im Marmorsektor relativ unabhängig seien, vertritt dezidiert der Faschist und Unternehmer Gualtiero Betti (Alalà vom 18. 2. 1922) und etwas abgeschwächt auch der Liberale Enrico Marchetti (Il Giornale di Carrara vom 8. 4. 1922).

29 Diesen Befürchtungen gibt auch Pocherra Ausdruck (ACS, MI, Gabinetto Finzi, b. 6, f. 61: Memorandum vom 24. 4. 1923). Ob das auch die Position von C. A. Fabbricotti war, wie die Darstellung von Ricci nahelegt (ACS, SPD/CR 1922-43, b. 48, f. ${ }_{\text {R }}$. Ricci“: Aussage vor der Disziplinarkommission der MVSN vom 18. 4. 1923), ist fraglich. Vom September 1923 ist jedenfalls eine Äußerung von Fabbricotti zu belegen, die darauf hindeutet, daß auch er kein grundsätzlicher Gegner jeglicher Preisbindung war; BCM, Archivio Fabbricotti (noch ohne Signatur): C. A. Fabbricotti an Schiff (Giorgini) vom 29. 9. 1923. 
re 1919/20, viel billiger produziert worden ${ }^{30}$. Einige Firmen hatten anscheinend auch ernste Liquiditätsprobleme und waren zu diesem „Ausverkauf“ regelrecht gezwungen ${ }^{31}$. Die im Faschismus besonders aktiven mittleren und kleineren Marmorunternehmer, die selbst oft keinen direkten Zugang zum Export hatten, fühlten sich durch diese Praxis bedroht. Sie traten am vehementesten für die Preisbindung ein ${ }^{32}$. Bei den ganz kleinen Unternehmern und Händlern, die ihre Marktnischen oft durch das Unterbieten der Großen sicherten, war die Situation grundsätzlich anders. Hier waren die Widerstände gegen die Preisbindung sogar besonders stark ${ }^{33}$.

Eine ganz entscheidende Rolle für die kompromißlose Haltung Riccis in der Frage der Preisbindung spielte seine Orientierung in der Gewerkschaftspolitik. Ein Andauern des Preisverfalls nach dem Abbau der Depots hätte zwangsläufig einen massiven Druck auf die Löhne zur Folge gehabt, und er war um keinen Preis bereit, eine weitere Lohnsenkung zuzulassen ${ }^{34}$. Schon für die Lohnsenkung vom Juli 1921, die noch von der alten Camera del lavoro akzeptiert werden mußte, waren die Faschisten in der Arbeiterschaft allgemein verantwortlich gemacht worden ${ }^{35}$. Die faschistische Gewerkschaftsorganisation konnte es sich nicht leisten, einem weiteren Lohnabbau zuzustimmen. Sie hätte so den bescheidenen Kredit in der Arbeiterschaft sofort wieder verspielt, den sie sich mühsam im Laufe des Jahres 1922 in diversen kleinen Auseinandersetzungen mit den Arbeitgebern erworben hatte ${ }^{36}$. Eine solche Diskreditierung der Sindacati nazionali hätte die Grundlagen des regionalen Machtsystems unterminiert, in dem die Gewerkschaften einen zunehmend wichtigeren Grundpfeiler bildeten. Auf keines der Elemente seines Herrschaftssystems konnte sich der Ras Renato Ricci so verlassen wie auf die Sindaca$t i$. Die Fasci, vor allem die älteren unter ihnen, hatten noch ein ausgeprägtes Eigenleben. Die Miliz unterstand nach ihrer "Verstaatlichung" einer strengen und in den höheren Rängen von Berufsoffizieren dominierten Hierarchie und war so dem direkten Zugriff

30 Dieser Sachverhalt geht aus dem Interview hervor, das der Direktor der Firma Walton, Noël Cripps, im Juli 1923 der englischen Zeitung The Oberserver gewährte (abgedruckt in Alalà vom 11. 8. 1923). Hier singt der britische Großexporteur eine Lobeshymne auf Ricci und den Faschismus, obwohl sich seine Firma schon zwei Monate darauf zur unternehmerischen Opponentengruppe gesellen sollte.

31 Ausführungen von Enrico Marchetti in Il Giornale di Carrara vom 8. 4. 1922.

32 Als besonders engagierte faschistische Verbandspolitiker fallen folgende Unternehmer auf: Oreste Ascoli, Carlo Gattini, Egisto Lodovici, Giuseppe Lagomarsini, Francesco Dazzi. Es handelt sich hier durchwegs um Vertreter von mittelgroßen bis kleinen Firmen.

33 ACS, MI, Gabinetto Finzi, b. 6, f. 61: Präfekt an das Innenministerium vom 23.3. 1923 und Memorandum von Pocherra vom 24. 4. 1923.

34 Schon in Alalà vom 4. 3. 1922 heißt es: „Die Löhne sind zur Zeit, bei den herrschenden Lebenshaltungskosten, nicht reduktionsfähig. Nur wenn diese sich verringern sollten, kann man über Lohnkürzungen reden. Andernfalls nicht! Die Arbeiterklasse würde uns auf unserem Kampfposten finden, um ihre gerechte Sache zu verteidigen, egal gegen wen. “ Weitere Artikel mit diesem Tenor in Alalà vom 18. 3. und 1. 4. 1922.

35 ACS, SPD/CR 1922 - 43, b. 48, f. „R. Ricci“: Aussage Riccis vor der Disziplinarkommission der MVSN vom 18. 4. 1923.

${ }^{36}$ Die faschistischen Gewerkschaften achteten auf die Einhaltung der verschiedenen Tarifverträge, die noch von der Camera del lavoro abgeschlossen worden waren. Sie bekämpften vor allem die Ausweitung der Akkordarbeit in den Steinbrüchen und die Überstunden in den Marmorwerkstätten, die oft nicht mit den tarifvertraglich festgelegten Zuschlägen entlohnt wurden. Ein Schwerpunkt ihrer Aktivität bestand auch in der Kontrolle des ordnungsgemäßen Ablaufs und der tarifvertragsgemäßen Entlohnung der „lizzatura“; Alalà vom 18. 3., 8. 4. und 8. 7. 1922. 
der politischen Instanzen der Provinzorganisation entzogen ${ }^{37}$. Außerdem waren die meisten Offiziere der lokalen Einheiten der Milizia volontaria di sicurezza nazionale verdiente Frontkämpfer und Squadrenführer und hatten daher ein zu großes persönliches Eigengewicht, um sich mit einer servilen Komparsenrolle abzufinden. Am allerprekärsten war schließlich die Machtbasis des Ras in der Unternehmerschaft. Sie hatte mit ihrem Geld den lokalen Faschismus großgezogen, hatte aber in entscheidenden Situationen immer wieder ihre Unabhängigkeit demonstriert und allen Versuchen der institutionellen Vereinnahmung widerstanden. Selbst die dezidiert faschistischen Unternehmer hatten sich nie vom Einfluß der unabhängigen, wirtschaftlich bestimmenden Kräfte im Unternehmerlager freimachen können. Eine absolute Loyalität zur faschistischen Provinzorganisation war so auch von ihnen nicht zu erwarten.

Es ist nicht zu ermitteln, wieviel Mitglieder die von Ricci kontrollierten Gewerkschaftsorganisationen am Ende des Jahres 1922 hatten, aber in jedem Fall stellten sie schon einen entscheidenden und ausbaufähigen Machtfaktor dar. An die Spitze der Federazione provinciale sindacale hatte Ricci seinen treuen Gefolgsmann Claudio Papini berufen, den der PNF-Provinzsekretär von Lucca, Carlo Scorza, als Sekretär des PNFOrtsvereins von Pietrasanta ausgebootet hatte ${ }^{38}$. Diese Wahl war nicht zufällig. Ricci gedachte nämlich, mit Hilfe der Gewerkschaftsorganisation seinen traditionellen Einflußbereich in der Versilia gegen die Angriffe des rivalisierenden Ras Scorza zu bewahren und auszubauen. Seine weiteren Pläne liefen auf eine Angliederung der Versilia an die Provinz Massa-Carrara und auf die Kontrolle der gesamten regionalen Marmorwirtschaft hinaus. Dieses Vorhaben hatte über den reinen Machtdrang hinaus seine innere Logik, denn für seine Uniformierungspläne war die Beseitigung der traditionellen Konkurrenzsituation zwischen den verschiedenen Marmorabbauzonen der Region die allererste Voraussetzung. Bezeichnenderweise erfolgte die faschistische „Erschließung“ der Garfagnana durch Papini und den einheimischen Vertrauensmann Riccis, Mario Prantoni, über die Sindacati, ohne daß die lokalen Fasci vorher überhaupt eine nennenswerte Bedeutung erlangt hatten ${ }^{39}$. Anders als in Carrara, Massa und der Versilia konnte dort eine gewisse Kontinuität zwischen den alten Steinbrucharbeiterligen und den faschistischen Sindacati gewahrt werden. In den Steinbrüchen von Gorfigliano etwa, dem wichtigsten Marmorabbaugebiet der Garfagnana, „übernahmen“ die Faschisten eine

37 Die Einrichtung der Milizia volontaria per la sicurezza nazionale (MVSN) sollte mit der Säuberung und Disziplinierung der Squadrenorganisation einhergehen und bedeutete ihre Umwandlung in eine polizeilich-militärische Institution des Staates, ohne daß sie den Charakter der Parteimiliz verlor. Siehe dazu De Felice, Mussolini il fascista 1, S. 430-439. Grundlegende Dokumente bei Aquarone, Stato totalitario, S. 332 - 337. Zusammenhängende Darstellung: ders., Milizia volontaria; außerdem Valleri, Partito armato.

${ }^{38} \mathrm{Vgl}$. Gianelli, Versilia, S. 71. Der Vorgang ist hier wohl etwas schief dargestellt.

${ }^{39}$ Der erste Fascio der Garfagnana wurde im Hauptort des „circondario“, Castelnuovo, erst am 31. 7. 1922 gegründet und hatte anfangs nur 39 Mitglieder. Im September/Oktober folgten die PNF-Orstsvereine in den Steinbrucharbeitergemeinden Vagli und Minucciano (ACS, MI, DGPS 1923, b. 91, f. „Fasci Massa“, sf. „Costituzione fasci“). Gleichzeitig kam es zu einem konsistenten Zulauf von Arbeitern zu den faschistischen Sindacati. In Gorfigliano, dem Zentrum des Marmorabbaus in der Garfagnana, traten schon im September 1922100 Steinbrucharbeiter zu den faschistischen Gewerkschaften über (Alalà vom 16. 9. 1922). Die Organisation der alten Camera del lavoro hatte dort vorher circa 200 Mitglieder (ASM, Questura Massa, b. 16, f. „Lega cavatori“: „prospetto statistico" vom 28.6. 1920). 
laufende Tarifauseinandersetzung mit dem Großunternehmen „Nord Carrara", die noch unter der Leitung der alten Camera del lavoro begonnen worden war, und führten sie mit Nachdruck, wenn auch erfolglos, weiter ${ }^{40}$. Der zunehmende Populismus der faschistischen Gewerkschaftspolitik ging allerdings nicht mit der Gewährung innergewerkschaftlicher Demokratie einher. Ganz im Gegenteil setzte sich das Prinzip der Ernennung der Gewerkschaftsfunktionäre von oben immer stärker durch ${ }^{41}$. Dies erlaubte Ricci eine autokratische Kontrolle der regionalen Sindacati, die weit über das hinausging, was bezüglich der einzelnen Fasci der Federazione möglich war, welche sich trotz seiner diktatorischen Eingriffe noch einen Rest interner Demokratie bewahren konnten ${ }^{42}$.

Die Erfolge bei der Organisierung von Arbeitern und Angestellten, so willkommen sie waren, reichten Ricci nicht aus. Er und mit ihm die meisten anderen führenden Faschisten Carraras waren von Anfang an ausgesprochene Anhänger des ,integralen Syndikalismus": Aus den Grundsatzartikeln von Alalà über die Gewerkschaftsfrage ist herauszulesen, daß der Carrareser Faschismus sich ab Anfang 1922 die Zusammenfassung von Arbeitgebern und Beschäftigten unter einem gemeinsamen Dach zum Ziel setzte ${ }^{43}$. Das Führungsgremium dieser „Korporation“ sollte als permanente Schiedsstelle die auftretenden Konflikte schlichten und so jeglichen „Klassenkampf“ beseitigen. Über die gewis-

${ }^{40}$ Der Streik in den Steinbrüchen von Gorfigliano war am 4. 7. 1922 wegen der Ausweitung der Akkordarbeit mit Niedriglöhnen spontan ausgebrochen. Die Tarifverhandlungen wurden zunächst von Attilio Fellini als Vertreter der alten Camera del lavoro geführt. Dieser hatte sich nach seiner Verbannung aus Seravezza und einem kurzen „Exil“-Aufenthalt in Sampierdarena (Genua) in der Garfagnana niedergelassen, wo die letzten funktionierenden Ligen der alten Gewerkschaftskammer bestanden. Im September „eroberten“ die Faschisten dieses Gebiet und vertrieben ihn auch von dort. Die Aktionen wurden von Papini angeführt, der dabei aber offensichtlich jede Kompromittierung mit der Nord Carrara S. A. vermied. Papini gelang die rasche Rekrutierung der streikenden Arbeiter, und seine Verhandlungsführung im Tarifkonflikt war keineswegs zurückhaltend; Il Cavatore vom 8. und 22. 7. 1922; Alalà vom 9. 9., 16. 9. und 14. 10. 1922; ACS, MI, DGPS 1922, b. 70, f. „Ordine pubblico Massa“, sf. 3: mehrere Berichte; ACS, MI, CPC, b. 1995, f. „Attilio Fellini“. Daß sich Papini zuletzt doch dem Tarifdiktat der Nord Carrara S. A. unterwerfen mußte, lag nicht an einer wie auch immer gearteten Komplizenschaft mit dem Unternehmen, wie Snowden, Fascist Revolution, S. $115 \mathrm{f}$, unterstellt, sondern an der Schwäche der gewerkschaftlichen Organisation, der Quasi-Monopolstellung der Firma als lokaler Arbeitgeber und auch der politischen Rückendeckung, die sie von übergeordneten PNFStellen erhielt. Zu letzterem: APC, b. B 10, Bd. IV bis, S. 358: Perrone an Ricci vom 7. 10. 1922.

41 Es handelte sich hier um ein Grundprinzip der faschistischen Gewerkschaftsorganisation, das die Unabhängigkeit der Funktionäre von der Basis garantieren sollte (vgl. Cordova, Sindacati fascisti, S. 149). Auf der Sekretärsebene der lokalen Einzelgewerkschaften wurde es aber zumindest anfangs nicht immer durchgeführt: Siehe etwa die Wahl des Führungsgremiums des Sindacato tranvieri von Carrara (Alalà vom 19, 8. 1922).

42 Was die Fasci des sogenannten "Gruppo di Carrara" angeht, war die innerparteiliche Demokratie schon 1922 weitgehend eliminiert. Von April bis Dezember 1922 bestand kein gewähltes Direktorium des „Gruppo“, und Ricci leitete ihn über das Provinzialsekretariat. Bei der anschließenden Direktoriumswahl am 10.12. 1922 präsentierte er den Mitgliedern eine fertige Liste, die sie nur noch zu bestätigen hatten. Sie bestand ausschließlich aus „alten Kämpfern“, von denen fast alle zu seinen treuen Gefolgsleuten gehörten: Neben ihm selbst handelte es sich um Oreste Ascoli, Luciano Bacciola, Italo Barattini, Gualtiero Betti, Silvio Cattani, Goffredo Corsi, Ugo Dell'Amico, Ghino Faggioni, Oreste Giorgi, Gino Faggioni. In den meisten anderen Fasci herrschten in der Regel demokratischere Verhältnisse. Allerdings konnte der Provinzsekretär mißliebige Ortsvereine auflösen und neugründen.

${ }^{43}$ Siehe vor allem die Artikel von Gualtiero Betti in Alalà vom 11. und 18. 2. 1922. 
senhafte Einhaltung der Regeln der collaborazione di classe sollte der Faschismus wachen, notfalls mit Ausübung von Zwang.

An der Spitze der Federazione industriali del marmo stand mittlerweile Emilio Quaglino, ein Mann, der den wirtschafts- und sozialpolitischen Vorstellungen der Faschisten recht nahestand. Er war ein junger, aus dem Piemont eingewanderter Unternehmer, der außer im Bereich der Marmorverarbeitung auch als Bauunternehmer und im Möbelhandel tätig war. Quaglino, der sich aus Arbeiterverhältnissen hochgearbeitet hatte, war im Maßstab Carraras ein ausgesprochen dynamischer Unternehmer mit weitreichenden Ideen zur Verbesserung der industriellen Infrastruktur der Region und einer aufgeschlossenen Haltung gegenüber sozialpolitischen Maßnahmen ${ }^{44}$. Er war anfangs kein Faschist, aber ein überzeugter Anhänger der Preisbindung. Als sich um die Jahreswende 1922/23 ein Vorstoß der Faschisten zur „Eroberung“ und Umwandlung der Industriellenvereinigung abzeichnete, versuchte er der Initiative den Wind aus den Segeln zu nehmen, indem er verbandsintern massiv auf eine neue Preisbindungsabsprache drängte $\mathrm{e}^{45}$.

Renato Ricci hatte kein Interesse daran, daß eine Lösung ohne sein Zutun gefunden wurde, und schritt sofort ein. Anfang Februar 1923 berief er eine Versammlung aller faschistischen Marmorunternehmer ein und gründete den Gruppo di competenza fra gli industriali fascisti, den er sofort einen Maßnahmenkatalog für eine strenge Preiskontrolle ausarbeiten ließ ${ }^{46}$. Dieser wurde von Ricci ultimativ der Federazione industriali zur Annahme vorgelegt. Doch obwohl Quaglino unter dem Druck der Ereignisse jetzt vom Unternehmerverband ein Mandat zur Durchführung der Preiskontrolle erlangte, kam es zu keiner Einigung mit Ricci. Das faschistische Projekt sah nämlich die Einrichtung eines Kontrollorgans durch den Gruppo di competenza und damit die Kaltstellung des Verbands vor ${ }^{47}$. Quaglino und das gesamte Führungsgremium der Federazione industriali traten daraufhin zurück und machten so die Bahn frei für Riccis weitergehende Pläne ${ }^{48}$. Dieser berief eine Generalversammlung der Marmorunternehmer Carraras ein und ließ dort ohne jede Diskussion über den faschistischen Entwurf abstimmen. Diesem „faschistischen Stil“ waren die Versammelten nicht gewachsen; ohne Widerspruch hoben sie die Hände ${ }^{49}$.

Logische Konsequenz dieser Kapitulation war kurz darauf die Gründung der Federazione industriale fascista del marmo als Mitgliedsverband der Corporazione nazionale dell'industria, die den alten Unternehmerverband ersetzte. Die alte Marmorunternehmerorganisation, die dem nationalen Industriellenverband Confindustria angehört hat-

44 Siehe sein Interview in Il Giornale di Carrara vom 20.1. 1923 und sein Porträt in Alalà vom 27. 1. 1923.

45 Sein ausführliches Interview in Il Giornale di Carrara vom 20.1. 1923 ist in diesem Zusammenhang zu sehen. Als eine der treibenden Kräfte dieses Vorstoßes ist der Sekretär der Federazione industriali und Führer der liberalen Partei, Oreste Nori, zu vermuten.

46 Alalà vom 10. 2. 1923 und Il Giornale di Carrara vom 17. 2. 1923.

47 Das jedenfalls läßt sich zwischen den Zeilen im Bericht des Giornale di Carrara vom 24. 2. 1923 lesen.

${ }^{48}$ Es ist aus den Quellen nicht herauszulesen, ob hier irgendwelche Drohungen von Ricci im Spiel waren oder ob Quaglino die Faschisten freiwillig begünstigt hat.

49 Il Giornale di Carrara vom 24. 2. 1923 und Alalà vom 24. 2. 1923. Das autoritäre Vorgehen von Ricci scheint allerdings weite Kreise der Unternehmerschaft befremdet zu haben; ACS, MI, Gabinetto Finzi, b. 6, f. 61: Memorandum von Pocherra vom 24. 4. 1923. 
te, war damit beseitigt. Doch der Kontinuitätsbruch war weniger einschneidend, als man auf den ersten Blick vermuten könnte. Nach einem anderthalbmonatigen Intermezzo, in dem die Unternehmerorganisation unter dem Vorsitz von Ghino Faggioni stand und auch sonst von hundertprozentigen Faschisten dominiert wurde ${ }^{50}$, erhielt der Verband im April wieder Führungsgremien, die die Zusammensetzung der Carrareser Unternehmerschaft einigermaßen widerspiegelten. Man trug dem Unabhängigkeitsstreben der Großfirmen Rechnung und spaltete die neue Federazione, so wie es bei der alten gewesen war, in einen Sindacato esportatori und einen Sindacato industriali auf. Und das Sekretariat der „Exporteure" unterschied sich in der Zusammensetzung kaum vom Führungsgremium der alten Unione esportatori: Die Liberalen Gino Salvini und Battista Cucchiari behielten ihre Position, und als dritter Sekretär der Organisation wurde Renato Lazzoni bestimmt, an dessen Zugehörigkeit zur faschistischen Dissidentengruppe zu diesem Zeitpunkt schon kein Zweifel mehr bestehen konnte ${ }^{51}$. Es ist ganz deutlich, daß der Faschismus den großen Handelshäusern, die gleichzeitig auch Großproduzenten waren, eine gewisse Unabhängigkeit konzedieren mußte. Völlig in der Hand von Riccis Gefolgsleuten war hingegen der Sindacato industriali, der die kleinen und mittleren Unternehmer zusammenfaßte; allerdings war das bei der alten Unione industriali auch schon annähernd so gewesen ${ }^{52}$. Als Zeichen der Kontinuität ist außerdem zu werten, daß Emilio Quaglino jetzt wieder Sekretär des Gesamtverbands wurde. In Zukunft muß man allerdings auch ihn als verläßlichen Faschisten betrachten ${ }^{53}$.

Die faschistische Durchsetzung des alten Verbands hat zweifellos den Coup von Renato Ricci begünstigt. So reibungslos gelingen konnte er aber nur, weil auch bedeutende Teile der nichtfaschistischen Unternehmerschaft und die liberalen und unabhängigen Funktionäre des alten Verbands, also Emilio Quaglino, Gino Salvini, Battista Cucchiari und Oreste Nori, ihn unterstützten oder wenigstens mit Sympathie betrachteten. Symptomatisch ist der Beifall, den der Giornale di Carrara und Noël Cripps, der Leiter der Firma Walton, spendeten ${ }^{54}$. Doch andererseits löste das brutale und selbstherrliche Vorgehen Riccis in manchen Kreisen auch Befremden aus ${ }^{55}$. Der Marmorunternehmer und Sekretär des Carrareser PNF, Ghino Faggioni, war gezwungen, die Aktion ausführlich zu begründen. Der Kern seiner Argumentation lautete sehr aufschlußreich: „Wenn eine

50 Außer Emilio Quaglino und dem Liberalen Gino Salvini gehörten dem Führungsgremium der Federazione industriale fascista del marmo an: Carlo Gattini, Carlo Lena, Dario Orlandi, Egisto Lodovici, Giuseppe Lagomarsini, Francesco Dazzi (Il Giornale di Carrara vom 2. 3. 1923).

51 Gino Salvini fungierte hier als Vertreter des Branchenführers Walton. Zur Rolle von Renato Lazzoni im "dissidentismo" siehe weiter unten, S. 229.

52 Schon vor dem Auftreten des Faschismus gaben dort die späteren Faschisten Carlo und Giovanni Gattini, Egisto Lodovici und Giuseppe Lagomarsini den Ton an. Auch Francesco Dazzi und Gino Nicoli, ebenfalls Faschisten, saßen als Vertreter der Unione industriali und des Consorzio laboratori im Führungsgremium des alten Verbandes. Die Nichtfaschisten spielten hier schon immer eine völlig untergeordnete Rolle; ASM, Questura Massa, b. 13, f. „Federazione industriale ": „prospetto statistico" vom 6. 9.1920 und Kommissar an Questore vom 25. 10.1921; Il Giornale di Carrara vom 17. 2. 1923.

53 Es ist nicht zu ermitteln, ob und wann er Mitglied des PNF geworden ist, aber seine Rolle bei den folgenden Auseinandersetzungen lassen keinen Zweifel über seine Gesinnung zu.

54 Il Giornale di Carrara vom 24. 2. 1923 und das Interview von Cripps (Alalà vom 11. 8. 1923); siehe dazu auch Anm. 30.

55 ACS, MI, Gabinetto Finzi, b. 6, f. 61: Memorandum von Pocherra vom 24. 4. 1923. 
soziale Gruppe das Pflichtbewußtsein gegenüber dem Gemeinwohl verliert, nur noch den falschen Eingebungen ihres Egoismus und ihrer Ängste folgt und in dieser Weise den eigenen Ruin und den des ganzen Landes betreibt, so kann der Ruf zur Pflicht [...] nur schroff und energisch erfolgen, auch wenn das den Anschein eines Diktats erweckt. "56

Zeitgleich mit den Vorstößen zur Einverleibung der Unternehmerorganisation trieb Ricci den Ausbau der faschistischen Gewerkschaftsorganisation erfolgreich voran. Der Generalsekretär des Provinzialverbandes der Sindacatinazionali, Claudio Papini, erwies sich hierbei als geschickter Propagandist und guter Organisator. Vor allem unter den Angestellten und in der Lehrerschaft kam die Organisationsarbeit zügig voran ${ }^{57}$. Außerdem konnte ein Teil der Genossenschaften der Provinz, vor allem Bauarbeiterkooperativen, für die Sindacati nazionali gewonnen werden. Auch die Straßenbahner, Kellner, Friseure, Bäcker und pastai sowie die Metallarbeiter besaßen in Carrara mittlerweile relativ etablierte faschistische Berufsgewerkschaften ${ }^{58}$. Politisch entscheidender war allerdings die Erfassung der Marmorarbeiter; diese hatte lange Zeit ziemlich stagniert. Als Berufsgewerkschaft existierte nach wie vor nur der Sindacato lizzatori. Ansonsten hatte man sich damit begnügen müssen, die organisierungswilligen Arbeiter der verschiedenen Berufe in gewerkschaftlichen Ortsgruppen zusammenzufassen ${ }^{59}$. Aber auch hier gelang am Anfang des Jahres 1923 der Durchbruch. Die Faschisten gewannen den ehemaligen Sekretär der alten Lega cavatori città, Ercole Cargioli, für den Wiederaufbau der Organisation im Rahmen der Sindacati nazionali ${ }^{60}$. Cargioli, der in den Polizeiakten bis dahin als Anarchist geführt wurde, war keineswegs eine zweitrangige Figur in der Carrareser Gewerkschaftsbewegung. Von 1914 bis 1922 war er ununterbrochen Leiter dieser größten und wichtigsten Gewerkschaft Carraras und gleichzeitig Mitglied der Exekutivkommission der Gewerkschaftskammer gewesen ${ }^{61}$. Seine „Wiederauferstehung “ als Vertreter der faschistischen Organisation mußte auf der psychologischen Ebene eine große Wirkung haben. Im Februar 1923 rief Cargioli neben dem Sindacato cavatori città auch die kleine, aber organisationsstrategisch enorm wichtige Gewerkschaft der capi cava, der Steinbruchvorarbeiter, wieder ins Leben ${ }^{62}$. Beide Organisationen hatten zusammen das Herzstück der alten Camera del lavoro gebildet, und ihr Wiederaufleben zog

56 "Ai facili censori“ in Alalà vom 3. 3. 1923. Mit dem "ganzen Land“ ("del paese tutto") ist hier nur die Marmorregion gemeint.

${ }^{57}$ Alalà vom 20. 1., 10. 2., 24. 2. und 17.3. 1923.

${ }^{58}$ Diese Gewerkschaften waren auf dem Provinzialkongreß vom 14. 1. 1923 schon vertreten (Alalà vom 20. 1. 1923).

59 Die Aufzählung der sogenannten „sezioni sindacali locali“ läßt erkennen, daß sich die Zentren der faschistischen Gewerkschaftsorganisation in den Marmorabbaugebieten von Carrara und "Nord Carrara" (Monzone, Vinca, Casola, Gorfigliano, Minucciano, Vagli) befanden. Im Massese und der Lunigiana war sie zu diesem Zeitpunkt hingegen schwach bis inexistent.

${ }^{60}$ Alalà vom 24. 2. 1923.

61 ACS, MI, DGPS G-1, b. 105, f. „Massa“: Präfekt an Innenministerium vom 14. 7.1914 und vom 24. 10. 1919; ACS, MI, DGPS 1921, b. 79, f. „Movimento sovversivo Massa“: Präfekt an Innenministerium vom 8. 2. und 4. 5. 1921; ASM, Commissariato Carrara, b. 59: Liste der Mitglieder der „commissione esecutiva“ 1922; ASM, Questura Massa, b. 12, f. „Unione cavatori città“: „prospetto statistico" vom 5. 5.1914.

62 Die "capi“ und "sottocapi cava" leiteten in den Steinbrüchen den technischen Ablauf des Marmorabbaus und den Arbeitseinsatz. Obwohl sie organisatorisch als Vermittlungsinstanz zwischen Arbeitern und Betriebsleitung fungierten, fühlten sie sich der Arbeiterschaft zugehörig, 
weitere Organisationserfolge nach sich. Im März konnten in Carrara der Sindacato marmisti und der Sindacato segatori aus der Taufe gehoben werden ${ }^{63}$, und somit funktionierten die drei wichtigsten Marmorarbeitergewerkschaften wieder.

Es gibt keine genauen Zahlen zur Größenordnung dieser Organisationen, aber alles deutet darauf hin, daß sie bald die der alten Ligen erreichte. Angaben gibt es für Aven$\mathrm{za}$, die als einigermaßen repräsentativ für das ganze Gemeindegebiet anzusehen sind. Hier sind schon im April rund 500 Organisierte zu verzeichnen, die sich auf die Sindacati der Steinbrucharbeiter, lizzatori, Steinmetzen, segatori, Wagenbauer, Schreiner, Metallarbeiter und Pächter verteilten ${ }^{64}$. Das entspricht ungefähr der früheren Präsenz der alten Camera del lavoro in diesem Ort ${ }^{65}$. Der Provinzialverband der faschistischen Gewerkschaften erreichte zur gleichen Zeit 34000 Mitglieder, rund 70 Prozent mehr als die Camera del lavoro zum Zeitpunkt ihrer größten Ausdehnung ${ }^{66}$. Dieses erstaunliche Faktum ist darauf zurückzuführen, daß die faschistische Organisation in einem ungleich größeren geographischen und sozialen Rahmen tätig war. Sie erfaßte zum Beispiel auch jene Gebiete der Lunigiana, deren Arbeiterorganisationen früher zu den Gewerkschaftskammern von La Spezia gehört hatten ${ }^{67}$. Außerdem gewann sie nennenswerte Teile der Angestelltenschaft; die alte Gewerkschaftskammer hatte sich in diesem Bereich immer enorm schwer getan ${ }^{68}$.

Die Erfolge des Carrareser Faschismus auf dem Weg zum sindacalismo integrale veranlaßten den Generalsekretär der Confederazione delle corporazioni, Edmondo Rossoni, dazu, Ende März 1923 eine Sezione marmifera der Corporazione nazionale dell'industria mit Sitz in Carrara einzurichten. Den korporativen Plänen Rossonis war auf Sitzungen des faschistischen Großrats im Januar und März gerade erst ein Dämpfer erteilt worden. Er hatte hier das prinzipielle Recht der Unternehmer, autonom organisiert zu bleiben, akzeptieren müssen, und Mussolini hatte dieses Prinzip am 20. März 1923 nach einem Treffen mit dem Vorsitzenden der Confindustria nochmals bekräftigt ${ }^{69}$. Ohne eine

aus der sie kamen, und spielten eine zentrale Rolle in der gewerkschaftlichen Organisation, etwa bei Streiks. Die alte Camera del lavoro hatte sich gehütet, diese wichtige Gruppe durch Nivellierungsbestrebungen zu verärgern. Die "capi cava" behielten ihre eigene Organisation und ihre eigenen Tarife. Sie stand bis zum Schluß zur alten Camera del lavoro und löste sich wie die anderen Steinbrucharbeitergewerkschaften nach ihrer Ausschaltung zunächst auf.

63 Alalà vom 17. und 24. 3. 1923.

64 Alalà vom 14. 4. 1923.

${ }^{65}$ Der Vergleich ist problematisch, weil die Zahlen für die Ligen der alten Camera del lavoro lückenhaft sind: Lega cavatori, Lega lizzatori und Lega muratori hatten zusammen 190 Mitglieder (siehe Übersicht im Anhang, S. 288). Die Daten zur Lega segatori Avenza fehlen, und die restlichen Berufsgruppen waren zentral in den Carrareser Ligen organisiert.

${ }_{66}$ Alalà vom 21. 4. 1923, Artikel aus La Nazione vom 17. 4. 1923 übernommen.

67 Die geographische Ausdehnung der alten Camera del lavoro deckte sich ziemlich genau mit den Grenzen der Marmorregion.

${ }^{68}$ In der Camera del lavoro waren nur die Kommunalangestellten, die Angestellten von Post- und Telegraphenamt sowie die der Ferrovia marmifera organisiert. Die Lehrer hatten ursprünglich ihre eigenen Organisationen, vor allem die Unione magistrale nazionale. Dem Faschismus gelang ihre Einbindung in die Provinzialorganisation der Sindacati und die Organisierung verschiedener Gruppen von Privatangestellten. Schon im Januar 1923 zählte die Corporazione dell'impiego privato der Gemeinde Carrara über 100 Mitglieder (Alalà vom 20. 1. 1923). Auch die Bankangestellten hatten schon bald eine rührige Gewerkschaft (Alalà vom 31. 3. 1923).

$69 \mathrm{Vgl}$. Cordova, Sindacati fascisti, S. 134 und 149-153. 
entschiedene Unterstützung durch die PNF-Führung und die Regierung mußte Rossoni sich darauf beschränken, Entwicklungen in die gewünschte Richtung auf lokaler Ebenen zu unterstützen. Es gibt eindeutige Anzeichen dafür, daß er Renato Ricci bei seinem Anschlag auf den alten Industriellenverband den Rücken gestärkt hat ${ }^{70}$. Jedenfalls war er ihm höchst willkommen, und seine Bestrebungen, das Erreichte zu zementieren und auszubauen, sind unübersehbar, obwohl dies einem feindlichen Akt gegen die Confindustria gleichkam, die nach den Worten Mussolinis „weder angerührt noch geschmälert“ werden sollte ${ }^{71}$.

Die Sezione marmifera der Corporazione nazionale dell'industria war ihrem Selbstverständnis nach das Spitzenorgan der italienischen Marmorwirtschaft. Ihr unterstanden in der Theorie alle Gewerkschaften, Berufs- und Unternehmerverbände des Sektors. Als Generalsekretäre der Sezione marmifera setzte Rossoni Ghino Faggioni und Renato Ricci ein. Er gab dem Ras damit ein Instrument in die Hand, mit dem es ihm in der Folgezeit gelang, auch die Kontrolle über die Verbände der anderen apuanischen Marmorindustriezonen zu erlangen. Die Sezione besaß ein Direktorium, das sich gemäß den Prinzipien des „integralen Syndikalismus “ aus je drei Vertretern der Arbeiter, der kaufmännisch-technischen Intelligenz und der Arbeitgeber zusammensetzte. In dieses Gremium berief Ricci paritätisch Vertreter aus Carrara, Massa und der Versilia ${ }^{72}$. Seine Politik zielte auf die Beseitigung der traditionellen Konkurrenzsituation zwischen den verschiedenen Produktionszonen, denen auch unterschiedliche Tarifgebiete mit deutlichen Lohnunterschieden entsprachen. In Carrara waren die Löhne traditionell am höchsten und hatten 1921 im Zuge der Tarifoffensive der Unternehmer die geringsten Kürzungen erfahren ${ }^{73}$. Das protektionistische System Riccis konnte aber nur dann richtig funktionieren, wenn diese Unterschiede eingeebnet wurden und die Carrareser Preisbindung auch von den anderen Gebieten übernommen und beachtet wurde. Der Ras war fest entschlossen, diese Uniformierung gegen den vorhersehbaren Widerstand der Unternehmer in diesen Gebieten durchzusetzen; hierüber wird später noch zu berichten sein.

Es war fast zwangsläufig, daß der „totalitäre“ Ausbau des lokalen faschistischen Machtsystems, die zunehmende Machtkonzentration in den Händen Riccis und seine wachsende Selbstherrlichkeit breiten Unmut erzeugten, der bis in die Reihen des Faschismus hineinwirkte. Widerspruch oder auch nur Zweifel wurden von Ricci immer weniger geduldet, und so begannen in der faschistischen Organisation die Personen mit wenig Profil und wenig Skrupeln, die bereit waren, unbedingte Gefolgschaft zu leisten, die unabhängigeren Geister an den Rand zu drängen. Es schälte sich eine Gruppe von ricciani heraus, zu der der Ras ein besonderes Vertrauensverhältnis hatte und die er zur Durchsetzung seiner Ziele und zunehmend auch zur Kontrolle der „unzuverlässigen “

70 Bei seinem Besuch im Dezember 1922 hatte er Ricci die Einrichtung der nationalen Marmorkorporation mit Sitz in Carrara zugesichert, wenn die Voraussetzungen dafür geschaffen seien; Alalà vom 23. 12. 1922 und 31. 3. 1923.

71 Zitiert nach Cordova, Sindacati fascisti, S. 152.

72 Das Direktorium wurde wie folgt besetzt: Als Unternehmervertreter Giorgio Nicoli Berring aus Carrara, Alessandro Giorgini aus Massa, Giovanni Denoth aus Seravezza; als Vertreter der "tecnici“ Augusto Fabbricotti aus Carrara, Giovanni Andreani aus Massa und Oscar Bresciani aus Pietrasanta; als Arbeitervertreter Argante Tramontana aus Carrara, Ercole Manini aus Massa und Raniero Cei aus Seravezza (Alalà vom 14. 4. 1923).

73 Vgl. oben, S. 113-115. 
Elemente einsetzte. Bei den ricciani handelte es sich anfangs in der Hauptsache um die „hauptberuflichen“ Squadrenführer der ersten Stunde. Zu nennen sind hier vor allem Giuseppe Aloisi, Ugo Dell'Amico, Oreste Giorgi, Goffredo Corsi und Luciano Bacciola, die vor allem in der Pionierzeit die Aktionen des Squadrismus getragen, aber niemals ein politisches Profil erlangt hatten. Obwohl sie fast alle ständig dem Fascio-Direktorium von Carrara angehörten, ist keiner von ihnen je als Kundgebungsredner oder als Autor eines politischen Zeitungsartikels aufgefallen. Außer vielleicht bei Giorgi, der der Sohn eines Steinbruchunternehmers war, ist bei keinem von ihnen eine berufliche Ausbildung oder Tätigkeit zu ermitteln oder zu vermuten, obwohl die benutzten Quellenbestände Angaben hierzu enthalten müßten ${ }^{74}$. Nach der Kommunalwahl im November 1922 zogen alle Genannten in den Gemeinderat von Carrara ein; Aloisi und Giorgi wurden sogar assessori. Obwohl diese Ämter damals nicht mit nennenswerten Vergütungen verbunden waren, ist unübersehbar, daß die erlangten Positionen für sie persönlich wichtig waren, zumal sie ihnen für die Zukunft auch noch andere Chancen erschließen konnten. Besonders deutlich wird dieser Umstand bei Aloisi. Sein Werdegang und seine Rolle als assessore comunale seien daher etwas ausführlicher skizziert:

Giuseppe Aloisi war Anfang des Jahres 1923 gerade erst 26 Jahre alt. Sein Vater Vittorio Aloisi war früher kein ganz kleiner Geschäftsmann gewesen und besaß den Titel eines Cavaliere della Corona d'Italia. Im September 1921 ging er allerdings in Konkurs ${ }^{75}$. Der Sohn hatte am Krieg teilgenommen, zuletzt als sottotenente („Unterleutnant“). Große Lorbeeren hatte er sich dort nicht erworben. Anscheinend war er sogar degradiert worden ${ }^{76}$. Was er zwischen Kriegsende und dem Jahresbeginn 1921 gemacht hat, liegt im dunkeln. Gesichert ist allerdings, daß er nicht legionario fiumano war ${ }^{77}$. Kurz vor der Gründung des Fascio ist seine Aktivität in der Associazione democratica liberale dokumentiert, wo er zur Gruppe um Renato Ricci gehörte ${ }^{78}$. Sofort nach der Gründung des Fascio von Carrara wurde er in sein Direktorium gewählt und in dieser Position immer wieder bestätigt ${ }^{79}$. Im Frühsommer fiel er als einer der aktivsten Squadrenführer auf: Aktenkundig ist seine Beteiligung an den spedizioni nach Codena, Monzone und Sarzana sowie die Beteiligung an dem Überfall auf die Wohnung des Gewerkschaftsführers Andrea Giandalasini. Am 22. Oktober 1921 führte er die blutige spedi-

${ }^{74}$ In den verwendeten Polizei- und Justizakten, die auch die Genannten wiederholt aufführen, sind normalerweise Angaben zum Beruf verzeichnet. Bei Bacciola kann man lediglich den Akten des Militärdistrikts entnehmen, daß er zum Zeitpunkt der Musterung (November 1915) Oberschüler oder Student war (ASM, DM, cl. 1896, nm. 908).

75 ASM, Commissariato Carrara, b. 57, f. „V. Aloisi“": Tribunale di Massa an Kommissar von Carrara vom 13.11. 1921.

${ }^{76}$ Das jedenfalls behauptet Ettore Viola in seinem Memorandum ohne Datum (Mai 1924), wo er ihn einen „retrocesso di guerra" nennt (ACS, MI, Gabinetto Finzi, b. 12, f. 145). Sein letzter Dienstgrad geht hervor aus APC, b. B1, f. 6: Überblick über die Squadren von Carrara ohne Datum (März 1922).

77 Er ist nicht unter den Unterzeichnern der profaschistischen Erklärung der ehemaligen FiumeKämpfer Carraras in Alalà vom 19. 11. 1921.

78 Vgl. oben, S. 46.

79 ACS, MI, DGPS 1923, b. 91, f. „Fasci Massa“, sf. „Costituzione fasci“: Präfekt an Innenministerium vom 17.6. und 1.10.1921; Alalà vom 9. 12. 1922. 
zione nach Pontecimato an, die zwei Todesopfer kostete ${ }^{80}$. Im Jahr 1922 wirkte er als capo der berüchtigten Elitesquadra Disperata ciclisti und als Sekretär des Fascio von Aven$\mathrm{za}^{81}$. In dieser Funktion beseitigte er noch vor dem „Marsch auf Rom“ mit ungewöhnlicher Härte die Reste der republikanischen Machtpositionen in ihrer einstigen Hochburg ${ }^{82}$. Als assessore comunale entwickelte sich Aloisi bald zum "Aufpasser" Riccis gegenüber den nicht ganz „linientreuen “ Faschisten Bernardo Pocherra, Luigi Da Pozzo und Andrea Nicoli, die in der Gemeindeexekutive Carraras den Ton angaben und entscheidende Ressorts bekleideten ${ }^{83}$. Zwischen dem Bürgermeister Pocherra und Aloisi kam es bald zu einem Dauerkonflikt. Er und andere ricciani waren der Meinung, daß bei der Ämterbesetzung hauptsächlich die squadristi der ersten Stunde berücksichtigt werden müßten, und Pocherra antwortete darauf etwas arrogant, der Faschismus brauche jetzt „Hirne" 84 . Als es um die Bestellung des neuen Leiters des Ente autonomo per le case popolari ging, vertrat Aloisi die bemerkenswerte Ansicht, dieser Posten stehe ihm zu, weil er gut dotiert sei ${ }^{85}$; wahrscheinlich spielte er auf seine Verdienste als „alter Kämpfer ${ }^{\text {“ }}$ und seine schlechte finanzielle Situation an. Pocherra erklärte ihm rundweg, daß ihm für dieses Amt die Fähigkeiten fehlten, und fügte hinzu, die Gemeinde sei kein Arbeitsamt. Für den Posten designierte er den gutsituierten Zahnarzt Da Pozzo, der von vornherein auf die Bezüge verzichtete, und als die ricciani versuchten, im Gemeinderat doch noch die Ernennung von Aloisi durchzuboxen, vereitelte er das Vorhaben ${ }^{86}$.

Der Fall Aloisi zeigt mit kaum zu überbietender Deutlichkeit, wie sich der Ras und seine Gefolgsleute gegenseitig stützten. Ricci, der häufig in Rom und in anderen Provinzen beschäftigt war, benötigte für seine persönliche Diktatur Handlanger und Informanten, und diese benutzten seine Macht auch für ihre ganz persönlichen Kämpfe. Aus den Quellen ist klar ersichtlich, wie Aloisi und andere ricciani den Konflikt zwischen

${ }^{80} \mathrm{Zu}$ den Aktionen von Codena, Monzone und Sarzana siehe oben, S. 83, 91 -94; zum Überfall auf das Haus von Giandalasini: ASM, Tribunale Massa, Sentenza penale 1922/123; zur Aktion in Pontecimato siehe oben, S. 129.

81 Alalà vom 16. 9. 1922. Die Radfahrer-Squadra „Disperata“ bestand aus „altgedienten“ und besonders kämpferischen „squadristi“. Ihr gehörten z. B. die beiden Fiume-Kämpfer Ovidio Passani und Alberto Carli an. Sie war ursprünglich für rasche Einsätze im Nahgebiet vorgesehen. Nach dem „Marsch auf Rom“ entwickelte sie sich zu einer persönlichen Prätorianertruppe von Renato Ricci. Unter Umgehung der MVSN-Hierarchie erteilte er ihr delikate Aufgaben; ACS, SPD/CR 1922 - 43, b. 48, f. „R. Ricci“: Aussage von Prayer Galetti vor der Disziplinarkommission der MVSN vom 18. 4. 1923; ACS, MI, Gabinetto Finzi, b. 12, f. 145: Memorandum von Ettore Viola ohne Datum (Mai 1924).

82 Seine Aktivitäten gipfelten in der gewaltsamen „Übernahme“ des traditionsreichen republikanischen Zirkels "Giovanni Bovio" einschließlich der angeschlossenen Kooperative. Aufschlußreich ist die in diesem Zusammenhang in Anwesenheit von Polizeifunktionären erfolgte Drohung von Aloisi, er werde den Republikanern die Köpfe einschlagen, wenn sie sich in Zukunft nicht jeglicher Propaganda enthielten; ASM, Questura Massa, b. 11, f. „Circolo G. Bovio": Kommissar an Questore vom 16. 11. 1922.

${ }^{83}$ Aloisi war für das Standesamt und das Personal zuständig, Nicoli für öffentliche Bauvorhaben, Straßen und Friedhöfe und Da Pozzo für den Bereich Arbeit, Wohlfahrt und Hygiene. Weitere "assessori“ waren Adolfo Angeli (Unterricht), Carlo Lena (Finanzen) und Giuseppe Onniboni (Rechtsabteilung, Polizei). Letztere kann man als gemäßigte "ricciani“ ansehen (Il Giornale di Carrara vom 16. 12. 1922).

84 ACS, MI, Gabinetto Finzi, b. 6, f. 61: Memorandum von Pocherra vom 24. 4. 1923.

85 Ebenda.

${ }^{86}$ Ebenda. 
dem Ras und den unabhängigeren faschistischen Elementen künstlich schürten. Wie noch ausführlich zu behandeln sein wird, wurden selbst minimale Abweichungen von den Vorstellungen Riccis zu verräterischen Machenschaften hochstilisiert. So produzierte das System der Ras-Diktatur auch dort "Dissidenten“, wo von substantiellen politischen Differenzen gar nicht die Rede sein konnte. Bei den führenden dissidenti Bernardo Pocherra, Andrea Nicoli, Gualtiero Betti, Luigi Da Pozzo und Pietro Prayer Galetti handelte es sich durchwegs um Faschisten, die nicht nur gegenüber dem Regime, sondern im Grunde auch gegenüber Ricci loyal waren. Sie bildeten keine wirkliche politische Fraktion innerhalb der faschistischen Organisation. Gemeinsam war ihnen allen nur eine solide gesellschaftliche Position ${ }^{87}$, die ihnen eine persönliche Unabhängigkeit von der faschistischen Organisation gewährte, sowie die Opposition gegen Riccis Ämterhäufung und die herrschenden Tendenzen zur Willkür und Postenjägerei.

Der dissidentismo in der PNF-Organisation von Carrara ist in einem engen Zusammenhang mit der Opposition bestimmter Unternehmerkreise gegen die korporative und protektionistische Politik Riccis gesehen worden ${ }^{88}$. Das ist nur zum Teil richtig, denn der dissidentismo war schon lange in seine heiße Phase getreten, bevor sich im Unternehmerlager die Oppositionsgruppe wirklich formierte. Der Ras und seine Anhänger bemühten sich natürlich auf demagogische Weise, die Dissidenten in Bausch und Bogen als Handlanger der oppositionellen Marmorbarone hinzustellen ${ }^{89}$. Auch die Polizeistellen Carraras gefielen sich dabei, Gerüchte über die „Fernsteuerung" von Pocherra durch Carlo Andrea Fabbricotti nach oben weiterzuleiten ${ }^{90}$. Diese Unterstellung erscheint als recht abwegig, denn die Quellen lassen vermuten, daß das Verhältnis von Pocherra und Fabbricotti eher schlecht war ${ }^{91}$.

Ähnliches gilt für den Vizesekretär des PNF-Provinzverbandes, Gualtiero Betti. Ihm wurde von den ricciani unterstellt, der Führer einer "Clique von Unternehmern " $z u$ sein, die den Faschismus für ihre Interessen benutzen wollten ${ }^{92}$. Aber die Zeitungsartikel von Betti legen Zeugnis darüber $a b$, daß er trotz seiner Herkunft und seiner mannigfaltigen Beziehungen zum Unternehmerlager von Anfang an ein überzeugter Anhänger des „integralen Syndikalismus" war" ${ }^{93}$. Aus seiner Feder stammte ja auch die wüste Schmähschrift gegen die "großen und kleinen Bourgeois von Carrara" nach dem „Verrat" des Unternehmerverbands während der Affäre Pisani im Oktober $1921^{94}$. Außerdem sei in diesem

87 Andrea Nicoli kam aus einer wohlhabenden Marmorunternehmerfamilie. Zu den finanziellen Verhältnissen des Juweliers Prayer Galetti siehe oben, S. 169, Anm. 70.

${ }^{88}$ Bernieri, Carrara moderna, S. $204 \mathrm{f}$.

89 ACS, SPD/CR 1922 - 43, b. 48, f. „R. Ricci“: Aussage Riccis vor der Disziplinarkommission der MVSN vom 18. 4. 1922. Zentrale Passage bei Setta, Ricci, S. 73.

90 ASM, Questura Massa, b. 20: Polizeikommissar von Carrara an Questore vom 20. 4. 1923.

91 ASM, Questura Massa, b. 13, f. „Federazione industriale“: Kommissar an Questore vom 5. 8. 1920. Hieraus geht hervor, daß der Wahl von C. A. Fabbricotti zum Vorsitzenden des Verbands schwere Auseinandersetzungen und der Rücktritt der alten Führung bestehend aus Angelo Ricci (Vorsitzender), Umberto Ascoli (stellv. Vorsitzender) und Bernardo Pocherra (Sekretär) vorausgegangen waren.

92 Betti zitiert diesen Vorwurf im ,numero unico“ der Dissidenten, La Fiammata vom 16. 4. 1923 (ASM, Questura Massa, b. 20, f. „PNF dissidi“).

93 Wie Anm. 43.

94 Siehe oben, S. $129 \mathrm{f}$. 
Zusammenhang darauf verwiesen, daß sein Halbbruder, der Großunternehmer Renato Lazzoni, nach Bettis Parteiauschluß zwar sofort den PNF verließ, aber zwei Wochen später, wie schon erwähnt, zum Vizesekretär des Sindacato esportatori der Federazione industriale fascista ernannt wurde. Dies spricht gegen die Annahme, daß wirtschafts- und verbandspolitische Meinungsverschiedenheiten bei diesem Konflikt im Vordergrund standen. Ausdrücklich beteuerte Betti, daß er sich bewußt aus diesen Fragen herausgehalten habe. „Für die eigenen Interessen und für die Interessen anderer setzt man nicht das Leben aufs Spiel, so wie ich es hundertmal gemacht habe “, hielt er seinen Anklägern entgegen ${ }^{95}$, und tatsächlich galt seine Aufmerksamkeit ganz anderen Problemen. Betti war alles andere als ein Gemäßigter oder normalizzatore, wie sie im Jargon der Zeit hießen. In einem seiner letzten Alalà-Artikel betonte er, daß „die Zeit der despotischen Führer" und „der Schwarzhemden, die die Städte beherrschen " nicht vorbei sei. Im gleichen Atemzug wetterte er aber auch gegen „die wahnsinnige Jagd nach Ämtern“ und „die törichten Ambitionen“, die sich unter den Faschisten breitmachten. Hierin sah er die Ursache für die schweren inneren Auseinandersetzungen, von der die faschistische Bewegung in vielen Teilen Italiens heimgesucht wurde ${ }^{96}$.

Es ist nicht ganz klar, an welchen Meinungsverschiedenheiten sich der Konflikt endgültig entzündete. Bühne der erbittertsten Auseinandersetzung war jedenfalls die Giunta comunale von Carrara. Aloisi focht hier die in seiner Abwesenheit erfolgte Besetzung von verschiedenen Kommissionen an ${ }^{97}$. $\mathrm{Da}$ alle anderen assessori anwesend gewesen waren und zugestimmt hatten, lautete die aufschlußreiche Begründung hierfür, die Besetzungen hätten von Ricci abgesegnet werden müssen. Vor allem $\mathrm{Da}$ Pozzo trat diesem Ansinnen von Aloisi scharf entgegen, und die Auseinandersetzung mündete in einen direkten Konflikt mit Ricci, der der Kommunalverwaltung mangelnde Volksnähe vorwarf. Es folgte eine Zusammenkunft der führenden Faschisten in der Privatwohnung von Ghino Faggioni, bei der von verschiedener Seite die Ämterhäufung von Ricci kritisiert wurde ${ }^{98}$. Ricci meinte, einer regelrechten Verschwörung gegenüberzustehen, als deren Drahtzieher er Pocherra und die beiden Milizkommandanten Da Pozzo und Prayer Galetti verantwortlich machte. Es gibt Indizien dafür, daß seine Informanten, allen voran Aloisi, diese Überzeugung nicht ganz ohne persönliches Interesse nährten".

Als sich die Situation zuzuspitzen begann, bat Gualtiero Betti um seine Entlassung aus allen Parteiämtern. Er begründete diesen Schritt mit privaten Motiven ${ }^{100}$, aber es ist ganz offensichtlich, daß sein plötzlicher Rückzug politische Ursachen hatte. Als Vizesekretär des faschistischen Provinzialverbands wäre er früher oder später gezwungen gewesen, klarer Stellung zu beziehen, als er das bisher getan hatte, und das hätte ihn

95 La Fiammata vom 16. 4. 1923; wie Anm. 92.

96 Gualtiero Betti, „La scalata“, in Alalà vom 20. 1. 1923. Außerdem "Poche parole“ in Alalà vom 3. 2. 1923.

97 ACS, SPD/CR 1922 - 43, b. 48,f. „R. Ricci“: Aussage von Da Pozzo vor der Disziplinarkommission der MVSN vom 18. 4. 1923.

98 Ebenda.

99 Das Dissidentenblatt La Fiammata vom 16. 4. 1923 (wie Anm. 92) spielt darauf konkret an. Es schreibt: "Jede unserer Handlungen, jedes unserer Worte ist von denen mißgünstig registriert und mißgünstig weitergeleitet worden, die ein Interesse an unserer Entfernung hatten, um aufzusteigen, um herauszuragen, um sich einzunisten."

100 Alalà vom 10. 3. 1923. 
zwangsläufig zum Gegenspieler Riccis gemacht. Dieser letzte Akt der Loyalität wurde von den ricciani nicht gewürdigt. Der Ras nutzte den Rücktritt für ein Revirement in den faschistischen Führungsgremien. An die Stelle von Betti rückte der profillose Ghino Faggioni, und der „treue “ Aloisi wurde zum Sekretär des Carrareser PNF berufen ${ }^{101}$. Dieser ließ es sich nicht nehmen, seinen Triumph voll auszukosten. In einem Aufruf an die Faschisten Carraras erklärte er:

„Unsere Mission ist mit dem Ende des gewaltsamen Kampfes nicht beendet. Im Gegenteil, sie beginnt jetzt wieder in diesem neuen Leben, das ein Leben der Erlösung, der Gerechtigkeit und der Freiheit sein soll. Es wäre ein Verrat, jetzt unsere Plätze zu verlassen und die im Stich zu lassen, die uns mit Vertrauen und Begeisterung in unsere herrlichen und glorreichen Schlachten gefolgt sind, um dort alles zu opfern, ohne je etwas zu verlangen. Unsere Märtyrer würden uns bis in alle Ewigkeit verdammen." ${ }^{102}$

Betti verstand diese erste offizielle Verlautbarung des neuen Fascio-Sekretärs als einen Angriff auf seine Person und erklärte noch am Tag ihres Erscheinens seinen Austritt aus dem Fascio von Carrara. Außerdem bestellte er Da Pozzo und den Marmorunternehmer Francesco Trombella zu seinen Sekundanten mit dem Auftrag, Schritte zur Wiederherstellung seiner persönlichen Ehre einzuleiten. Ein Duell konnte Aloisi zwar mit der Erklärung vermeiden, er habe nur eine allgemeine Aussage machen und nicht auf Betti anspielen wollen ${ }^{103}$, aber politisch waren nun alle Dämme gebrochen. Noch am gleichen Tag kam es zu einem schweren Konflikt zwischen den ricciani und Da Pozzo. Dieser weigerte sich unter dem Vorwand, daß er sich als console der Miliz nicht in die politischen Querelen der Partei einmischen dürfe, an einer Sitzung des Fascio-Direktoriums teilzunehmen, von der er annahm, daß sie zu einem Tribunal gegen ihn und die anderen Dissidenten ausarten würde. Es kam auf offener Straße zu einer Diskussion, bei der Da Pozzo ausrief, das Entscheidende sei, daß Ricci in Carrara seine moralische und politische Position kläre ${ }^{104}$. Der Satz wurde dem Ras hinterbracht, und auch hier traten die Sekundanten in Aktion. Ricci akzeptierte zwar die Erklärung von Da Pozzo, er habe den Satz nicht in beleidigender, sondern in freundschaftlicher Absicht ausgesprochen. Das hinderte ihn allerdings nicht daran, seinen Kontrahenten anderthalb Stunden nach der Beilegung der Ehrenstreitsache wegen „Unwürdigkeit“ aus der Partei auszuschließen ${ }^{105}$.

Mit dem Parteiausschluß von Da Pozzo entwickelte sich die Dissidentenkrise zu einem Konflikt zwischen Miliz und Partei. Ricci hätte einen console der Miliz eigentlich gar nicht ausschließen dürfen, ohne zuvor die übergeordneten Stellen der MVSN in Florenz zu informieren. Ein Ausschluß aus dem PNF zog nämlich zwangsläufig den aus der Miliz nach sich. Als Ricci für den 25. März kurzfristig nun auch noch einen feierlichen Aufmarsch der "Schwarzhemden" ansetzte, um der Öffentlichkeit zu demonstrieren, daß Partei und Miliz in der Provinz geschlossen hinter ihm stünden, ging auch der console generale Prayer Galetti auf frontalen Kollisionskurs. Er erstattete dem Zonenkomman-

101 Alalà vom 17. 3. 1923.

102 Ebenda.

103 Alalà vom 24. 3. 1923.

104 ACS, SPD/CR 1922 - 43, b. 48, f. „R. Ricci“: Aussagen von Ricci und Da Pozzo vor der Disziplinarkommission der MVSN vom 18. 4. 1923.

105 Ausführliche Informationen zu diesem Aspekt der Affäre in ACS, SPD/CR 1922 - 43, b. 48, f. „R. Ricci“: Urteil des ständigen Ehrengerichts Florenz (Corte d'onore permanente Firenze) vom 16. 5. 1923; außerdem La Fiammata vom 16. 4. 1923 (wie Anm. 92). 
do in Florenz Bericht und erreichte, daß der Zonenkommandant für die Toskana, Teodoro Alessi, die Teilnahme der MVSN an Riccis Jubelzeremonie untersagte ${ }^{106}$. Und als Ricci versuchte, die Miliz mit Hilfe von untergeordneten Offizieren, die ihm treu ergeben waren, zu mobilisieren, drohte Prayer mit der öffentlichen Bekanntmachung der Anordnung des Zonenkommandos ${ }^{107}$.

Das Tauziehen zwischen Prayer und Ricci um die Mobilisierung der „Schwarzhemden" führte zu einem schweren Zwischenfall. In Anwesenheit von Prayer gab der Fascio-Sekretär Giuseppe Aloisi, der auch centurione der Miliz war, einem Faschisten, der nicht zur MVSN gehörte, die Anweisung, bei der Zeremonie im Schwarzhemd zu erscheinen. Das war eine schlicht illegale Anordnung, weil nach den rechtlichen Bestimmungen nur Milizangehörige im Dienst das Schwarzhemd tragen durften ${ }^{108}$. Es folgte eine harte Auseinandersetzung, die mit der Degradierung von Aloisi durch Prayer endete, und als dieser ihn auch noch aus seinem Büro in der MVSN-Kommandatur jagen wollte, zog Aloisi die Pistole und verhinderte so seinen Hinauswurf ${ }^{109}$.

Die Spannungen hatten mittlerweile einen bedrohlichen Punkt erreicht, und der Präfekt kabelte nach Rom, daß er die sofortige Intervention eines einflußreichen Vertreters der PNF-Führung für notwendig halte ${ }^{110}$. Es wurde Costanzo Ciano entsandt, der aber, soweit man das erkennen kann, keine wirkliche Schlichtung versuchte, sondern nur Renato Ricci den Rücken stärkte. Er bearbeitete Prayer, um ihn von seiner Weigerung abzubringen, an der Feier teilzunehmen ${ }^{111}$. Als dies aber nicht gelang, akzeptierte er, daß Renato Ricci Prayer als console generale absetzte, obwohl er dazu natürlich nicht befugt war. Prayer gab später zu Protokoll, er habe seine Absetzung in erster Linie deshalb hingenommen, weil sie im Beisein von Ciano erfolgt sei. Dessen Autorität als Regierungsmitglied und hochdekorierter Admiral außer Dienst war also ausschlaggebend für das Gelingen von Riccis Kompetenzüberschreitung ${ }^{112}$. Ob Ciano hier allerdings wirklich im Sinne der Partei oder Mussolinis wirkte, ist mehr als unklar. Die zum Teil widersprüchlichen Signale, die in dieser Sache aus Rom kamen, werden noch ausführlich zu interpretieren sein.

Daß Ricci die faschistische Provinzorganisation fest in der Hand hatte, zeigte sich am 25. März. Da die MVSN nicht aufmarschieren konnte, mußte Ricci auf die geplante feierliche Übergabe der Fasci-Wimpel an die Miliz verzichten, und die Veranstaltung bekam so den Charakter einer ganz ungeschminkten politischen Demonstration des Ras und seiner Anhänger. Trotz der demonstrativen Abwesenheit des Bürgermeisters und eines Teils der Faschisten Carraras gelang es den ricciani, 4000 Faschisten $^{113}$, zum Teil aus den

106 ACS, SPD/CR 1922 - 43, b. 48, f. „R. Ricci“: Aussage von Prayer Galetti vor der Disziplinarkommission der MVSN vom 18. 4. 1923.

107 Ebenda: Aussage von Prayer und Ricci vom 18. 4. 1923.

108 Ebenda: Entschließung der Disziplinarkommission ohne Datum.

109 Ebenda: Aussage von Prayer Galetti und Aloisi vom 18. 4. 1923.

110 ACS, MI, Gabinetto Finzi, b. 6, f. 61: Präfekt an Innenministerium vom 23. 3. 1923.

111 ACS, SPD/CR 1922 - 43, b. 48, f. „R. Ricci“: Aussage von Ricci vor der Disziplinarkommission der MVSN vom 18. 4. 1923.

112 Ebenda: Aussage von Prayer vom 18. 4. 1923. Das gleiche gilt auch für die Amtsenthebung von Da Pozzo; ebenda: Aussage von $\mathrm{Da}$ Pozzo vom 18. 4. 1923.

113 ASM, Questura Massa, b. 20, f. „PNF dissidi“: Polizeikommissar von Carrara an Questore vom 25. 3. 1923. 
entlegensten Teilen der Provinz, zu versammeln ${ }^{114}$ und den Eindruck zu erwecken, bei den Dissidenten handle es sich um eine kleine Verschwörergruppe ohne jeglichen Massenanhang. Ricci hielt eine nicht ungeschickte Rede, bei der er die Identität seiner lokalen Politik mit den Interessen des Faschismus und dem Willen der Regierung postulierte:

„Die Regierung weiß, daß sie hier heute wie in der Vergangenheit und auch für die Zukunft über eine unbändige Kraft, eine erprobte Kraft verfügt, die es immer wieder verstanden hat, neue Zuversicht zu finden, die es verstanden hat, nach jedem Rückschlag neue Festigkeit zu erlangen. Carrara wiederholt heute sein Ergebenheitsgelöbnis gegenüber der faschistischen Regierung. Das Werk ist vollbracht: Die apuanische Führung erneuert ihren größten Sieg. Sie hat heute mit ihren eigenen Händen den Auswuchs abgeschlagen, der ihrem eigenen Innern entsprossen ist, die Mißgeburt beseitigt, die sie selbst hervorgebracht hat. Der Faschismus unserer Region ist stark. Er muß und wird Benito Mussolini treue Soldaten stellen, denn er besteht aus Männern mit einem echten Glauben, die alle Bewährungen bestanden haben und bereit sind, ihr Blut zu geben, wenn es das Heil des Vaterlands erfordern sollte. Die Milizia nazionale, dieses herrliche Organ, das zum Schutz der Nation gegründet wurde, darf niemandem zu Diensten sein. Sie darf nicht den Sonderinteressen von verantwortungslosen Männern dienen. Es gibt hier keine Männer mehr, keine Persönlichkeiten. Alles hat sich aufgelöst, und es sind nur die Seelen zurückgeblieben. In diesen Tagen hat man versucht, den Faschismus zu besudeln, indem man Männer mit Kot bewarf. Diese aber blieben unerschütterbar. Sie haben gewonnen und den Faschismus gerettet. " 115

Anschließend ging Ricci in seiner Rede zu den Verdiensten des Faschismus bei der angeblich schon erfolgten Sanierung der Marmorwirtschaft über und sorgte dabei für eine Überraschung. Ohne daß dies vorher jemals ernsthaft im Gespräch gewesen war, kündigte er eine baldige Erhöhung der Marmorarbeiterlöhne an ${ }^{116}$. Dieser populistische Schachzug erschien ihm wohl jetzt geboten, nachdem die Dissidentenkrise die „Unzuverlässigkeit" der gutbürgerlichen Anhänger des Faschismus erwiesen hatte. Es war für den Ras notwendig geworden, sich in Zukunft noch stärker als bisher auf die Gewerkschaften zu stützen.

Im Zusammenhang mit der Kundgebung vom 5. März zeigte sich auch deutlich die tendenziöse Berichterstattung der staatlichen Funktionsträger in der Provinz, die insofern von großer Bedeutung ist, weil die zentralen Stellen in Rom vermutlich in der Annahme aus ihr schöpften, es handle sich um eine neutrale Quelle. Die Tatsache, daß ungewöhnlich viele Mitglieder des städtischen Fascio der Kundgebung fernblieben und die aus den kleinen frazioni und den entlegenen Orten der Lunigiana und Garfagnana herangekarrten Faschisten zum Teil gar nicht richtig wußten, was gespielt wurde ${ }^{117}$, fiel in den Berichten einfach unter den Tisch. Statt dessen schrieb der Präfekt, „die wirklich beeindruckende Kundgebung“ habe gezeigt, über „welche Gefolgschaft und Autorität“

114 La Fiarnmata vom 16. 4. 1923 (wie Anm. 92) behauptet, daß vom PNF-Ortsverein von Carra$\mathrm{ra}$ (Stadt), der 1400 Mitglieder hatte, nur 110 anwesend waren, während der ganze Rest aus der Provinz zusammengezogen worden sei, teilweise unter Vorspiegelung falscher Tatsachen. So hätten die Statthalter Riccis in der Lunigiana, Ulderico Sordi und Lorenzo Mattei, bei den dortigen Fasci verbreitet, Mussolini sei überraschend in Carrara zu Besuch und man müsse ihm die Ehre erweisen.

115 Alalà vom 31. 3. 1923.

116 Nach Angaben von Pocherra kam diese Ankündigung völlig aus heiterem Himmel; ACS, MI, Gabinetto Finzi, b. 6, f. 61: Memorandum vom 24. 4. 1923.

117 Ebenda. Pocherra schreibt: „Die Feier wurde durchgeführt, und man griff auf jedes erdenkliche Mittel zurück, um die A tmosphäre aufzuputschen, doch Carrara reagierte nicht." Vgl. Anm. 114. 
Ricci in der Provinz verfüge ${ }^{118}$. Wie wir noch im weiteren Verlauf der Dissidentenkrise sehen werden, muß man dem Präfekten Berti noch einen letzten Rest Unabhängigkeit vom lokalen Machtsystem zubilligen, aber er war selbst stark von den Informationen der untergeordneten Stellen in Carrara abhängig, und diese waren völlig auf der Linie Riccis.

Der entscheidende amtliche Berichterstatter war hier der Polizeikommissar von Carrara, De Mase. Er hatte den unmittelbaren Kontakt mit den Vorgängen, doch bei ihm ist nicht das geringste Bestreben nach Ausgewogenheit erkennbar. De Mase war ein ausgesprochener Parteigänger Riccis, der in enger Fühlung mit dem Ras wirkte. Seine Berichterstattung zu den dissidenti nährte sich ausgiebig aus der Gerüchteküche der ricciani, und seine politischen Einschätzungen lassen ihren Ursprung bis in die Wortwahl hinein eindeutig erkennen ${ }^{119}$. De Mase und sein Stellvertreter Papazafiropulo ließen es sich nicht nehmen, an der Kundgebung vom 25. März persönlich teilzunehmen ${ }^{120}$, und verliehen der Veranstaltung und ihrer Stoßrichtung gegen die Dissidenten damit eine regierungsoffizielle Weihe, die sie in Wirklichkeit gar nicht hatten.

Ganz reibungslos konnte jedoch die Säuberungsaktion Riccis nicht über die Bühne gehen. Zu sehr war er dabei der Milizführung auf die Füße getreten, die ihre Autorität ohnehin nicht nur in Massa-Carrara verteidigen mußte. Vor allem Alessi, der keine Parteikarriere hinter sich hatte, sondern wegen seiner Kriegsverdienste und seines Oberstengrades in die Position des Zoneninspekteurs berufen worden war ${ }^{121}$, hatte nicht sehr viel Verständnis für den Machiavellismus des Ras. Am 28. März kam er nach Carrara, um persönlich die Lage zu begutachten. Die Meldung, die er anschließend nach Rom sandte, fiel anscheinend für Ricci nicht sehr günstig aus, denn am folgenden Tag sandte der Generalkommandant der MVSN, Emilio De Bono, ein geharnischtes Protesttelegramm nach Massa, in dem er Ricci vorwarf, daß er mit seinem Vorgehen das Ansehen der Miliz geschädigt habe, „das der Regierung sehr am Herzen liegt und auch die Partei interessieren sollte "122. Bezeichnenderweise traf allerdings am gleichen Tag der Bescheid des stellvertretenden PNF-Generalsekretärs Achille Starace über die Ratifizierung der Parteiausschlüsse von Da Pozzo und Prayer ein ${ }^{123}$ : Die Parteileitung wollte und konnte

118 ACS, MI, Gabinetto Finzi, b. 6, f. 61: Präfekt an Innenministerium vom 25. 3. 1923.

119 ASM, Questura Massa, b. 20, f. „PNF dissidi“" Bericht von De Mase vom 20. 4. 1923. Hier ist in einem ganz unüblichen Ton vom „Multimillionär" Carlo Andrea Fabbricotti die Rede, zu dessen Gefolgschaft ,andere fette Marmorgeschäftsleute" gehörten. Außerdem nährt er sich von Einschätzungen aus der Flüsterpropaganda der „ricciani“. Er äußert z. B. die Vermutung, Pocherra sei von C. A. Fabbricotti „vor seinen Karren gespannt worden, indem er ihm die Möglichkeit eines zukünftigen vorteilhaften Unterkommens vor Augen geführt habe“.

120 Alalà vom 31. 3. 1923.

121 Alessi, der nicht aus der Toskana stammte und bis zum „Marsch auf Rom“ nur einfaches Parteimitglied gewesen war, wurde auf die Stelle von Perrone Compagni berufen, um das Milizkommando von den chronischen Zwistigkeiten des Florentiner Faschismus abzuschirmen. Er war Inhaber von fünf "medaglie al valore“ (vgl. Cantagalli, Fascismo fiorentino, S. 338 f. und 362). Die Umstände seiner Berufung erklären seine spontane Solidarität mit Prayer und $\mathrm{Da}$ Pozzo, die ebenfalls aufgrund ihrer Kriegsverdienste und nicht aufgrund ihrer Stellung in der Partei zu ihren Kommandos gekommen waren; SPD/CR 1922 - 43, b. 48, f. „R. Ricci“: Aussage von Renato Ricci vor der Disziplinarkommission der MVSN vom 18. 4. 1923.

122 ACS, MI, Gabinetto Finzi, b. 6, f. 61: Emilio De Bono an den Präfekten von Massa vom 29. 3. 1923.

${ }^{123}$ Alalà vom 31. 3. 1923. 
dem alto commissario in seinem eigenen Haus keine Schwierigkeiten machen. Unklar ist, ob Mussolini einen Anteil an dieser Entscheidung hatte. Volle Zustimmung gegenüber dem Vorgehen Riccis ist bei ihm jedenfalls nicht zu erkennen. Wenig später machte er sich nämlich die Kritik von De Bono zu eigen und telegraphierte an den Präfekten von Massa: „Stelle fest, daß der Hohe Kommissar Ricci sich in Angelegenheiten der Miliz hinsichtlich Organisation, Kommandos usw. einmischt. Würden Sie ihm kundtun, daß dieser Teil ihn nichts angeht. - Die höchte Militärgewalt in der Toskana ist dem Obersten Alessi und zwar ausschließlich ihm anvertraut. Erwarte telegraphische Bestätigung. "124

Am gleichen Tag zog De Bono die Konsequenzen aus Riccis Kompetenzüberschreitung und setzte Da Pozzo und Prayer wieder in ihre alten Ränge ein, was bei den Carrareser Dissidenten öffentliche Freudensausbrüche auslöste ${ }^{125}$. Bei den Verantwortlichen des Generalkommandos in Rom schien man dem Ras einen Dämpfer geben zu wollen. Gleichzeitig gärte es im Kommando der 8. MVSN-Zone. Alessi, der mit seinen traditionalistischen militärischen Maßstäben in der extremistischen Toskana überhaupt einen schweren Stand hatte, bat Anfang April um seinen Abschied ${ }^{126}$. Es ist nicht ganz klar, ob Alessi tatsächlich zurücktreten wollte oder ob es sich um einen taktischen Schachzug handelte. Er blieb jedenfalls vorerst auf seinem Posten. Die Carrareser Affäre scheint allerdings bei diesem Vorgang keine ganz untergeordnete Rolle gespielt zu haben. Seine Autorität war von Ricci einfach ignoriert worden, und das war charakteristisch für die Haltung der toskanischen ducini gegenüber allen Bestrebungen, die Squadren in ein legalistisches Korsett zu sperren. Es ist in diesem Zusammenhang von Interesse, daß Ricci sich bei seinem Konflikt mit der Milizführung Rückenstärkung beim console der MVSN und starken Mann des Florentiner Extremismus, Tullio Tamburini, holte, der ihm ans Herz legte, in Rom für die Berufung des Generals Sante Ceccherini auf die Stelle Alessis zu intrigieren ${ }^{127}$. Von ihm versprachen sich die toskanischen Extremisten freie Hand, und zwar zu Recht, wie sich später herausstellen sollte ${ }^{128}$.

Das Generalkommando der Miliz in Rom versuchte offensichtlich, solchen Entwicklungen entgegenzuarbeiten. Am 17. April 1923 traf nämlich in Carrara eine Disziplinarkommission der MVSN, bestehend aus dem Generalkommandanten Italo Balbo und den luogotenenti generali Giuseppe Bottai und Augusto Agostino, ein. Dieser hochkarätige Besuch zeigt, wie ernst die Milizführung die Carrareser Ereignisse nahm. Die Kommission tagte fast sieben Stunden lang in den Räumen des Gruppenkommandos und vernahm Ricci, Aloisi, Prayer Galetti und Da Pozzo. Der Polizeikommissar von Carrara meinte, das Gerücht aus den Kreisen der ricciani nach Massa übermitteln zu müssen, das Vorgehen von Prayer und Da Pozzo habe bei der Kommission einen sehr schlechten Ein-

124 ACS, MI, Gabinetto Finzi, b. 6, f. 61: Telegramm vom 4. 4. 1923.

125 ASM, Questura Massa, b. 20, f. "PNF dissidi“: Kommissar De Mase an Questore vom 5. 4. 1923.

126 ACS, Fondo Ricci, b. 5, f. „Carrara PNF 1921 - 23“: Tullio Tamburrini an Ricci vom 8. 4. 1923.

127 Ebenda; außerdem APC, b. B 11, Bd. VI, S. 480 f.: Perrone an Ricci vom 12. 4. 1923. Aus diesem Brief geht hervor, daß sich Tamburini in Rom auf Ricci berief. Perrone, der sich mittlerweile mit den Florentiner Extremisten völlig überworfen hatte, warnte Ricci vor einem harten Vorgehen gegen die Dissidenten und vor einer Allianz mit Tamburini. Ceccherini bezeichnete er als "politische Null“.

${ }^{128}$ Ceccherini wurde später tatsächlich zum Zoneninspekteur berufen und galt in diesem Amt als "von Tamburini vollständig gefesselt und versklavt" (Lyttelton, Seizure, S. 289). 
druck hinterlassen ${ }^{129}$. Das war geeignet, in der Präfektur Stimmung gegen die Dissidenten zu machen, entsprach aber, wie so oft bei den Informationen von De Mase, nicht der Wirklichkeit. Das Untersuchungsergebnis erbrachte das genaue Gegenteil: Prayer und Da Pozzo wurden von jeglichem Disziplinarvergehen freigesprochen. Der Kommissionsbericht betonte, daß sich ihr Ausschluß aus der MVSN lediglich aufgrund ihres Parteiausschlusses ergebe ${ }^{130}$. Die Miliz-Kommission war zwar nicht befugt, sich zu dieser Parteimaßnahme zu äußern, sie gab aber zu verstehen, daß die Rechtfertigungen von Ricci sie nicht überzeugt hatten, und sprach sich dafür aus, daß die MVSN der Parteileitung eine „strengere" Untersuchung der Vorgänge vorschlagen solle ${ }^{131}$. Die Situation in Riccis Provinzfürstentum charakterisierte sie so: „Es besteht in der Provinz Massa-Carrara eine permanente gefährliche Einmischung der politischen Instanzen in die Befugnisse und Verfügungen der militärischen Instanzen, ein Zustand, der durch die Zentralisierung der Kompetenzen noch verschlimmert wird und nach der derzeitigen Lage der Dinge die Erreichung der Ziele, für die die Miliz geschaffen wurde, praktisch verunmöglicht. "132

Als Beleg für ihre Einschätzung führte die Kommission die Absetzung von Prayer und Da Pozzo durch Ricci an. Dieser habe bis heute nicht zur Kenntnis genommen, daß er als commissario politico keinerlei militärische Befugnisse habe. Außerdem würden in der Provinz die von der Regierung erlassenen Bestimmungen systematisch mißachtet. So habe die Federazione wie selbstverständlich die Mobilisierung von squadristi im „Schwarzhemd" vorgenommen, die nicht der MVSN angehörten. Nach den Verfügungen des Innenministeriums hätten diese auf der Stelle von den Carabinieri verhaftet werden müssen. Als Hauptmaßnahme gegen die beklagten Carrareser Zustände schlug das von Balbo geleitete Gremium vor, einen „energischen Offizier" an die Spitze des 28. Gruppo di legioni zu berufen, der dem lokalen Milieu fremd sei. Außerdem empfahl es den Ausschluß von Aloisi aus Miliz und Partei, da er gegenüber seinem Vorgesetzten Prayer die Waffe gezogen habe. Dieser Akt sei mit einer „gewissen Feierlichkeit“ zu vollziehen, damit er als Exempel diene ${ }^{133}$.

Balbos strenge Kur war vorerst nicht durchzusetzen. Riccis Stellung in der Partei war offensichtlich schon zu stark, als daß man ihn in dieser Weise hätte demütigen können. Der Untersuchungsbericht lag fast zwei Monate folgenlos in der Schublade von De Bono. Ganz offensichtlich fehlte der Milizführung im Moment die notwendige politische Stärke, um ihre Vorstellungen durchzusetzen. Im Frühjahr 1923 war der Einfluß der intransigenti im PNF außerordentlich groß, und es paßte nicht in Mussolinis politischen Fahrplan, größere Konflikte mit ihnen auszufechten ${ }^{134}$. Im Mai 1923 wurde Ricci sogar zum

${ }^{129}$ ASM, Questura Massa, b. 20,f. „PNF dissidi“; Kommissar De Mase an Questore vom 20. 4. 1923.

130 ACS, SPD/CR 1922 -43, b. 48, f. „R. Ricci“: Entschließung der MVSN-Disziplinarkommission ohne Datum.

131 Ebenda.

132 Ebenda.

133 Ebenda.

${ }^{134}$ Symptomatisch hierfür ist der Angriff auf den PNF-Abgeordneten Alfredo Misuri nach seiner Parlamentsrede gegen die illegalen Umtriebe der „intransigenti“ am 29. 5. 1923, der von Mussolini zumindest gedeckt wurde, und der nachfolgende erzwungene Rücktritt des Staatssekretärs Ottavio Corgini. Vgl. Lyttleton, Seizure, S. 180. 
console generale des 28. Gruppo di legioni berufen, und so wurde zunächst das genaue Gegenteil von dem Wirklichkeit, was Balbo vorgeschlagen hatte. Durch die Verbindung von Provinzialsekretariat und Gruppenkommando in Personalunion war die Milizorganisation zum Instrument von Riccis Hausmachtspolitik geworden und so seinem eigentlichen Zweck entzogen ${ }^{135}$. Die Machtkonzentration in den Händen Riccis hatte jetzt ein geradezu groteskes Ausmaß erreicht. Alle entscheidenden politischen Organe in der Provinz standen jetzt unter seiner direkten Kontrolle: der PNF-Provinzialverband, die Miliz und die Marmorkorporation.

Eine solche Entwicklung wäre nicht möglich gewesen, wenn Mussolini sie nicht wenigstens wohlwollend geduldet hätte. Von den ricciani und im Organ der Federazione wurde die große Gunst, in der Ricci angeblich beim Duce stand, immer wieder groß herausgestellt ${ }^{136}$. Es handelte sich hier sicherlich weitgehend um eine $Z$ weckbehauptung. Schließlich war ihm an übergeordneten politischen Aufgaben bisher nicht viel anvertraut worden. Die Einsetzung in das Amt des alto commissario war eigentlich nur das Resultat seiner regionalen Machtstellung, und seine Berufung in die Parteikommission, die die Fusion des PNF mit der Associazione nazionalista italiana vorbereitete, war nur von relativer Bedeutung ${ }^{137}$. Trotzdem ist nicht zu übersehen, daß Ricci zu den aufstrebenden Persönlichkeiten im PNF gehörte, und es hat wahrscheinlich eher zu seinen Gunsten ausgeschlagen, daß er sich noch nicht zu stark profiliert hatte. In den kommenden Jahren sollte sich erweisen, daß Mussolini ihn als einen nützlichen und zuverlässigen Mann betrachtete. Ricci verband seinen Extremismus und die Willkürherrschaft im Bereich seiner Hausmacht mit einer regelrechten Demutshaltung vor dem Duce, und das trifft für die meisten anderen faschistischen Provinzpotentaten in dieser Weise nicht $\mathbf{z u}^{138}$.

Eine direkte Stellungnahme von Mussolini zum Dissidentenproblem in Carrara ist abgesehen vom schon zitierten Telegramm nicht überliefert. Daß Starace und Ciano den Ras von Carrara in der beschriebenen Weise begünstigen konnten, deutet allerdings auf eine für Ricci günstige Konstellation in der nationalen Führungsgruppe des PNF hin. Auch der Generalsekretär des PNF, Michele Bianchi, der seit November 1922 auch Generalsekretär im Innenministerium war, arbeitete eindeutig im Sinne Riccis. Der Bürgermeister Pocherra hatte sich wiederholt vergebens an ihn gewandt, um von ihm Unterstützung gegen die rechtswidrigen Eingriffe des Ras in die Angelegenheiten der Kommunalverwaltung zu bekommen ${ }^{139}$. Am 16. April scheinen die Würfel endgültig gefallen zu sein: Ricci begab sich zur Berichterstattung zu Mussolini, und gleichzeitig wurde

135 Hauptzweck der Miliz war zwar die „Verteidigung der faschistischen Revolution“. Mussolini beabsichtigte aber auch die Disziplinierung des Squadrismus und seine allmähliche Unterordnung unter die Regierungsautorität, was eine Zurückdrängung des Einflusses der Ras und der alten Squadrenführer zur Voraussetzung hatte (vgl. Anm. 37).

136 Alalà vom 14. 4. 1923. Auch der Polizeikommissar De Mase, dessen Berichte die Überzeugungen der "ricciani“ gut widerspiegeln, betont dies nachdrücklich; ASM, Questura Massa, b. 29, f. "PNF dissidi“: Bericht an den Questore vom 20.4.1923.

137 Zur Arbeit dieser Kommission siehe De Felice, Mussolini il fascista 1, S. 504- 506.

${ }^{138}$ Die absolute Treue Riccis zu Mussolini betont auch nachdrücklich Setta, Ricci, S. 118 f. Sie steht in einem deutlichen Kontrast zum gelegentlich rebellischen Verhalten etwa eines Farinacci, von dem Ricci politisch eigentlich gar nicht weit entfernt war.

139 ACS, MI, Gabinetto Finzi, b. 6. f. 61: Memorandum von Pocherra vom 24. 4. 1923; ASM, Questura Massa, b. 20, f. „PNF dissidi“: Telegramm von Pocherra an Michele Bianchi vom 29.3. 1923. 
Pocherra von Michele Bianchi ins Innenministerium bestellt. Die Entscheidung des Duce scheint sehr eindeutig ausgefallen zu sein, denn Pocherra bekam von Bianchi nur noch die Aufforderung zu hören, er solle zum Wohle der Partei zurücktreten ${ }^{140}$. Auch die zahlreichen dringenden Bitten der Dissidenten, die Partei möge eine Untersuchungskommission nach Carrara entsenden, blieben unerhört ${ }^{141}$. Aus den Berichten des Präfekten von Massa mußten die Regierungsstellen den Eindruck gewinnen, daß Riccis Handeln von der Zustimmung der großen Mehrheit der lokalen Faschisten getragen wurde. Und unter diesem Vorzeichen erschien eine eventuelle Rehabilitierung der Dissidenten im Rahmen eines von oben verordneten Versöhnungsaktes für nicht angezeigt. Aus der Perspektive der PNF-Leitung hätte das mehr Schaden anrichten können, als es an Gewinn versprach. Die Dissidenten waren ja von Ricci schon so verteufelt worden, daß jedes echte Zugeständnis ihnen gegenüber eine Bloßstellung des Ras bedeutet hätte, und die Polarisierung zwischen den beiden Lagern war schon so fortgeschritten, daß ein wirklicher Ausgleich kaum mehr denkbar war.

Da die Parteileitung keinen Finger zu ihren Gunsten rührte, griffen die Dissidenten zur Selbsthilfe. Am 15. April machte Gualtiero Betti einen Versuch, den Geprächsfaden mit Ricci wieder anzuknüpfen, aber dieser erteilte ihm eine kategorische Absage ${ }^{142}$. Daraufhin ließ Betti gleich am folgenden Tag die schon fertig vorbereitete Zeitung La Fiammata in den Druck gehen, in der die Dissidenten mit ihrer Position an die Öffentlichkeit zu treten gedachten, nachdem sie wochenlang einer intensiven Rufmordkampagne ausgesetzt gewesen waren. Der Questore von Massa, Piano, hatte keine Einwände und erlaubte die Verteilung ${ }^{143}$. Doch vermutlich erreichten nur wenige Exemplare die Leser Carraras, für die sie in erster Linie bestimmt waren. Die Anhänger des Ras waren nämlich von der bevorstehenden Publikation unterrichtet worden. Noch vor der Auslieferung hatten Giuseppe Aloisi und Luciano Bacciola sich in der Druckerei Cappelletti in Massa zwei Exemplare besorgt, und Ghino Faggioni ließ eines davon gleich dem in Rom weilenden Ricci zukommen ${ }^{144}$. Doch noch bevor der Ras aus der Hauptstadt Weisungen erteilen konnte, wußten die ricciani, was sie zu tun hatten. Sie drohten, daß sie die Verteiler der bastonatura unterziehen und auch sonst alle Mittel in Bewegung setzen würden, um die Verbreitung der Zeitung zu verhindern ${ }^{145}$. Das reichte dem Kommissar

140 ASM, Questura Massa, b. 20, f. „PNF dissidi“: Berichte des Kommissars De Mase vom 16. und 20. 4. 1923.

141 Vorstöße in diese Richtung wurden gemacht von Pocherra (an Direzione PNF vom 9. 4. 1923), Gualtiero Betti (an Mussolini und De Bono vom 9. 4. 1923) und Andrea Nicoli (an Finzi vom 2. 4. 1923). Die Schreiben in ACS, MI, Gabinetto Finzi, b. 6, f. 61. Nicoli kannte den Staatssekretär im Innenministerium Aldo Finzi persönlich. Daß Finzi ganz offensichtlich für die Dissidenten nichts tun konnte, verdeutlicht die Aussichtslosigkeit ihrer Lage.

142 ACS, Fondo Ricci, b. 5, f. "Carrara PNF 1921 - 23“: Gualtiero Betti an Ricci vom 15. 4. 1923. Der Brief wurde von einem persönlichen Kurier überbracht, der sofort mit der negativen Antwort zurückkam. Es ist bezeichnend, daß der Polizeikommissar De Mase schon am folgenden Tag von diesem $n$ vertraulichen " Vorgang informiert war; ASM, Questura Massa, b. 20, f. "PNF dissidi" : Bericht vom 16. 4. 1923.

143 Ebenda: Antrag von Betti vom 16. 4. 1923 mit der entsprechenden Notiz des Questore, der der Ansicht war, daß die Artikel nichts enthielten, was der Öffentlichkeit nicht schon aus anderen Presseorganen bekannt sei.

144 ACS, Fondo Ricci, b. 5, f. „Carrara PNF 1921 - 23: (vermutlich) Ghino Faggioni an Ricci vom 16. 4.1923.

145 ASM, Questura Massa, b. 20, f. „PNF dissidi“: De Mase an Questore vom 16. 4. 1923. 
De Mase, um die Verteilung in Carrara aus Gründen der öffentlichen Ordnung zu verbieten ${ }^{146}$. An den Questore schrieb er, daß man Betti dringend von einer eventuellen regelmäßigen Herausgabe abbringen müsse, weil das Blatt in Carrara in keinem Fall geduldet würde und die Wiederkehr jener Zwischenfälle in verstärkter Form zu erwarten seien, die sich zu den Zeiten des Cavatore ereigneten ${ }^{147}$.

Der Inhalt von La Fiammata war nicht besonders aggressiv gehalten. Sie enthielt neben dem ausgiebigen Rückgriff auf die typisch faschistische Märtyrerbeschwörung im wesentlichen Richtigstellungen hinsichtlich der Auseinandersetzungen des letzten Monats. Persönlich angegriffen wurden vor allem Ghino Faggioni und die „professori di Belle lettere" Adolfo Angeli und Ottorino Biscioni, weil sie keine squadristi gewesen waren und daher die entsprechenden Angriffsflächen boten. So wie bei den ricciani dienten die Lorbeeren der Kampfzeit auch bei den dissidenti als die entscheidende Legitimation ihres Führungsanspruchs. Die alten Squadrenführer unter den ricciani wurden abgesehen von Aloisi nicht direkt angegriffen, und auch die Kritik an Ricci hielt sich in Grenzen. Der weitestgehende Angriff auf den Ras war in der Feststellung versteckt: „Die Beachtung der Disziplin muß als Grundsatz für alle gelten. Wenn aber der, der höhere Pflichten zu erfüllen hat und daher auch einen höheren Sinn für die Disziplin haben müßte, seine Willkür gegen alles und alle walten läßt und seinen Willen auch dort durchsetzt, wo dieser gar nicht wirksam werden dürfte, so erweist er sich selbst als das Muster der Disziplinlosigkeit und rechtfertigt damit die undisziplinierten Handlungen der anderen.“148

Die Reaktion der ricciani auf das Dissidentenblatt zeigt, daß im System des Provinzfaschismus keinerlei Raum für öffentlichen Widerspruch verblieben war, gerade auch dann, wenn es sich um die abweichenden Ansichten von Faschisten handelte. Diese waren viel gefährlicher als die gelegentliche, bis zur Unkenntlichkeit verschlüsselte Kritik der lokalen Republikaner und Liberalen, denn sie konnten den Anspruch auf Gültigkeit im Rahmen des Systems erheben und hatten die Chance, in die faschistische Organisation hineinzuwirken. Entsprechend hart gingen die ricciani gegen alle vor, die sich offen als Dissidenten bekannten. Der esercente lizza Antonio Formai, ein enger Freund von Gualtiero Betti, der für den Marmortransport aus den Steinbrüchen von Cirillo Figaia, dem Vater der Verlobten Riccis, zuständig war, verlor von heute auf morgen diesen Auftrag, der die Grundlage seiner wirtschaftlichen Existenz bildete ${ }^{149}$. Der Dissident und segretario amministrativo der Federazione provinciale dei sindacati Raimondo Tonini wurde nach Bekanntwerden seiner Gesinnung fristlos entlassen ${ }^{150}$. Andere behielten ihre Stellungen nur deshalb, weil sie sich zum Abschwören bereitfanden. Es erwies sich, daß das Phänomen des dissidentismo nicht so marginal war, wie die ricciani immer vollmundig behauptet hatten. Es betraf auch keineswegs nur die saturierten Kreise des Carrareser Faschismus, sondern breitete sich auch in anderen sozialen Sphären aus. Gualtiero Bet-

146 Ebenda: Aktennotiz des Questore vom 16. 4. 1923.

147 Ebenda: De Mase an Questore vom 20.4. 1923.

148 Ebenda: La Fiammata vom 16. 4. 1923.

149 Ebenda.

150 Ebenda. Tonini arrangierte sich allerdings später mit den „ricciani“ und erhielt seine alte Stellung zurïck. 
tis Anhang bestand aus einer Reihe ganz junger squadristi ${ }^{151}$. Auch der ambulante Händler Giuseppe Procuranti, der Sohn des faschistischen „Märtyrers“ Pietro Procuranti, und der cavatore-possidente Eugenio Torri, einer der aktivsten squadristi der ersten Stunde, waren beispielsweise unter den dissidenti. Um die Dissidenten einzuschüchtern, ließ Ricci seine "Prätorianer" von der Disperata und andere treue squadristi bewaffnet in der Stadt patrouillieren. Das Haus von Pocherra wurde vor seinem Rücktritt zum Teil regelrecht belagert ${ }^{152}$. Einige kleinere Gewalttätigkeiten zwischen ricciani und dissidenti hatten sich auch schon ereignet, und der Polizeikommissar De Mase hatte darauf mit der Entwaffnung von einigen Dissidenten reagiert ${ }^{153}$.

Die Spannung war so groß, daß am 24. April ein geringfügiger Anlaß ausreichte, um einen ersten ernsten Zwischenfall auszulösen. Einer der "Prätorianer" Riccis, der ehemalige Fiume-Kämpfer Ovidio Passani, rempelte den betrunkenen Dissidenten Eugenio Torri an. Dieser stieß Drohungen gegen die ricciani aus, die er wenig später auch gegenüber dem Fascio-Sekretär Aloisi wiederholte, woraufhin er von den Carabinieri festgenommen wurde ${ }^{154}$. Die Dissidenten reagierten empört. Eine Gruppe von ihnen, darunter Betti und Da Pozzo, versammelte sich in der zentralen Via Roma und stieß dort mit einer Gruppe von ricciani unter der Führung von Aloisi zusammen. Es entstand eine Schlägerei, in deren Verlauf Gualtiero Betti seinen Revolver zog und von hinzugeeilten Carabinieri ebenfalls festgenommen wurde.

Es folgte eine Zeit der relativen Ruhe. Doch als die dissidenti Mitte Mai begannen, Unterschriften für die Entsendung einer Untersuchungskommission zu sammeln, kam es zu einem regelrechten Gewaltausbruch von seiten der ricciani. Den Anfang machte Ricci am 15. Mai selbst, und es lohnt sich, diesen Vorfall etwas ausführlicher zu schildern, weil er eine Vorstellung über die Persönlichkeit des Ras und die in faschistischen Kreisen herrschenden Umgangsformen vermittelt. Ricci befahl dem Marmorunternehmer Alessandro Manfredi, einem der Initiatoren der Unterschriftenaktion, der noch ordentliches Mitglied der faschistischen Organisation war, in die Lokale des Fascio zu kommen, und stellte ihn dort zur Rede. Als Manfredi antwortete, er wolle nur der Wahrheit und der Gerechtigkeit zum Durchbruch verhelfen, ergriff er ihn am Hals, und es kam zu einem Ringen zwischen den beiden, in dessen Verlauf Ricci ihm einen tiefen Biß in die Wange versetzte. Dann konnte sich Manfredi von ihm befreien und floh ins Freie ${ }^{155}$.

Es folgten Angriffe auf die Milizoffiziere Noël Cricca, Francesco Gianotti und Sergio Nicoli, auf den Dissidenten Giuseppe Procuranti und auf den Zahntechniker von Da Pozzo, Willy Cucuin, bei dem es sich um einen Schweizer Staatsbürger handelte, der in

151 Ghino Faggioni nahm diesen Sachverhalt zum Anlaß, süffisant von den „verantwortungslosen Minderjährigen" zu sprechen (ebenda).

152 ACS, MI, Gabinetto Finzi, b. 6, f. 61: Memorandum von Pocherra vom 24. 4. 1923.

153 ASM, Questura Massa, b. 20, f. „PNF dissidi“: De Mase an Questore vom 30. 3. 1923 und vom 26. 4. 1923. Beteiligt waren die Dissidenten Mario Rocca, Giuseppe Procuranti, Renato Mazzi und Cesare Nicolai sowie die „ricciani“ Giulio Gandolfo und Carlo Pezzica, ein Marmorunternehmer. Auch Renato Ricci hatte sich schon tätlich hervorgetan und den Dissidenten Giuseppe Carrozzi angegriffen (siehe ebenda: La Fiammata vom 16. 4. 1923).

154 Ebenda: De Mase an Questore vom 25. 4. 1923; außerdem Carabinieri-Kommandant der Provinz, Alessandro Caravadossi, an den Präfekten Berti vom 29. 4. 1923.

155 Ebenda: Strafanzeige von Manfredi vom 16. 5. 1923. 
die politischen Kontroversen überhaupt nicht verwickelt war ${ }^{156}$. Die Angriffe kulminierten am Abend mit dem Überfall von circa 100 ricciani auf das Casino civico, den exklusiven Klub des feinen Carrareser Bürgertums. Der Ras war der Ansicht, daß dort gegen ihn konspiriert würde. Während das Gros der squadristi das Gebäude umzingelte, drang eine kleine Gruppe von Faschisten, unter ihnen Renato Ricci, Giuseppe Aloisi, Luciano Bacciola, Oreste Giorgi, Carlo Gattini und Ferdinando Pellini, in die Klubräume ein. Ricci stürzte sich als erster auf den anwesenden Andrea Nicoli. Er warf ihm vor, einer der Hauptverantwortlichen der Konspiration zu sein, und riß ihn zu Boden, wo er anschließend vom Ras und seinem Gefolge wüst zusammengeschlagen wurde. Ähnlich erging es dem Schwager von Nicoli, Attilio Rocchi, und dem Sekretär des Casino civico, Giorgio Arata, der Mitglied des PNF war und sich lautstark gegen die Unterstellung der Konspiration gewandt hatte. Ricci und die obengenannten führenden Faschisten, welche allesamt Gemeinderäte waren und auch sonst noch wichtige Ämter bekleideten, traktierten ihre Opfer mit Fäusten, Tritten und Stockschlägen, bis sie mit beachtlichen Verletzungen liegenblieben ${ }^{157}$. Der Präsident des Casino civico, Camillo Micheli, der bei den letzten nationalen Wahlen der Vertreter der Liberalen von Massa-Carrara auf der Liste des Blocco nazionale gewesen war, telegraphierte an Mussolini: „Gestern abend drangen zahlreiche Carrareser Faschisten unter der Führung von Renato Ricci in das hiesige Casino civico, dem Versammlungsort des auserwähltesten Teils der Bürgerschaft, ein, das seit 60 Jahren immer, auch in den bewegtesten Zeiten, unangetastet geblieben war, und gingen sofort zu Tätlichkeiten gegen einige Mitglieder über. Gegen diesen unerhörten Gewaltakt erhebe ich energischen Protest und rufe Eure Exzellenz um Maßnahmen der Wiedergutmachung an. ${ }^{\text {158 }}$

Die Ereignisse, die ein besorgtes Telegramm des Generaldirektors der Polizei, Emilio De Bono, zur Folge hatten, überzeugten den Präfekten von Massa davon, daß die öffentliche Ordnung in Carrara beim Kommissar De Mase nicht mehr in den richtigen Händen war. Er entsandte den Kommissar Dino Fabris von der Questura di Massa und den Carabinieri-Kommandanten der Provinzdivision, Alessandro Caravadossi, nach Carrara und nahm den dortigen Polizeifunktionären, die ja wiederholt gezeigt hatten, daß sie dem Ras bedingungslos gefügig waren, die Ermittlungen und die Verantwortung für den Einsatz der Polizeikräfte aus der Hand ${ }^{159}$. Fabris ging, gemessen an der in Carrara üblichen Praxis, ganz außergewöhnlich resolut vor. Er fand die Stadt in einem Zustand der Belagerung vor: Mit Schlagstöcken bewaffnet und in aggressiver Haltung patrouillierten die Squadren Riccis durch die Straßen. Der Kommissar stellte sofort die führenden Dissidenten unter Polizeischutz und legte Ricci nahe, alle Squadren umgehend abzuziehen, weil er nicht zögern würde, beim geringsten $Z$ wischenfall gegen sie vorzugehen ${ }^{160}$.

156 Der Angriff auf W. Cucuin führte zu einer Intervention des Schweizer Konsulats in Livorno und zu einer Anfrage des Außenministeriums beim Innenministerium (ebenda).

157 Ebenda: Strafanzeigen von Nicoli, Rocchi und Arata. Zusammenfassend ebenda: Berichte vom Carabinieri-Kommando Massa vom 16. 5. 1923 und von Kommissar Fabris vom 17. 5. 1923; außerdem ACS, MI, Gabinetto Finzi, b. 6, f. 61: Präfekt an Innenministerium vom 17. 5. 1923.

158 Ebenda: Telegramm von Micheli vom 16. 5. 1923.

159 Ebenda: Präfekt an Innenministerium vom 17. 5. 1923.

160 ASM, Questura Massa, b. 20, f. „PNF dissidi“: Kommissar Fabris an den Präfekten vom 17. 5. 1923. 
Es ist bemerkenswert, daß Ricci auf diesen ungewohnten Stil völlig defensiv reagierte und sofort alle squadristi heimschickte.

Auch auf der Ebene der Ermittlungen ging diesmal alles einen etwas unüblichen Gang. Die Opfer der Gewalttätigkeiten wurden ausführlich vernommen, und es kam zu Strafanzeigen wegen Körperverletzung gegen zwölf ricciani, unter ihnen Renato Ricci selbst sowie Giuseppe Aloisi, Oreste Giorgi, Giovanni Gattini und Ferdinando Pellini ${ }^{161}$. Doch auch diesmal griff Mussolini zugunsten des Ras ein. Wieder entsandte er Riccis Mentor Costanzo Ciano mit dem Auftrag, „Befriedungsverhandlungen“ in Gang zu setzen. Auch der Zonenkommandeur der Miliz Alessi begab sich nach Carrara. Er hatte ursprünglich damit gedroht, er werde alle Mitglieder der Miliz, die sich im Zuge der Auseinandersetzung an ranghöheren Milizangehörigen vergriffen hätten, vor das Militärgericht bringen $^{162}$, doch seine energischen Vorsätze wurden durch die Initiative Cianos neutralisiert. Ciano erreichte eine Pseudobefriedung, bei der sich beide Seiten verpflichteten, die vergangenen Auseinandersetzungen zu vergessen. $\mathrm{Zu}$ Zugeständnissen an die Dissidenten kam es dabei nicht; sogar die Frage ihrer Wiederaufnahme in die Partei wurde ausgeklammert ${ }^{163}$. Die Strafverfahren gegen die ricciani hingegen wurden durch die „Befriedungs"-Vereinbarung verhindert. Daß es sich um einen äußerst faulen Frieden handelte, dokumentiert allein schon der Umstand, daß Prayer, Betti und Da Pozzo der Versammlung fernblieben, auf der die angeblich erfolgte Versöhnung feierlich abgesegnet wurde $e^{164}$.

Mit dem Sieg über die dissidenti und der Ernennung zum console generale der Miliz hatte Ricci ein halbes Jahr nach dem „Marsch auf Rom“ den Gipfel der Macht in seiner Heimatprovinz erreicht. Er begann jetzt verstärkt, sich seiner „Sozialpolitik“ zuzuwenden. Bei dieser handelte es sich gewissermaßen um den materiellen Aspekt seines Populismus, welcher immer ausgeprägter wurde, je stärker er sich in Konflikte mit Teilen der lokalen Eliten verstrickte. Es soll hier nochmals betont werden, daß der dissidentismo nicht allein in diesem Licht zu sehen ist. Zum Beispiel war auch die Politik, die Da Pozzo als kommunaler Verantwortlicher für den Bereich Gesundheit betrieben hatte, ausgesprochen sozial. Nicht zuletzt deshalb hatte er sich viele seiner Standesgenossen und die Apotheker zu Feinden gemacht, welche kräftig für die ricciani Partei ergriffen ${ }^{165}$. Verschiedene Parteigänger Riccis zeichneten sich auch nicht unbedingt durch ihre soziale Ader aus: Man denke etwa an den Reaktionär Guido Fabbricotti. Trotzdem bestimmten Vorstöße in der Sozialpolitik immer stärker die Herrschaftspraxis des Ras und dienten zunehmend zu seiner Legitimation.

161 Ebenda: Strafanzeigen gegen die Genannten, zum Teil von Fabris persönlich zu Protokoll genommen.

162 ACS, MI, Gabinetto Finzi, b. 6, f. 61: Alessi an Generalkommando der MVSN vom 17. 5. 1923.

${ }_{163}$ ASM, Questura Massa, b. 20, f. „PNF dissidi“: De Mase an Questore vom 20. 5. 1923.

164 Ebenda: Randnotiz von Questore Piano, der dies von einem eigenen Informanten erfahren hat. Die meisten Strafanzeigen wurden von den Betroffenen zurückgenommen. Andrea Nicoli, sein Schwager Attilio Rocchi und der Zahntechniker von Luigi Da Pozzo nahmen ihre Anzeigen nicht zurück. Trotzdem wurden sie von De Mase mit dem Hinweis auf die erfolgte „Befriedung“ außer Kraft gesetzt (ebenda, Schreiben an den Staatsanwalt von Massa vom 24. 7. 1923). Er bediente sich dabei des Artikels 160 der Strafprozeßordnung, dessen Gültigkeit bei einer nicht individuell erfolgten Versöhnung mehr als fraglich ist.

165 ACS, MI, Gabinetto Finzi, b. 6, f. 61: Memorandum von Pocherra vom 24. 4. 1923. 
Am 9. Mai hatte das Direktorium der Sezione marmifera der faschistischen Industriekorporation unter dem Vorsitz von Ricci den Unternehmern eine Lohnerhöhung von zehn Prozent für alle Arbeiter des Marmorabbaus auferlegt, so wie er es in der Hitze des Gefechts auf der Kundgebung vom 25. März versprochen hatte ${ }^{166}$. In Carrara regte sich kein sichtbarer Widerstand dagegen, aber in Massa rebellierten die Unternehmer. Erst wollten sie die Lohnerhöhung überhaupt nicht akzeptieren, und dann beschlossen sie, diese erst im Juni zu gewähren anstatt, wie von Ricci festgelegt, rückwirkend ab April ${ }^{167}$. Daraufhin ließen die Masseser sindacati die Arbeiter in den Streik treten. Es ist nicht ganz klar, ob das im Sinne Riccis war. Es gibt Hinweise dafür, daß die relativ radikale, unter der Führung des ehemaligen Republikaners Dario Cuturi stehende Gewerkschaftsorganisation von Massa selbständig vorgeprescht war. Der Ras jedenfalls eilte in die Provinzhauptstadt und schickte die Streikenden zurück an die Arbeit, während Alalà den Arbeitern in der Sache recht gab, den Streik aber als einen gefährlichen Ausbruch von Klassenkampf deutete.

Ricci konnte die Auseinandersetzung ganz nach seinem Geschmack lösen. In seiner Eigenschaft als Sekretär der Marmorkorporation konzedierte er den Masseser Industriellen einige Sonderregelungen hinsichtlich der Marmorfestpreise, die bisher am Widerstand der Industriellen von Carrara gescheitert waren, und erhielt im Austausch dafür die Lohnerhöhung zum festgesetzten Termin. Ganz ohne Druck war dieses Ergebnis allerdings nicht zustande gekommen. Im Falle eines Scheiterns der Verhandlungen hatte Alalà schon angekündigt, daß der Industriellenverband von Massa „als außerhalb unserer Organisation stehend, ja als Feind unserer Organisation“ zu betrachten sein würde und alle Maßnahmen gegen ihn eingeleitet werden müßten, die notwendig seien, um ihn unschädlich zu machen ${ }^{168}$.

Doch die Marmorwirtschaft von Massa war aufgrund ihrer geringeren wirtschaftlichen Bedeutung ein Nebenkriegsschauplatz, und solange Riccis Politik in Carrara erfolgreich war, hatten die Masseser Unternehmer keine Chance, sich gegen den Ras durchzusetzen. Im Sommer 1923 begann sich allerdings auch hier das Blatt zu wenden. Die sozialpolitischen und stadtplanerischen Renommierprojekte von Ricci wurden immer anspruchsvoller und kostspieliger, und es waren zwangsläufig die Marmorunternehmer, die immer stärker zur Kasse gebeten wurden. Das Lieblingsprojekt von Ricci war das Istituto di prevvidenza ed assistenza operaia, das eine Marmorgewerbeschule, eine Krankenunterstützungskasse für die Marmorarbeiter und ein Mutter-und-Kind-Ambulatorium vorsah. Es handelte sich um ein altes Vorhaben der faschistischen Gewerkschaftsorganisation, das schon Anfang des Jahres an der Frage der Trägerschaft gescheitert war ${ }^{169}$. Obwohl sich jetzt die Planung unter der Ägide der Marmorkorporation vollzog, tauchte dieses Problem ganz ähnlich wieder auf. Fünf große einheimische Marmorunternehmen unter der Führung von Carlo Andrea Fabbricotti und den Grafen Lazzoni legten ein Gegenprojekt vor, das die gleichen Einrichtungen vorsah, aber hinsichtlich Finanzierung und Verwaltung den vom Ras direkt kontrollierten Institutionen entzo-

166 Alalà vom 12. 5. 1923.

167 Alalà vom 16. 6. 1923; Giovinezza vom 17. und 24. 6. 1923.

168 Alalà vom 16. 6. 1923.

169 Interview von Emilio Quaglino in Il Giornale di Carrara vom 20. 1. 1923. 
gen sein sollte ${ }^{170}$. Um eventuelle unerwünschte Entwicklungen zu vermeiden, machten die Faschisten daraufhin ihr Projekt bekannt, und der dem Ras gefügige neue Bürgermeister von Carrara, Adolfo Angeli, erhöhte gleichzeitig die kommunale Marmorsteuer, um die Mittel dafür bereitzustellen ${ }^{171}$. Um gar keinen Zweifel darüber aufkommen zu lassen, wem die Lorbeeren für diese Einrichtung zufallen sollten, wurde sie wenig später Istituto di assistenza operaia Renato Ricci getauft. Dieser Coup, der zumindest sittenwidrig war, weil die einseitige Erhöhung der Marmorsteuer in diesem Ausmaße von den bestehenden Vereinbarungen nicht gedeckt wurde ${ }^{172}$, führte zu einer Solidarisierung im Lager der „Exporteure“. Der Protest gegen die Maßnahme vereinte jetzt alle führenden Exportunternehmen, einschließlich des Branchenführers Walton, der bisher eine äußerst Ricci-freundliche Linie bezogen hatte ${ }^{173}$. Bemerkenswert ist in diesem Zusammenhang, daß sich auch die anderen Firmen im Rahmen der Federazione industriale fascista gegen die Erhöhung ausgesprochen hatten ${ }^{174}$.

Im Juni 1923 beließen es die großen Exportfirmen noch beim Protest. Zu einem Bruch konnte es zu diesem Zeitpunkt nicht kommen, weil die Loyalität gegenüber Ricci bei einigen Vertretern dieser Firmen noch recht ausgeprägt war ${ }^{175}$. Außerdem befand sich der Ras, wie schon erwähnt, genau zu dieser Zeit auf dem Höhepunkt seiner Macht. Die Rückendeckung, die Ricci von den römischen Regierungs- und Parteistellen erhielt, schien nahezu bedingungslos zu sein. Doch hier ergab sich im Frühsommer eine Wende. Mit der Verabschiedung des Wahlreformgesetzes, der sogenannten legge Acerbo, am 15. Juli änderte Mussolini deutlich seine politische Taktik. Ihm ging es jetzt darum, für seine Politik eine breite politische Basis zu schaffen. Den intransigenti begann jetzt von Rom aus der Wind ins Gesicht zu blasen ${ }^{176}$. Schon im Juni hatte De Bono das Untersuchungsergebnis der Balbo-Kommission zu den Märzereignissen wieder hervorgeholt. Da Pozzo hatte ihm außerdem den Urteilsspruch des Ehrengerichts Florenz zugesandt, der Ricci im Zusammenhang mit der vertenza cavalleresca von Ende März mehrere Verstöße gegen die „Ehrengesetze" vorwarf ${ }^{177}$. Diese Dokumente schickte De Bono jetzt in Abschrift an die Giunta esecutiva des PNF und an das Kommando der 8. MVSN-Zone. In den Begleitschreiben stellte er die rhetorische Frage, ob es angesichts dieser Schiedssprüche zu vertreten sei, daß Ricci den Grad eines console generale der Miliz bekleide, zumal in seinem Fall eine Ämterhäufung vorliege, die er selbst „aus naheliegenden Grün-

170 Das Projekt der Firmen C. A. Fabbricotti, Lazzoni, Pisani, Corsi und Vennai wurde nachträglich veröffentlicht in Il Giornale di Carrara vom 6. 10. 1923.

171 Alalà vom 16. und 23. 6. 1923; Il Giornale di Carrara vom 16. 6. 1923.

172 Das jedenfalls behaupteten die protestierenden Firmen in einem Memorandum vom 18. 6. 1923 (Il Giornale di Carrara vom 23. 6. 1923).

${ }^{173}$ Sogar noch einen Monat später äußerte sich der Walton-Chef positiv über die Politik Riccis (vgl. Anm. 30). Die Firma Walton war geschäftlich mit dem Unternehmer Cirillo Figaia liiert, dessen Tochter Ricci im April 1923 geheiratet hatte.

174 Beleg wie Anm. 172.

175 Der politisch einflußreiche Liberale und Vertreter der Firma Walton, Gino Salvini, hatte noch in der Affäre um den Überfall auf das "Casino civico" ein Schreiben an Mussolini mitunterzeichnet, in dem die Vorgänge heruntergespielt wurden; ASM, Questura Massa, b. 20, f. „PNF dissidi“: Abschrift ohne Datum.

176 Vgl. Lyttelton, Seizure, S. 180-182 und De Felice, Mussolini il fascista 1, S. 539 - 546.

177 ACS, SPD/CR $1922-43$, b. 48, f. „R. Ricci“ : Urteil des ständigen Ehrengerichts (Corte d'onore permanente) Florenz vom 16. 5. 1923. 
den " für unzulässig halte ${ }^{178}$. Die unmittelbare Reaktion auf diese Initiative De Bonos ist nicht erhalten, aber am 28. August 1923 mußte Ricci das Milizkommando an den entsandten Berufsoffizier Guidoni abgeben ${ }^{179}$. Dies ist ihm bestimmt nicht leichtgefallen, denn die Stellung des console generale hatte seinen Auftritten bei verschiedenen feierlichen Anlässen trefflich gedient ${ }^{180}$.

Die Quellen enthalten keine konkreten Anhaltspunkte darüber, ob und inwieweit die anderen Empfehlungen der Balbo-Kommission berücksichtigt worden sind. Sollten Da Pozzo und Prayer Galetti wieder in den PNF aufgenommen worden sein, so hat das keine Spur in den Quellen hinterlassen und keine Auswirkungen auf die innerparteilichen Verhältnisse in Carrara gehabt. Auch ein Ausschluß von Giuseppe Aloisi aus Miliz und Partei ist aus den Quellen nicht zu ersehen. Allerdings fällt auf, daß er offiziell aus dem politischen Verkehr gezogen wurde. Als Fascio-Sekretär taucht sein Name nirgendwo mehr auf, und im neuen Direktorium des Fascio von Carrara, das im Dezember 1923 gewählt wurde, war er nicht einmal mehr als einfacher consigliere vertreten, obwohl er auch später noch als enger Vertrauter von Ricci galt und auch seinen Posten als assessore comunale zunächst noch behalten konnte ${ }^{181}$.

Die Veränderung der politischen Großwetterlage ist von den lokalen Gegnern Riccis wahrscheinlich genau beobachtet worden. Jedenfalls gingen sie im September zum Angriff über. Als die Gemeinde Carrara die Herabsetzung der Tarife der Ferrovia marmifera zum Anlaß nahm, die Differenz zwischen alten und neuen Beförderungspreisen erst mal für einige Zeit zu kassieren, um damit einen aufwendigen Parco della Rimembranza und ein als Kriegerdenkmal konzipiertes Waisenhaus zu finanzieren ${ }^{182}$, setzte die oppositionelle Unternehmergruppe alle Hebel in Bewegung, um den Ras schachmatt zu setzen. Zwar war der Anlaß relativ nichtig, aber in diesem Fall war die Rechtswidrigkeit so eindeutig, daß die Aussichten, mit einem auf die Spitze getriebenen Konflikt zu einer prinzipiellen Bereinigung der Situation zu kommen, günstig waren. Außerdem war abzusehen, daß die Praxis, die Unternehmen bei jeder Gelegenheit zu Sonderleistungen heranzuziehen, auch in Zukunft anhalten würde, zumal Ricci für Carrara grandiose städtebauliche Projekte in der Schublade hatte, die die Kommune anders gar nicht bezahlen konnte ${ }^{183}$.

Eine Kommission der oppositionellen Unternehmer begab sich Ende September nach Rom und sprach dort mehrmals beim Staatssekretär im Innenministerium, Aldo Finzi, vor. Flankenschutz erhielt sie von der Confindustria und vom ehemaligen Ministerpräsidenten Vittorio Emanuele Orlando, dessen politisches Wohlwollen für Musso-

${ }^{178}$ Ebenda: De Bono an Giunta esecutiva des PNF und an das Kommando der 8. MVSN-Zone vom 13. 6.1923.

179 Alalà vom 1.9. 1922.

180 So trat Ricci im Mai 1922 beim Besuch des Königs in Massa als "console generale" auf (Alalà vom 26. 5. 1923). Am 5. 8., dem Jahrestag der "Befreiung Genuas“, ließ er die apuanischen Legionen dort in der Pose des Feldherrn aufmarschieren (Alalà vom 11. 8. 1923).

${ }^{181}$ Die Zusammensetzung des neuen Direktoriums, das diesmal gemäß den Richtlinien der PNFLeitung durch eine weitgehend demokratische Abstimmung zustande kam, zeigt einen deutlichen Wandel in der Führungsmannschaft des Carrareser Faschismus (siehe dazu weiter unten, S. 259f.)

182 Alalà vom 29. 9. 1923.

${ }^{183}$ Brief der 14 oppositionellen Firmen in Il Giornale di Carrara vom 29. 9. 1923. 
linis Bündnisstrategie im Zusammenhang mit den geplanten Wahlen von großer Bedeutung war. Finzi setzte dem Duce den Sachverhalt auseinander, und dieser zögerte diesmal nicht mit seiner Entscheidung. Er akzeptierte den Standpunkt der Kommission nicht nur hinsichtlich der „Sondersteuer“ vollständig, sondern gab dem Generalsekretär der Confindustria, Gino Olivetti, auch gleich das Mandat, die organisatorische Autonomie der oppositionellen Unternehmer wiederherzustellen. Edmondo Rossoni, der zu den Verhandlungen hinzugezogen wurde, mußte diese Lösung wohl oder übel mittragen $^{184}$.

Am 27. September traten die 14 Firmen aus der Corporazione provinciale dell'industria aus und gründeten die Associazione industriali del marmo als Mitgliedsorganisation der Confindustria. In das Führungsgremium der neuen Organisation wurden Carlo Andrea Fabbricotti, Graf Renato Lazzoni, Giulio Corsi, Gino Salvini und Giulio Pisani gewählt ${ }^{185}$. Die Brücken zwischen den Großunternehmern der Provinz und dem System des Provinzfaschismus waren gefallen, das Korporativsystem zerbrochen. Wütend und enttäuscht zugleich klingt das unmittelbar nach dem Bruch veröffentlichte Plakat der Federazione provinciale sindacale: „Vierzebn Reiche, die alles vergessen haben, behindern unsere Entwicklung. Sie pilgern [nach Rom] und machen sich zu Opfern eingebildeter Verfolgungen. Sie suchen andere Strände, nur um einem Akt der gebührenden Anerkennung aus dem Weg zu gehen, und schaffen Klassenorgane, die darauf zielen, uns zu treffen. ${ }^{\times 186}$

Den fast automatischen Vorwurf des „Antifaschismus“ aus dem Lager des Ras wiesen die oppositionellen Unternehmer natürlich zurück. Sie betonten, daß die übergroße Mehrheit von ihnen den Faschisten Carraras von Anfang an zur Seite gestanden sei und daß ,ihr ganzes Werk hier wie anderswo immer offen darauf gezielt habe, das Entstehen, Wachsen und Sich-Behaupten des Faschismus zu fördern ${ }^{\text {187. }}$. Wie schon mehrmals angesprochen, war in Wirklichkeit das Verhältnis der führenden Unternehmer zum lokalen Faschismus sehr viel zwiespältiger. Dieser Sachverhalt soll hier anhand der politisch und wirtschaftlich führenden Familien von Carlo Andrea Fabbricotti und der Grafen Lazzoni nochmals verdeutlicht werden. Beide Familien sind nicht als geschlossene Einheiten zu betrachten. Am markantesten ist die kritische Haltung von Carlo Andrea Fabbricotti: Sein Verhalten im Zuge der Pisani-Äffäre zeigt, daß er schon frühzeitig die Gefahr erkannt hat, die auch den Unternehmern durch die Totalisierungsbestrebungen der Faschisten drohte ${ }^{188}$. Sein Sohn Bernardo Fabbricotti trat allerdings, wie auch die Brüder Bruno und Renato Lazzoni, dem Fascio noch vor dem März 1922 bei. Alle waren sie ehemalige Frontoffiziere, und bei den Aktionen um den Marsch auf Rom hatten sie teilweise entscheidende Positionen inne: Renato Lazzoni als aiutante maggiore im "Generalstab“ Riccis und Bernardo Fabbricotti als vicecommandante der Maschinenge-

184 Il Giornale di Carrara vom 29. 9. 1923. Zur Bedeutung Orlandos für die Wahlrechtsreform siehe Sabbatucci, Suicidio, S. 65-67.

185 Il Giornale di Carrara vom 29. 9. 1923.

186 ACS, MI, Gabinetto Finzi, b. 6, f. 61: Handzettel der Federazione provinciale sindacale fascista vom 26. 9. 1923.

187 Wie Anm. 183.

188 Vgl. oben, S. 128-130. 
wehrabteilung ${ }^{189}$. Wie schon an anderer Stelle erwähnt, flossen in dieser Zeit beträchtliche Summen aus den Kassen von Carlo Andrea Fabbricotti in die faschistische Organisation $^{190}$; taktische Motive mögen hier eine gewisse Rolle gespielt haben.

Fabbricotti war im Prinzip ein Gegner protektionistischer Maßnahmen, während Renato Lazzoni zu den Initiatoren der ersten, später gescheiterten Preisbindungsvereinbarung vom Juli 1922 gehörte ${ }^{191}$. Es verwundert daher nicht, daß er als Mitglied des Gruppo di competenza fra gli industriali fascisti an der Ausarbeitung der endgültigen Preisbindungsregeln beteiligt und auch später noch in der Federazione industriale fascista führend tätig war ${ }^{192}$. Er wie auch Bernardo Fabbricotti traten während der Dissidentenkrise aus dem PNF aus ${ }^{193}$, als deutlich geworden war, daß der Ras und seine Anhänger nicht bereit waren, einen internen Diskussionsspielraum zuzulassen. Von diesem Zeitpunkt an ist zu erkennen, daß die führenden Unternehmer außerhalb der faschistischen Institutionen an der Rekonstruktion ihrer autonomen Machtstellung arbeiteten. Mit der Loslösung im September 1923 war die Stunde von Carlo Andrea Fabbricotti gekommen, der jetzt nach genau zwei Jahren verbandspolitischer Abstinenz die Fäden wieder in die Hand nehmen konnte.

Es ist bemerkenswert, wie parallel zur Revolte der „Exporteure“ die liberale Partei in Carrara wieder ein sichtbares politisches Profil gewinnt. Der Giornale di Carrara wurde zum Sprachrohr der unternehmerischen Opposition und wagte auf einmal prinzipielle Kritik am Provinzfaschismus. Bezeichnenderweise holten sie sich dabei Argumentationshilfe bei den faschistischen „Revisionisten“. Als eine unmißverständliche Kritik an der Politik Riccis mußte der Nachdruck eines Artikels aus dem regierungsoffizösen Corriere italiano klingen, in dem es unter anderem hieß:

„Die Hohen Kommissare wurden sehr bald abgeschafft, nicht weil diese Institution keinem realen Bedürfnis entsprach, sondern hauptsächlich weil die Männer ihrer Aufgabe nicht gewachsen waren. Sie verwechselten zu oft ihre Parteiaufgaben mit politischen Aufgaben, die der Regierung und den Präfekten zugeordnet sind. Die Kirchturmpolitik tat das übrige, indem sie die Provinzzwiste zu nationalen Problemen erhob und wegen der nichtigsten Anläße die öffentliche Meinung durcheinanderbrachte. "194

Der zitierte Artikel, bei dem es sich um einen der radikalsten Beiträge der „revisionistischen" Kampagne handelte, endete mit dem provokativen Vorschlag, den PNF abzuschaffen, wenn es sich erweisen sollte, daß er zu einer grundlegenden Erneuerung unfähig sei $^{195}$. Die Publizierung solcher häretischen Töne wäre in Carrara noch vor wenigen Wochen unvorstellbar gewesen. Selbst die Dissidenten waren mit ihrer Kritik nicht annähernd so weit gegangen und hatten trotzdem ihre körperliche Unversehrtheit aufs

189 Chiurco, Rivoluzione fascista, Bd. 1, S. 391. Als Faschisten erstmals aktenkundig sind Bernardo Fabbricotti und Bruno Lazzoni als „capi squadra“ der Reiterstaffel bzw. der 3, „squadra triari $^{\text {cc }}$ in APC, b. B 1, f. 6: Aufstellung der Carrareser Squadren ohne Datum (März 1922).

190 Vgl. oben, S. 200, Anm. 136.

191 Il Giornale di Carrara vom 1. 7. 1922.

192 Alalà vom 10. 2. und 14. 4. 1923.

193 Liste der Ausgetretenen in Alalà vom 31. 3. 1923.

194 Il Giornale di Carrara vom 29. 9. 1923.

195 Der anonyme Artikel mit dem Titel "Governo e fascismo nella realtà politica“ nimmt einen zentralen Platz in der "revisionistischen" Kampagne des Corriere Italiano ein. Eine längere Passage dieses Artikels ist zitiert bei De Felice, Mussolini il fascista 1, S. 548. 
Spiel gesetzt. Doch diesmal war Ricci hilflos. Der Versuch, die liberale Organisation durch Drohungen und einen internen Putsch einer Gruppe von bedingungslosen fiancheggiatori $^{196}$ gegen den mittlerweile Ricci-kritischen Sekretär Oreste Nori gefügig zu machen, konnte im Januar 1924 durch die persönliche Intervention des PLI-Chefs, Alberto Giovannini, verhindert werden ${ }^{197}$. Der Ras mußte sich damit abfinden, daß eine Bresche in sein "totalitäres" System geschlagen war, die sich durch Gewaltakte nicht ohne weiteres wieder schließen ließ. Die eingeworfenen Fensterscheiben des liberalen Parteilokals ${ }^{198}$ waren das einzige konkrete Ergebnis, das die lokalen Faschisten kurzfristig erzielen konnten. Das System der Provinzdiktatur war entscheidend geschwächt, ein Zustand, der das ganze Jahr 1924 anhalten sollte.

Riccis Projekt eines regionalen „Totalitarismus“ blieb unvollendet, weil das System des Provinzfaschismus nicht in der Lage war, der sozialen und politischen Autonomie der Großunternehmer die Basis zu entziehen. Ihre wirtschaftliche Macht und der politische Rückhalt, den sie auch in Zukunft immer wieder in Rom und Mailand finden würden, erlaubte ihnen als einziger sozialer Gruppe, sich der Despotie des Ras zu entziehen. Im Schlepptau der Großexporteure kehrten auch die anderen Unternehmer wieder in die Confindustria zurück, der Mussolini am 20. Dezember 1923 im Patto di Palazzo Chigi das ausschließliche Recht zuerkannte, die Interessen der gewerblichen Wirtschaft zu organisieren ${ }^{199}$. Der Traum von der Gemeinschaft aller „Produzenten“ unter dem einheitlichen Dach der faschistischen Organisation war zerronnen.

\section{Das Jahr 1924: faschistischer Extremismus gegen die alten Eliten}

Das Jahr 1924 wurde für Ricci und den faschistischen Extremismus in der Provinz ein Jahr der Rückschläge und Anfechtungen. Im bürgerlich-faschistischen Lager war ein Differenzierungsprozeß zwischen Extremisten und Gemäßigten eingeleitet, der nicht mehr rückgängig zu machen war. Das radikalfaschistische Ziel, ein geschlossenes regionales Herrschaftssystem, in dem die traditionelle Elite der selbsternannten „neuen Aristokratie " der Squadrenführer den gesellschaftlichen Führungsanspruch abtreten und sich den autoritären Konfliktlösungsstrategien des Ras widerspruchslos fügen würde, war wieder in weite Ferne gerückt. Die bündnispolitischen Notwendigkeiten der römischen Politik hatten im ökonomischen Bereich zur Restauration der alten Strukturen geführt. Das

${ }^{196}$ Bei den Frondeuren scheint es sich u. a. um Angelo Ricci (nicht mit Renato Ricci verwandt) und Umberto Ascoli gehandelt zu haben, die als „ricciani“ im Carrareser Ortsverein der liberalen Partei gelten können.

197 Oreste Nori wehrte das Kreuzfeuer der Vorwürfe aus dem eigenen und dem faschistischen Lager ab, indem er Giovannini dazu veranlaßte, ein Untersuchungsverfahren gegen ihn einzuleiten. Dies gab dem Parteichef die Gelegenheit, in Carrara persönlich zu erscheinen, Nori von allen Vorwürfen reinzuwaschen und nachdrücklich seinen Standpunkt vorzutragen, nachdem die liberale Partei keine Dependance des PNF sei. Einer der Hauptvorwürfe, die gegen Nori erhoben wurden, lautete bemerkenswerterweise, er habe als Mitglied im Leitungsrat des exklusiven „Casino civico" gegen die Aufnahme Riccis gestimmt. Dem Ras war wegen seiner Rowdieaktion vom 16. 5. 1923 die Mitgliedschaft verweigert worden (Il Giornale di Carrara vom 26. 1. 1924).

198 ACS, MI, DGPS 1924, b. 80, f. „Fasci Massa“: Präfekt an Innenministerium vom 17. 12. 1923.

199 Vgl. Cordova, Sindacati fascisti, S. 194-196. 
Wiedererstarken der alten lokalen Eliten hatte seinen sinnfälligsten Ausdruck in der wiedergewonnenen Autonomie und Aktionsfähigkeit der liberalen Partei in Carrara, die zunehmend mutiger und konzeptionell klarer gegen die Provinzdiktatur und gegen Tendenzen, diese zum Muster für Veränderungen auf nationaler Ebene zu machen, Stellung bezog. Doch Kristallisationsfigur der regionalen bürgerlichen Opposition gegen Extremismus und Ras-Herrschaft wurde zunächst kein Liberaler, sondern der gemäßigte Faschist Ettore Viola, ein Mann, der 1924 für kurze Zeit als Wortführer der normalizzatori eine wichtigere Rolle in der nationalen Politik spielen sollte als sein Rivale Renato Ricci.

Viola stammte aus Villafranca, einer Gemeinde der Alta Lunigiana mit damals gut 5000 Einwohnern, in der es zu keiner Zeit zu größeren politischen Konflikten gekommen war. Der Fascio wurde dort erst am 20. August 1922 gegründet und zählte ganze 50 Mitglieder ${ }^{1}$. Ettore Viola war vor 1915 ein kleiner Bahnangestellter gewesen und wurde im Krieg zu einem der höchstdekorierten Hauptleute des italienischen Heeres. Als Offizier der arditi erwarb er sich durch einige tollkühne Aktionen den legendären Beinamen Arditissimo del Grappa sowie zwei medaglie d'argento, eine medaglia d'oro und das Verdienstkreuz des Ordine militare di Savoia ${ }^{2}$. Diese Auszeichnungen bildeten die Grundlage für seine steile politische Karriere im Jahre 1924, obwohl er erst 1922 in den römischen Fascio eingetreten und sich dort in keiner Weise hervorgetan hatte. Bis zum Herbst 1922 war er in seiner Heimatprovinz praktisch gar nicht aufgetaucht, seine ganze Aufmerksamkeit hatte dem Projekt einer genossenschaftlich organisierten Reederei mit Sitz in Triest gegolten, die ehemaligen Frontsoldaten Arbeit geben sollte, aber bankrott ging, noch bevor sie richtig zu funktionieren begonnen hatte ${ }^{3}$. Nach diesem Fehlschlag begann Viola, sich in der Politik zu engagieren, und seine Rede auf der Siegesgedenkfeier vom 4. November 1923 in Massa, seinem ersten öffentlichen Auftritt in der Provinz, machte sofort deutlich, daß seine Auffassung von Faschismus sich sehr von der Lesart der ricciani unterschied. Er erschien auf der Tribüne mit seinem Freund Alessandro Tangorra, dem Bruder des verstorbenen PPI-Ministers, und hielt eine Rede, die von der für seine politische Orientierung typischen Verbindung von Frontkampf- und Versöhnungsideologie geprägt war. ${ }^{4}$. Der combattentismo - das wurde schon bei diesem Auftritt deutlich - war bei ihm auf die Überwindung der politischen Polarisierung hin ausgerichtet und mußte daher bei den ricciani auf schärfste Ablehnung stoßen, denn ihre politische Ausschließlichkeitshaltung nährte sich von der permanenten künstlichen Wiederbelebung der Bürgerkriegsatmosphäre von 1921/22. Es ist daher kaum verwunderlich, daß die Berichterstattung von Alalà die Rede Violas völlig entstellte, ihre Grundaussage fast in ihr Gegenteil verkehrte und Violas Forderung nach einer Berichtigung einfach ignorierte ${ }^{5}$.

1 ACS, MI, DGPS 1923, b. 100 bis, f. „Costituzione fasci Massa“: Präfekt an Innenministerium vom 28. 8. 1922.

2 ACS, SPD/CR RSI, b. 37, f. 336 („Ettore Viola“): Kurzer Lebenslauf (Januar 1929); La Trincea vom 8. 11. 1924.

${ }^{3}$ ACS, SPD/CR RSI, b. 37, f. 336: Ausführlicher Bericht des Präfekten von Triest an Mussolini vom 5. 9. 1924.

${ }^{4}$ Rede in La Trincea vom 19. 1. 1924.

5 ACS, MI, Gabinetto Finzi, b. 12, f. 145: Memorandum von Viola ohne Datum (Mai 1924). Die verfälschte Wiedergabe der Rede Violas in Alalà vom 10.11. 1923. 
Ricci erkannte sehr schnell, daß ihm mit Viola ein ernstzunehmender Rivale erwachsen war, der bestrebt war, das gesamte "gemäßigte“ Lager, von den latenten anti-riccia$n i$ im PNF-Provinzialverband über die ausgeschlossenen dissidenti bis hin zu den liberalen und katholischen Honoratioren der Provinz, um sich zu sammeln. Als organisatorische Basis für diese Politik diente Viola der Provinzverband der Associazione nationale combattenti (ANC), dessen Ehrenvorsitzender er wurde, und der vom Oktober 1923 an das Wochenblatt La Trincea herausgab, das sich bald völlig dem Kampf gegen den faschistischen Extremismus verschrieb.

Viola trieb den organisatorischen Ausbau der ANC in der Provinz zielstrebig voran, stieß hier aber bald auf den Widerstand des Ras. Erfolge konnte er nur außerhalb des Bereichs der unmittelbaren Hausmacht Riccis erzielen, in den kleinen Gemeinden der Lunigiana und im Gemeindegebiet von Massa, wo die Gemäßigten innerhalb und außerhalb des PNF eine relativ starke Stellung hatten. Im Gemeindegebiet von Carrara war an die Gründung eines ANC-Ortsvereins überhaupt nicht zu denken. Hier bestand ein vom Ras erlassenes „Verbot“ ${ }^{\text {“ }}$ der ANC, das noch immer mit den fatti di Bergiola vom Januar 1922 begründet wurde ${ }^{6}$. Ricci war nicht bereit, in seinem eigenen Haus die Gründung einer mitgliederstarken Organisation zu dulden, die - das stand zu befürchten ihm nicht völlig gefügig sein würde.

In Aulla war die Situation ambivalent. Viola war hier vor dem Krieg beschäftigt gewesen und besaß in der Gemeinde einen persönlichen Anhang. Doch Ricci, der in der Vergangenheit systematisch daran gearbeitet hatte, den Ort seiner unmittelbaren Regie zu unterwerfen, gab nicht klein bei, als dort die Gründung des örtlichen ANC-Ortsvereins vorbereitet wurde. Viola war es gelungen, die örtlichen Verantwortlichen des Fascio für diesen Plan zu gewinnen, und so blieb dem Ras nichts anderes übrig, als Gewalt anzuwenden. Drei Tage vor der geplanten Gründung rückten 50 squadristi aus Monzone unter der Führung des dortigen Sekretärs Giuseppe Montefiori ${ }^{7}$, eines äußerst simplen Haudegens, der Ricci treu ergeben war, an. Die Faschisten aus Monzone begannen in der üblichen Weise den Ort zu terrorisieren. Es kam zu Prügeleien mit Einheimischen, und die auswärtigen Faschisten stürmten das Fascio-Lokal. Die Situation eskalierte: Als Montefiori sich auf den Bruder des Fascio-Sekretärs von Aulla stürzte, der zu den Initiatoren der ANC-Ortsvereinsgründung gehörte, fiel ein Pistolenschuß, und Dante Ricciotti, ein Faschist aus Monzone, blieb tödlich getroffen am Boden liegen. Anschließend wurde der Ort von über 300 weiteren, offensichtlich schon bereitstehenden auswärtigen Faschisten besetzt. Ricci erschien, und einer Darstellung Violas zufolge drohte er den Einwohnern von Aulla Rache an, falls sie sich gegen ihn stellen sollten. Vor den einheimischen Faschisten distanzierte er sich auch vom Vorgehen Montefioris, obwohl kaum ein Zweifel darüber bestehen konnte, daß er die Aktion selbst angeordnet hatte. Von den empörten

6 Die wenig verhüllte Drohung gegen alle potentiellen Initiatoren eines ANC-Ortsvereins in Alalà vom 7. 6. 1924.

7 Giuseppe Montefiori war Arbeiter und einer der Gründer des Fascio von Monzone (ACS, MI, DGPS 1923, b. 91, f. „Fasci Massa“" sf. „Costituzione fasci“: Präfekt an Innenministerium vom 25. 1.1922). Nach Angaben von Viola (Memorandum, wie Anm. 5) war Montefiori wegen Desertion vorbestraft und ein ehemaliger "Rotgardist". 
Faschisten Aullas ließ er sich sogar das Versprechen abringen, Montefiori aus dem PNF auszuschließen, doch war davon später keine Rede mehr ${ }^{8}$.

Die Vorgänge von Aulla erregten größtes Aufsehen. Der Vorsitzende der ANC, Vittorio Arangio Ruiz, bequemte sich persönlich nach Massa, um Ricci zu einer versöhnlicheren Haltung gegenüber seiner Organisation zu bewegen. Doch diese Bemühungen scheinen keinen großen Erfolg gehabt zu haben, denn der Ras sperrte sich weiterhin gegen einen ANC-Ortsverein in Aulla, und der Präfekt von Massa hielt ihm die Stange, indem er sich bemühte, dieses Vorhaben wenigstens hinauszuzögern'. Es entsprach allerdings nicht dem Temperament Violas, sich in die Defensive drängen zu lassen, und so setzte er am 20. Januar 1924, nur neun Tage nach dem blutigen Vorfall, die Gründung des ANC-Vereins von Aulla an und nutzte sie sogleich zu einer unerhörten Attacke auf den Ras. Auf die Gewaltaktion bezugnehmend sagte er laut Bericht der Trincea:

„Das Gedächtnis der Toten möge in dieser Stunde den Gebrauch des Wortes rechtfertigen, zumal wir auch einen Protestschrei zum Schutze derjenigen erheben werden, die - [als] arme blinde Werkzeuge in den Händen von zynischen Spekulanten aller mehr oder weniger politischen, aller mehr oder weniger wahlkämpferischen Situationen - sich immer haben umbringen lassen, ohne wenigstens die notwendigen Voraussetzungen für den Eingang in die Geschichte der berühmten Eunuchen zu erwerben. [.. . ] Derjenige, der unerwarteterweise angefangen hat, den Don Rodrigo zu spielen, der seine Schergen (i bravi) ${ }^{10}$ benutzt, um das monumentale Gebäude seines ungebremsten und zügellosen Ehrgeizes zu beschützen, und der sich nicht vorher klargemacht hat, daß dies anachronistisch ist, weil Italien ein [solch] erzoligarchisches Regime niemals akzeptiert hat und niemals akzeptieren wird, und nur die wenigen überlebenden Provinzfürsten und Lokalpotentaten (ras provinciali e sottoprovinciali) danach rufen. Derjenige also, der hier den Don Rodrigo spielt und sich nicht klargemacht hat, daß das neue Italien nur einen Duce zuläßt und wünscht, den nämlich, den es sich auserwählt hat, wird früher oder später unerbittlich an der Pest seiner eigenen unermeßlichen Dummheit erkranken und von ihr auf lächerlichste Weise entstellt werden. "11

Niemals zuvor war Ricci öffentlich in einer nur annähernd so scharfen und beleidigenden Form angegriffen worden. Die ricciani machten überall in den Gliederungen der PNF-Provinzorganisation mobil. Eine Flut von Telegrammen mit Stellungnahmen gegen die Äußerungen Violas wurde verfaßt und im Alalà abgedruckt; nicht nur der Angriff auf den Ras, sondern auch die angebliche Herabwürdigung der faschistischen „Märty-

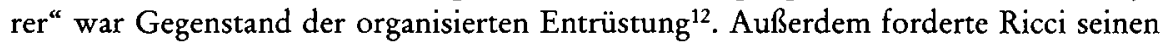
Widersacher zum Duell. Gegen den ausdrücklichen Wunsch Mussolinis wurde es ausgetragen und endete, nachdem Ricci verletzt worden war, mit der formellen Versöhnung der Kontrahenten ${ }^{13}$.

Es ist bemerkenswert, daß die Rede von Aulla nicht das frühzeitige Ende, sondern erst den eigentlichen Anfang der politischen Karriere Violas markierte. Als klares Signal schickte Mussolini ihm wenig später eine Duce-Photographie mit der bezeichnenden

${ }^{8}$ Die Darstellung folgt hier im wesentlichen den recht plausiblen Angaben im Memorandum von Viola (ebenda). Der entsprechende Polizeibericht ist in sich völlig widersprüchlich und erscheint auf eine Version hingetrimmt, mit der der Ras leben konnte; ACS, MI, DGPS 1924, b. 72, f. „Fasci dissidenti Massa“: Protokoll der Carabinieri-Station von Aulla vom 15. 1. 1924.

9 Memorandum (wie Anm. 5).

10 Don Rodrigo und die „bravi“ sind Figuren aus Alessandro Manzonis „Promessi sposi“ (1827, dt.: „Die Verlobten“), dem Hauptwerk der italienischen Romantik. Der Name des Feudalherrn Don Rodrigo steht für schrankenlose Willkür und Brutalität. Die „bravi“ sind seine Schergen.

11 Die vollständige Rede in La Trincea vom 26.1. 1924.

12 Abdruck der Telegramme in Alalà vom 26. 1. 1924.

13 Memorandum von Viola (wie Anm. 5); zum Verlauf des Duells Alalà vom 2. 2. 1924. 
Widmung: „Dem Hauptmann Viola, heldenhaft im Krieg und treu im Frieden, mit brüderlichem Sinn", und La Trincea ließ es sich natürlich nicht nehmen, dies unverzüglich zu veröffentlichen ${ }^{14}$. In der delikaten Phase der Kandidatenaufstellung für die bürgerlich-faschistische Einheitsliste, den sogenannten listone, die dem Duce nach dem geltenden neuen Wahlrecht eine erdrückende Mehrheit im Parlament sichern sollte, war ein Einvernehmen mit den „gemäßigten “ Kräften von zentraler strategischer Bedeutung. Es ist daher wenig verwunderlich, daß - trotz der offenen Feindseligkeiten zwischen Ricci und Viola - beide als Vertreter der Provinz Massa-Carrara zu Kandidaten der toskanischen Lista nazionale gekürt wurden. Viola hatte die Aufgabe, dem listone jene potentiell „regierungsfreundlichen“ Wählerkreise zuzuführen, für die der Ras mittlerweile ein rotes Tuch geworden war: die alte liberale Elite, die nicht parteigebundenen combatten$t i$ und die "nationalgesinnten" (ehemaligen) Republikaner und popolari, zu denen der Arditissimo notorisch gute Beziehungen unterhielt ${ }^{15}$.

Natürlich war ein gemeinsamer Wahlkampf der beiden Rivalen nicht möglich. Als sie aus "protokollarischen " Gründen in Massa gemeinsam auftreten mußten, kam es prompt wieder zu Zwischenfällen ${ }^{16}$, und danach kann eigentlich nur noch von einem erbitterten Wahlkampf gegeneinander die Rede sein. Heftige Auseinandersetzungen, Beleidigungen und Duelle zwischen Anhängern der beiden Kandidaten waren an der Tagesordnung ${ }^{17}$. Wahlhelfer von Viola wurden bedroht und am Austeilen ihrer Bröschüren gehindert. Während er in Pontremoli eine Kundgebung abhielt, zog Ricci alle „Schwarzhemden“ der Provinz zu einer Machtdemonstration in seinem Heimatort Villafranca zusammen, und anschließend versuchten Riccis „Prätorianer" von der Disperata-Squadra, Viola und seinen Anhang sogar direkt einzuschüchtern ${ }^{18}$. Als sich in Massa und Carrara ein Komitee bildete, das zu Ehren Violas eine Goldmedallie prägen lassen wollte, machte Ricci gegen dessen Spendenaufruf mobil ${ }^{19}$. Dem Komitee gehörten die Ricci-feindlichen Industriellen Carlo Andrea Fabbricotti und Giulio Lazzoni an. Ganz im Sinne seines Chefs bezeichnete sie Luciano Bacciola auf einer Kundgebung in Marina di Carrara als „Schurken in Glacéhandschuhen [...], die Ränke gegen den Faschismus schmieden "20. Und um das Maß vollzumachen, wurde der Rechtsanwalt Adriano Galanti aus Massa, ein

14 La Trincea vom 2. 2. 1924.

15 Viola wollte im „circondario“ von Pontremoli Wahlkomitees aus unabhängigen Anhängern der Regierung schaffen, wurde daran aber von Ernesto Buttini gehindert, der soweit ging, ihm gute Beziehungen zu den PSU-Sozialisten Pontremolis um Pietro Bologna vorzuwerfen (Memorandum von Viola, wie Anm. 5). Neben Violas Beziehungen zur Familie Tangorra ist die Tatsache bemerkenswert, daß La Trincea vom 9. 2. 1924 einen Bericht über den Provinzialkongreß des PPI in Massa veröffentlichte.

16 Bei der Vorstellung der Kandidaten der „Lista nazionale“ in Massa am 2. 3. 1924 verließ Ricci die Tribüne, als Viola mit seiner Rede begann, und zog mit den Männern der "Disperata" von dannen. Anschließend kam es zu einem Wortwechsel, in dem Ricci bis hart an die Grenze der Beleidigung ging (Memorandum von Viola, wie Anm. 5).

17 Ernesto Buttini duellierte sich einmal mit dem Ricci-kritischen Bürgermeister von Massa, Carlo Giorgini, und einmal mit Viola selbst. Zur Beleidigung der Industriellen C. A. Fabbricotti und Giulio Lazzoni durch den „ricciano“ Luciano Bacciola siehe Anm. 20.

18 Memorandum von Viola (wie Anm. 5).

${ }^{19}$ Er ließ Plakate drucken, auf denen er die Bürger von Carrara davor warnte zu spenden, abgedruckt in Alalà vom 8. 3. 1924.

20 Alalà vom 29. 3. 1924. 
Freund Violas, mitten im Wahlkampf vom Provinzdirektorium demonstrativ "wegen fehlender faschistischer Gesinnung “ aus dem PNF ausgeschlossen ${ }^{21}$.

$\mathrm{Daß}$ in der Provinz die politischen Alternativen durch zwei Kandidaten der Lista nazionale repräsentiert wurden, ist symptomatisch für den minimalen Spielraum, den die eigentliche Opposition hier noch besaß. Dieser Tatbestand spiegelte sich auch im Ergebnis wider: Die faschistische Lista nazionale und die liberal-faschistische Lista nazionale bis errangen in der Provinz zusammengenommen 78,6 Prozent der Stimmen. Die Oppositionsparteien waren zu Splittergruppen herabgesunken. Am besten behaupteten sich noch die Republikaner mit 7,3 Prozent (1921: 18,3\%), während die popolari mit 5,1 Prozent (1921: 21,1\%), der reformsozialistische PSU mit 3,4 Prozent (1921 noch im PSI), der "maximalistische" PSI mit 2,2 Prozent (1921: 22,7\%) und die kommunistische Partei mit 1,9 Prozent (1921: 7,6\%) völlig einbrachen ${ }^{22}$.

Natürlich handelte es sich in der Provinz Massa-Carrara um Wahlen, die man selbst mit Einschränkungen nicht als demokratisch bezeichnen kann. Politische Propaganda der Oppositionsparteien, ja schon öffentliches Eintreten für sie war so gut wie unmöglich. Zwar läßt sich anhand der Quellen keine direkte Einflußnahme auf den eigentlichen Wahlakt oder Wahlfälschung großen Stils belegen, aber eine vergleichende Analyse von Einzelergebnissen gibt doch klaren Aufschluß über ihren tendenziell „totalitären“ Charakter. Wie schon bei den Kommunalwahlen von 1922 zeigt sich in den Ergebnissen ein äußerst signifikanter Unterschied zwischen Carrara und Massa, den man mit der wesentlich „pluralistischeren“ und legalistischeren Atmosphäre in Massa in Beziehung setzen kann. ${ }^{23}$

Ergebnisse der nationalen Wahlen vom 6. April 192424:

\begin{tabular}{lcc}
\hline & Massa & Carrara \\
\hline Wahlbeteiligung: & $71,9 \%$ & $79,4 \%$ \\
Enthaltungen / ungültige Stimmen & $10,4 \%$ & $2,7 \%$ \\
Lista nazionale & $58,4 \%$ & $89,8 \%$ \\
Lista nazionale bis & $1,7 \%$ & $1,1 \%$ \\
Liberali indipendenti & $0,9 \%$ & $0,3 \%$ \\
Democratici sociali & $0,6 \%$ & $0,3 \%$ \\
Republikaner (PRI) & $18,2 \%$ & $5,1 \%$ \\
"Popolari“ (PPI) & $8,2 \%$ & $0,6 \%$ \\
Reformsozialisten (PSU) & $4,2 \%$ & $1,4 \%$ \\
"Maximalisten “ (PSI) & $3,0 \%$ & $1,1 \%$ \\
Kommunisten (PCd'I) & $4,4 \%$ & $0,3 \%$ \\
\hline
\end{tabular}

21 Alalà vom 8. 3. 1924.

22 Zahlen bei Bianchi, Lotte sociali, S. 252 (in Prozente umgerechnet).

${ }^{23}$ Dieser Befund gilt durchaus auch noch für das Jahr 1924. Man denke an die Abhaltung des PPIKongresses in Massa Anfang Februar 1924 (vgl. Anm. 15). Etwas Vergleichbares wäre in Carrara unmöglich gewesen. Die Masseser Zustände konnten dem Ras natürlich nicht gefallen, und so produzierten die "ricciani" eine Krise in Partei und Stadtverwaltung, die mit dem Rücktritt des Bürgermeisters endete (Alalà vom 2. und 23. 8. 1924 und La Trincea vom 23. 8. 1924).

24 Daten bei Bianchi, Lotte sociali, S. 252 (in Prozente umgerechnet). Zur Errechnung der Wahl- 
Während die Oppositionsparteien in Massa auf immerhin knapp 40 Prozent der Stimmen kamen und sich dort in der relativ niedrigen Wahlbeteiligung sowie der enorm hohen Zahl der leeren und ungültigen Stimmzettel noch zusätzlich eine gewisse Protesthaltung zeigt, ist das Ergebnis in Carrara geradezu „plebiszitär“. Über 90 Prozent der Stimmen für die faschistischen Listen bei einer Wahlbeteiligung von knapp 80 Prozent können nur mit der fast lückenlosen sozialen Kontrolle erklärt werden, die der Faschismus in Carrara mittlerweile etabliert hatte. Man denke allein an die schon erwähnte Tatsache, daß hier früher bei der Wahlbeteiligung wegen der Enthaltungspropaganda der Anarchisten niemals die 50-Prozent-Marke erreicht wurde ${ }^{25}$ und daß die auf fünf Prozent zusammengeschrumpften Republikaner im Jahre 1921 noch die absolute Mehrheit der Stimmen auf sich vereinigt hatten. Trotz der formalen Zulassung der Oppositionsparteien ist das Wahlergebnis von Carrara als eindeutiges Symptom für nahezu vollständig „totalitäre" Verhältnisse anzusehen. Das grundlegend andere Ergebnis von Massa ergibt sich hingegen aus einer Situation, in der der Opposition zwar auch keine echten Entfaltungsmöglichkeiten mehr verblieben waren, aber die faschistische Organisation nicht annähernd die gleiche Allgegenwart, Intoleranz und Gewalttätigkeit entfaltete.

Die Gewichtung der Elemente des Zwanges und des Konsenses in der sich herausbildenden "totalitären“ Ordnung ist ein analytisches Problem, das sich durch Quellenstudium nur begrenzt lösen läßt. Allein die offene Stimmenabgabe hätte eine direkte Einflußnahme auf den Wahlakt ermöglicht, und, wie schon angedeutet, findet sich für diese Praxis kein Beleg in den Quellen. Gemäß den Anordnungen von Mussolini hat Alalà sogar auf die Benutzung der Wahlkabine als Bestandteil eines ordnungsgemäßen Wahlakts hingewiesen ${ }^{26}$. Eine Abweichung von dieser Empfehlung in der Praxis und Unregelmäßigkeiten bei der Auszählung ${ }^{27}$ sind zwar nicht auszuschließen, doch wäre es wohl verfehlt, die Erklärung etwa des Carrareser Wahlergebnisses allein auf derartigen Spekulationen aufzubauen. Vielmehr muß davon ausgegangen werden, daß nur sehr kleine, stark politisierte Gruppen in der Lage waren, dem Konformitätsdruck in Carrara psychologisch auszuweichen. Die übergroße Mehrheit der Bevölkerung erlag ihm offensichtlich in einem solchen $\mathrm{Maße}$, daß er auch noch in der Wahlkabine, auch ohne direkte Überwachung, wirksam werden konnte.

Außerdem, und auch hierfür ist der Vergleich zu Massa aufschlußreich, war es dem Faschismus in Carrara ja gelungen, die traditionelle Basis der oppositionellen Parteien, die Arbeiter, in seine Gewerkschaften einzubinden und ihren tariflichen und sozialen

beteiligung und des Anteils der leeren und ungültigen Stimmzettel wurden die Daten von Il Giornale di Carrara vom 12. 4. 1924 herangezogen. Die Stimmquoten der einzelnen Parteien beziehen sich auf die Zahl der gültigen Stimmen.

25 Vgl. S. 214, Anm. 12.

26 Alalà vom 3. 4. 1924.

${ }^{27}$ Lyttelton, Seizure, S. 147, weist auf verschiedene Methoden der Wahlbeeinflussung hin. Die sogenannte Bocchini-Methode (benannt nach dem damaligen Präfekten von Bologna und späteren obersten Polizeichef), die darin bestand, daß die faschistische Organisation den einzelnen Wählern jeweils verschiedene Kombinationen der drei Präferenzstimmen vorschrieb, welche bei der Auszählung einen Aufschluß über die Personen ermöglichten, die "falsch" gewählt hatten, kam in Carrara mit Sicherheit nicht zur Anwendung. Das läßt sich an der Verteilung der Präferenzstimmen eindeutig feststellen. Ob bei der Auszählung der Stimmen nur absolut zuverlässige „ricciani“ zugegen waren, läßt sich nicht sagen, ist aber möglich, da die Kommunalverwaltung völlig in ihrer Hand war. 
Besitzstand zu sichern und ansatzweise auszubauen. Man muß daher davon ausgehen, daß auch Elemente des Konsenses eine nicht unmaßgebliche Rolle spielten. Absolute politische Unduldsamkeit, maximale organisatorische Erfassung der Bevölkerung und materielle Gratifikationen bildeten für den apuanischen Radikalfaschismus eine untrennbare Einheit. Dies war die Grundlage für die tendenziell „totalitären“ Wahlergebnisse in der größten und wirtschaftlich wichtigsten Gemeinde. Die Ergebnisse in anderen Teilen der Provinz, vor allem in Massa, fielen dagegen ab, weil dort die Verhältnisse noch nicht so weit „fortgeschritten " waren. Wie weitgehend faschisiert insgesamt die Provinz im italienischen Maßstab allerdings schon war, zeigt der Vergleich mit den Wahlergebnissen anderer Regionen, wo die nationalen Listen zumeist erheblich unter den in MassaCarrara erzielten 78,6 Prozent der Stimmen blieben ${ }^{28}$.

$\mathrm{Ob}$ Viola bei dieser Wahl die ihm zugedachte Rolle erfült hat, der Lista nazionale Kräfte zuzuführen, die ihr aus Abneigung gegen den Extremismus des PNF-Provinzialverbands sonst ferngeblieben wären, läßt sich ansatzweise klären. Immerhin errang er in der Provinz 3876 Präferenzstimmen, das zweitbeste Ergebnis nach Ciano (7617 Stimmen) und vor Ricci (3622 Stimmen). Zu diesem etwas merkwürdigen Ergebnis ist zu sagen, daß Mussolini den Kandidaten der rein faschistischen Listen untersagt hatte, um Präferenzstimmen zu kämpfen. Aus diesem Grund hatte Ricci unmittelbar vor der Wahl vor allem in Massa und Carrara die Parole ausgegeben, man solle nicht ihm, sondern Ciano die Präferenzstimme geben. Nach der Wahl interpretierte Alalà dann natürlich die Präferenzstimmen für Ciano als Zustimmung für Riccii ${ }^{29}$. Da der Löwenanteil von Cianos Präferenzstimmen in der Provinz, nämlich 6500, aus Carrara kam, ist diese Interpretation auch nicht abwegig. Es zeigt darüber hinaus, wie stark die faschistische Organisation in Carrara die Wählerschaft im Griff hatte. Nach Angaben von Viola soll diese Parole erst am Morgen vor der Wahl ausgegeben worden $\operatorname{sein}^{30}$, und trotzdem erreichte sie in der Gemeinde mehr als die Hälfte aller PNF-Wähler.

Selbst wenn man jedoch die Präferenzstimmen für Ciano, so wie Alalà das tat, ganz auf das Konto Riccis bucht, bedeuteten Violas fast 4000 Präferenzstimmen ein Problem für die ricciani. Denn so wie der Wahlkampf abgelaufen war, kann jede dieser Stimmen als eine Mißtrauenskundgebung gegen Ricci angesehen werden. Viola sammelte diese Stimmen vor allem in den kleineren Orten der Lunigiana, in denen früher die costitutionali und popolari stark gewesen waren. In seinem Heimatort Villafranca errang er zehnmal soviel Präferenzstimmen wie Ricci, obwohl der Sekretär des lokalen PNF, Augusto Rossi, ein lupenreiner ricciano war. Selbst in Pontremoli, dem Hauptort der Alta Lunigiana, konnte er gut 60 Prozent mehr Präferenzstimmen verbuchen als sein Gegenspie-

${ }^{28}$ Sogar das hervorragende Gesamtergebnis der Toskana fiel mit 77,4 Prozent etwas niedriger aus. Im italienischen Landesmittel erlangten die „Liste nazionali“ 66,3 Prozent. Selbst in der Emilia Romagna, der anderen traditionellen faschistischen Hochburg unter den Regionen Italiens, kamen sie "nur" auf 72,0 Prozent. Die hohen Ergebnisse der Regierungslisten im Süden haben in diesem Zusammenhang keine Bedeutung, weil in ihr die alten liberalen Eliten stark vertreten waren. Sie sind daher, vielleicht außer in Apulien, kein Gradmesser für die Faschisierung der Gesellschaft (vgl. Sabbatucci, Suicidio, S. 79 f.). Illegale Praktiken zur Wahlbeeinflussung wurden dort von den lokalen Eliten schon immer eingesetzt, jetzt erfuhren sie nur eine gewisse Steigerung (vgl. Lyttelton, Seizure, S. 148).

29 Alalà vom 12. 4. 1924.

30 Memorandum von Viola (wie Anm. 5). 
ler ${ }^{31}$, und auch hier war der lokale PNF unter Ernesto Buttini eindeutig auf der Linie der Provinzialorganisation. Angesichts dieses Szenarios ist recht zweifelhaft, ob alle jene Wähler, die den Namen Viola auf den Stimmzettel schrieben, überhaupt die Lista nazionale gewählt hätten, wenn die Provinz nur durch Ricci und eventuell einen weiteren ricciano repräsentiert gewesen wäre. So läßt sich abschließend feststellen, daß zwei Kandidaten maßgeblich zum großen Wahlerfolg des PNF in der Provinz beigetragen haben, die sich zuvor öffentlich bis aufs Messer bekämpft hatten und deren politische Positionen sich letztlich gegenseitig ausschlossen. Wie zu erwarten gewesen war, zog mit Viola allerdings auch kein partei- und regierungsfrommer Abgeordneter in das römische Parlament ein. Unter dem Eindruck der Matteotti-Krise radikalisierte er seine Positionen nicht zuletzt auch in Auseinandersetzung mit den Verhältnissen in seiner Heimatprovinz, bis er schließlich in den Reihen der Opposition landete.

Die Ermordung des PSU-Führers und Abgeordneten Giacomo Matteotti am 10. Juni 1924 löste in ganz Italien eine Welle des Entsetzens und der Entrüstung aus. Viele liberale fiancheggiatori begannen, sich von Mussolini und dem Faschismus abzuwenden, was sich etwa in der zunehmend kritischeren Haltung ihres wichtigsten Presseorgans, $I l$ Giornale d'Italia, ausdrückte, der auf der Ebene der toskanischen Regionalpresse ein entsprechender Gesinnungswandel beim Nuovo Giornale entsprach. Es ist hier nicht der Ort, auf Einzelheiten dieses Vorgangs auf nationaler Ebene oder gar auf die Frage der persönlichen Mitverantwortung des Duce an dem Mord einzugehen. Tatsache ist, daß Mussolini in der Parlamentssitzung unmittelbar nach dem Verschwinden Matteottis in starke Bedrängnis geriet. $\mathrm{Zu}$ sehr verwiesen die bis dahin bekanntgewordenen Tatumstände auf das unmittelbare Umfeld des Duce. Es ist im Zusammenhang mit der Geschichte der Provinz nicht völlig unerheblich, daß der Carrareser PRI-Abgeordnete Eugenio Chiesa, inzwischen ein kompromißloser Gegner Mussolinis, mit seinem berühmten Zwischenruf im Parlament: „Er schweigt, also ist er Komplize!“, die Krise auslöste ${ }^{32}$. Die Verhältnisse in seinem ehemaligen Wahlkreis, aus dem er seit zwei Jahren praktisch verbannt war ${ }^{33}$, boten aufschlußreiches Anschauungsmaterial dafür, wohin die Methoden des Provinzfaschismus führten, die mit dem Anschlag auf Matteotti und den vorangegegangenen Gewaltaktionen gegen die oppositionellen Abgeordneten Alfredo Misuri und Giovanni Amendola jetzt auch Eingang in die römische Politik gefunden hatten. Es ist symptomatisch, daß Giovanni Marinelli bei der Einrichtung der „faschistischen Tscheka“, die das Verbrechen an Matteotti ausführte, auf die Skrupellosigkeit und das „Know how" des berüchtigten Florentiner Squadrenführers Amerigo Dumini zurückgriff ${ }^{34}$.

${ }^{31}$ Alle Daten ebenda.

32 Zu den Vorgängen im Parlament: Chiesa, Discorsi parlamentari, S. 509 - 512. Zur Matteotti-Krise umfassend De Felice, Mussolini il fascista 1, S. 619 - 730; speziell zum Problem der Verantwortung für das Verbrechen ebenda, S. 621-626. Eine noch ausgewogenere Darstellung und Analyse der Krise bei Lyttelton, Seizure, S. 237 - 268.

${ }^{33}$ Chiesa besaß zwar noch ein Haus in Marina di Carrara, ist dort aber höchstens als Privatmann noch gelegentlich aufgetaucht. Obwohl er 1924 Spitzendandidat des PRI in der Toskana war, verzichtete er von vornherein auf den aussichtslosen Versuch, in der Provinz Wahlkampf zu führen. Die Faschisten hätten sicherlich mit Gewalt reagiert.

34 Siehe hierzu De Felice, Mussolini il fascista 1, S. 619 f. 
Entscheidend ist, daß durch den Matteotti-Mord eine atmosphärische Wende eintrat, die die Regierung Mussolini in ihre bis dahin tiefste Krise stürzte, und daß diese Wende selbst im Zentrum von Riccis Provinzdiktatur gewisse politische Spielräume für die Opposition eröffnete. Als die aus dem römischen Parlament ausgezogenen Oppositionsfraktionen zu einer zehnminütigen Arbeitsniederlegung für den 27. Juni aufriefen, wurde dieser Aufruf in Carrara auf einem Plakat bekanntgemacht, das von den Ortsvereinen des PSU, PSI, PRI und PPI unterschrieben war ${ }^{35}$. Dies war eigentlich ein Bluff, weil es außer Resten der republikanischen Organisation diese Parteien in Carrara gar nicht mehr gab. Alalà höhnte: „Die Entdeckung aller dieser Ortsvereine, von denen niemand weiß, wo sie sich befinden und von wem sie gebildet werden, war nicht wenig überraschend. “36 Doch die Verunsicherung der Carrareser Faschisten war enorm: Sie veröffentlichten ihrerseits ein Plakat, in dem sie der Opposition drohten: „3000 tote Faschisten sollten euch zum Nachdenken bringen. Wir werden ihnen, wenn es notwendig sein sollte, ebensoviele hinzufügen, um eure Revanchegelüste unter einer Lawine von Leichen zu begraben. " ${ }^{\text {"37 }}$ Renato Ricci forderte kaum geschminkt die Illegalisierung der Oppositionsparteien ${ }^{38}$. Faschistische Squadren wurden in die Betriebe abkommandiert, um die Arbeitsniederlegungen zu verhindern, was allerdings nicht durchgängig gelang, weil eine Reihe Unternehmer, den Weisungen der Confindustria folgend, die Aktion unterstützten ${ }^{39}$.

Eine der wichtigsten Folgen der Matteotti-Krise in der Provinz war, daß es der liberalen Organisation endgültig gelang, sich aus der Umklammerung des Faschismus zu befreien. Ende 1923 waren die bedingungslosen Philofaschisten schon aus dem Carrareser Ortsverein ausgetreten ${ }^{40}$, und die neue Führungsmannschaft stand geschlossen hinter ihrem Sekretär Oreste Nori, der immer deutlicher faschismuskritische Positionen bezog. Die Redebeiträge Noris auf den Parteikonferenzen des PLI und die Grundsatzartikel im Giornale di Carrara ließen deutlich erkennen, daß die legge Acerbo und der Verzicht auf eine eigenständige liberale Liste bei den nationalen Wahlen die letzten Kröten gewesen waren, die die Carrareser Organisation gewillt war zu schlucken ${ }^{41}$. Offensichtlich hatte die Gruppe um Nori begriffen, daß nur über eine offensivere Politik auf

35 Veröffentlicht von La Sveglia repubblicana vom 28. 6. 1924, die jetzt für kurze Zeit wieder etwas mutiger wurde. Wortlaut bei Bianchi, Lotte sociali, S. 259.

36 Alalà vom 28.6. 1924.

37 Ebenda.

38 Ebenda.

${ }^{39}$ Il Giornale di Carrara vom 28. 6. 1924.

40 ACS, MI, DGPS 1924, b. 80, f. „Fasci Massa“: Präfekt an Innenministerium vom 18. 12. 1923. Bei diesen handelte es sich um Umberto Ascoli, Achille Attuoni und Angelo Ricci. Mit Einschränkung gilt das auch für Camillo Micheli und Emilio Orsini, die zu diesem Zeitpunkt auch aus der liberalen Vereinigung austraten, aber nicht unbedingt als extreme Philofaschisten anzusprechen sind. Möglicherweise haben hier auch persönliche Querelen eine Rolle gespielt.

${ }^{41}$ Nachdem sich der toskanische Parteitag des PLI dem Willen der Regierung Mussolini, die keine eigene liberale Liste in der Toskana wünschte, gebeugt hatte, verließen die Vertreter von Florenz (Vittorio Fossombroni), Pisa (Andrea Piegaia) und Massa-Carrara (Oreste Nori) unter Protest den Kongreß (Il Giornale di Carrara vom 1. 3. 1924). Zur Opposition der Pisaner Liberalen gegen den „listone“ siehe Nello, Vocazione, S. 649 f. Die "legge Acerbo" charakterisierte Il Giornale di Carrara vom 9. 8. 1924 im nachhinein als „schroff illiberal“. Freilich hatten die politischen Führer der Liberalen in Rom zu ihrem Zustandekommen entscheidend beigetragen (vgl. Sabbatucci, Suicidio, passim). 
nationaler Ebene der sehr bescheiden gewordene eigene Spielraum in der Provinz wieder erweitert werden konnte. Nach dem Matteotti-Mord gehörte der Carrareser PLI zu den liberalen Ortsvereinen, die sich am deutlichsten äußerten: Die Liberalen Carraras erwarteten, so hieß es in der Resolution des Direktoriums, „daß die Regierung aus der Erschütterung und der Entrüstung, die das Land erfaßt hat, die Kraft schöpfe, unerbittlich gegen alle Verantwortlichen des finsteren Verbrechens vorzugehen “, und wünschten inständig, „daß die Italiener aller Parteien [... .] das Wissen um die Pflichten wiedererwerben mögen, die ein zivilisiertes Zusammenleben erfordert, dessen unabdingbare Basis die Toleranz und die Achtung gegenüber allen Ideen und Meinungen sind “42.

Vor allem die am 8. Juli 1924 erlassene Presseverordnung der Mussolini-Regierung, die willkürliche Eingriffe der Exekutive in die Pressefreiheit ermöglichte, brachte die Liberalen auf die Barrikaden ${ }^{43}$. Nach der Zusammenkunft des consiglio nazionale des PNF Anfang August, welche ein Dokument hervorbrachte, das den „formellen Bruch des Faschismus mit dem liberalen Staat ${ }^{\star 44}$ bedeutete, argwöhnten sie nicht zu Unrecht, daß Mussolini, anstatt die „Normalisierung“ voranzutreiben, wie er es unmittelbar nach der Bluttat in beiden Kammern des Parlaments versprochen hatte, immer stärker in das Fahrwasser der Parteiextremisten gerate ${ }^{45}$. Auch in den Frontkämpferorganisationen regte sich Widerspruch. Auf dem Kongreß des Kriegsversehrtenverbandes in Fiume hielt ihr Vorsitzender Carlo Delcroix, der auf der toskanischen Lista nazionale ins Parlament gewählt worden war, eine Ansprache, deren letzte Passage, eine Anrede an Mussolini, gewissermaßen zum Credo der auf Distanz gehenden fiancheggiatori wurde. Wie fast überall in der ihnen nahestehenden Presse wurden Delcroix' warnende Worte in der Trincea und im Giornale di Carrara dokumentiert ${ }^{46}$ :

„Wenn Sie, der Sie sich feierlich vor der Nation dazu verpflichtet haben, den Weg des Gesetzes, den Weg der Eintracht gehen werden, werden alle Kriegsversehrten, alle Italiener mit Ihnen sein. Aber wenn Sie dies nicht tun wollen oder können, so vergessen Sie nicht, daß Italien ein großes Volk ist, das zu jedem Wunder und jeder Kühnheit in der Lage ist, daß alle notwendig sind, aber niemand unersetzbar, und daß die Nation durch ihr Gewissen die Kraft finden wird, nochmals ihre letzte Schlacht zu schlagen, um nochmals ihren letzten Sieg zu erringen."

Ende Juli fand dann der nationale Kongreß der ANC in Assisi statt, auf dem Ettore Viola zum Vorsitzenden der Organisation gewählt wurde. Mit dieser Wahl honorierten die Delegierten seine entscheidende Rolle bei der Herstellung eines internen Konsenses. Die von ihm eingebrachte Resolution vermied eine Zerreißprobe, fand eine große Mehrheit und legte die ANC auf eine kritische Distanz zu Regierung und PNF fest. Der sogenannte Ordine del giorno Viola erlangte historische Bedeutung, weil er eine Absage der über 300000 Mitglieder starken Kriegsteilnehmerorganisation an den Weg in die offene Diktatur markierte. Ganz ähnlich wie Delcroix knüpfte die ANC-Resolution die Unterstützung der Regierung an die Bedingung, daß ihre Tätigkeit auch „wirklich auf das Ziel

42 Il Giornale di Carrara vom 28.6.1924.

${ }^{43}$ Il Giornale di Carrara vom 12., 19. und 26. 8. 1924.

44 Lyttelton, Seizure, S. 254.

45 Il Giornale di Carrara vom 9. 8. 1924.

46 La Trincea vom 12. 7. 1924. Il Giornale di Carrara vom 20. 9. 1924 setzte das Zitat bezeichnenderweise unter einen Bericht über die faschistischen Übergriffe in Carrara nach der Ermordung des PNF-Abgeordneten Armando Casalini, die unter den Augen der Polizei stattfanden. 
gerichtet sei, die gesellschaftliche Eintracht zu sichern, auf der Basis einer absoluten Verdammung der noch anhaltenden Rechtsverletzungen, der ausschließlichen Souveränität des Staates gemäß der Tradition unseres Risorgimento sowie der Erhebung und Förderung der Kräfte der Arbeit in der wiedergeborenen Liebe zum Vaterland “47.

Die Extremisten in Carrara begriffen sofort die Gefahr, die von diesem Beschluß ausging, und legten sich sogleich publizistisch gegen die „Zweideutigkeit“ des combattentismo ins Zeug ${ }^{48}$. Nachdem auch Mussolini den Kongreß der ANC kritisiert hatte, nahmen sie kein Blatt mehr vor den Mund. Die Resolution wurde als „die Krönung der wenig faschistischen, wenn nicht sogar eindeutig antifaschistischen Tätigkeit" gebrandmarkt, die Viola in der Provinz ausgeübt habe ${ }^{49}$. Alalà machte kein Hehl aus seiner Meinung, daß dieser Mann nicht in den PNF gehöre. Doch der Ausschluß von Viola erfolgte noch nicht, obwohl die hierfür formal zuständige Federazione provinciale wohl nichts lieber als das getan hätte. Offensichtlich waren ihr aber von Rom aus noch die Hände gebunden. Für Mussolini war die Zeit für den Bruch mit der ANC-Führung noch nicht gekommen. Zu diesem Zeitpunkt hätte er damit nur die Abspaltung der gemäßigten Abgeordneten von seiner Parlamentsmehrheit riskiert, unter denen, neben den Liberalen, die combattenti die Hauptrolle spielten ${ }^{50}$.

Kurz nach dem ANC-Kongreß von Assisi, dessen Ausgang ein außerordentliches Echo in der politischen Öffentlichkeit hatte, rangen sich die Liberalen Carraras zu einer grundsätzlichen Kritik des Faschismus und der Regierungspolitik durch. In einem schon deutlich pessimistischen, wahrscheinlich von Oreste Nori selbst verfaßten Grundsatzartikel des Giornale di Carrara mit dem bezeichnenden Titel „Il Rubicone“ heißt es:

„Wir waren unter jenen Italienern [. . .], die dachten, daß die Tragödie, die den Namen des sozialistischen Abgeordneten trägt, dem Regierungschef und dem Faschismus den Antrieb und die Kraft verleihen würde [...], die Verantwortung für das Verbrechen eindeutig zu klären, sich endgültig von allen extremistischen und intransigenten Kräften ihrer Partei zu trennen, die Provinzherrschaften der Ras (il rassismo provinciale) niederzuschlagen, ohne ihnen eine Chance zur Wiedergeburt zu lassen. [... Doch die Hoffnungen] sinken angesichts der Schläge der illegalen Verordnungen zur Einschränkung der Pressefreiheit, die kein Liberaler aus der Schule von Camillo Cavour jemals unterschreiben kann. Sie sinken mit der alltäglichen Wahrnehmung von Verletzungen der verfassungsmäßigen Freiheiten, in erster Linie der Versammlungsfreiheit. Sie fallen mit der Enttäuschung über die ausgebliebene Konstitutionalisierung der Miliz, die auf gefährliche und zweideutige Weise dem Ministerpräsidenten unterstellt bleibt, anstatt sich mit den anderen staatlichen Institutionen zu verzahnen. Sie sinken angesichts der erneut verkündeten Konzeption des ,Stato-partito', welche auf unverzeihliche Weise die Zusammenführung und Befriedung aller Italiener verhindert, die sich im Namen des Vaterlandes wiederversöhnt haben. "51

Der Artikel schließt mit der ultimativen Forderung an den Duce, sich von den „Vorstellungen und Vorsätzen des Abgeordneten Farinacci und seiner Freunde" deutlich zu distanzieren. „Andernfalls, darüber gibt es zumindest für die Liberalen keinen Zweifel, wird der Rubikon überschritten werden." Nachdem die Liberalen Carraras durch ihr Schweigen zu den alltäglichen Rechtsverletzungen, durch Vertuschung und Verharmlo-

\footnotetext{
47 Wortlaut bei De Felice, Mussolini il fascista 1, S. 660; zum ANC-Kongreß von Assisi: Sabbatucci, Combattenti, S. 370 f.; Viola, Combattenti, S. 13-18.

48 Alalà vom 2. 8. 1924.

49 Alalà vom 9.8. 1924.

${ }^{50}$ Hierzu sehr prägnant Lytteiton, Seizure, S. 254.

${ }^{51}$ Il Giornale di Carrara vom 9. 8. 1924.
} 
sung der faschistischen Übergriffe, durch politische Flankierung der spedizioni und manchmal sogar durch tatkrättige Teilnahme an den Gewaltaktionen in den Jahren 1921/22 und zum Teil noch 1923 den Status quo mit herbeigeführt hatten, nachdem sie die Resultate des „Marsches auf Rom“ befürwortet und die Regierungstätigkeit Mussolinis auch in den Punkten mitgetragen hatten, die eindeutig auf eine Überwindung des liberalen Rechtstaates hinausliefen ${ }^{52}$, besannen sie sich jetzt, die eigene politische Ausschaltung vor Augen, auf ihre Traditionen. Alalà ließ es sich nicht nehmen, spöttisch darauf aufmerksam zu machen, daß die Liberalen den Rubikon in die andere Richtung schon einmal überschritten hätten, als sie „den Geist des Risorgimento “ und „die geheiligten liberalen Prinzipien [...] am Ufer zurückgelassen haben, indem sie anerkannten [...], daß diese wesentlich weniger wirksam waren als der heilige Schlagstock (il Santo Manganello) “. Der „Ein Ex-Liberaler" gezeichnete Artikel endet mit dem vielsagenden Satz: "Cavour ist tot, Mussolini lebt. ${ }^{53}$ Die Faschisten Carraras, unter denen sich ja nicht wenige ehemalige Liberale befanden, hatten keine Veranlassung, sich vom örtlichen PLI Lektionen erteilen zu lassen. Hier in der Provinz war jene politische Bedeutungslosigkeit des Liberalismus nahezu schon erreicht, die es aus der Sicht der intransigenti auf nationaler Ebene noch zu bewerkstelligen galt.

Trotz der Absatzbewegungen der gemäßigten fiancheggiatori hat die Matteotti-Krise die Extremisten des faschistischen Provinzverbands von Massa-Carrara nicht geschwächt. Auf der Zusammenkunft des consiglio nazionale Anfang August 1924 wurde Ricci in das nationale Direktorium des PNF gewählt und gehörte damit dem obersten Führungsgremium des Faschismus an. Damit wurde indirekt auch seine Stellung in der Provinz gestärkt. Die ricciani lenkten systematisch den Lokalpatriotismus auf ihre Mühlen, indem sie den Ruhm, der ihrem Führer im fernen Rom zuteil wurde, wortreich herausstrichen ${ }^{54}$. Daß sich der ehemals einflußreichste Teil der liberalen Elite jetzt öffentlich und lautstark vom Faschismus, so wie die ricciani ihn verstanden, absetzte, hat ihm bei der einfachen Bevölkerung wohl kaum Popularität gekostet. Im Gegenteil, es ist anzunehmen, daß dies den Populismus des Ras glaubwürdiger machte. Die führenden Marmorunternehmer und die mit ihnen eng verbundene liberale Führungsgruppe waren bei den Marmorarbeitern nie besonders beliebt gewesen, und wenn der Arbeitersohn Ricci den Konflikt mit ihnen suchte, waren ihre Sympathien wohl eher auf seiner Seite. Die Erinnerung an seine Rolle bei der gewaltsamen Zerstörung der Arbeiterorganisationen in den Jahren 1921/22 konnte wohl so von manchen verdrängt werden. Offensichtlich waren Ideologie und Politik des "Marmorfaschismus“, so wie sie sich 1923 herausgebildet hatten, auch unter den veränderten Bedingungen des Jahres 1924 noch in der Lage, seine regionale Hegemonie zu sichern. Das Scheitern seiner korporativen Pläne hatte hier keine grundlegende Veränderung bewirkt.

In der Führungsgruppe des PNF von Carrara gab es allerdings einige auffällige Verschiebungen. Im Dezember des Jahres 1923 wurde der Unternehmer und Chemiker Dario Orlandi, Schwiegersohn des ricciano und Marmormagnaten Guido Murray Fabbricotti, zum Sekretär der Ortsgruppe gewählt, ein Mann, der bis dahin in der Organisati-

\footnotetext{
52 Hier sind vor allem die Einrichtung der MVSN und die "legge Acerbo“ zu nennen.

53 "Ai liberali che vogliono passare il Rubicone" in Alalà vom 16.8.1924.

54 Siehe Alalà vom 9. 8. 1924.
} 
on praktisch keine Rolle gespielt hatte ${ }^{55}$. Vizesekretär wurde der Arzt Amerigo Gianfranchi, der nur als Provinzsekretär der Corporazione sanità in Erscheinung getreten war ${ }^{56}$. Beide waren weder ehemalige Kriegsteilnehmer noch squadristi und hatten sich auch sonst in der Kampfzeit in erkennbarer Weise nicht verdient gemach $t^{57}$. Unter den neun weiteren Mitgliedern des örtlichen PNF-Direktoriums waren nur noch drei alte Squadrenführer: Oreste Giorgi, Luciano Bacciola und Italo Barattini ${ }^{58}$. Dafür befand sich unter ihnen der ehemalige Sozialist Arturo Giampaoli, dessen Aufstieg erst zum Weingroßhändler und später zum führenden Privatbankier Carraras zu den erstaunlichsten Karrieren gehört, die in Carrara in der Zeit um den Ersten Weltkrieg zu verzeichnen $\operatorname{sind}^{59}$. Es ist unverkennbar, daß sich in der faschistischen Führungsgruppe einige sozial erfolgreiche Newcomer breitmachten, die sich nicht durch ihre Verdienste als nalte Kämpfer" legitimieren konnten. Besonders auffällig ist hierbei die Karriere von Orlandi, dessen Eintritt in die faschistische Organisation wohl sehr spät erfolgte; seine Personalakten verschweigen das Datum jedenfalls ${ }^{60}$. Schon im Mai 1924 wurde er Nachfolger von Ricci als Sekretär der Provinzorganisation und übte dieses Amt als treuer und geschickter Statthalter des Ras bis 1929 aus.

Symptomatisch für die zunehmende „Professionalisierung“ des lokalen faschistischen Führungspersonals ist auch die endgültige Ausbootung des "alten Kämpfers" und "enfant terrible" des Fascio von Carrara, Giuseppe Aloisi, der, wie dargestellt, entscheidenden Anteil an den innerparteilichen Wirren des Jahres 1923 gehabt hatte ${ }^{61}$. Seine Verfehlungen während der Dissidenten-Krise waren in Rom so stark registriert worden, daß er für ein führendes Parteiamt nicht mehr in Frage kam, obwohl er weiterhin zu den Vertrauten Riccis gehörte ${ }^{62}$. Er behielt auch zunächst noch sein Amt als assessore comunale und löste in dieser Funktion einen internen Konflikt in der faschistischen Gemeindeverwaltung aus, an dem deutliche Analogien zu denen von 1923 erkennbar sind. Der Vorgang soll hier ausführlich geschildert werden, weil er Einblicke in das veränderte interne Kräfteverhältnis und die gewandelte Atmosphäre in der Führungsgruppe des apuanischen Faschismus erlaubt.

Die Auseinandersetzung entzündete sich an Aloisis Projekt zur Einrichtung einer kommunalen Berufsfeuerwehr, die wohl als eine weitere Pfründe für die „alten Kämpfer" gedacht war, aber wegen ihrer Kostspieligkeit in Stadtrat und Gemeindeverwaltung auf Widerspruch stieß. Wortführer der Gegner des Projektes war Ferdinando Pellini, der 1923 zu den entschiedenen ricciani gehört hatte, als Arzt aber - auch das ist eine Analogie zu 1923 - zu den sozial Arrivierten in der faschistischen Organisation gehörte. Mit einer beherzten Stellungnahme vereitelte er im Gemeinderat die von der Aloisi-Gruppe

\footnotetext{
${ }^{55}$ Zur Wahl des neuen Direktoriums siehe Alalà vom 8. 12. 1923.

56 Alalà vom 14. 7. 1923.

57 Das betont Viola in seinem Memorandum ohne Datum (Mai 1924); ACS, MI, Gabinetto Finzi, b. 12, f. 145. Für Dario Orlandi auch Missori, PNF, S. 250.

58 Wie Anm. 55.

59 Zu Giampaolis Wirken als Sozialist vor dem Ersten Weltkrieg siehe Mori, Lunigiana, S. 226 und 229 sowie Gestri, Capitalismo, S. 222, 235 und 274. Zu seinem Werdegang außerdem ACS, MI, CPC, b. 2383, f. "Arturo Giampaoli“.

${ }_{60}$ Missori, PNF, S. 250.

${ }^{61}$ Siehe oben, S. 229-231.

62 Siehe das Memorandum von Viola ohne Datum (Mai 1924), wie Anm. 57.
} 
geplante handstreichartige Verabschiedung des Projekts ${ }^{63}$. Es kam zu Tumulten, und Luciano Bacciola, der Wortführer der "alten Kämpfer“, stieß heftige Beleidigungen gegen Pellini aus, die später noch ein gerichtliches Nachspiel hatten. Auch diesmal versuchte die Gruppe um Aloisi und Bacciola wieder, sich bei Ricci Rückendeckung zu verschaffen und den Widerstand gegen ihre Pläne als Machenschaften gegen den Ras zu brandmarken, doch diesmal funktionierte ihre Strategie nicht. Ricci versagte ihnen die Unterstützung, der Bürgermeister Adolfo Angeli schlug sich auf die Seite ihrer Gegner, und der zum Störenfried gestempelte Aloisi mußte sein Amt niederlegen ${ }^{64}$. Offensichtlich war der Ras nicht bereit, eine Neuauflage der Ereignisse von 1923 zu riskieren, die unter den Bedingungen der Matteotti-Krise unabsehbare Folgen nach sich ziehen konnte. Außerdem war seine Stellung mittlerweile so gefestigt und den kleinen lokalen Affären enthoben, daß die Anliegen seiner nicht ganz uneigennützigen Freunde in Carrara ihn nicht mehr aus der Reserve locken konnten, zumal ihm nicht entgangen sein dürfte, daß die Amtsführung seines alten Kampfgefährten sich nicht gerade durch Kompetenz und Verantwortungsbewußtsein auszeichnete. Es ist anzunehmen, daß der Giornale di Carrara vor allem Giuseppe Aloisi im Visier hatte, als er feststellte, der Faschismus habe den Kommunalverwaltungen die „letzten Nullen der Bürgerschaft ${ }^{\star}$ beschert $^{65}$.

Der Aufstieg von Männern wie Orlandi, Gianfranchi und Giampaoli und der politische Niedergang der Gruppe der alten Squadrenführer verweist darauf, daß auch Ricci jetzt der Meinung war, daß der Provinzfaschismus „Köpfe“ brauche, wie Bernardo Pocherra in der Auseinandersetzung von 1923 schon beton hatte ${ }^{66}$. Es ist in diesem Zusammenhang nicht uninteressant, daß es die aus dem PNF ausgeschlossenen Dissidenten Pocherra und Luigi Da Pozzo in der späteren Regimezeit zum Federale der Provinz Apuania brachten, aber kein einziger aus der Gruppe der Squadrenführer der ersten Stunde, die in den Auseinandersetzungen von 1923 das Rückgrat der ricciani gebildet hatten, je in dieses Amt einrückte ${ }^{67}$. Der vom Faschismus in der Provinz bewirkte Elitenwechsel vollzog sich also längerfristig nicht unbedingt zugunsten der ehemaligen Protagonisten des Squadrismus. Statt dessen drängten wendige Aufsteiger und gutbürgerliche Pragmatiker ohne ausgesprochene militante Meriten mehr und mehr nach vorne.

In den Führungsgremien der Syndikate hatten ehemalige squadristi schon von Anfang an kaum eine Rolle gespielt. Keiner der Sekretäre der mittleren und unteren Ebene war zuvor in den Squadren oder in der politischen Organisation der Fasci stärker hervorgetreten. Eher noch war der umgekehrte Weg möglich, wie der Fall von Gianfranchi zeigt. Das Provinzdirektorium der Syndikate von 1924 war, soweit man ihre Herkunft erkennen kann, mit Männern besetzt, die unmittelbar aus der Gewerkschaftsarbeit stammten. Als einziger Pionier aus der Gründungszeit der Camera carrarese dei sindacati economici im September 1922 befand sich der tecnico segherie Alfonso Fazzi unter ihnen ${ }^{68}$. Die meisten anderen stammten aus der Aufbauphase der faschistischen Gewerkschafts-

${ }^{63}$ Siehe hierzu Alalà vom 23. und 30. 8. 1924 und Il Giornale di Carrara vom 6. 9. 1924.

${ }^{64}$ Ebenda. Allerdings wurde kurz darauf Ferdinando Pellini wegen „indisciplina“ aus dem PNF ausgeschlossen (Alalà vom 13. 9.1924).

65 Il Giornale di Carrara vom 9. 8. 1924.

66 Vgl. oben, S. 227.

${ }^{67}$ Missori, PNF, S. 94.

68 Alalà vom 28.6. 1924. 
organisation in der ersten Hälfte des Jahres 1923. Zu nennen wären hier vor allem Gino Permalosi, einer der Initiatoren der Corporazione magistrale, des Lehrerverbands, und Andrea Frediani, der Gründer der faschistischen Angestelltenorganisation ${ }^{69}$. Das gleiche gilt für Alessandro Dell'Amico, den Sekretär der segatori-Gewerkschaft ${ }^{70}$. Der (Noch-)Liberale Alfredo Bizzarri, ein weiteres Mitglied des Provinzialdirektoriums, personifizierte in seiner Funktion als Sekretär der Corporazione della stampa die Kontinuität zur alten Journalistenvereinigung ${ }^{71}$. Bei den Steinbrucharbeitern und lizzatori zeigte sich sogar noch die personelle Kontinuität zu den alten Ligen der anarchosyndikalistischen Camera del lavoro. Diese wurden im Syndikatsdirektorium nach wie vor durch ihre alten Sekretäre Ercole Cargioli und Antonio Zanichelli vertreten, die mittlerweile allerdings dem PNF angehörten ${ }^{72}$.

Nur als Generalsekretäre der Provinzsyndikate wirkten ehemalige Squadrenführer aus der politischen Führungsgruppe des lokalen Faschismus. Als solcher ist ohne Einschränkungen Claudio Papini anzusehen, der Fascio-Gründer von Pietrasanta, der bis Januar 1924 Generalsekretär der Federazione provinciale sindacale war, bis er vom Leiter des nationalen Dachverbands, Edmondo Rossoni, in die Zentralverwaltung nach Rom berufen wurde ${ }^{73}$. Es ist bezeichnend, daß Renato Ricci daraufhin wieder persönlich in diese Position einrückte und sie auch beibehielt, als er im Mai das PNF-Provinzsekretariat an Orlandi abgab und im August in das nationale PNF-Direktorium gewählt wurde. Dies zeigt, welchen Stellenwert die Syndikate für ihn hatten. Als seinen Stellvertreter ernannte er den Rechtsanwalt Mario Prantoni, den Fascio-Mitbegründer von Castelnuovo Garfagnana ${ }^{74}$. Prantoni kann man nicht ohne große Einschränkungen als ehemaligen Squadrenführer bezeichnen, denn der Schwerpunkt seiner Tätigkeit in der Garfagnana lag schon im Sommer/Herbst 1922 nicht im Squadrismus, sondern, wie bereits dargestellt, in der Gewerkschaftsarbeit ${ }^{75}$. Der „Syndikalist“ und ricciano Prantoni hatte gegen die konservative Elite in der Garfagnana einen schweren Stand. Ihr war der autoritäre Populismus der PNF-Provinzorganisation nicht geheuer, und dies war für sie ein Grund mehr, die Abspaltung der Region von Massa-Carrara und den Anschluß

69 Das erste Auftauchen des Namens von Gino Permalosi als Sekretär des Sindacato magistrale von Carrara in Alalà vom 21. 2. 1923. Frediani war der erste Provinzsekretär der Corporazione dell'impiego (Alalà vom 14.7. 1923).

70 Dell'Amico wird im August 1924 als Provinzsekretär des Sindacato operai segatori a macchina genannt (Alalà vom 18. 8. 1924). Ein früheres Wirken oder gar die Herkunft aus der Führungsgruppe einer alten Marmorsägewerksarbeiterliga ist nicht zu belegen, aber auch nicht auszuschließen.

71 Alalà vom 14. 7. 1924. Zum journalistischen Werdegang von Alfredo Bizzarri, der zu dieser Zeit noch Liberaler und leitender Redakteur von Il Giornale di Carrara war, später aber zu Il Popolo apuano, dem Nachfolgeorgan von Alalà, überwechselte, siehe Bertozzi, Stampa, S. 35, 140, $164,174,245$.

72 Zum Eintritt von Zanichelli und Cargioli in die faschistische Gewerkschaftsorganisation siehe S. 184 und S. 223. Daß sie jetzt Mitglieder des PNF waren, ist angesichts ihrer Stellung als zwangsläufig anzusehen und wird auch durch ihre Mitgliedschaft im faschistischen Wahlkomitee belegt (Alalà vom 3. 3.1924, „Supplemento“ Nr. 9).

73 Alalà vom 9. 2. 1924.

74 ACS, MI, DGPS 1922, b. 101 bis, f. „Costituzione fasci Massa": Präfekt an Innenministerium vom 23. 8. 1922.

75 Vgl. oben, S. $219 f$. 
an Lucca zu betreiben ${ }^{76}$. Als ihre Wünsche dann Ende 1923 in Erfüllung gingen, mußte Prantoni nach Carrara ins "Exil“ gehen. Der sozialkonservative Ras von Lucca, Carlo Scorza, hatte keine Verwendung für diesen Mann, der sich die Anliegen der Arbeiter in den Marmorsteinbrüchen der „Società Nord Carrara“ von Gorfigliano/Minucciano zu eigen gemacht hatte, anstatt sie auf die übliche Weise zu „befrieden" $"$.

Es muß hier offenbleiben, welche Rolle die wirtschaftliche Macht und der politische Einfluß unternehmerischer Kreise bei der Vereitelung der Träume Riccis von der Bildung einer „Marmorprovinz“ unter Einschluß der Versilia lucchese gespielt haben. Daß nicht nur die Pläne zum Anschluß der Versilia, sondern sogar der Kampf um den Verbleib der Garfagnana bei Massa-Carrara scheiterten, und so ein wichtiges Marmorabbaugebiet der Zuständigkeit des Carrareser Syndikalismus entzogen wurde, läßt die Vermutung als nicht abwegig erscheinen, daß hier eine Einflußnahme des Montecatini-Chefs Guido Donegani stattgefunden hat, welcher einen guten Draht zu Mussolini besaß und zu seinen wichtigsten Verbündeten innerhalb der Confindustria gehörte. Die krasse Unvereinbarkeit der ausgesprochen aggressiven Tarifpolitik des Montecatini-Marmorunternehmens „Nord Carrara“ mit Riccis syndikalistischer Politik, die eine Angleichung der Tarifbedingungen in der apuanischen Marmorindustrie auf einem hohen Niveau anvisierte, ist jedenfalls offenkundig ${ }^{78}$.

Die politischen Hintergründe der Rivalität zwischen den Ras Ricci und Scorza und das „Exildasein“ der beiden prominenten „Syndikalisten“ aus der Provinz Lucca, Papini und Prantoni, an der Spitze der apuanischen Gewerkschaftsorganisation werfen ein klares Licht auf den spezifischen Charakter dieses Provinzfaschismus. Kaum einer der unterschiedlichen Provinzfaschismen war im Jahr 1924 so klar syndikalistisch orientiert wie der von Carrara. Diese Tendenz, die sich schon in den Jahren 1922/23 herausgebildet hatte, verstärkte sich in der Matteotti-Krise noch merklich. Für die Verantwortlichen des apuanischen Faschismus war spätestens im August 1924, nach der Versammlung des consiglio nazionale, der radikale und endgültige Bruch mit dem Liberalismus eine ausgemachte Sache. Alalà veröffentlichte wenig später einen aufschlußreichen Artikel des Vizesekretärs der faschistischen Confederazione delle corporazioni sindacali, Armando Casalini, der den „antiliberalen“ Geist des Kongresses und den „unzweideutigen Willen

${ }^{76}$ Dieser Gegensatz äußerte sich vor allem in den Konflikten zwischen dem "fiduciario circondariale" des PNF Prantoni als Anführer der Radikalen einerseits und dem Bürgermeister von Castelnuovo Giuseppe Bernardini sowie dem Fascio-Mitbegründer und lokalen ANC-Vorsitzenden Almiro Zerbini, die beide aus der Partei ausgeschlossen wurden, andererseits. Dokumente dazu in ACS, MI, DGPS 1923, b. 91, f. „Fasci Massa“, sf. „Castelnuovo“, vor allem: Präfekt an Innenministerium vom 17. 9. 1923.

77 Im Sommer/Herbst 1923, unmittelbar vor der Abtrennung der Garfagnana, kam es wieder zu heftigen Tarifauseinandersetzungen in den Steinbrüchen der „Nord-Carrara S. A. “, bei denen die Arbeitgeberseite unerhört hart und kompromißlos vorging. Die Absicht der Provinzorganisation der Syndikate unter Claudio Papini, die dortigen ungünstigen Tarifbedingungen an die von Carrara und Massa anzunähern, scheiterte auf der ganzen Linie, nachdem die „Nord Carrara S. A." die Entlassung streikender Arbeiter angedroht und diese Drohung teilweise auch wahrgemacht hatte. Nirgendwo in der Marmorregion ist der Wille der Unternehmerseite, das faktische Verbot jeglicher gewerkschaftlicher Tätigkeit durchzusetzen, ungeschminkter erkennbar als bei dieser Firma. Akten hierzu: ACS, MI, DGPS 1923, b. 57, f. „Ordine pubblico Massa", sf. „Varia“: Präfekt an Innenministerium vom 20. 7. bis 16.11.1923.

${ }^{78}$ Hinweise auf die Rolle von Donegani bei Lyttelton, Seizure, S. 257 und Snowden, Fascist Revolution, S. 115 f., 125 f., 148 f. 
des Faschismus, das revolutionäre Faktum rechtlich, das heißt institutionell umzusetzen", herausstellte. Der faschistische Syndikalismus mache sich "die gerechtfertigten Bestrebungen“ der Arbeitenden zu eigen, „nicht um den Staat zu zersetzen, sondern um ihn zu stärken. [...] Wenn der Liberalismus also - wie die Erfahrung lehrt - Anarchie, Rebellion und Elend bedeutet, so ist der Faschismus Größe und Wohlstand “, fährt Casalini fort und weist, ganz im Sinne des Vordenkers der ,revolutionären" Strömung im Faschismus, Curzio Suckert (Malaparte), den Provinzen im Prozeß der Faschisierung des Staates die Rolle des vorwärtstreibenden Elementes $\mathbf{z u}^{79}$.

Angesichts der gegebenen Konstellation auf lokaler und nationaler Ebene und der politischen Orientierung des apuanischen Faschismus ist es nur konsequent, daß Ricci im Spätsommer 1924 wieder eine Offensive in der Tarif- und Sozialpolitik startete. Ein Erfolg in diesem Bereich war nach der Loslösung der liberalen fiancheggiatori besonders wichtig. Der apuanische Faschismus mußte jetzt seine Verankerung in der Arbeiterschaft festigen und weiter ausbauen. Der Ras mußte dabei berücksichtigen, daß die Preise seit der Jahresmitte 1923 nach einer deflationären Atempause wieder angezogen hatten. Im zweiten Halbjahr 1924 beschleunigte sich die Teuerung und überschritt im November wieder die Zehn-Prozent-Marke.

Entwicklung der Lebenshaltungskosten in Carrara (im Verhältnis zum gleichen Monat des Vorjahres) $)^{80}$

\begin{tabular}{lrr}
\hline Januar & 1923 & $-3,7 \%$ \\
Januar & 1924 & $5,1 \%$ \\
Juli & 1924 & $4,8 \%$ \\
August & 1924 & $5,3 \%$ \\
September & 1924 & $5,7 \%$ \\
Oktober & 1924 & $6,6 \%$ \\
November & 1924 & $11,0 \%$ \\
\hline
\end{tabular}

Der sprunghafte Preisanstieg machte sich in Carrara insofern besonders bemerkbar, als das Preisniveau bei den Grundnahrungsmitteln hier ohnehin traditionell sehr hoch lag ${ }^{81}$. Dieser Umstand läßt sich wohl mit der geringen Leistungsfähigkeit der Landwirtschaft im unmittelbaren Umland und der Unterentwicklung des Konsumgenossenschaftswesens erklären ${ }^{82}$. Einen gewissen Einfluß wird dabei aber auch das relativ hohe Lohnniveau gehabt haben.

79 Alalà vom 23. 8. 1924.

${ }^{80}$ In prozentuale Steigerungsraten umgerechnete Zahlen aus Il Giornale di Carrara vom 6. 12. 1924.

81 Alalà vom 23. 8. 1924. Hier vergleicht Athos Poli die Preise in Carrara mit denen von Pisa, La Spezia und Massa und kommt zu dem Schluß, daß das hohe Preisniveau durch Spekulation bedingt sei.

82 Dies lag an der Ablehnung des Konsumgenossenschaftswesens durch die anarchosyndikalistische Führung der alten Camera del lavoro. Es gab zwar, vor allem in den „frazioni“, einige hauptsächlich auf Initiative der Republikaner zurückgehende Konsumgenossenschaften (Notizie statistiche 1922, S. 79 f.), diese scheinen aber weder besonders groß noch besonders effektiv gewesen zu sein. Als bedeutendste unter ihnen sind die 19201000 Mitglieder zählende Fratellanza cooperativa repubblicana in Carrara (Stadt) und eine an den "Circolo Bovio" von Avenza angeschlossene Genossenschaft anzusehen (ASM, Questura Massa, b. 11, 12, entsprechende Faszikel). 
Der hier angesprochene Sachverhalt spielte eine große Rolle bei den Tarifverhandlungen, die Prantoni Anfang September 1924 einleitete. Es gibt verschiedene Hinweise darauf, daß die Basis der Marmorarbeitergewerkschaften Lohnerhöhungen anstrebte, die auf einen vollständigen Inflationsausgleich hinauslaufen sollten, was ihr nach den immer noch geltenden Regelungen des Tarifvertrags von 1920 auch zustand. Das hätte Lohnsteigerungen von mindestens zehn Prozent bedeutet, denn die seit der letzten Lohnanpassung im Frühjahr 1923 erfolgte Teuerung betrug zu diesem Zeitpunkt schon fast zwölf Prozent. Eine Lohnerhöhung dieses Ausmaßes lehnten die Unternehmer mit dem Hinweis auf die prekäre Absatzlage kategorisch ab. Die faschistisch geführten Vereinigungen der produttori, esercenti segherie und esercenti laboratori unterbreiteten statt dessen den Vorschlag, den Aufgabenbereich des Istituto di prevvidenza e assistenza operaia auch auf die „Bekämpfung der Teuerung“ zu erweitern. Obwohl man sich auf die Mittel hierzu noch nicht festlegen wollte, lief dies auf die Einrichtung einer großen, von den Unternehmern finanzierten Konsumgenossenschaft hinaus, ein Projekt, das der Industriellenverband 1919 vergeblich schon der alten Camera del lavoro vorgeschlagen hatte ${ }^{83}$.

Am 10. September 1924 einigte sich die Gewerkschaftsleitung mit den Führungsgremien der drei genannten Vereinigungen auf die Finanzierung des Projekts durch Abgaben der Betriebe in der Höhe von fünf Prozent der Lohnsumme ${ }^{84}$. Man hoffte mit dieser Maßnahme, die die Betriebe wesentlich weniger belastet hätte, den gleichen Effekt zu erreichen wie mit einem Lohnausgleich direkt in der Lohntüte. Wie dies ohne die Schädigung der Händler vonstatten gehen sollte, blieb unklar. Hier liegt auch der Grund für das Zögern der Faschisten bei der Konkretisierung des Projekts. Wie schon an anderer Stelle deutlich geworden ist, waren die Kaufleute zwar keine besondere Klientel des Carrareser Faschismus, aber ganz zu ihren Lasten wollte man das Problem wohl doch nicht lösen, zumal zu erwarten war, daß die liberal-konservativen Gegner daraus politisches Kapital schlagen würden ${ }^{85}$.

Dieses Dilemma lösen zu müssen, blieb den Faschisten allerdings erspart, denn das Abkommen wurde von der Associazione esportatori, der vierten und wichtigsten Unternehmervereinigung, einfach ignoriert. Die Gewerkschaftsführung hatte sich Verhandlungen mit den von Carlo Andrea Fabbricotti geführten Exporteuren mit der Begründung entzogen, sie seien als solche von den Abmachungen nicht tangiert ${ }^{86}$. Da aber die sogenannten esportatori gleichzeitig die wichtigsten Steinbruchbetreiber waren, zusätzlich auch noch zahlreiche Marmorsägewerke besaßen und so ein gutes Drittel aller Mar-

83 Die Camera del lavoro hatte das Projekt damals abgelehnt, obwohl die Leitung der Genossenschaft ganz in ihren Händen liegen sollte (Rückblick in Il Cavatore vom 15. 4. 1922). Das Projekt war federführend von Adolfo Corsi ausgearbeitet worden (Alalà vom 13. 9. 1924), der jetzt zu den Gegnern des Abkommens mit den faschistischen Gewerkschaften gehörte.

84 Wortlaut des Abkommens in Alalà vom 13. 9. 1924.

${ }^{85}$ Das Problem wird ganz offen ausgesprochen (ebenda). Die Interessen der Händler wurden eigentlich vom faschistischen Sindacato del commercio vertreten. Die Art allerdings, wie Il Giornale di Carrara vom 9. 8. 1922 für die Kaufleute in die Bresche springt, zeigt ziemlich unmißverständlich, daß es sich hier eher um eine Klientel der Liberalen handelte.

${ }^{86}$ Diese Argumentation ist wiedergegeben im Bericht des Präfekten an das Innenministerium vom 26. 9. 1924 (ACS, MI, DGPS 1925, b. 81, f. „Ordine pubblico Massa“). 
morarbeiter Carraras beschäftigten ${ }^{87}$, war das Abkommen vom 10. September nicht das Papier wert, auf dem es geschrieben stand.

Hatten die Faschisten geglaubt, die gegnerische Großunternehmergruppe um Carlo Andrea Fabbricotti austricksen zu können, so waren sie einer völligen Fehleinschätzung erlegen. Diese ließ sich durch die Zustimmung der anderen Unternehmerorganisationen überhaupt nicht in Zugzwang bringen. Sie zeigte den Faschisten die kalte Schulter und weigerte sich, überhaupt in Verhandlungen einzutreten. Die Associazione esportatori hatte aus den Ereignissen des Jahres 1923 gelernt und ihr Mandat, Tarifverhandlungen zu führen, an die Confindustria abgetreten ${ }^{88}$, womit sie offensichtlich beabsichtigte, sich lokalen Pressionen zu entziehen und die faschistische Mehrheit unter den lokalen Unternehmern auszumanövrieren. Die Confindustria ihrerseits tat alles, um die Tarifauseinandersetzung zu verschleppen, da sie sich nicht offen gegen die Mehrheit der lokalen Unternehmer stellen konnte. Wie sich später allerdings unmißverständlich zeigen sollte, stand sie bedingungslos auf der Seite der esportatori.

Als fast vier Wochen verstrichen waren, ohne daß es zu Verhandlungen gekommen war, unternahm Bürgermeister Angeli doch noch einen Versuch, zu einer lokalen Lösung des Konflikts zu kommen, indem er alle Unternehmer zu Verhandlungen ins Rathaus bat. Die Vertreter der „Exporteure“ erschienen erst gar nicht und verwiesen wieder nur lakonisch auf das Verhandlungsmandat der Confindustria ${ }^{89}$. Wenig später ließen sie die Katze allerdings aus dem Sack: Sie beschieden Prantoni, daß sie zu Lohnerhöhungen oder zu Regelungen, die auf anderem Wege zu einer Erhöhung der Lohnkosten führen würden, nicht bereit seien ${ }^{90}$. Als Vorschlag zur Verminderung des Preisniveaus gruben sie ein Verfahren aus dem 19. Jahrhundert wieder aus, das die En-bloc-Abrechnung der von den Arbeitern erstandenen Waren mit den Einzelhändlern durch die Arbeitgeber im Austausch gegen Preisreduktionen zwischen fünf und 20 Prozent vorsah ${ }^{91}$. Dieser Vorschlag war insofern recht geschickt, als er nicht nur den unmittelbaren Interessen der Unternehmer entsprach, sondern auch geeignet war, die Händler, über denen das Damoklesschwert der großen Konsumgenossenschaft schwebte, auf ihre Seite zu bringen. Die faschistischen Gewerkschaften waren dagegen von diesem Projekt überhaupt nicht angetan. Als sich erste Gerüchte über das Vorhaben der esportatori verbreitet hatten, geißelte es Alalà als „Exhumierung eines Sklavenhaltersystems“, das die Arbeiter „wie zu den Zeiten unserer Großeltern“ in den Genuß „aller Abfälle der Lagerhäuser, aller verdorbenen Überreste der Militärlieferungen" brächte"

Es half Renato Ricci wenig, daß es ihm gelang, nicht nur die Unterstützung von Rossoni, sondern auch die Solidarität des nationalen PNF-Direktoriums zu erlangen ${ }^{93}$. Sei-

${ }^{87}$ Nach einer Aufstellung von Ricci vom 9. 11.1924 gab es in Carrara 8800 Marmorarbeiter (ASM, Commissariato Carrara, b. 61, f. „Agitazione lavoratori marmo“). Circa 3000 davon waren nach Angaben des Präfekten vom 11. 10.1924 bei den sog. ,esportatori“ beschäftigt (ACS, MI, DGPS 1925 , b. 81, f. "Ordine pubblico Massa“).

88 Wie Anm. 86.

89 ACS, MI, DGPS 1925, b. 81, f. „Ordine pubblico Massa“: Präfekt an Innenministerium vom 7. 10. 1924.

90 Ebenda: Präfekt an Innenministerium vom 15. 10. 1924.

91 Ebenda.

92 Alalà vom 4. 10. 1924.

93 Ebenda und ACS, MI, DGPS 1925, b. 81,f. „Ordine pubblico Massa“: Confederazione delle corporazioni fasciste an Innenministerium vom 14. 10. 1924. 
ne Gegner im Unternehmerlager blieben selbstbewußt und kompromißlos. Als er sie unter Druck setzen wollte, indem er kurzfristig eine Kundgebung für den 20. Oktober 1924 ansetzte, bei der er entweder eine Einigung oder die Kündigung des Abkommens vom 10. September und die Einleitung von Kampfmaßnahmen zu verkünden gedachte, ließen sich die Führer der Exporteure überhaupt nicht beeindrucken. Dem Ras, der sie zu einer eiligen Zusammenkunft gebeten hatte, wurde Bescheid gegeben, dies sei leider erst nach der Kundgebung möglich ${ }^{94}$. Dieser Affront macht deutlich, daß es den esportatori gar nicht darum ging, eine Einigung zu erzielen, sondern daß sie auf totale Konfrontation setzten.

Vom 31. Oktober bis zum 18. Dezember 1924 erlebte Carrara den härtesten Arbeitskampf seiner Geschichte. In den verschiedenen Phasen der Auseinandersetzung waren zwischen 4000 und 13000 Arbeiter am Ausstand beteiligt ${ }^{95}$. Dieser bis dahin "größte Streik der faschistischen Epoche ${ }^{\text {"96 }}$ erregte nationales Aufsehen und spielte eine nicht unwesentliche Rolle bei den politischen Verwicklungen in der Endphase der MatteottiKrise. In der Literatur ist er in den wesentlichen Zügen schon gewürdigt worden ${ }^{97}$, so daß sich die folgende Darstellung auf die weniger beleuchteten Aspekte konzentrieren kann. Insbesondere kommt in den bisherigen Darstellungen die Analyse der Rolle der Fabbricotti-Gruppe und der Confindustria zu kurz. Angesichts ihrer frappierend kompromißlosen Haltung erscheint dies aber der entscheidende Schlüssel zur Deutung des Geschehens zu sein. Die Faschisten Carraras jedenfalls ließen keine Gelegenheit aus, auf die „dunklen politischen Zielsetzungen“ zu verweisen, die hinter dem tariflichen Konfrontationskurs der esportatori stünden ${ }^{98}$.

Im Giornale di Carrara, dem die Faschisten nun spöttisch den Beinamen „die Wochenzeitung der Associazione esportatori“ gaben, erschien am 18. Oktober ein Artikel, in dem die wirtschaftlichen Gründe dargelegt wurden, die einer Erhöhung der Lohnkosten in der Marmorwirtschaft Carraras entgegenstanden: In Carrara sei die Mar-

94 Alalà vom 25.10.1924.

95 Am ersten Tag und in der letzten Woche, als Generalstreik ausgerufen wurde, streikten mindestens 13000 Beschäftigte (ACS, MI, DGPS 1925, b. 81, f. „Ordine pubblico Massa“: Carabinieri-Major Caravadossi an Innenministerium vom 31. 10. 1924). Nach dem partiellen Tarifabschluß vom 5. 11. 1924 streikten zunächst nur noch 4000 (Beleg wie Anm. 87).

96 Alalà vom 1.11. 1924.

97 Setta widmet ihm ein ganzes Kapitel seiner Ricci-Biographie ( $\$ .81$ - 100) und verwendet neben Alalà-Artikeln und DGPS-Akten auch die Korrespondentenberichte in der überregionalen Oppositionspresse, die er teilweise ausführlich zitiert, was aufschlußreiche Einblicke in ihre zumeist sehr starren Interpretationsmuster erlaubt. Daneben ist die Behandlung des Streiks bei Cordova, Sindacati fascisti, S. 317-321 zu nennen, der sich ganz von der Berichterstattung in der bürgerlichen Oppositionspresse leiten läßt. Er zeichnet das unzutreffende Bild eines völlig kompromißlosen, nahezu unzurechnungsfähigen Ricci und übernimmt ungeprüft die ökonomischen Argumente der „esportatori“. Recht knapp hat Bernieri (Fascismo a Carrara, S. 106; Carrara moderna, S. 205 - 207) den Streik behandelt und dabei im Werk von 1983 im wesentlichen die sachlichen Fehler und Fehldeutungen des Aufsatzes von 1964 korrigiert. Auf diesen alten Aufsatz stützt sich Bianchi, Lotte sociali, S. 264-266, und wiederholt so die Fehler von Bernieri, die in der Behauptung kulminieren, der Streik sei für Ricci erfolgreich gewesen, weil er die Einschüchterung und Unterordnung der oppositionellen Unternehmer und die Rekrutierung von „Entwurzelten und Subproletariern“ in den faschistischen Gewerkschaften bewirkt habe.

98 Alalà vom 25. 10., 8. 11. und 22. 11. 1924. 
morproduktion im Vergleich mit den anderen italienischen Abbaugebieten ohnehin schon durch die höchsten Löhne und Abgaben belastet. Die Marktlage für den CarraraMarmor sei prekär; auf Preiserhöhungen reagiere die Nachfrage sofort mit einschneidenden Rückgängen. Der Carrara-Marmor habe die Monopolstellung verloren, welche er vor dem Krieg auf einigen Märkten besessen habe. Große Bestellungen für Monumentalbauten gebe es kaum mehr, und die Konkurrenz von weißem Marmor anderer Herkunft sowic die anderer Marmor- und Steinarten würde sich immer stärker bemerkbar machen"9.

Wahrscheinlich handelte es sich hier nicht nur um Zweckpessimismus. Daß der Marmormarkt nach dem Ersten Weltkrieg nicht mehr auf besonders stabilen Fundamenten ruhte, sollte sich in der Weltwirtschaftskrise erweisen, als er völlig zusammenbrach ${ }^{100}$. Die Großexporteure hatten wohl einen besseren Überblick über die Marktlage als die kleineren und mittleren Marmorunternehmer, die selbst nicht oder nur im kleinen Stil exportierten, und daher auf ihrer Auffassung beharren konnten, der Carrara-Marmor habe nach wie vor eine Monopolstellung auf dem Weltmarkt; fallende Preise seien daher allein Ausdruck der rücksichtslosen und unnötigen Konkurrenz unter den Exporteuren ${ }^{101}$. Die wirtschaftlichen Daten zeigen jedoch, daß die Situation nicht so schlecht war, daß die extrem harte Verhandlungsposition der Associazione esportatori sich allein auf ökonomische Gründe zurückführen ließe.

Daten zur wirtschaftlichen Entwicklung in Carrara

\begin{tabular}{llll}
\hline & $\begin{array}{l}\text { Marmorabsatz } \\
(\text { in Tonnen) }\end{array}$ & $\begin{array}{l}\text { versteuertes } \\
\text { Einkommen }{ }^{103} \text { (in Lire) }\end{array}$ & $\begin{array}{l}\text { "tassa camerale“104 } \\
\text { (in Lire) }\end{array}$ \\
\hline 1921 & 124555 & 7110295 & 121380 \\
1922 & 175570 & 12533707 & 146996 \\
1923 & 194789 & 15758848 & 163030 \\
1924 & 193196 & 18126788 & 191643 \\
1925 & 247643 & 19370497 & 181867 \\
\hline
\end{tabular}

Alle Daten zeigen eine kräftige und kontinuierliche Aufwärtsentwicklung bis zum Jahr 1924, wo der lange Streik einen Rückgang der „Marmorausfuhr“ aus dem Gemeindegebiet von Carrara verursachte, der sich aber aus verschiedenen Gründen ${ }^{105}$ erst im folgenden Jahr auf die Einkommensentwicklung auswirkte, als der Marmorabsatz schon wieder zugenommen hatte - und das aufgrund des Nachholbedarfs sogar überpropor-

\footnotetext{
99 Il Giornale di Carrara vom 18. 10. 1924.

100 Siehe hierzu Bernieri, Carrara moderna, S. 209-218.

101 Vgl. oben, S. 217.

102 La vita economica 1925, S. 15.

103 Ebenda, S. 96.

104 Ebenda, S. 82 f.

105 Die Depots der Exporteure im Hafen von Livorno waren so voll, daß die Lieferungen noch zwei Monate ohne Nachschub aus Carrara möglich waren (ACS, MI, DGPS 1925, b. 81, f. „Ordine pubblico Massa ${ }^{c}$ : Präfekt von Livorno an Innenministerium vom 5. 11. 1924). Außerdem ist bei der Begleichung von Rechnungen von einer gewissen Zeitverschiebung auszugehen.
} 
tional. Angesichts dieser insgesamt guten globalen Entwicklung, die etwa in der Steigerung der Unternehmergewinne um 17,5 Prozent im Jahr 1924 ihren Ausdruck findet ${ }^{106}$, bleibt die unnachgiebige Haltung der Fabbricotti-Gruppe gegenüber der bescheidenen Fünf-Prozent-Regelung im Abkommen vom 10. September unverständlich, wenn man die politische Dimension der Auseinandersetzung nicht ins Zentrum der Betrachtung rückt.

Ricci und der apuanische Provinzfaschismus brauchten einen tarifpolitischen Erfolg, um ihre Position zu festigen, und die Exporteure wollten ihnen diesen um keinen Preis verschaffen ${ }^{107}$. Die Matteotti-Krise schien die Chance zu bieten, die Extremisten auszumanövrieren, und eine Niederlage des faschistischen Syndikalismus in der Provinz Massa-Carrara konnte hier nur nützlich sein. So erhielt die Kraftprobe sehr schnell eine nationale Bedeutung, was sich im außergewöhnlichen Engagement der Confindustria zeigt, die systematisch den Schwerpunkt der Auseinandersetzung nach Rom hin verlagerte, um sie auf einem Terrain führen zu können, auf dem Ricci relativ schwach war. Von einem exemplarischen Sieg über den extremistisch-syndikalistischen apuanischen Faschismus konnten sich die Confindustria und die liberalen Politiker in ihrem Umfeld eine nationale Signalwirkung in ihrem Sinne versprechen.

Für beide Seiten schien in diesem Konflikt sehr viel auf dem Spiel zu stehen, mit entsprechend harten Bandagen wurde gekämpft. Auf der erwähnten Kundgebung vom 20. Oktober kündigte Ricci das Abkommen vom 10. September auf und forderte nun Lohnerhöhungen in der Größenordnung des Inflationsausgleichs ${ }^{108}$. Nachdem es jetzt natürlich erst recht zu keiner Einigung kam, riefen die Gewerkschaften in Carrara für den 31. Oktober einen eintägigen Protestgeneralstreik, von dem nur der öffentliche Dienst ausgenommen wurde, und einen unbefristeten Streik aller Marmorarbeiter aus ${ }^{109}$. Am 5. Oktober einigten sich die Gewerkschaften mit den drei Unternehmervereinigungen, die schon das Abkommen vom 10. September unterschrieben hatten, auf Lohnerhöhungen von zehn Prozent ${ }^{110}$, und unmittelbar darauf wurde eine Liste derjenigen Firmen veröffentlicht, die der Vereinbarung beigetreten waren und bei denen daher die Arbeit wieder aufgenommen werden sollte. Aus der Front der Befürworter des Abkommens vom 10. September scherten jetzt allerdings die Firmen von Isaia Cucchiari und

${ }^{106}$ Diese ist ziemlich genau an der Steigerung des Gesamtaufkommens der „tassa camerale“, also der Summe der Beiträge an die Handelskammer, abzulesen, die proportional auf der Basis der angegebenen Nettojahresgewinne der Unternehmer berechnet wurden; ACCIA: Listen der "tassa camerale".

107 Giovanni Ansaldo, der während des Streiks als Sonderkorrespondent für die Genueser Zeitung Il Lavoro in Carrara weilte und dem Ras alles andere als wohlgesonnen war, gewann den Eindruck, daß die Exporteure Ricci „um jeden Preis liquidieren wollten“ (Setta, Ricci, S. 100, Anm. 68).

108 Alalà vom 25. 10. 1924.

${ }^{109}$ Streikaufruf abgedruckt in Alalà vom 1. 11. 1924. Am 1. 11. hielt Ricci vor 5000 Personen eine Kundgebung ab. Anschließend wurde die Wiederaufnahme der Arbeit bei den nicht in der Marmorindustrie Beschäftigten verkündet; ASM, Commissariato Carrara, b. 61: Polizeikommissar von Carrara an Questore von Massa vom 1.11.1924.

${ }_{110}$ Diesem Prozentsatz entsprechen die ausgehandelten Erhöhungen von 2,00 Lire für die "segatori“ und von 2,50 Lire für die Arbeiter der Steinbrüche und „laboratori“ (Alalà vom 8. 11. 1924). 
Agostino Marchetti sowie die von Italo und Augusto Faggioni aus ${ }^{111}$. Dies war schmerzlich, weil es sich bei den Faggioni um wirtschaftlich bedeutende Unternehmer handelte, die sich von den ersten Anfängen an besonders eng mit dem Faschismus verbunden hatten $^{112}$. Die vier Firmen bemängelten vor allem die Höhe des Abschlusses, der „über ihre Verhältnisse" gehe, und die unverhüllte Absicht der Gewerkschaften, mit Hilfe dieses Teilabschlusses den Kampf gegen die übrigen Unternehmer um so effektiver führen zu können. Denn die zur Arbeit zurückkehrenden Arbeiter sollten dazu angehalten werden, einen Teil ihres Lohnes in die Streikkasse abzuführen ${ }^{113}$.

Trotz des Absprungs der genannten Unternehmergruppe kamen circa 4880 Arbeiter (ca. 60 Prozent) in den Genuß des Tarifabschlusses und kehrten in die Betriebe zurück ${ }^{114}$. Die Gegner der Vereinbarung waren somit in einer unbequemen Lage. Da reagierte die Confindustria. Sie löste kurzerhand die Associazione nazionale del marmo und damit de facto auch die von Faschisten geführten Carrareser Mitgliedsvereinigungen auf und beauftragte einen Kommissar mit dem Wiederaufbau der Organisation „auf neuer Grundlage“. Begründet wurde diese Maßnahme mit der Verletzung elementarer Grundsätze der Confindustria, der sich die drei Carrareser Organisationen schuldig gemacht hätten, indem sie eine Vereinbarung unterzeichneten, die der Gegenseite zur Finanzierung des Streiks gegen die übrigen Unternehmer diente und außerdem die Zwangsmitgliedschaft ihrer Arbeiter in den Sindacati beinhaltete ${ }^{115}$. Angesichts der Desavouierung der drei faschistisch geführten Unternehmervereinigungen durch die Confindustria ist es nicht verwunderlich, daß selbst Firmen, die den Vertrag unterzeichnet hatten, nicht daran dachten, die vereinbarten Lohnerhöhungen zu zahlen. Die Streikleitung überlegte daher eine Wiederausweitung des Streiks auf alle Marmorarbeiter ${ }^{116}$, beließ es aber dann mit gutem Grund beim gegebenen Zustand: Eine Finanzierung des Ausstands ohne die beachtlichen Zahlungen der arbeitenden Belegschaften wäre wohl enorm schwierig geworden ${ }^{117}$.

111 Diese drei Firmen gehörten zu den sogenannten „produttori“, beschäftigten also hauptsächlich Steinbrucharbeiter. Die Familien Cucchiari und Marchetti können als engagierte Parteigänger der Liberalen angesehen werden.

${ }^{112}$ Die Brüder Faggioni waren nicht nur große Steinbruchunternehmer, sie exportierten auch selbst im großen Stil (ACS, MI, DGPS 1925, b. 81: Präfekt an Innenministerium vom 6. 11. 1924) und teilten offensichtlich die Ansicht der Associazione esportatori hinsichtlich der prekären Lage auf dem Weltmarkt. Ghino Faggioni, der sich noch in den Auseinandersetzungen des Jahres 1923 entschieden auf die Seite Riccis geschlagen hatte, hielt sich schon seit Anfang des Jahres 1924 politisch stark zurück. Bei diesen Vorgängen scheint Italo Faggioni, der nie eine aktive Rolle im Faschismus gespielt hatte, der entscheidende Akteur gewesen zu sein (ebenda).

113 Plakat der Firmen Cucchiari, Marchetti und Faggioni, abgedruckt in Il Giornale di Carrara vom 8. 11.1924.

114 ASM, Commissariato Carrara, b. 61, f. „Agitazione lavoratori del marmo“: Aufstellung von Ricci vom 9.11. 1924.

115 Brief des Generalsekretärs der Confindustria, Gino Olivetti, an den Vorsitzenden der Associazione nazionale del marmo vom 14. 11. 1924, abgedruckt in Il Giornale di Carrara vom 22. 11. 1924.

${ }^{116}$ Siehe den Bericht über die Sitzung des Streikkomitees in Alalà vom 29.11. 1924.

117 Allein in der letzten Novemberwoche zahlten die Arbeiter der Unterzeichnerfirmen 29893 Lire in die Streikkasse ein (Alalà vom 29. 11. 1924). In der folgenden Woche erreichten die Zahlungen (unter denen allerdings auch eine Spende des nationalen PNF-Direktoriums von 25000 Lire war) eine Summe von 51610 Lire (Alalà vom 6. 12. 1924). Das entspricht immerhin ungefähr einem Zehntel der normalen Wochenlohnsumme der 4000 Streikenden. 
Als der Sonderbevollmächtigte der Confindustria, Francesco Ricci, am 25. November nach Carrara kam, um den Wiederaufbau des Unternehmerverbandes einzuleiten, aber kein Verhandlungsmandat mitbrachte ${ }^{118}$, wurde deutlich, daß der nationale Industriellenverband gedachte, die Zeit für sich arbeiten zu lassen. Bei den nachfolgenden Verhandlungen in Rom, die unter Leitung des Staatssekretärs im Innenministerium, Dino Grandi, stattfanden, beharrte die Arbeitgeberseite auf der bekannten Position der esportatori, der Tarifabschluß dürfe zu keiner Verteuerung der Marmorproduktion führen, und bot für die Steinbrucharbeiter eine Weihnachtsgratifikation von 30 Lire und einen Kredit von 500000 Lire zur Bekämpfung der Teuerung, was Alalà dazu veranlaßte, von einer „Verhöhnung der Arbeiter" zu sprechen ${ }^{119}$.

Um das Maß vollzumachen, beabsichtigten die esportatori, mit einem Plakat zur Wiederaufnahme der Arbeit unter den alten Bedingungen aufzurufen. Dies wurde aber vom Präfekt untersagt, weil er eine unkontrollierbare Anheizung des Konflikts befürchte$t^{120}$. Als zur gleichen Zeit die als Ultima ratio anvisierte Schlichtungslösung in Rom an der Unnachgiebigkeit der Unternehmer scheiterte ${ }^{121}$, kam es trotzdem zur Eskalation. Am 11. Dezember riefen die Gewerkschaften in Carrara einen unbefristeten Generalstreik aus, an dem sich diesmal auch Teile des öffentlichen Dienstes beteiligten. Jetzt herrschte praktisch Ausnahmezustand: Die Läden waren nur einige Stunden am Tag geöffnet. Die Straßenbahn verkehrte nicht, und selbst das Gas wurde zeitweise gesperrt $^{122}$. Der Präfekt bezeichnete die Situation in Carrara als "sehr schlimm“. Nachdem Ende Oktober ohnehin schon 130 zusätzliche Carabinieri nach Carrara entsandt worden waren, forderte er jetzt weitere $100 \mathrm{an}^{123}$.

Die Polizeifunktionäre der Provinz hatten schon seit dem Beginn des Streiks das Problem der öffentlichen Ordnung als sehr ernst angesehen. Der Questore ordnete die Bewachung von Betrieben und Wohnhäusern der führenden Exporteure an und legte dem

${ }^{118}$ ACS, MI, DGPS 1925, b. 81, f. „Ordine pubblico Massa“: Präfekt an Innenministerium vom 25. 11.1924.

119 Alalà vom 6. 12. 1924.

120 ACS, MI, DGPS 1925, b. 81, f. „Ordine pubblico Massa“: Präfekt an Innenministerium vom 13. 12.1924.

121 Das wird trotz der gegenseitigen Schuldzuweisungen ziemlich deutlich, wenn man die Verlautbarungen der beiden Seiten gegenüberstellt (abgedruckt in Il Giornale di Carrara vom 13. 12. 1924) und noch andere Quellen heranzieht. Hinter der von der Confindustria geforderten Festlegung eines Spielraums für die Schlichtung verbarg sich die Absicht, eine Entscheidung zugunsten von Lohnerhöhungen gar nicht zuzulassen. Die Schlichtungskommission hätte danach nur über die Arbeitsmodalitäten und die Finanzierung des Ente annonario zu befinden gehabt, das mit der Bekämpfung der Teuerung betraut werden sollte (Mitteilung des Staatssekretärs im Innenministerium Dino Grandi, abgedruckt in Alalà vom 13. 12. 1924). Als eine Versammlung von circa 50 Unternehmern, unter denen sich auch die Vertreter der Firmen Marchetti, Cucchiari und Faggioni befanden, am 14. 12. eine Schlichtung ohne Vorbedingungen anregte, ignorierte die Confindustria dieses Ansinnen einfach, obwohl sich zwei Tage darauf 116 Firmen, das heißt die große Mehrheit der Betroffenen, dieser Resolution anschlossen; ACS, MI, DGPS 1925, b. 81, f. „Ordine pubblico Massa“: Präfekt an Innenministerium vom 14., 15. und 16. 12. 1924.

122 ACS, MI, DGPS 1925, b. 81, f. „Ordine pubblico Massa“: Präfekt an Innenministerium vom 12. 12.1924.

${ }^{123}$ Ebenda. Zum Polizeiaufgebor im einzelnen: ASM, Commissariato Carrara, b. 61, f. „Agitazione lavoratori del marmo“: Polizeikommissar von Carrara an Questore von Massa vom 1. und 30. 10. 1924; Questore an Polizeikommissar vom 12. 12. 1924. 
Polizeikommissar von Carrara vor allem den Schutz der ausländischen Firmen ans Herz, deren Schädigung - so der Polizeichef - der Regierung Probleme bereiten könnte ${ }^{124}$. Diese Vorsichtsmaßnahmen waren wohl auch angezeigt, denn die ausländischen Unternehmen Walton, Odling, Dervillé und Berring gehörten zum Kern der dissidenti. Doch nicht sie wurden zur Zielscheibe von Gewaltakten, sondern die italienischen Exporteure Corsi, Papasogli und Pisani. In den Nächten zum 12. und zum 13. Dezember wurden trotz aller polizeilichen Vorkehrungen Bombenanschläge auf ihre Villen verübt. Es kam zwar niemand zu Schaden, und die Staatsgewalt versuchte die Vorkommnisse herunterzuspielen, indem sie sie als reine Einschüchterungsaktionen und nicht als Mordversuche deutete $^{125}$, doch war es unübersehbar, daß die Auseinandersetzung auszuarten drohte, zumal sich auch noch einige kleinere Anschläge auf Betriebsanlagen oppositioneller Unternehmer und das Casino civico ereigneten.

Diese Anschläge sind nicht einfach als "nach oben“ "gerichtete faschistische Gewalt zu deuten, wie es Bernieri 1964 tat $^{126}$, denn nicht nur die Zielrichtung war hier eine andere als gewöhnlich, sondern auch die Qualität. Zum „klassischen“ Repertoire des Squadrismus gehörten diese Aktionen jedenfalls nicht. Zwar kann man daraus nicht mit Gewißheit den Schluß ziehen, daß die Anschläge von anderer Seite verübt wurden, aber es wäre wohl abwegig, sie als Teil einer gar von Ricci persönlich entworfenen Gewaltstrategie zu interpretieren. Die Faschisten verurteilten die Attentate und schrieben sie Verzweifelten, die die Selbstkontrolle verloren hätten, oder gar „agents provocateurs" ${ }^{\text {" }} \mathrm{zu}^{127}$. Von der Einschüchterung einzelner Unternehmer konnten sich die apuanischen Faschisten in der Tat keinen Nutzen versprechen. Im Gegenteil, die Ereignisse verschlechterten die Position Riccis auf dem römischen Parkett. Dem bedrängten Duce konnte gerade jetzt eine derartige Diskreditierung des Faschismus bei den wankelmütigen fiancheggiatori nicht ins Konzept passen ${ }^{128}$. Die Confindustria nahm die Ereignisse zum Anlaß, ihre weitere Verhandlungsbereitschaft als reine Gnade und Ausdruck ihrer übergroßen Loyalität gegenüber der Regierung darzustellen ${ }^{129}$, und für die bürgerliche Oppositionspresse waren sie ein gefundenes Fressen. Bei der Beschreibung der Carrareser Verhältnisse verwendete sie Vokabeln wie „faschistischer Subversivismus" und „schwarzer Bolschewismus ${ }^{\alpha 130}$.

In der Tat war der Carrareser PNF im Verlauf der Auseinandersetzung fast in klassenkämpferisches Fahrwasser geraten. Symptomatisch ist die Selbstdefinition als „Arbei-

${ }^{124}$ Ebenda: Questore Piano an Polizeikommissar von Carrara vom 29. 10. 1924.

125 Ebenda: Abschrift eines Berichts des (zuständigen) Generalstaatsanwalts von Genua an das Justizministerium vom 19.12.1924.

126 Bernieri, Fascismo a Carrara, S. 106.

127 Alalà vom 13.12. 1924.

${ }^{128} \mathrm{Zu}$ den Schwierigkeiten Mussolinis nach der Wiedereröffnung der Abgeordnetenkammer am 12. 11. 1924 siehe De Felice, Mussolini il fascista 1, S. 682 - 706. Gerade um den 15. 12. herum war die Position des Duce besonders kritisch (ebenda, S. 691 - 699).

129 ASM, Commissariato Carrara, b. 61, f. „Agitazione lavoratori del marmo“: Telegramm der Confindustria vom 16. 12. 1924.

130 Siehe etwa den Bericht von Giovanni Ansaldo in Il Lavoro vom 20. 12. 1924, zitiert bei Setta, Ricci, S. 95. Der Giornale d'Italia, die überregionale Zeitung der liberalen „fiancheggiatori“, enthielt schon am 16. 11. einen Bericht mit dem Titel „Aspetti bolscevichi dello sciopero nel Car-

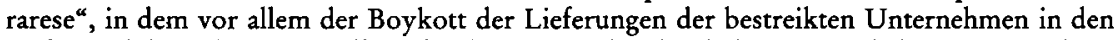
Häfen und die Arbeitsbeschaffung für die Streikenden durch die Gemeinde kritisiert wurde. 
terpartei“ ${ }^{131}$. Bemerkenswert sind auch die Angriffe auf Streikbrecher, die aktive Unterstützung der Streikenden durch Arbeitsbeschaffungsmaßnahmen der faschistischen Kommunalverwaltung und Maßnahmen, die Verladung des Carrara-Marmors in den Häfen von Forte dei Marmi und Livorno zu verhindern ${ }^{132}$. Auf einer Kundgebung vor Arbeitern am 10. Dezember ließ sich Ricci zu der Feststellung hinreißen, die Geschichte Carraras zeige, „daß die historischen Gegner der Marmorarbeiterschaft eindeutig die Herren Unternehmer sind “133. Und fünf Tage später verbot das Polizeikommissariat ein Plakat des faschistischen Streikkomitees wegen „Aufhetzung zum Klassenhaß “, das mit den Worten schließt: „Widerstand um jeden Preis, was immer auch geschehen mag! “ 134

Es ist unübersehbar, daß im Zuge der harten Streikauseinandersetzung eine Verbindung des faschistischen Extremismus mit dem traditionellen lokalen Arbeiterradikalismus wirksam wurde. Die Hinweise darauf, daß der Streik keine künstliche Inszenierung der Faschisten war, sondern von der Arbeiterbasis mitgetragen wurde, sind eindeutig. Die Selbständigkeit der Arbeiterbasis zeigte sich etwa ganz deutlich, als nach der Unterzeichnung der partiellen Tarifvereinbarung Streikposten gegen den Willen der Streikleitung die Wiederaufnahme der Arbeit in den Steinbrüchen der Unterzeichnerfirmen zunächst verhinderten ${ }^{135}$. Bemerkenswert ist in diesem Zusammenhang auch die Einschätzung von Eugenio Chiesa, der im Gegensatz zu den meisten anderen oppositionellen Kommentatoren ein Kenner der lokalen Verhältnisse war. Nach dem Scheitern des Streiks betonte er, daß es sich hier in erster Linie um eine Niederlage der Arbeiter handle; jede unterschwellige Schadenfreude bezeichnete er als deplaziert ${ }^{136}$.

Die Attentate sind möglicherweise, so wie der erwähnte Alleingang der Streikposten, von besonders militanten Gruppen an der Basis geplant und durchgeführt worden höchstwahrscheinlich ohne Wissen und Zustimmung der faschistischen Verantwortlichen. Der Zugang zu Sprengstoffen war für die Steinbrucharbeiter kein großes Problem, und ihre Verwendung in politisch-sozialen Kämpfen hatte eine gewisse „Tradition “ in Carrara ${ }^{137}$. Doch unabhängig von der Klärung der Frage, wer im einzelnen für die Anschläge verantwortlich zu machen ist, läßt sich folgendes Fazit formulieren: Das Auftauchen dieser „anarchistischen “ Aktionsformen dokumentierte die Revitalisierung des alten Carrareser Arbeiterradikalismus auf eine Weise, die den bürgerlichen Beobachtern

131 Alalà vom 6. 12. 1924.

132 ACS, MI, DGPS 1925, b. 81, f. „Ordine pubblico Massa“: Berichte des Präfekten von Livorno an das Innenministerium vom 5. und 6.11. 1924. Hier ist nicht ganz klar, ob der Boykott im Endeffekt wirklich längerfristig durchgeführt wurde. In Forte dei Marmi mußte Ricci den Boykott mit dem Hinweis auf Anweisungen von Rossoni gegen Carlo Scorza durchsetzen (Alalà vom 15. 11. 1924).

133 Rede im Wortlaut in Alalà vom 13. 12. 1924.

134 Nachricht des Polizeikommissars von Carrara über die Verbotsverfügung an den Questore von Massa vom 16. 12. 1924 (ASM, Commissariato Carrara, b. 61); das Plakat wurde dann in einer Beilage zu Alalà vom 16. 12. 1924 veröffentlicht. Wortlaut bei Setta, Ricci, S. 91 f. (vollständig) und Cordova, Sindacati fascisti, S. 320 (Auszug).

135 ASM, Commissariato Carrara, b. 61, f. „Agitazione lavoratori del marmo“: Polizeikommissar an Questore von Massa vom 8. 11. 1924. Dem Bericht zufolge handelte es sich bei den Akteuren um „dipendenti dei sindacati“. In einem Flugblatt (ebenda im Akt) macht Ricci „dunkle anarchoide Bewegungen " für diese Vorfälle verantwortlich.

136 Chiesa, La mano nel sacco, S. 124-127.

137 Vgl. oben S. 56, Text und Anm. 28. 
zwangsläufig das Stichwort „Bolschewismus“ eingab, zumal sich dieser Vorwurf auch darauf stützen konnte, daß die Verantwortlichen des apuanischen Faschismus immer mehr zu klassenkämpferischer Rhetorik und Praxis Zuflucht nahmen.

Die Dynamik der Auseinandersetzung führte zu dem paradoxen Ergebnis, daß der apuanische Faschismus zunehmend sein „antibürgerliches" Profil hervorkehrte und gleichzeitig jene absolute Kontrolle über die Arbeiter verlor, die die notwendige Voraussetzung für den "nationalen Syndikalismus" war ${ }^{138}$. Beides war nicht geeignet, die politischen Konstellationen in Rom zugunsten Mussolinis zu beeinflussen. Ein Eingreifen der Regierung konnte deshalb nicht ausbleiben: Am 17. Dezember bestellte der Duce den Ras in das Innenministerium und befahl in Anwesenheit des Ministers Federzoni den sofortigen Abbruch des Generalstreiks ${ }^{139}$. Dieses Machtwort zerstörte auf einen Schlag Riccis Verhandlungsposition. Wenige Stunden später wurden die Tarifverhandlungen mit seiner bedingungslosen Kapitulation beendet. Die Beschäftigten der segherie und laboratori bekamen die 10 Prozent Lohnerhöhung, die ihnen die betroffenen Unternehmer schon am 6. November zugestanden hatten. Bei der Lohngestaltung für die Steinbrucharbeiter, die der eigentliche Streitpunkt mit den esportatori gewesen war, setzte sich die Confindustria ohne Abstriche durch. Die cavatori mußten am folgenden Tag die Arbeit zu den alten Bedingungen wieder aufnehmen.

Renato Ricci gab sich alle Mühe, die erlittene Schlappe, so gut es ging, zu kaschieren. Auf einer Kundgebung am 21. Dezember in Carrara stritt er entschieden ab, daß Mussolini ihm den Abbruch des Streiks befohlen hatte, und sagte, es gebe "weder Sieger noch Besiegte“. Er habe den Streik nur beendet, um den Arbeitern ein Weihnachten "in Trauer und Armut" zu ersparen. Es handle sich nicht um eine Niederlage, sondern nur um einen Waffenstillstand ${ }^{140}$. Der Ras konnte aber nicht verhindern, daß die überregionale Oppositionspresse sich mehr oder weniger genüßlich über das Debakel des faschistischen Syndikalismus in Carrara ausließ. Die kommunistische Unità sprach das aus, was viele Beobachter, einschließlich des Präfekten Berti ${ }^{141}$, glaubten: „Ihre Niederlage ist irreparabel. Der Abgeordnete Ricci, Dario Orlandi, der Sekretär des Fascio und des Streikkomitees, Aloisi, Giorgi und die anderen Anführer sind definitiv liquidiert worden. ${ }^{\text {“142 }}$

Es handelte sich hierbei jedoch um eine fundamentale Fehleinschätzung. Die kurzfristige Schwächung der faschistischen Position in der Provinz spielte keine große Rolle mehr. Denn schon zwei Wochen, nachdem Ricci sich dem Duce unterworfen hatte, erran-

${ }^{138}$ Diese diente ja erklärtermaßen dem Ziel, einen autonomen „egoistischen“ Interessenskampf der Arbeiter, der sich nicht am "Wohl des Vaterlands" orientiere, zu unterbinden. Die Frontstellung gegen den "proletarischen Egoismus“ war praktisch von Anfang an eines der Hauptelemente der faschistischen Ideologie und Politik. Sehr aufschlußreich hierzu: Paolo Orano, „L'ora della demenza “, in Pagine libere vom 15. 3. 1920, zitiert nach S. Solinas (Hrsg.), Alla conquista dello Stato, Antologia della stampa fascista dal 1919 al 1925, Rom 1978, S. 66-69.

139 ACS, MI, DGPS 1925, b. 81, f. „Ordine pubblico Massa“: Innenminister Federzoni an den Präfekten von Massa vom 17. 12. 1924.

140 Alalà vom 31. 12. 1924.

141 ACS, MI, DGPS 1925, b. 81, f. „Ordine pubblico Massa“: Präfekt an Innenministerium vom 13. 11. 1924. Er schreibt: „Eine Lösung, die ganz zu ihrem [der Arbeiter] Nachteil wäre, würde den Zusammenbruch der Sindacati economici mit schweren Auswirkungen für die Stärke des Faschismus in der Provinz bedeuten."

142 L'Unità vom 19. 12. 1924. Längere Passage bei Setta, Ricci, S. 100. 
gen die Extremisten auf nationaler Ebene den entscheidenden Sieg. Den intransigenti in Miliz und Parteiführung gelang es, Mussolini zum Sprung in die offene Diktatur zu bewegen. Mit seiner berühmten Rede vom 3. Januar 1925 vollzog er den endgültigen Bruch mit der konstitutionellen Tradition und leitete die eigentliche Regimephase des Faschismus ein.

Die Vorgeschichte dieser Wende, die die Matteotti-Krise mit einer Flucht nach vorne beendete, kann hier nicht im Detail nachgezeichnet werden. Es soll hier nur die nicht unmaßgebliche Rolle von Renato Ricci bei diesen Vorgängen beleuchtet werden: Dieser sprach am 31. Dezember bei einem großen Squadrenaufmarsch in Florenz als Vertreter der PNF-Führung. Er kündigte vor den versammelten squadristi das Ende der Oppositionskampagne an und forderte sie dazu auf, diszipliniert den Anordnungen des Duce zu folgen. Anschließend verlas er aber im Namen der versammelten Florentiner Faschisten eine Resolution, in der Gehorsam und Disziplin von einem resoluten, „wenn nötig, diktatorischen Vorgehen" der Regierung abhängig gemacht wurden. Sie wurde mit großem Jubel aufgenommen, und anschließend demonstrierten die squadristi unmißverständlich, welches Vorgehen sie von Mussolini erwarteten. Sie überfielen unter anderem den rechtsliberalen, aber jetzt oppositionellen Nuovo Giornale, die Combattenti-Zeitung Fanteria, die Freimaurerloge und einen bürgerlichen Kulturverein ${ }^{143}$. Es handelte sich um die erste spedizione punitiva gegen die abtrünnig gewordenen fiancheggiatori.

Wie Lyttelton nachgewiesen hat, ist die erwähnte Resolution nicht von Angehörigen der Florentiner Provinzorganisation formuliert worden, wie es offiziell hieß, sondern vom nationalen PNF-Direktorium ${ }^{144}$. Ob Mussolini bei der Inszenierung dieses Theaters selbst beteiligt war oder ob er durch einen Alleingang des direttorio und den gleichgerichteten Vorstoß von 34 consoli der MVSN erst zum entscheidenden Schritt vom 3. Januar gedrängt wurde, läßt sich nicht eindeutig klären ${ }^{145}$. Sicher ist allerdings, daß diese Wendung in der PNF-Führung längerfristig angebahnt worden war. Angesichts der entscheidenden Rolle, die Ricci bei ihrer Umsetzung spielte, ist anzunehmen, daß er auch einen maßgeblichen Anteil an ihrer Vorbereitung hatte.

Ricci hat seine unmittelbaren Interessen in der Provinz zugunsten einer globalen Lösung im Sinne der intransigenti zurückgestellt. Er hatte so eine Schlacht verloren und gleichzeitig den Krieg gewonnen. Jetzt war die Krise im Sinne der Extremisten überwunden. Der Präfekt Berti legte die Weisung des Innenministers Federzoni vom 3. Januar 1925, daß „alle politisch verdächtigen Vereine und Lokale“ zu schließen seien, sehr weit aus und verbot die letzten Reste der republikanischen Organisation, die sich mehr schlecht als recht noch hatten halten können, und den PSU in Pontremoli, der dort im Zusammenhang mit der Matteotti-Krise Fuß gefaßt hatte ${ }^{146}$. Im Laufe des Jahres 1925

143 Lyttelton, Second Wave, S. 93.

144 Ebenda, S. $93 \mathrm{f}$.

145 Ebenda, S. $94 \mathrm{f}$.

${ }^{146}$ Zum PSU in Pontremoli siehe die Akten in ASM, Questura Massa, b. 15, f. „Sezione PSU“: Auflösungsanordnung des Sottoprefetto vom 1. 2. 1925 u. a. Bei den republikanischen Organisationen handelte es sich um den Ortsverein Carrara, der im Mai 1924 immerhin wieder 150 Mitglieder zählte (ebenda, b. 11,f. „Sezione PRI“: „prospetto statistico“ vom 12.5. 1924; Schließungsanordnung des Vereinslokals durch den Präfekten vom 5. 1. 1925), und um einige kleinere Clubs: Club „Eugenio Chiesa " in Fontia, Club mazziniano Avenza (beide ebenda, b. 11, entsprechende Faszikel), Club federale repubblicano (ebenda, b. 13). 
verschwanden die Sveglia repubblicana und der Giornale di Carrara von der Bildfläche ${ }^{147}$, die sich während der Krise wieder etwas von der erzwungenen Selbstzensur befreit hatten. Das in Il Popolo apuano umbenannte Organ der PNF-Provinzorganisation übernahm in Carrara endgültig das Informations- und Meinungsmonopo ${ }^{148}$.

Damit war jegliche legale Opposition beseitigt. Abweichende Auffassungen konnten nur noch hinter den Kulissen von Angehörigen der Stadtnotabilität vertreten werden. Die einfache Bevölkerung war politisch ohnehin vollständig entmündigt. Hier konnten sich oppositionelle Haltungen schon seit langem nur noch in der Privatsphäre und im Untergrund artikulieren. Schon seit 1922 befand sich die Mehrzahl der anarchistischen Arbeiterführer in Frankreich im Exil ${ }^{149}$. Andere führende Vertreter der lokalen Linken hatten sich zunächst in verschiedenen Großstädten niedergelassen, wo das faschistische Regiment noch nicht so erdrückend war wie in der Provinz Massa-Carrara, und waren später zumeist ebenfalls ins Ausland gegangen ${ }^{150}$.

Es wäre allerdings verfehlt anzunehmen, die traditionell rebellische Arbeiterbasis der apuanischen Region sei durch den demagogischen Populismus und den scheinbaren gewerkschaftlichen Radikalismus der ricciani reibungslos in den Faschismus zu integrieren und zu neutralisieren gewesen. Die partielle Einbindung in das faschistische System bedeutete keinen bedingungslosen Konsens. Symptomatisch ist, daß „subversive" Kommunikation unter halbkonspirativen Bedingungen fortbestehen konnte. Nicht nur in den informellen Beziehungen, den „unpolitischen "Freizeit- und Kulturvereinen und - wie schon ausgeführt - den faschistischen Gewerkschaften, sondern sogar in der Miliz machten sich oppositionelle Regungen bemerkbar ${ }^{151}$. Hier zeigte sich, daß der Provinzfaschismus in seinem Bemühen, gerade auch die soziale Basis seiner Gegner einzubinden, Elemente in sich aufgenommen hatte, deren Loyalität mehr als fraglich war. Hinzu kamen jene meist anarchistisch geprägten Gruppen und Individuen, die in Todfeindschaft zum Faschismus verharrten und dieser Gesinnung auch zuweilen Ausdruck verliehen. Immer wieder kam es zu Ausbrüchen individueller Gewalt gegenüber Symbolfiguren des lokalen Faschismus. Im März 1924 wurde ein Sprengstoffanschlag auf den Wagen von Renato Ricci verübt ${ }^{152}$. Wenig später streckte der Anarchist Primino Gabelloni den legendären squadrista "Cipolla" (Zwiebel) alias Eugenio Torri mit einem Revolverschuß nieder und verletzte ihn dabei lebensgefährlich ${ }^{153}$. Im Februar 1925 wurde ein weiterer berüchtigter squadrista, der Landarbeiter Pietro Pellicia, erschossen $^{154}$. Im September 1925 schließlich beschossen Unbekannte den Wagen des segretario provinciale Dario Orlandi ${ }^{155}$.

147 Bertozzi, Stampa, S. 132, $164 \mathrm{f}$.

148 Ebenda, S. $171 \mathrm{f}$.

149 Cerrito, Anarchici, S. 15-24.

150 Ebenda.

${ }^{151}$ Archivio dell'Istituto storico della Resistenza in Toscana, Fondo CPLN Apuania, Segreteria, b. 1, f. 1: Notizen eines Polizeispitzels von Mai - November 1926.

152 ASM, Commissariato Carrara, b. 61, f. „ordine pubblico": Vicequestore von Massa an Carabinieri vom 22. 3. 1924.

${ }^{153}$ ASM, Corte d'assise, Sentenza 1926/7 (28. 6. 1926).

154 ASM, Corte d'assise, Sentenza 1926/8 (28. 6. 1926).

155 ACS, MI, DGPS 1925, b. 95, f. „Ordine pubblico Massa“: Präfekt an Innenministerium vom 13. 9.1925. 
In das nationale Blickfeld rückte der anarchistische Untergrund, als am 11. September 1926 ein lizzatore aus Carrara, Gino Lucetti, ein Bombenattentat auf Mussolini verübte ${ }^{156}$. Lucetti lebte, nachdem er ein Jahr zuvor in Avenza in eine Schießerei mit Faschisten verwickelt worden war, in Südfrankreich im Exil, kam aber unmittelbar vor seiner Tat mehrmals heimlich zu Zusammenkünften mit Gesinnungsgenossen nach Carrara. Unter diesen befand sich der spätere Partisanenführer Ugo Mazzucchelli, der noch nicht lange aus der Haft entlassen worden war, die ihm seine Beteiligung an der militanten antifaschistischen Aktion von Nazzano im Juni 1921 eingebracht hatte ${ }^{157}$. Es ist in diesem Zusammenhang bemerkenswert, daß nicht nur Mazzucchelli, sondern auch Romualdo Del Papa, ebenfalls ein Anarchist, sowie der Kommunist Balilla Grillotti und der zum Kommunismus konvertierte ehemalige Republikaner Gino Menconi, die sich 1921 als junge Männer in den Auseinandersetzungen mit den Faschisten ebenfalls hervorgetan hatten, nach dem 8. September 1943 Partisaneneinheiten anführten ${ }^{158}$. Das subversive Milieu ließ sich nicht trockenlegen, trotz faschistischer Repression und Massenmobilisierung überlebte es 20 Jahre Diktatur.

Was den Konflikt zwischen Provinzfaschismus und den oppositionellen Unternehmern angeht, nahm die Entwicklung einen bemerkenswerten Verlauf. Als die Marmorwirtschaft 1927 in die nächste Absatzkrise schlitterte, war für Renato Ricci die Stunde der Revanche gegen seine Widersacher unter den Marmorbaronen gekommen. Dem Ras, der mittlerweile zum Vizesekretär des PNF und zum Leiter der faschistischen Staatsjugendorganisation Opera nazionale Balilla aufgerückt war ${ }^{159}$, gelang es, bei Mussolini ein Gesetz zu erwirken, das mit dem Consorzio per l'industria ed il commercio dei marmi di Carrara eine Zwangsorganisation der heimischen Marmorwirtschaft schuf, die für die Vermarktung des Marmors die alleinige Zuständigkeit erhielt ${ }^{160}$. Die Wettbewerbsvorteile der großen Exportunternehmen mit ihrem weitverzweigten Handelsnetz im Ausland wurden somit zunichte gemacht. Es kam hinzu, daß das Consorzio, dessen Leitung Ricci 1928 persönlich übertragen wurde, die Marktquoten der einzelnen Unternehmen weitgehend nach eigenem Ermessen festlegte und dabei - wie es scheint - die Gegner des Ras im Unternehmerlager systematisch schädigte ${ }^{161}$. Zwar gelang es der Gruppe um Carlo Andrea Fabbricotti, abermals im Zusammenspiel mit der Confindustria, das consorzio schließlich 1930 zu Fall zu bringen, aber dabei handelte es sich um einen PyrrhusSieg. Inzwischen hatte sich die Branchenkrise mit den allgemeinen Wirkungen der Weltwirtschaftskrise überlagert, und die großen Marmorunternehmer, vor allem die der „oppositionellen “ Familien C. A. Fabbricotti, Lazzoni, Marchetti, Cucchiari und Faggioni - letztere müssen mittlerweile auch zu ihnen gerechnet werden -, standen vor dem wirtschaftlichen Ruin. Im Jahre 1935 gingen diese Firmen, die sich inzwischen zur Unternehmensgruppe SAMA - Marmifera Ligure Faggioni Cucchiari \& C. zusammengeschlossen hatten, in den Konkurs. Sie wurden daraufhin von der staatlichen Gläubiger-

156 Siehe hierzu das Material in ACS, SPD/CR 1922 - 43, b. 64, f. „Gino Lucetti“.

157 Interview mit Mazzucchelli vom 23. 5. 1989.

158 Näheres hierzu in Cerrito, Anarchici, S. 45 - 81; Bertolucci, Anarchia, passim; Bianchi, Lotte sociali, S. 181, Anm. 70; Bernieri, Menconi, passim.

159 Zur Rolle Riccis als Leiter der faschistischen Staatsjugendorganisation siehe Setta, Ricci, S. 113196.

160 Ebenda, S. $101-112$ und Bernieri, Carrara moderna, S. $207-215$.

161 Bernieri, Carrara moderna, S. 214. 
bank Banca nazionale del lavoro für einen Spottpreis an den Montecatini-Konzern versteigert, der durch die Neuerwerbung und mit der schon in seinem Besitz befindlichen "Società Nord Carrara“, im Verein mit der genannten Großbank und der Staatsholding IRI, die Kontrolle über die apuanische Marmorwirtschaft erlangte ${ }^{162}$.

So hatte der Faschismus, dessen dynamische Entwicklung in der Marmorregion anfangs wesentlich vom Schutzbedürfnis der kleineren und mittleren Marmorunternehmer genährt worden war, zuletzt einen extremen Konzentrationsprozeß begünstigt. Nutznießer dieses Vorgangs wurde ausgerechnet jener Konzern, der in der Gestalt seiner Tochterfirma „Nord Carrara" den faschistischen Syndikalismus am rücksichtslosesten bekämpft hatte. Eindeutiger konnte das politische Scheitern des apuanischen Provinzfaschismus, wenn man seine gesellschaftspolitischen Entwürfe zum Maßstab nimmt, nicht dokumentiert werden. Doch zu diesem Zeitpunkt spielte das keine Rolle mehr. Das Regime stand national auf festen Fundamenten, und die ökonomische Dauerkrise der Marmorwirtschaft hatte die 1921 - 24 gültigen politisch-sozialen Koordinaten ohnehin völlig verschoben. Jetzt war es der staatlichen Strukturpolitik des Faschismus aufgegeben, von Rom aus in der Region für Stabilität zu sorgen ${ }^{163}$.

162 Ebenda, S. $215-218$.

${ }^{163}$ Zur Errichtung der „Zona industriale di Apuania “ siehe Petri, Frontiera industriale, S. $191-220$. 